\title{
Palladium-Mediated Decarboxylative Cross-Coupling Reactions: Synthesis of Complex Polycyclic Amines
}

\author{
Wendy Fields Ballard \\ Charlottesville, Virginia
}

Bachelors of Science, North Carolina State University, 2006

A Dissertation presented to the Graduate Faculty of the University of Virginia in Candidacy for the Degree of

Doctor of Philosophy

\section{Department of Chemistry}

University of Virginia

May 2011

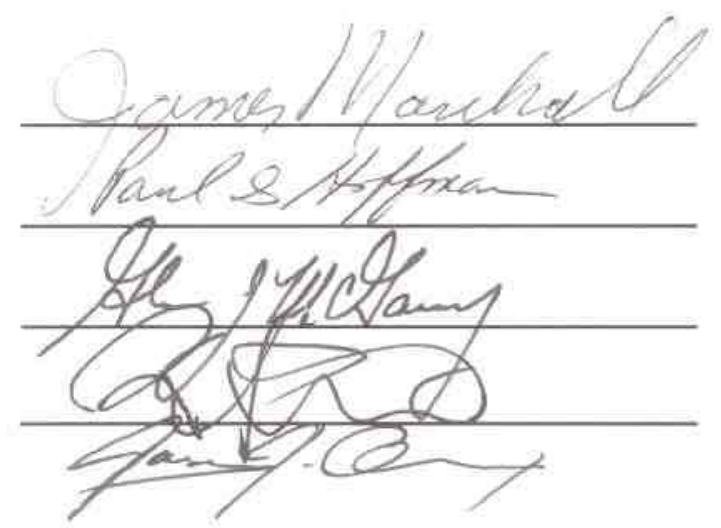




\section{DEDICATION}

For my parents,

Keith and Un Suk Fields,

who taught me the true meaning of

success through their own hard work,

love, and enduring dedication

to their children. 
ABSTRACT

\section{Palladium-Mediated Decarboxylative Cross-Coupling Reactions: Synthesis of Complex Polycyclic Amines}

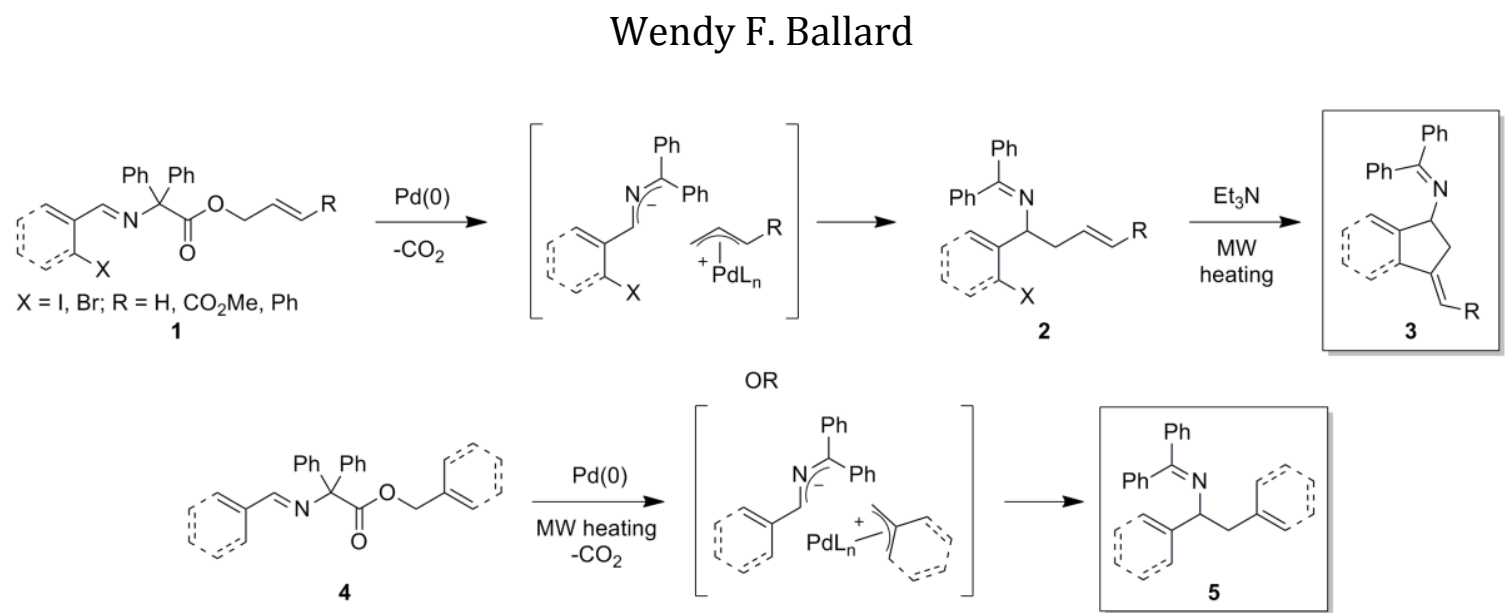

A variety of allyl and benzyl diphenylglycinate imine precursors were synthesized and they successfully underwent a facile palladium-catalyzed decarboxylative alkylation. 1-Iminoindanes 3 were synthesized from allyl diphenylglycinate imines 1 employing a microwave-promoted "one-pot" palladiumcatalyzed decarboxylative allylation-Heck cyclization cascade. Variation of both the aryl and imine moieties furnished a diverse range of complex polycyclic imines amenable to the synthesis of biologically active natural products. General reaction conditions were also elucidated for the palladium-catalyzed decarboxylative benzylation of benzyl diphenylglycinate imines 4. Microwave irradiation greatly accelerated the transformation and various heteroaromatic moieties were tolerated in both the imine and ester components. Furthermore, this method has proved to be applicable toward the synthesis of a complex 2-aryl- $\beta$-carboline derivative. 


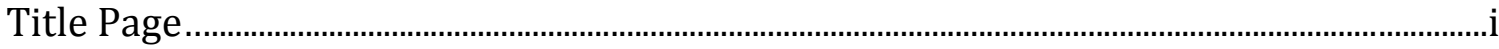

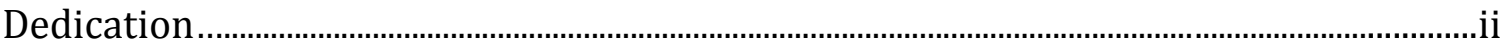

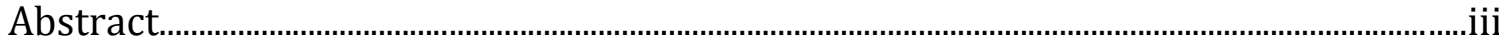

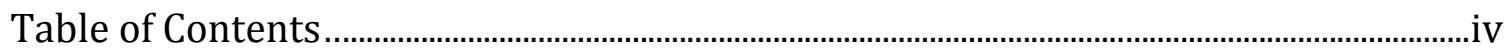

List of Figures

List of Schemes.........................................................................................................................................

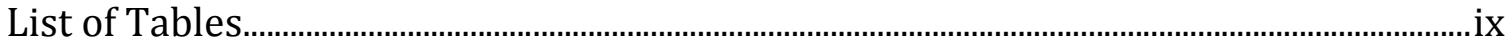

Abbreviations

Chapter 1 Introduction to Palladium-Catalyzed Decarboxylative Alkylations................2

Chapter 2 Microwaves in Organic Synthesi...................................................................................33

Chapter 3 Tandem Decarboxylative Allylation-Heck Cyclization.......................................51

Chapter 4 Decarboxylative Benzylation.........................................................................................70

Chapter 5 Conclusions

Chapter 6 Experimentals...................................................................................................................

Appendix A. NMR Spectra

Appendix B. X-Ray Crystallographic Data ………………........................................................231 


\section{LIST OF FIGURES}

Figure 1.1

Figure 1.2

Figure 1.3

Figure 1.4

Figure 1.5

Figure 2.1

Figure 3.1

Figure 3.2

Figure 4.1

Figure 4.2

Figure 4.3

Figure 4.4

Figure 4.5

Figure 5.1
Representative decarboxylative allylations. 9

Oxidative addition of palladium. 10

Proposed routes for allylation of $\beta$-ketoesters. 11

Chruma vs. Tunge methods of decarboxylative allylation..........16

Relative rates for formation of $\pi$-allyl and benzyl palladium

complexes.

22

Temperature gradients of microwave vs. oil-bath heating after

$60 \mathrm{sec}$ 35

X-ray crystallographic analysis of 3.4 …………………………….....54

Heck reaction mechanism. .64

Major side products for the decarboxylative benzylation of

ester 4.1a .74

Isomer of decarboxylative benzylation product $4.2 \mathrm{~g} \ldots \ldots \ldots \ldots \ldots \ldots \ldots . . .78$

Possible mechanism for decarboxylative benzylation. 81

$\beta$-Carboline scaffold... 83

Deprotected imine $\mathbf{4 . 2 2}$ .86

N9-Butylharmine. 96 


\section{LIST OF SCHEMES}

Scheme 1.1

Scheme 1.2

Scheme 1.3

Scheme 1.4

Scheme 1.5

Scheme 1.6

Scheme 1.7

Scheme 1.8

Scheme 1.9

Scheme 1.10

Scheme 1.11

Scheme 1.12

Scheme 1.13

Scheme 1.14

Scheme 1.15
Saegusa's route to $\alpha$-allylic acylation of enolates 3

Tsuji's method of decarboxylative allylation of enolates................

Decarboxylative allylation of non-enolate functionalities..............5

Regiospecific decarboxylative allylation............................................6

Tunge's asymmetric allylation of $\beta$-ketoesters.................................. 7

Asymmetric decarboxylative allylation of allyl enol

carbonates/silyl enol ethers.

Tunge's decarboxylative allylation of coumarin derivatives.....12

Chruma's decarboxylative allylation of diphenylglycinate

imines.. .14

Regioselectivity of electron-deficient substituents.

Myer's palladium-catalyzed decarboxylation-Heck type

coupling.

Progress of decarboxylative-Heck olefination

Unsymmetrical bisarylated alkynes by Sonogashira-

decarboxylative coupling.......

19

Liang's palladium-catalyzed decarboxylation-coupling of allyl

derivatives. .20

Tandem Michael addition-decarboxylative allylation. .20

Aza-Michael addition-allylation.. 21 
Scheme 1.16

Scheme 1.17

Scheme 1.18.

Scheme 2.1

Scheme 2.2

Scheme 2.3

Scheme 2.4

Scheme 2.5

Scheme 2.6

Scheme 2.7

Scheme 3.1

Scheme 3.2

Scheme 3.3

Scheme 3.4

Scheme 3.5

Scheme 3.6
First example of palladium-catalyzed decarboxylative

benzylation

Tunge's decarboxylative benzylation of benzyl $\beta$-ketoesters

and benzyl propioliates. 24

Decarboxylative benzylation of alkynyl carboxylic acids. 25

Initial reports on microwave-assisted (MW) organic

reactions

MW heated palladium-catalyzed asymmetric allylic

alkylation .38

Palladium-catalyzed coupling of aryl chlorides utilizing MW

heating. 40

Initial report of MW-promoted olefin metathesis 41

MW-assisted Heck reaction........................................................................42

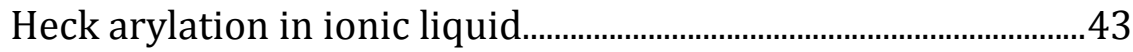

One-pot MW-promoted isomerization-Heck reaction.................44

Decarboxylative allylation of diphenylglycinate imines..............51

Proposed synthetic route....................................................................52

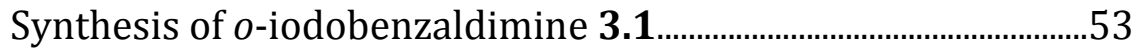

Two-step decarboxylative allylation-Heck cascade......................54

Deprotection of $\mathbf{3 . 9}$ followed by imine formation...........................61

Olefin cross-metathesis on imine 3.1a 
Scheme 3.7

Scheme 4.1

Scheme 4.2

Scheme 4.3

Scheme 4.4

Scheme 4.5

Scheme 4.6

Scheme 4.7

Scheme 4.8

Scheme 4.9

Scheme 4.10

Scheme 4.11

Scheme 4.12

Scheme 4.13

Scheme 4.14

Scheme 4.15

Scheme 4.16

Scheme 5.1
Tandem decarboxylative allylation-interception-Heck

cyclization. .65

Decarboxylative benzylation of $\alpha$-imino anions...............................70

Preparation of diphenylglycinate ester 4.1a... 71

Stoltz's enantioselective decarboxylative protonation of $\beta$-keto

esters. .74

Preparation of benzyl bromide substrates........................................75

Synthesis of benzyl diphenylglycinate amine 4.3

Imine condensation to furnish imines 4.1a-h..................................76

Imine condensation to furnish imines 4.1i-r......................................77

Methods for synthesis of $\beta$-carboline scaffold..

Retrosynthetic analysis of 2-aryl- $\beta$-carbolines via Pictet-

Spengler cyclization. .84

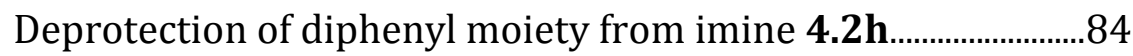

Synthesis of imine $\mathbf{4 . 1 6}$ .85

Attempts at Pictet-Spengler cyclization.............................................85

Decarboxylative benzylation of imines 4.18 and 4.20. .86

Retrosynthesis of 2-aryl- $\beta$-carbolines via Bischler-Napieralski

cyclization. .87

Synthesis of Bischler-Napieralski precursor 4.22. .88

Oxidation of imine $\mathbf{4 . 2 3}$ .89

Diversification of $\mathbf{4 . 2 2}$. .96 


\section{LIST OF TABLES}

Table 2.1

Table 3.1

Table 3.2

Table 3.3

Table 3.4

Table 3.5

Table 3.6

Table 4.1

Table 4.2

Table 4.3
Tangent loss factors $(\tan (\delta))$ of selected solvents at $2.45 \mathrm{GHz}$

and $20^{\circ} \mathrm{C}$ 37

Optimization studies of thermally heated one-pot reaction......55

Optimization studies of microwave-promoted one-pot

reaction

Synthesis of imines 3.1. 58

MW-promoted tandem-decarboxylative allylation-Heck

cyclization.

Optimization of olefin metathesis reactions on imine 3.1.........61

Tandem decarboxylative allylation-Heck cyclization of imine

3.12

Decarboxylative benzylation optimization conditions..................73

Substrate scope for palladium-catalyzed decarboxylative

benzylation of ester $\mathbf{4 . 1}$ .80

Bischler-Napieralski reaction. .88 


\section{ABBREVIATIONS}

$\begin{array}{ll}\text { Ac } & \text { acetyl } \\ \text { aq. } & \text { aqueous } \\ \text { Ar } & \text { aromatic } \\ \text { B } & \text { bite angle } \\ \text { BINAP } & \text { 1,1'-binaphthalene-2,2'-diyl)bis(diphenylphosphine) } \\ \text { Bn } & \text { benzyl } \\ \text { Boc } & \text { tert-butoxy carbonyl } \\ \text { bmimPF } & \text { 1-butyl-3-methylimidazolium hexafluorophosphate } \\ \text { br } & \text { broad (NMR) } \\ \text { BSA } & \text { N,O-bis(trimethylsilyl)acetamide } \\ \text { Bu } & \text { butyl } \\ { }^{\circ} \mathrm{C} & \text { degrees Celsius } \\ \text { C } & \text { concentration } \\ \text { Cbz } & \text { carboxybenzyl } \\ \text { CM } & \text { cross-methathesis } \\ \text { Cp } & \text { cyclopentyl } \\ \text { Cy } & \text { cyclohexyl } \\ \text { dba } & \text { chemical shift in ppm (NMR) } \\ \text { DCM } & \text { dichloromethane } \\ & \end{array}$




\begin{tabular}{|c|c|}
\hline$\Delta$ & heat \\
\hline DIAD & di-iso-propyl azodicarboxylate \\
\hline DIPEA & $N, N$-diisopropylethylamine \\
\hline DMA & dimethylacetamide \\
\hline DMAP & 4-dimethylaminopyridine \\
\hline DMF & $\mathrm{N}, \mathrm{N}$-dimethylformamide \\
\hline DMSO & dimethylsulfoxide \\
\hline DPEphos & bis[(2-diphenylphosphino)phenyl] ether \\
\hline dppe & 1,1'-bis(diphenylphosphino)ethane \\
\hline $\mathrm{dr}$ & diastereomeric ratio \\
\hline dppf & 1,1'-bis(diphenylphosphino)ferrocene \\
\hline $\mathrm{E}$ & entgegan (trans) \\
\hline EDC & 1-ethyl-3-(3-dimethylaminopropyl)carbodiimide \\
\hline EDG & electron donating group \\
\hline ee & enantiomeric excess \\
\hline equiv. & equivalent(s) \\
\hline ESI & electronspray ionization \\
\hline $\mathrm{EtOH}$ & ethanol \\
\hline Et & ethyl \\
\hline EtOAc & ethyl acetate \\
\hline EWG & electron withdrawing group \\
\hline g & $\operatorname{gram}(\mathrm{s})$ \\
\hline $\mathrm{GHz}$ & gigahertz \\
\hline
\end{tabular}




\begin{tabular}{|c|c|}
\hline $\mathrm{h}$ & hour(s) \\
\hline HPLC & high performance liquid chromatography \\
\hline HRMS & high resolution mass spectrometry \\
\hline $\mathrm{Hz}$ & hertz \\
\hline IR & infrared \\
\hline$i-\operatorname{Pr}$ & isopropyl \\
\hline$J$ & coupling constant \\
\hline kcal & kilocalorie \\
\hline $\mathrm{L}$ & $\operatorname{liter}(s)$ \\
\hline LA & Lewis acid \\
\hline $\mathrm{LC}$ & liquid chromatography \\
\hline LDA & lithium diisopropylamide \\
\hline $\mathrm{LG}$ & leaving group \\
\hline LHMDS & lithium hexamethyldisilazide \\
\hline $\mathrm{m}$ & multiplet (NMR) \\
\hline M & molar (moles per liter)/metal \\
\hline $\mathrm{MeOH}$ & methanol \\
\hline Me & methyl \\
\hline $\mathrm{mg}$ & milligram \\
\hline $\mathrm{MHz}$ & megahertz \\
\hline $\min$ & minute(s) \\
\hline $\mathrm{mL}$ & milliliter(s) \\
\hline mol & $\operatorname{mole}(\mathrm{s})$ \\
\hline
\end{tabular}




\begin{tabular}{|c|c|}
\hline MS & molecular sieves \\
\hline$m / z$ & mass to charge ratio (MS) \\
\hline MW & microwave \\
\hline$n \mathrm{Bu}$ & normal butyl \\
\hline Ns & para-nitrobenzenesulfonyl ("nosyl") \\
\hline NMP & $N$-methyl-2-pyrrolidone \\
\hline NMR & nuclear magnetic resonance \\
\hline NOESY & nuclear Overhauser effect spectroscopy \\
\hline $\mathrm{Nu}$ & nucleophile \\
\hline$\rho$ & reaction constant \\
\hline PEG & polyethylene glycol \\
\hline PG & protecting group \\
\hline $\mathrm{Ph}$ & phenyl \\
\hline PHOX & phosphinooxazoline \\
\hline ppm & parts per million (NMR) \\
\hline PTC & phase transfer catalysis (catalyst) \\
\hline Pyr & pyridine \\
\hline $\mathrm{q}$ & quartet \\
\hline rac & racemic \\
\hline $\mathrm{R}_{\mathrm{f}}$ & retention factor (TLC) \\
\hline $\mathrm{RCM}$ & ring-closing metathesis \\
\hline $\mathrm{rt}$ & room temperature \\
\hline
\end{tabular}


sat. $\quad$ saturated

triplet (NMR)

TBAB tetrabutylammonium bromide

TBAC tetrabutylammonium chloride

TBAI tetrabutylammonium iodide

TBAT tetrabutylammonium triphenydifluorosilicate

t-Bu tert-butyl

temp temperature

Tf trifluoromethylsulfonate ("triflate")

tol tolyl

Ts toluenesulfonate ("tosyl")

THF tetrahydrofuran

TMS trimethylsilyl

TMSI trimethylsilyliodide

UV ultraviolet

W watt

Xantphos 4,5-bis(diphenylphosphino)-9,9-dimehtylxanthene

XPHOS 2-dicyclohexylphosphino-2', $4^{\prime}, 6^{\prime}$-triisopropylbiphenyl

Z zutsammen (cis) 
Palladium-Mediated Decarboxylative Cross-Coupling Reactions: Synthesis of Complex Polycyclic Amines 


\section{Chapter 1. Introduction to Palladium-Catalyzed Decarboxylative Alkylations}

\subsection{Transition Metal-Catalyzed Decarboxylative Coupling}

The formation of carbon-carbon bonds remains a central focus in organic synthesis. Methods that achieve these goals typically involve nucleophilic, possibly anionic and electrophilic components. In either the generation of the nucleophile or the concomitant loss of a leaving group from the electrophile, a requisite loss of undesired and possibly toxic stoichiometric side products is a general concern. An increasingly preferred reaction manifold would involve non-toxic and readily removed leaving groups. Moreover, the ability to generate a nucleophile and an electrophile from the same starting material could represent a more efficient reaction process. Transition-metal-mediated pathways for the construction of Csp ${ }^{3}$ $\mathrm{Csp}^{3}$ bonds have received substantial attention due to their relatively efficient, flexible, and selective (chemo-, regio-, diastereo-, and enantio-) methods. Even for these reactions, however, the generation of stoichiometric inorganic and/or organometallic side products is a concern. Accordingly, the use of transition metals in decarboxylative cross-coupling reactions provides a relatively mild and environmentally benign strategy for the formation of carbon-carbon bonds. This essentially neutral tactic removes the necessity for strong bases in such coupling reactions and is particularly significant in instances of reactants with sensitive functional groups. Furthermore, the stoichiometric expulsion of $\mathrm{CO}_{2}$ furnishes both 
a relatively non-toxic byproduct and a thermodynamic impetus toward the formation of reactive intermediates. ${ }^{1}$

\subsection{Palladium-Catalyzed Decarboxylative Allylic Alkylation of Enolates}

Now associated under the scope of the well-known Tsuji-Trost reaction, ${ }^{2}$ the use of palladium complexes in allylic decarboxylative rearrangements was first reported independently by Tsuji and Saegusa in the transformations of allyl $\beta$ ketocarboxylates to $\alpha$-allylic ketones. ${ }^{3,4}$ In early 1980 , Saegusa reported the facile palladium-catalyzed decarboxylation of allylic $\beta$-ketocarboxylates. ${ }^{3}$ By treatment of allyl $\beta$-ketocarboxylic esters with a substoichiometric amount of $\mathrm{Pd}\left(\mathrm{PPh}_{3}\right)_{4}$ at ambient temperatures, the formation of a $\pi$-allyl palladium (II) - enolate complex furnished the $\alpha$-allylic acylation product 1.2 (Scheme 1.1). In most of the reported cases, monoalkylation at the alpha position was the primary if not sole product obtained in moderate to high yields.

Scheme 1.1 Saegusa's route to $\alpha$-allylic acylation of enolates.

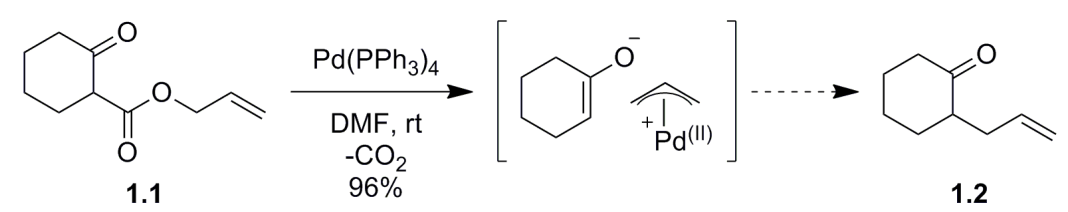

Through his studies on palladium-catalyzed Claisen rearrangements of allyl vinyl ethers in the formation of cyclic lactones and ketones, ${ }^{5}$ Tsuji ascertained the utility of palladium to induce rearrangements of allylic esters. In 1980, he reported the conversion of allyl acetoacetic acid esters by a palladium catalyzed Carroll 
rearrangement followed by concomitant loss of $\mathrm{CO}_{2}$ to furnish $\gamma, \delta$-unsaturated methyl ketones 1.4 (Scheme 1.2). ${ }^{4}$ In this example, Tsuji describes the intramolecular attack of the $\beta$-ketocarboxylate carbanion, formed following elimination of $\mathrm{CO}_{2}$, on the intermediate $\pi$-allylpalladium species. In addition, his report provided examples for the formation of quaternary carbon centers from $\alpha, \alpha$ disubstituted esters. This was an important development since prior to this report, thermal Claisen rearrangement of $\alpha, \alpha$-disubstituted esters was impossible due to the lack of an $\alpha$-hydrogen necessary for proton transfer.

Scheme 1.2 Tsuji's method of decarboxylative allylation of enolates.

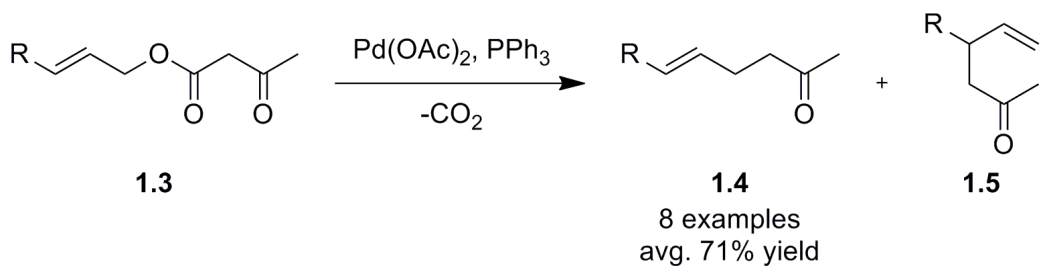

In 1986, Saegusa reported the decarboxylative allylation of $\beta$-keto acids and allylic acetates. ${ }^{6}$ The following year, Tsuji determined that the successful allylation of $\beta$-keto carboxylates by decarboxylation was due primarily to the stabilization of the carbanion by a ketone. To this end, he demonstrated that similar electronwithdrawing functional groups were also able to undergo the transformation in place of the ketone functionality, including malonate, cyanoacetate and $\beta$-nitro ketoacetate (Scheme 1.3). ${ }^{7}$ In those cases, higher temperatures and reaction times were required and products often resulted in decarboxylative-protonation or diallylation side products. This demonstrated utility of palladium decarboxylative 
allylation beyond the scope of $\beta$-ketocarboxylates shifted the focus of the methodology toward a broader range of substrates.

Scheme 1.3 Decarboxylative allylation of non-enolate functionalities.

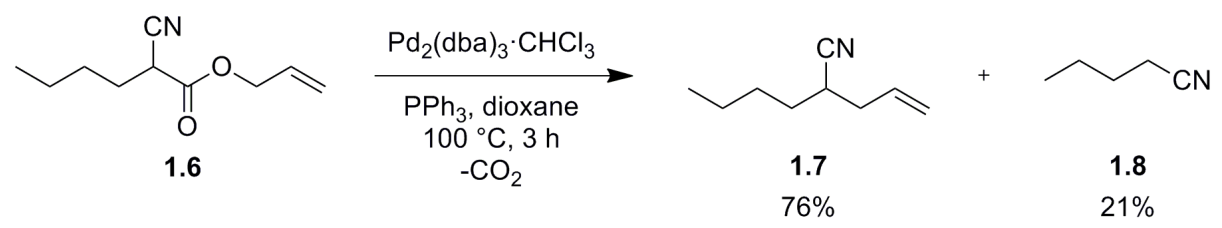

Prior to these seminal studies, palladium-catalyzed nucleophilic additions to allylic acetates often required stabilized "soft" carbanions to avoid dialkylation and poor regioselectivity. These nucleophiles were the conjugate bases of acids with $\mathrm{p} K_{a}$ values typically $<20$, such as malonate diesters (diethyl malonate $\mathrm{p} K_{a}\left(\mathrm{H}_{2} \mathrm{O}\right)=13$ ). ${ }^{8}$ To this end, a method to form both the nucleophile and the electrophile in situ was attractive. A particularly noteworthy advantage of decarboxylation over typical acid/base synthesis of the carbanion is the regioselective formation of an enolate at the $\alpha$-position which contains the $\mathrm{CO}_{2}$ moiety. The subsequent carbanion typically does not isomerize to thermodynamically more stable enolates prior to rapid alkylation with a $\pi$-allyl species. For example, Tunge and coworkers reported a regiospecific decarboxylative allylation of vinyl $\beta$-ketoesters in which a dienolate was generated. ${ }^{9}$ The authors observed only allylation at the more hindered $\alpha$ position $\mathbf{1 . 1 0}$ and propose this is the kinetic product while allylation at the least hindered $\gamma$-position $\mathbf{1 . 1 1}$ is the thermodynamic product (Scheme 1.4). Additionally, catalytic decarboxylative allylations often display increased reaction 
rates in comparison to competing processes, such as intramolecular protonation from acidic functional groups. ${ }^{10}$

Scheme 1.4 Regiospecific decarboxylative allylation.

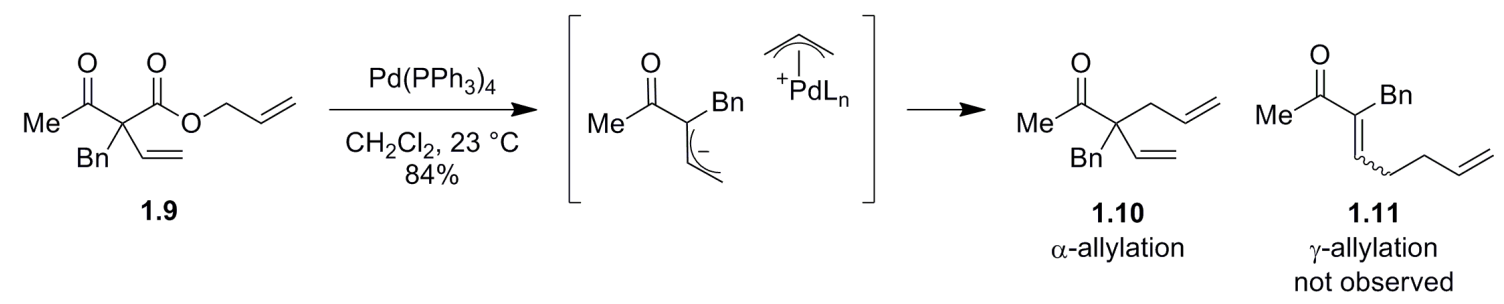

\subsection{Recent Advances in Decarboxylative Allylation}

Since the initial publications of Tsuji and Saegusa, extensive work has greatly expanded the application and scope of palladium-mediated decarboxylative alkylations. Recent studies have focused on the asymmetric allylic alkylation of $\beta$ ketocarboxylates. ${ }^{11}$ In 2004, Tunge reported the first asymmetric allylic alkylation of $\beta$-ketoesters with substoichiometric amounts of a palladium-Trost ligand complex by means of a surrogate Claisen rearrangement (Scheme 1.5).12 Tunge's revised method proceeded at room temperature and provided both high yields and remarkable enantioselectivites of the resulting allylated products from a range of racemic starting esters. 
Scheme 1.5 Tunge's asymmetric allylation of $\beta$-ketoesters.
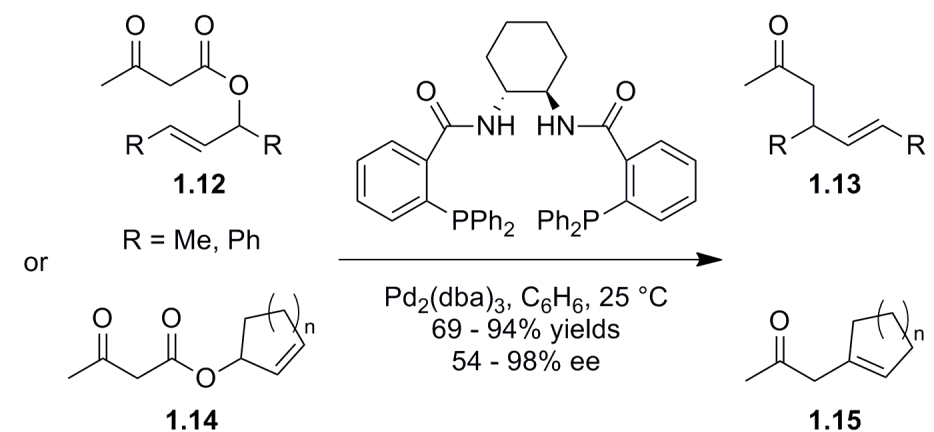

Furthermore, additional stabilized carbanions capable of palladiumcatalyzed decarboxylative allylation have been discovered. Initial studies by Tsuji probed the decarboxylative allylation of allyl enol carbonates, ${ }^{13}$ and recent studies have explored asymmetric variants of the reaction including acyclic moieties. ${ }^{14}$ Allyl enol carbonates have a significant advantage over $\beta$-ketoesters, specifically in the formation of homoallylic ketones. Stoltz et. al. reported the asymmetric allylic alkylation of allyl enol carbonates and silyl enol ethers that resulted in the synthesis of various quaternary substituted $\alpha$-carbons (Scheme 1.6). ${ }^{15}$ Ligand screening revealed the $(S)$-tert-butyl PHOX ligand produced the best enantioselectivites and further optimized conditions resulted in the synthesis of a variety of substituted cyclic ketones with moderate to high enantioselectivites. Stoltz and co-workers have applied this method to the total synthesis of enantiopure natural products including (+)-dichroanone, ${ }^{16}(-)$-cyanthiwigin $F,{ }^{17}(+)$-carissone, ${ }^{18}(+)$-cassiol, ${ }^{19}$ and (+)-hamigeran B. ${ }^{20}$ 
Scheme 1.6 Asymmetric decarboxylative allylation of allyl enol carbonates/silyl enol ethers.

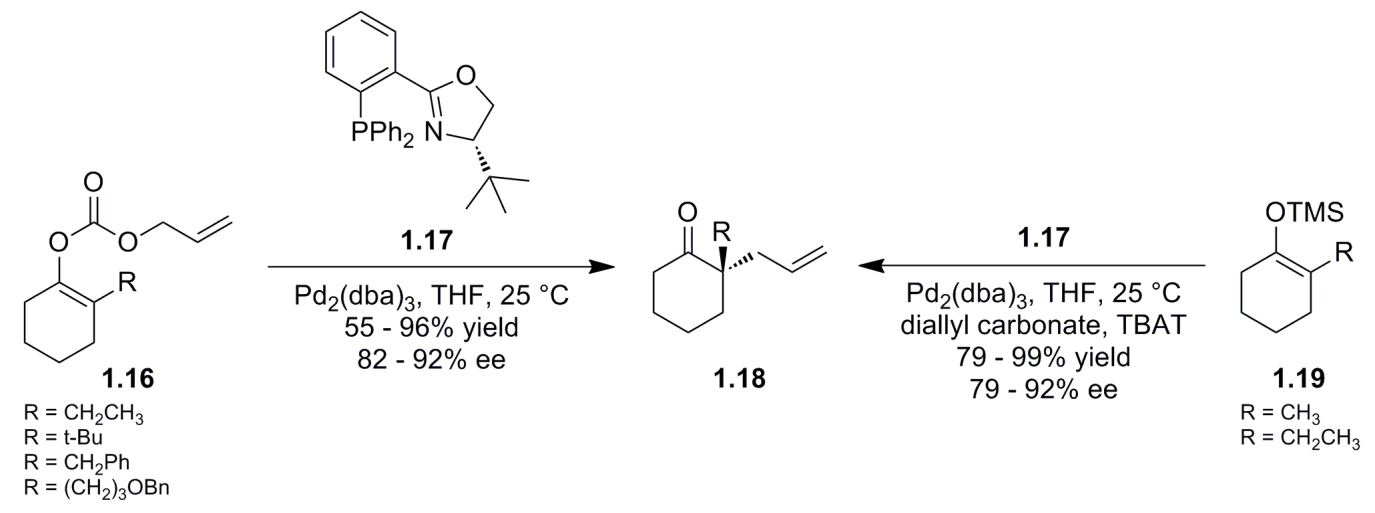

Following the success with palladium in decarboxylative allylations of enolates, Tsuji reported the allylation of carbon-centered nucleophiles by allylic carbonates in the presence of substoichiometric rhodium, ruthenium, molybdenum, and nickel complexes under neutral and mild conditions. ${ }^{21}$ Tunge has more recently reported the ruthenium-catalyzed Claisen rearrangements of $\beta$-ketocarboxylate esters and an iron-catalyzed decarboxylative allylic esterification of allyl carbonates. $^{22}$

Over the last ten years, an influx of additional studies have been reported involving the decarboxylative allylation of several unique substrates including $\alpha$ fluoro- $\beta$-ketoesters, ${ }^{23}$ vinylogous $\beta$-ketoester derivatives, ${ }^{24}$ asymmetric ringexpanding allylation, ${ }^{25} \alpha$-acetamido- $\beta$-ketoesters, ${ }^{26}$ and protected $\alpha$-hydroxyl allyl vinyl carbonates (Figure 1.1). ${ }^{27}$ 
Figure 1.1 Representative decarboxylative allylations.

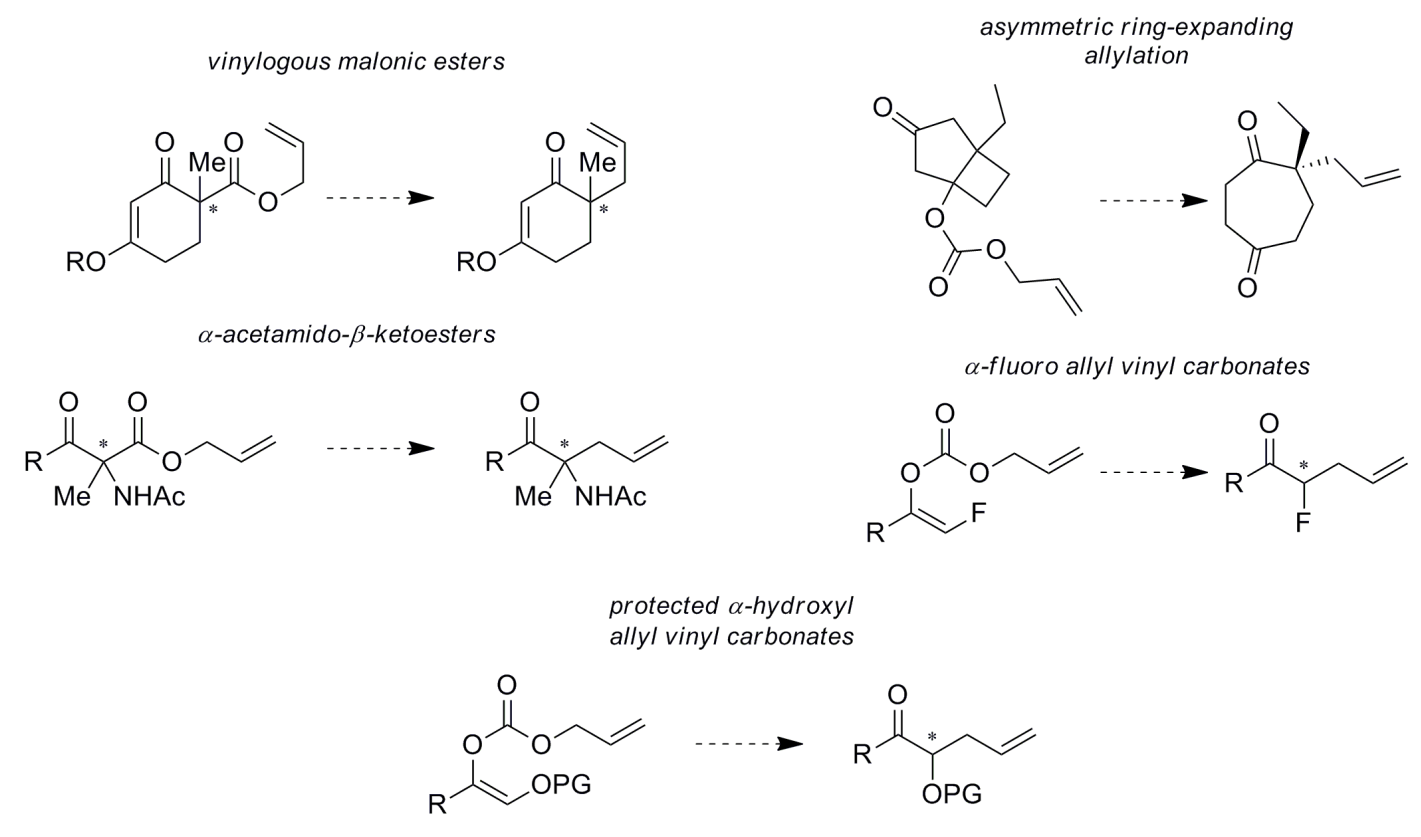

\subsection{Mechanistic Studies in Decarboxylative Allylation of Enolates}

Few mechanistic studies have ascertained the exact route for the decarboxylative allylation of enolates, primarily due to perceivable changes in the mechanism caused by both substrate and ligand modifications. However, the preliminary steps of decarboxylative allylation of enolates are generally accepted. The reaction is initiated by oxidative addition of palladium into the $\mathrm{C}-\mathrm{O}$ ester or carbonate bond, which may be in equilibrium with an ionized palladium-carboxylate pair and the $\sigma$-bound allyl palladium complex (Figure 1.2). In the case of bidenate ligands, the necessity for the ligand to access the metal center may result in slippage of the $\eta^{3}$ allyl fragment to $\eta^{1}$ binding in order to allow palladium(II), a 16-electron species, to adopt a square planar geometry. Stoltz et. al. recently reported 
mechanistic studies in which the $\eta^{1}$-allyl palladium intermediate was isolated and characterized as a 5-membered palladacycle (through coordination of the phosphine and nitrogen atom of $\mathbf{1 . 1 7}$ to the Pd center) prior to loss of $\mathrm{CO}_{2}{ }^{28}$ It is noteworthy that isolation of this species implies that it is, at best, a resting state for the catalyst.

Figure 1.2 Oxidative addition of palladium.

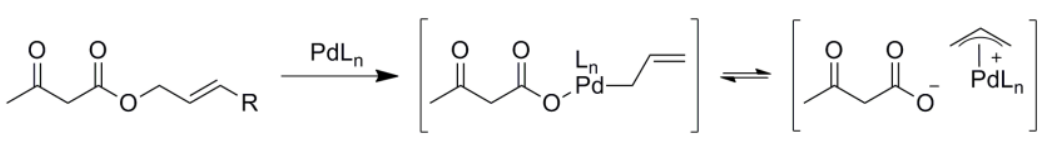

Recent studies to uncover the mechanistic steps following oxidative addition have become increasingly popular. In regards to $\beta$-ketoesters, reports have proposed allylation may occur in one of two manners: prior to (route A) or immediately after (route $\mathbf{B}$ ) the elimination of $\mathrm{CO}_{2}$, depending on substitution of the $\alpha$-carbon. (Figure 1.3). ${ }^{7,10}$ If an $\alpha$-proton is available, deprotonation by the carboxylate anion may occur to form a stabilized enolate, which then undergoes allylation followed by loss of $\mathrm{CO}_{2}$. This effect can be rationalized by comparing the relative $\mathrm{p} K_{\mathrm{a}}$ in DMSO for the $\alpha$-proton of a $\beta$-ketocarboxylate $(\sim 12)$ with that of the $\beta$-ketocarboxylate anion $(\sim 14) .{ }^{29}$ In cases of $\alpha, \alpha$-disubstituted esters, the lack of an $\alpha$-proton dictates that decarboxylation must occur prior to allylation in order to produce a reactive nucleophilic site. 
Figure 1.3 Proposed routes for allylation of $\beta$-ketoesters.

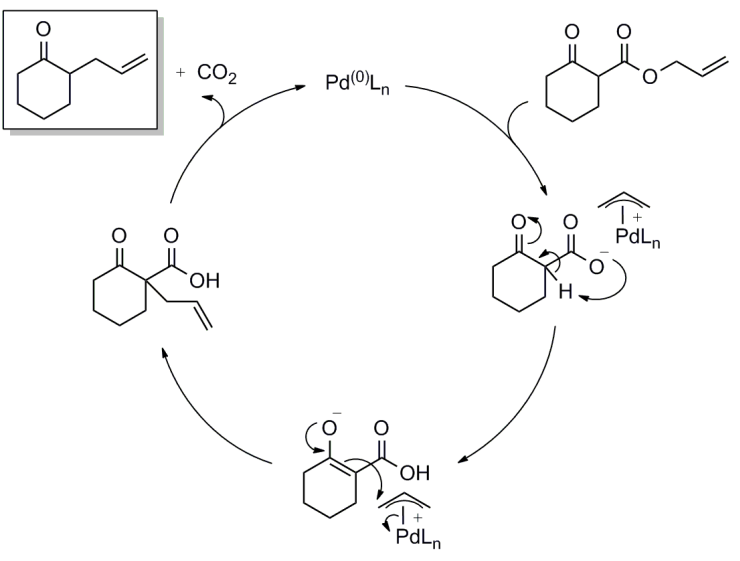

A

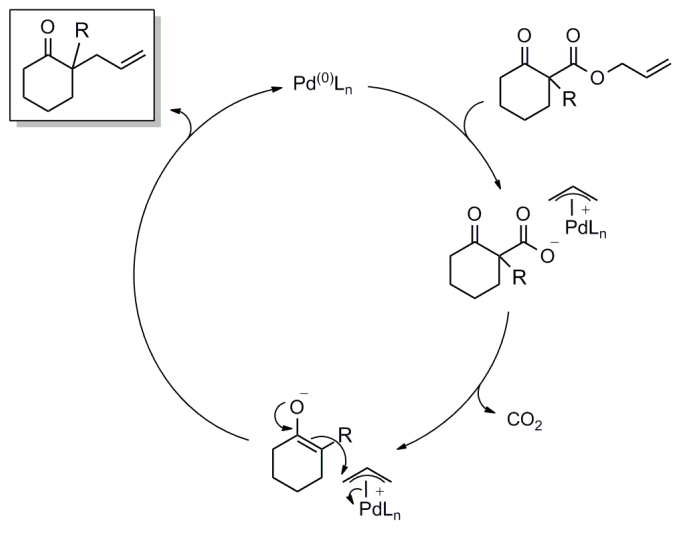

B

In a recent review on palladium decarboxylative allylation, Tunge and coworkers report that this hypothesis is supported by his latest stereochemical studies on the decarboxylative allylation of 3-carboxydihydrocoumarin derivatives, 7,30 in which substitution of the $\alpha$-carbon determined the subsequent stereochemistry of allylation. In all of the examples, $\alpha$-protonated derivatives resulted in a majority of the cis stereoisomer of allylated coumarin 1.21 , while $\alpha, \alpha-$ disubstituted coumarins produced the trans isomer of $\mathbf{1 . 2 3}$ exclusively (Scheme 1.7). By monitoring the decarboxylative allylation reaction through ${ }^{1} \mathrm{H}$ NMR spectroscopy, a noticeable carboxylic acid peak formed and disappeared during the course of the reaction of $\mathbf{1 . 2 0}$ while no intermediate was visible by spectroscopy in the reaction of $\mathbf{1 . 2 2}$. They attributed this acid peak to the formation of the acid intermediate after intramolecular proton transfer found in route $\mathbf{A}$. 
Scheme 1.7 Tunge's decarboxylative allylation of coumarin derivatives.

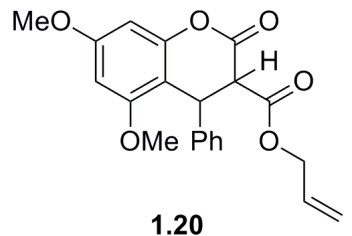

1.20

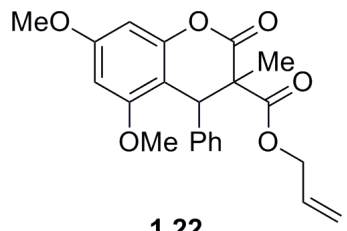

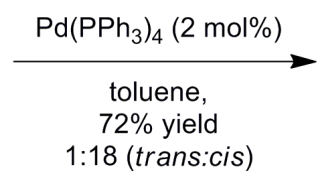

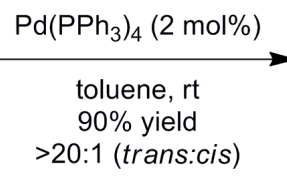

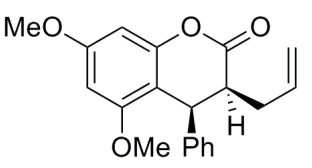

1.21

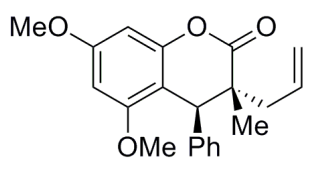

1.23

The authors described the reaction of the monosubstituted coumarin to follow mechanism route $\mathbf{A}$, while that of the $\alpha, \alpha$-disubstituted coumarin occur by the route B. Stereochemical determination was defined as the critical difference between the two possible pathways in which protonation is decisive in route $\mathbf{A}$ while allylation is in route B. Protonation was expected to occur anti to the aryl group and resulted in cis addition of the allyl moiety for route A. Allylation proceeded anti to the bulky aryl group in route $\mathbf{A}$ and resulted in trans addition.

The mechanistic evidence is regrettably less clear in regards to the decarboxylative allylation of allyl enol carbonates due to fewer experimental studies. It is typically postulated that enol carbonates undergo decarboxylation more readily than $\beta$-ketoesters, and examples of the spontaneous decarboxylation of alkyl carbonates have been reported to occur in water. ${ }^{31}$ Although water solvation is markedly different than that of organic solvents typically used in palladium decarboxylative allylations, purported enol carbonate reactivity has led 
researchers to conclude that elimination of $\mathrm{CO}_{2}$ precedes allylation. However, there are no direct mechanistic studies to support this theory, particularly in regards to modifications in the substrate which, as previously mentioned, may influence possible mechanistic pathways.

\subsection{Decarboxylative Allylic Alkylation of Non-Enolate Nucleophiles}

Palladium-catalyzed decarboxylative allylation has evolved into an established method for the coupling of carbon-carbon bonds with an extensive focus on the formation of nucleophilic enolates. While lagging, the decarboxylative generation of non-enolate nucleophiles has also grown considerably. Examples include early work by Saegusa in the decarboxylative generation of nucleophilic acetylides, ${ }^{6} \alpha$-cyano anions, ${ }^{6}$ and acrylonitriles, ${ }^{6}$ in addition to work by Tsuji (vide supra). Recent work in the decarboxylative generation of non-enolate nucleophiles, including $\alpha$-sulfonyl anions ${ }^{32}$ and heteroaromatic alkanes, ${ }^{33}$ has been extensively pioneered by Tunge and co-workers.

Of particular interest, 2-azaallyl anions have been reported in the synthesis of homoallylic amines, a useful synthetic precursor for alkaloids and azaheterocycles. $^{34}$ Traditional methods for the synthesis of homoallylic amines include the addition of nucleophilic allyl organometallics, ${ }^{35}$ allyl organoboranes, ${ }^{36}$ and silanes $^{37}$ into activated electrophilic imines. A complementary scheme utilizes the addition of an $\alpha$-imino anion (azaallyl anion) into an electrophilic allyl moiety. 
Classical conditions for the formation of this anion are often harsh and require strong base in order to deprotonate the carbon alpha to the imine nitrogen.

The Chruma group has reported the use of palladium-mediated decarboxylative allylation of diphenylglycinateimines for the formation of a putative $\alpha$-imino anion in the synthesis of protected $\alpha$-heteroaryl and $\alpha$-aryl homoallylic imines (Scheme 1.8). ${ }^{38}$ This method has exploited the advantageous conditions of decarboxylative allylation and furnished an essentially neutral method toward a versatile synthon for the rapid synthesis of organoamines in the absence of toxic byproducts.

Scheme 1.8 Chruma's decarboxylative allylation of diphenylglycinate imines.

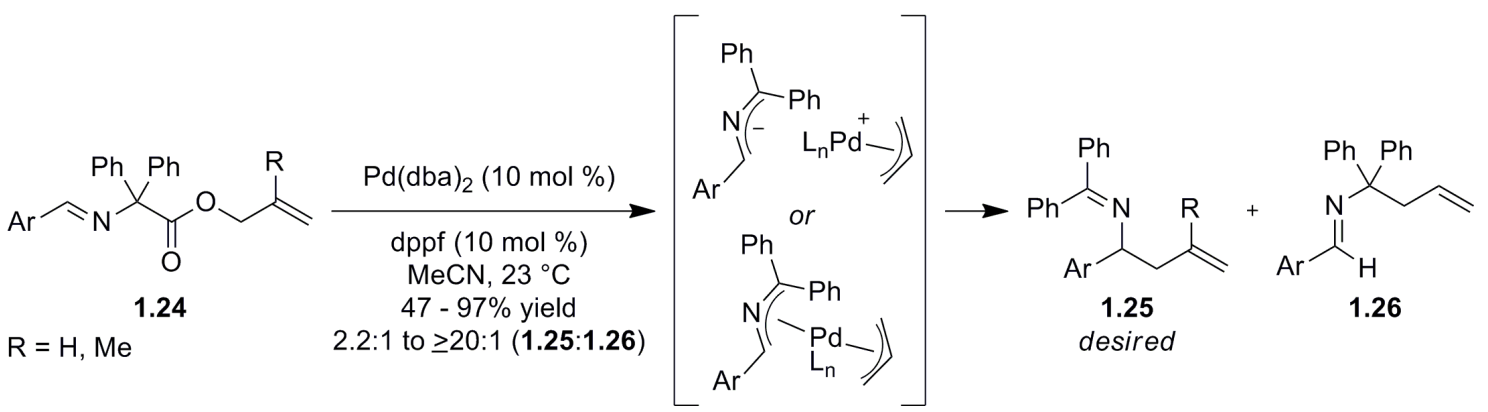

The electronic characteristics of the imine substituent proved to be a significant factor on the regioselectivity of allylation (Scheme 1.9). Particularly, electron-deficient imines provided excellent regioselectivity for the desired isomer (e.g. 1.28). In contrast, electron-releasing substituents had a reduced selectivity for the desired regioisomer. Accordingly, electron-rich aldimines exhibited reduced selectivity between regioisomers (1.31 versus 1.32$)$. Save for some notable exceptions, the regioselectivity exhibits a positive linear Hammett correlation. 
Through condensation of allyl diphenylglycine with a variety of aryl aldehydes, this method has provided a direct route to unique protected homoallylic imines from relatively inexpensive non-natural amino acid derivatives.

Scheme 1.9 Regioselectivity of electron-deficient substituents.
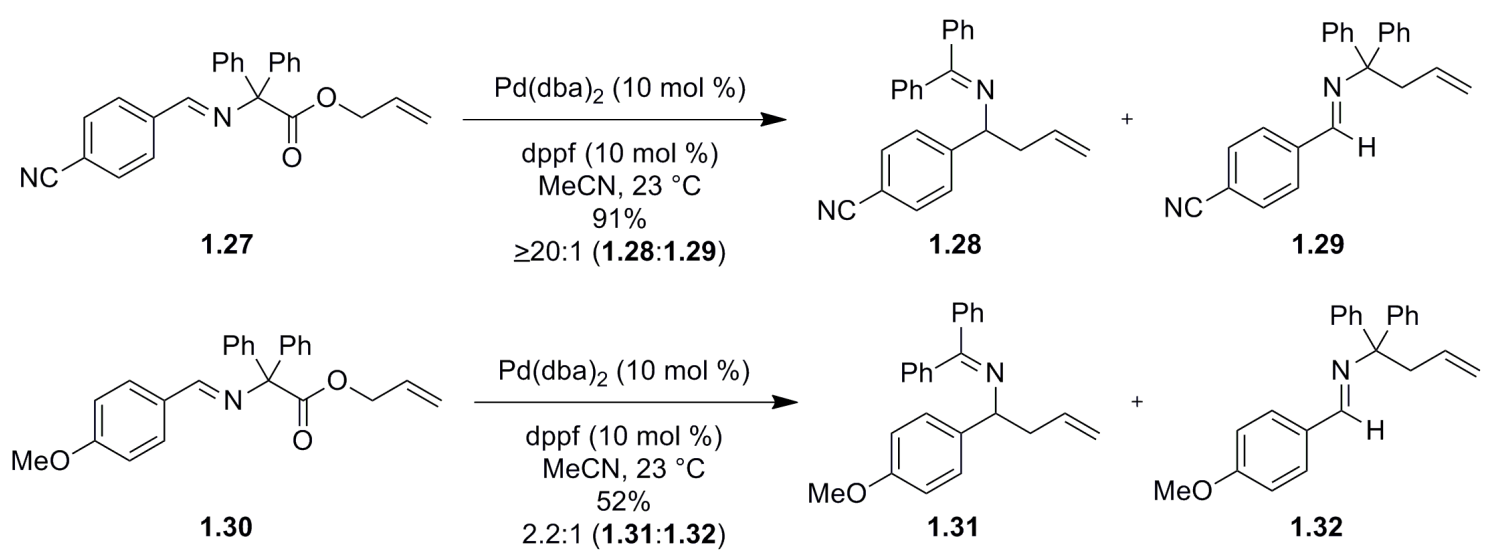

In 2006 and shortly before Chruma's initial reports, Burger and Tunge reported a complimentary method for the synthesis of homoallylic imines which employed $\alpha$-benzophenone imines of allyl $\alpha$-aminoesters. ${ }^{39}$ Beginning with the allylic ester of phenylglycine and various derivatives, their method led to a variety of functionalized amino acid substrates. Observed regioselectivity and its dependence on the electronic character of the $\alpha$-side chain were consistent with our observed trends. This suggests both Chruma and Tunge pathways undergo common putative intermediates (Figure 1.4) and determination of the actual intermediate is currently under investigation in our group. As a consequence to the nature of Tunge's original phenyl-derivative amino acid substrate, several examples were readily produced using Chruma's methods. In particular, heteroaromatic 
homoallylic imine derivatives would be relatively inaccessible utilizing Tunge's pathway without significant synthetic overhead.

Figure 1.4 Chruma vs. Tunge methods of decarboxylative allylation. ${ }^{5}$

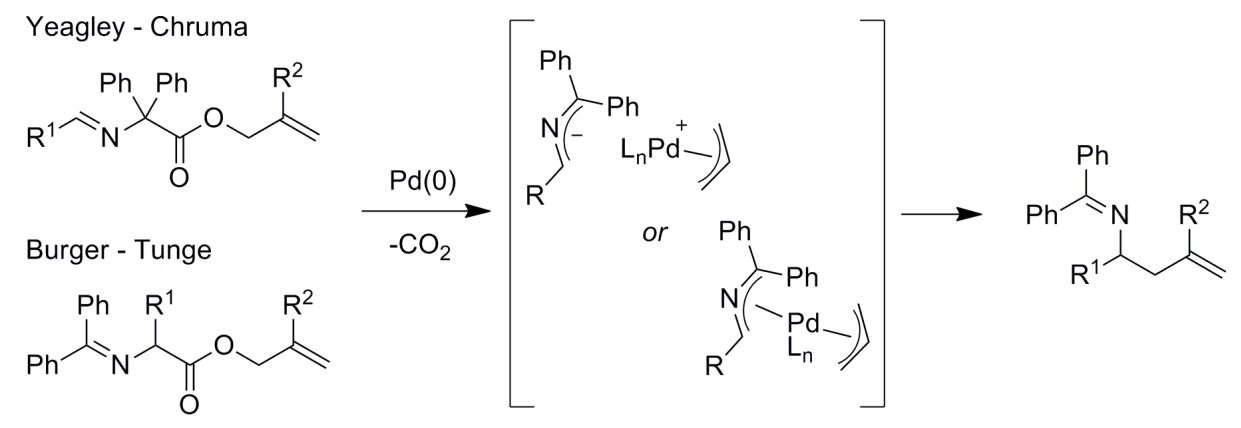

\subsection{Additional Palladium-Catalyzed Decarboxylative Cross-Coupling Reactions}

Recent investigations have focused on cross-coupling of the resulting carbanion formed following decarboxylation for use in additional palladiumcatalyzed transformations. ${ }^{40,41}$ In 2002, Myers and co-workers reported the palladium-catalyzed decarboxylation of arene carboxylates followed by an intermolecular Heck-type coupling with a variety of olefinic substrates (Scheme 1.10). ${ }^{42}$ Under optimized conditions, a wide range of aryl and heteroaryl carboxylates underwent the transformation in moderate to high yields of the resulting Heck coupled alkene. Noteworthy, the reactions were unaffected by subjection to air, nitrogen, pure oxygen or small amounts of water. The authors observed that substitution of the arene carboxylate at the ortho position was necessary for decarboxylative palladation to occur due to a competing $\mathrm{C}-\mathrm{H}$ insertion of palladium among substrates lacking this substitution. Moderate to excellent 
isolated yields were observed for both electron-rich and electron-deficient carboxylate derivatives. In addition to heterocyclic carboxylates, the reaction also proceeded efficiently with a variety of alkene coupling partners including styrene, cyclohexenone, acrylates, and (E)-ethyl crotonoate. Since the emergence of this publication, additional studies on palladium-catalyzed decarboxylative-Heck coupling reactions have been reported (Scheme 1.11). ${ }^{43}$ For example, Goossen et. al. reported an interesting decarboxylative-Heck olefination of benzoic acids in the synthesis of vinyl arenes. ${ }^{43 b}$ The synthesis provided a waste-free and atomeconomical pathway for the synthesis of these derivatives in moderate to high isolated yields. Recent reports have demonstrated a broad scope of possible decarboxylative cross-coupling reactions, including decarboxylative Michael reactions $^{44}$ and aldol reactions, ${ }^{45}$ in addition to the decarboxylative cross-coupling utilized in the synthesis of unsymmetrical biaryls, ${ }^{46}$ and benzyl alkynes. ${ }^{47}$

Scheme 1.10 Myer's palladium-catalyzed decarboxylation-Heck type coupling.

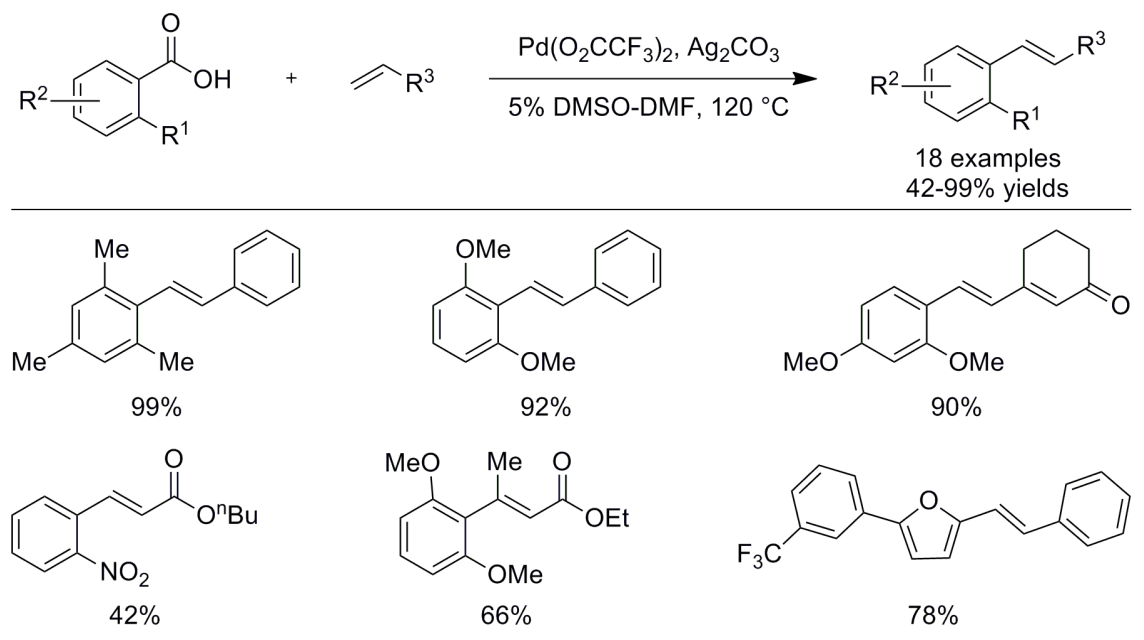


Scheme 1.11 Progress of decarboxylative-Heck olefination.

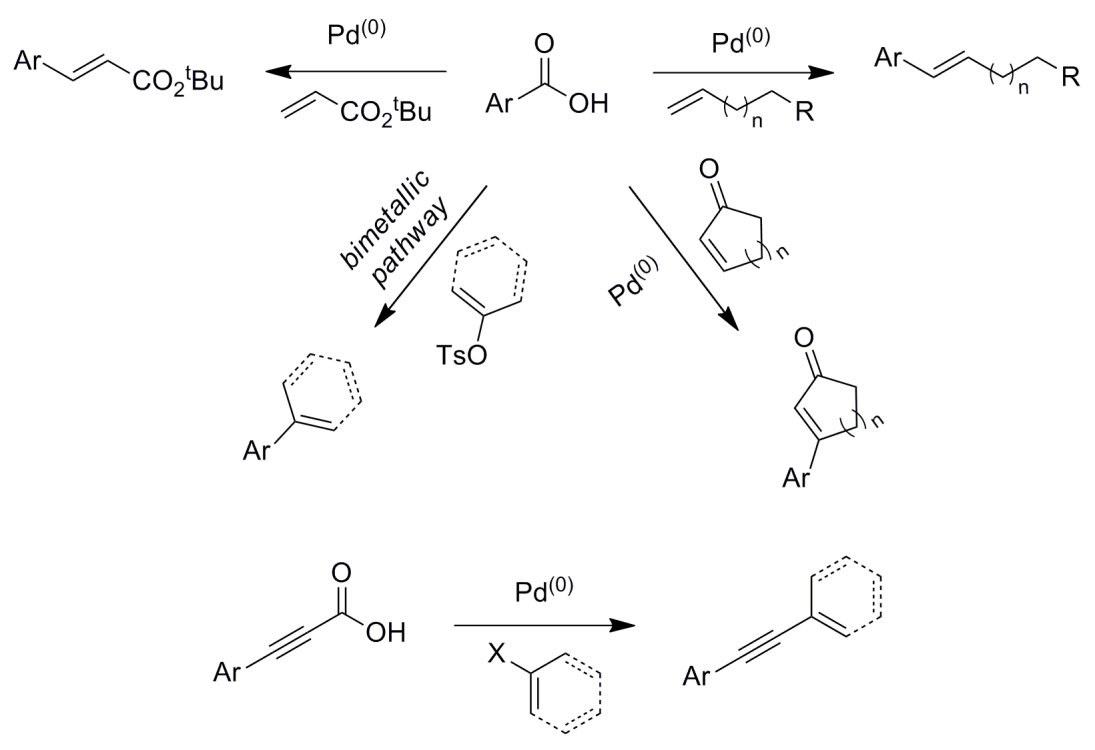

\subsection{Tandem Palladium-Catalyzed Decarboxylative Cross-Coupling Reactions}

Transition metal-catalyzed tandem or one-pot chemistry is a rapidly growing area of organic synthesis and provides advantages in efficiency and often increased regio-, diastereo-, and sometimes enantioselectivity in the synthesis of complex products. ${ }^{48}$ These sequential cascades connect several synthetic transformations into one step without isolating intermediates. Recently, interesting applications in tandem synthesis that utilize palladium-catalyzed decarboxylative-coupling chemistry have been reported. Notably, the decarboxylation precedes or follows additional carbon bond forming synthetic steps in these synthetic schemes.

In 2008, Lee and co-workers described an attractive synthesis of unsymmetrical biaryl alkynes utilizing a tandem palladium-catalyzed Sonogashira 
and decarboxylation reaction (Scheme 1.12). ${ }^{49}$ After the initial alkyne $\mathbf{1 . 3 4}$ is coupled to an aryl iodide $\mathbf{1 . 3 3}$ by subjection to substoichiometric $\mathrm{Pd}_{2}(\mathrm{dba})_{3} / \mathrm{dppf}$ conditions, addition of aryl bromide and heat furnished the bisarylated products in moderate to high yields within the same reaction vessel and without additional palladium catalyst. This pathway has provided a mild and simpler alternative to classical reagents typically employed in the synthesis of unsymmetrical biaryl derivatives using the Sonogashira reaction including copper under basic conditions. ${ }^{50}$ Additionally, it reduces the occurrence of homocoupling that is observed as a characteristic side product with classical Sonogashira reaction conditions.

Scheme 1.12 Unsymmetrical bisarylated alkynes by Sonogashira-decarboxylative coupling.

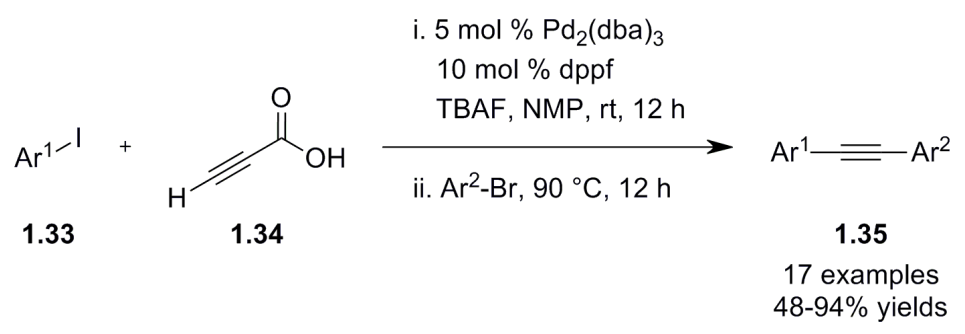

Recently, studies regarding domino palladium-catalyzed decarboxylative couplings of specifically allylic carboxylic acid derivatives have been reported. These transformations are especially unique given that the allylation resulting from nucleophilic attack on the $\pi$-allyl palladium complex is facile and characteristically regiospecific. For example, Liang and co-workers recently demonstrated a decarboxylative coupling of arynes and allylic alkynoates in a one-pot synthesis of $\mathrm{sp}^{2}-\mathrm{sp}^{3}$ and $\mathrm{sp}-\mathrm{sp}^{2}$ carbon bonds. ${ }^{51}$ Decarboxylation of various allylic alkynoates 
was utilized in the formation of two separate reaction species, which were subsequently cross-coupled with several aryne derivatives (Scheme 1.13). The authors' proposed mechanism described the trapping of an anionic alkyne by a benzyne intermediate prior to allylation from the transient $\operatorname{Pd}(\mathrm{II}) \pi$-allyl species.

Scheme 1.13 Liang's palladium-catalyzed decarboxylation-coupling of allyl derivatives.

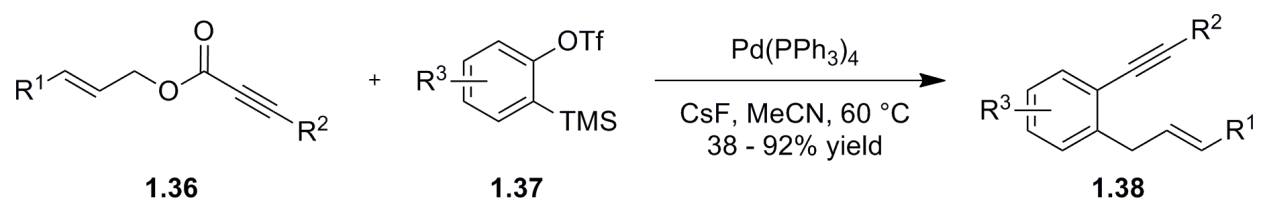

Palladium decarboxylative allylic alkylations have also been linked sequentially to Michael addition reactions in a one-pot procedure. Yamamoto demonstrated a regioselective intermolecular tandem Michael additiondecarboxylative allylation of activated olefins (Scheme 1.14). ${ }^{52}$ The reaction proceeded with a variety of activated aryl olefin derivatives in moderate to high yields. In an extension of this work, Yamamoto later reported an aza-Michael addition-allylation variant of the scheme (Scheme 1.15). ${ }^{53}$

Scheme 1.14 Tandem Michael addition-decarboxylative allylation.

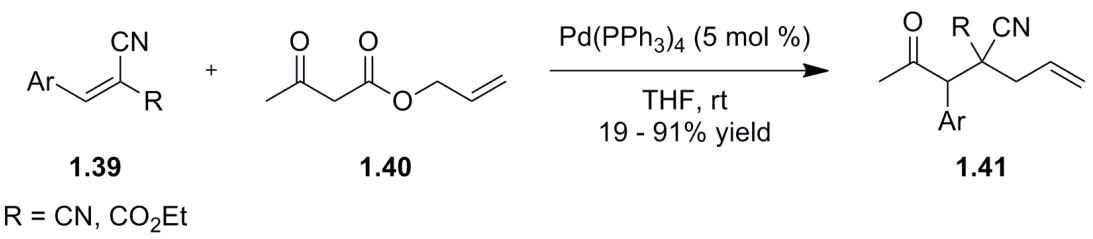


Scheme 1.15 Aza-Michael addition-allylation.

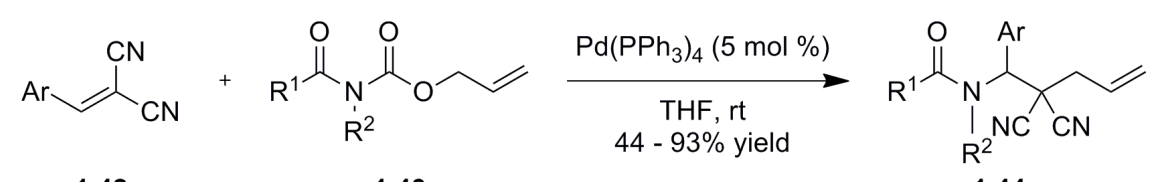

1.42

1.43

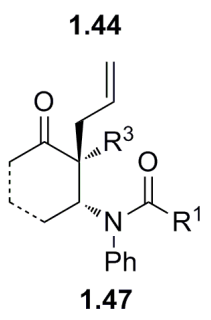

\subsection{Palladium-Mediated Decarboxylative Benzylation Reactions}

The number of electrophiles involved in palladium-catalyzed decarboxylative couplings has been primarily limited to allyl moieties. Benzylic derivatives including benzyl halides, carbonates, and acetates, have seen some use as coupling partners with stabilized nucleophiles in palladium-catalyzed carbon bond forming reactions. ${ }^{54}$ However, only recently have benzylic reagents been utilized in decarboxylative cross-coupling chemistry, particularly in reaction with unstabilized nucleophiles.

Early examples of intermolecular decarboxylative benzylations were reported by Fiaud. ${ }^{55}$ These examples were limited to the reaction of naphthyl acetates and carbonates with the stabilized nucleophile, sodium dimethyl malonate. Benzyl acetates were attempted with little success, and this result was attributed to a greater loss in resonance energy caused by disruption of aromaticity upon $\eta^{3}$ benzyl complexation that is observed particularly in aromatics with less extended 
aromatic systems (Figure 1.5).56 In regards to substituent effects of a simple benzylic ester, Kuwano later observed that both electron-donating and electronwithdrawing groups increased the reactivity of the benzyl moiety when treated with a palladium catalyst. This observation indicated a greater reactivity control resulting from an inductive rather than resonance effect. ${ }^{57}$

Figure 1.5 Relative rates for formation of $\pi$-allyl and benzyl palladium complexes. ${ }^{7}$

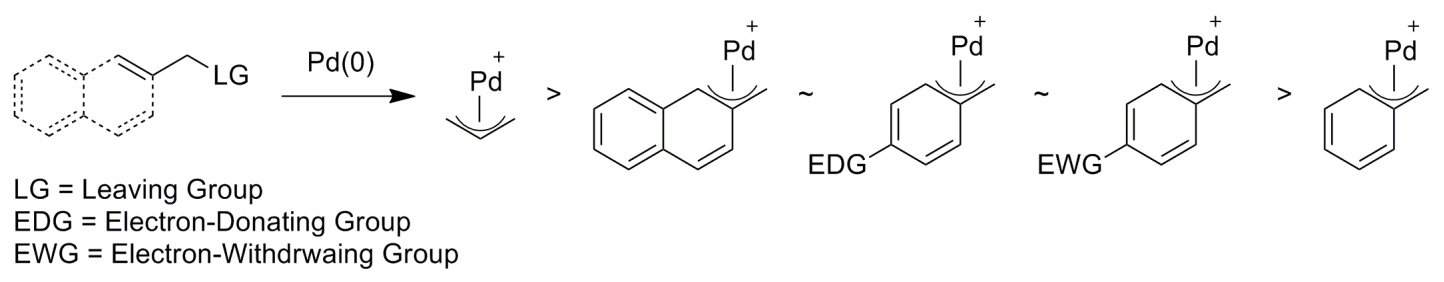

In 2008, Kuwano reported a synthesis of aryl benzyl ethers utilizing an intramolecular palladium-catalyzed decarboxylative benzylation from a wide range of substituted benzyl carbonates (Scheme 1.16). ${ }^{58}$ They observed little decrease in yield between aryl groups with para electron donating or deficient substitutions. Furthermore, the optimized conditions for the transformation of benzyl carbonates were amenable to the decarboxylative benzylation of benzyl methyl carbonate with various phenol derivatives that provided the resulting aryl benzyl ethers in moderate to excellent yields. This method is especially significant as benzyl ethers are a popular protecting group, yet they often require functional groups to be tolerant to strongly acidic or basic conditions in their synthesis. ${ }^{59}$ 
Scheme 1.16 Palladium-catalyzed decarboxylative benzylation.
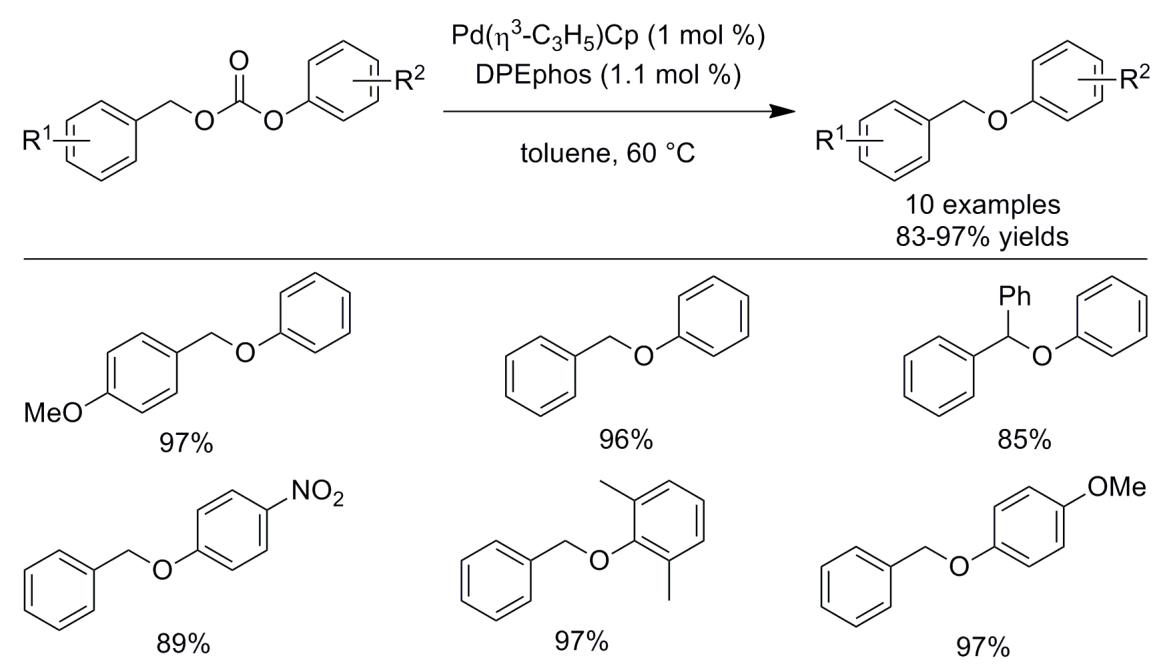

As stated, the formation of $\pi$-benzyl palladium complexes by decarboxylation of simple benzyl acetates has proven difficult, while substrates with extended conjugation more effectively undergo the transformation. After our initial reports in this arena (Chapter 4), Tunge demonstrated decarboxylative benzylation of heteroaromatic and naphthyl benzyl esters (Scheme 1.17). ${ }^{60}$ Unable to successfully catalyze the decarboxylative benzylation of simple phenylpropiolate, they observed that benzyl esters, as derivatives of naphthalene, quinoline and indole, rapidly underwent decarboxylation when subjected to their optimized catalytic conditions. Additionally under this system, they observed successful decarboxylative benzylation of benzyl $\beta$-ketoesters. 
Scheme 1.17 Tunge's decarboxylative benzylation of benzyl $\beta$-ketoesters and benzyl propioliates.

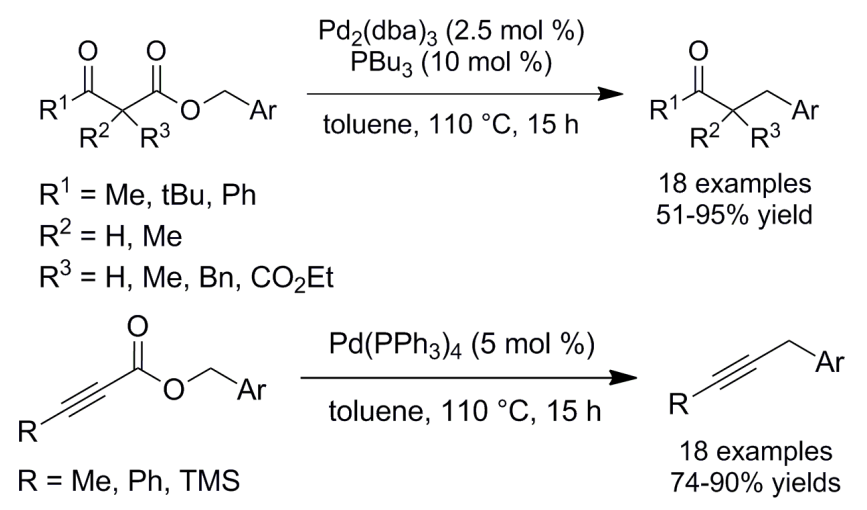

Recently, Li and co-workers circumvented issues concerning the decarboxylation of simple benzyl esters with the decarboxylative benzylation of alkynyl carboxylic acid derivatives with more reactive benzyl chlorides and aryl halides using a $\mathrm{Pd}(\mathrm{OAc})_{2} / \mathrm{XPhos}$ catalytic system (Scheme 1.18). ${ }^{61}$ The resulting benzyl alkynes and 1,2-diaryl alkynes were isolated in moderate to high yields. It is noteworthy that electron-withdrawing groups, particularly a para-nitro substitution, on benzyl chlorides did not convert to the desired product and resulted in recovery of the homocoupled product $\mathbf{1 . 4 8}$, presumably due to the deactivating affects of the nitro moiety. However, electron-donating substitutions effectively underwent the transformation. 
Scheme 1.18 Decarboxylative benzylation of alkynyl carboxylic acids.

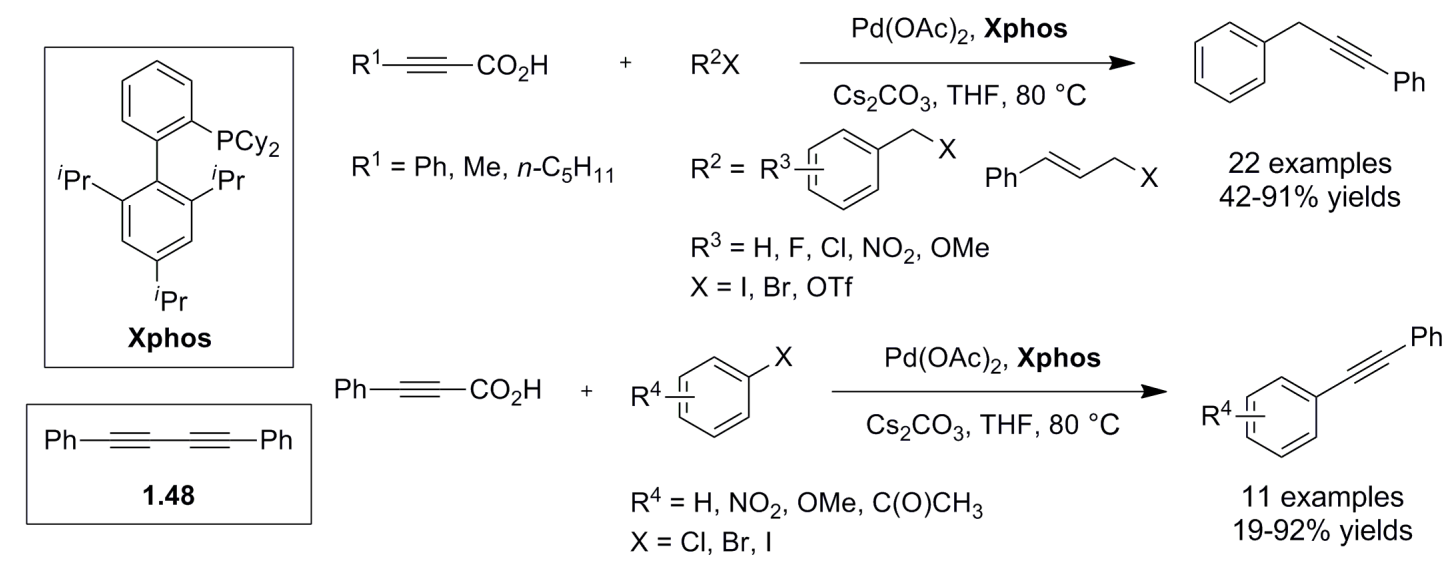

\subsection{Conclusion}

Palladium-catalyzed decarboxylative alkylations have made a significant impact in modern synthetic research efforts. In a relatively short time, a vast number of reports have emerged describing the utilization, improvement or investigation of palladium-catalyzed decarboxylation reactions. However, significant progress remains to be made and current limitations decrease the viability of decarboxylative alkylations as a green alternative to standard methods. For example, stabilized anions are typically necessary and the use of simple alkyl nucleophiles has yet to be fully investigated. Although the recent discovery of asymmetric decarboxylative alkylations has proved useful in the total synthesis of several natural products, it has seen limited application beyond allyl enolates. In addition, the reaction dependence on particular ligand and substrate modifications renders reaction optimization difficult and general (substrate independent) reaction 
methods do not exist at present. Several proposed mechanistic hypotheses have been described, yet few studies have delineated the exact route for decarboxylative alkylations.

Among transition metal-mediated tandem processes, to the best of our knowledge, there are limited examples that depict a one-pot pairing of the versatile palladium-catalyzed decarboxylative allylation reaction with another carboncarbon bond-forming palladium-mediated coupling, such as the Heck reaction. Furthermore, the palladium-catalyzed decarboxylative benzylation reaction scope is limited and additional efforts to improve this range are necessary to grasp a greater understanding of this relatively new method. 


\subsection{References}

${ }^{1}$ Villafranca, J. J.; Colman, R. F. Biochemistry 1974, 13, 1152 - 1160.

${ }^{2}$ For reviews on the Tsuji-Trost Reaction, please see: (a) Sesay, S. J.; Williams, J. M. J.; Adv. In Asymmetric Synth. 1998, 3, 235 - 271. (b) Trost, B.M.; Chem. Pharm. Bull. 2002, 50, 1 - 14. (c) Tsuji, J., Palladium-catalyzed nucleophilic substitution involving allylpalladium, propargylpalladium, and related derivatives: the TsujiTrost reaction and related carbon-carbon bond formation reactions: overview of the palladium-catalyzed carbon-carbon bond-formation via ?-allylpalladium and propargylpalladium intermediates in Handbook of Organopalladium Chemistry for Organic Synthesis (ed. Negishi, E-i.), 2, 1669 - 1687 (John Wiley \& Sons, New York, 2002).

3 Tsuda, T.; Chujo, Y.; Nishi, S.-I.; Tawara, K.; Saegusa, T., J. Am. Chem. Soc. 1980, $102,6381-6384$.

${ }^{4}$ Shimizu, I.; Yamada, T.; Tsuji, J., Tetrahedron Lett. 1980, 21, 3199 - 3202.

5 Tsuji, T.; Kobayashi, Y.; Kataoka, H.; Takahashi, T. Tetrahedron Lett. 1980, 1475 $-1478$.

${ }^{6}$ Tsuda, T.; Okada, M.; Nishi, S.-I.; Saegusa, T. J. Org. Chem. 1986, 51, 421 - 426.

7 Tsuji, J.; Yamada, T.; Minami, I.; Yuhara, M.; Nisar, M.; Shimizu, I. J. Org. Chem. $1987,52,2988-2995$.

8 (a) Trost, B. M.; Keinan, E. Tetrahedron Lett. 1980, 21, 2591 - 2594. (b) Trost, B. M. Tetrahedron. 1977, 33, 2615 - 2649. (c) Godleski, S. A., in Comprehensive 
Organic Synthesis, ed. Trost, B. M.; Pergamon Press, Oxford, 1991, vol 4, chap. 3.3. Fullerton, T. J.; Dietsche, T. J. J. Am. Chem. Soc. 1978, 100, 3416 - 3426.

9 Waetzig, S. R.; Rayabarapu, D. K.; Weaver, J. D.; Tunge, J. A. Angew. Chem. Int. Ed. 2006, 45, 4977 - 4980.

10 Weaver, J. D.; Recio, A.; Grenning, A. J.; Tunge, J. A. Chem. Rev. 2011, 111, 1846 $-1913$.

11 Mohr, J. T.; Behenna, D. C.; Harned, A. M.; Stoltz, B. M. Angew. Chem. Int. Ed. 2005, 117, $7084-7087$.

12 Burger, E. C.; Tunge, J. A. Org. Lett. 2004, 6, 4113 - 4115.

13 Tsuji, J.; Minami, I.;Shimizu, I. Tetrahedron Lett. 1983, 24, 1793 - 1796.

14 (a) Trost, B. M.; Xu, J. J. Am. Chem. Soc. 2005, 127, 2846 - 2847. (b) Mohr, J. T.; Behenna, D. C.; Harned, A. M.; Stoltz, B. M. Angew. Chem. Int. Ed. 2005, 44, 6924 6927. (c) Trost, B. M.; Xu, J. J. Am. Chem. Soc. 2005, 127, 17180 - 17181.

15 Behenna, D. C.; Stoltz, B. M. J. Am. Chem. Soc. 2004, 126, 15044 - 15045.

16 McFadden, R. M.; Stoltz, B. M. J. Am. Chem. Soc. 2006, 128, 7738 - 7739.

17 Enquist, J. A.; Stoltz, B. M. Nature 2008, 453, 1228 - 1231.

18 Levine, S. R.; Krout, M. R.; Stoltz, B. M. Org. Lett. 2009, 11, 289 - 292.

19 Petrova, K. V.; Mohr, J. T.; Stoltz, B. M.; Org. Lett. 2009, 11, 293 - 295.

${ }^{20}$ Mukherjee, H.; McDougal, N. T.; Virgil, S. C.; Stoltz, B. M. Org. Lett. 2011, 13, 825 $-827$.

21 (a) Tsuji, J.; Minami, I.; Shimizu, I. Tetrahedron Lett. 1984, 25, 5157 - 5160. (b) Minami, I.; Shimizu, I.; Tsuji, J. J. Organomet. Chem. 1985, 296, 269 - 280. 
22 (a) Burger, E. C.; Tunge, J. A. Org. Lett. 2004, 6, 2603 - 2605. (b) Trivedi, R.; Tunge, J. A. Org. Lett., 2009, 11, 5650 - 5652.

${ }^{23}$ (a) Mohr, T. J.; Behenna, D. C.; Harned, A. M.; Stolz, B. M. Angew. Chem. Int. Ed. 2005, 44, 6924 - 6827. (b) Nakamura, M.; Hajra, A.; Endo, K.; Nakamura, E. Angew. Chem. Int. Ed. 2005, 44, 7248 - 7251. (c) Burger, E. C.; Barron, B. R.; Tunge, J. A. Synlett 2006, 2824 - 2826. (d) Belanger, E.; Houze, C.; Guimond, N.; Cantin, K.; Paquin, J.-F. Chem. Commun. 2008, 3251 - 3253.

${ }^{24}$ (a) Trost, B. M.; Bream, R. N.; Xu, J. Angew. Chem. Int. Ed. 2006, 45, 3109 3112. (b) Levine, S. R.; Krout, M. R.; Stoltz, B. M. Org. Lett. 2009, 11, 289 - 292.

${ }^{25}$ Schulz, S. R.; Blechert, S. Angew. Chem. Int. Ed. 2007, 46, 3966 - 3970.

${ }^{26}$ Kuwano, R.; Naoki, I.; Murakami, M. Chem. Commun. 2005, 3951 - 3951.

27 Trost, B. M.; Xu, J.; Reichle, M. J. Am. Chem. Soc. 2007, 129, 282 - 283.

${ }^{28}$ Sherden, N. H.; Behenna, D. C.; Virgil, S. C.; Stoltz, B. M. Angew. Chem. Int. Ed. $2009,48,6840-6843$.

${ }^{29}$ Bordwell, F. G. Acc. Chem. Res. 1988, 21, 456 - 463.

${ }^{30}$ Chattopadhyay, K.; Jana, R.; Day, V. W.; Douglas, J. T.; Tunge, J. A. Org. Lett. 2010, 12, $3042-3045$.

31 (a) Pocker, Y.; Davison, B. L.; Deits, T. L. J. Am. Chem. Soc. 1978, 100, 3564 3567. (b) Sauers, C. K.; Jencks, W. P.; Groh, S. J. Am. Chem. Soc. 1975, 97, 5546 5553.

32 Weaver, J. D.; Tunge, J. A. Org. Lett. 2008, 10, 4657 - 4660.

33 Waetzig, S. R.; Tunge, J. A. J. Am. Chem. Soc. 2007, 129, 4138 - 4139. 
34 (a) Atobe, M.; Yamazaki, N.; Kibayashi, C. Tetrahedron Lett. 2005, 46, 2669 2673. (b) Puentes, C. 0.; Kouznetsov, V. J. Heterocycl. Chem. 2002, 39, 595 - 614. 35 Fernandes, R. A.; Stimac, A.; Yamamoto, Y.; J. Am. Chem. Soc. 2003, 39, 14133 14139.

${ }^{36}$ Seguira, M.; Hirano, K.; Kobayashi, S. J. Am. Chem. Soc. 2004, 126, 7182 - 7183.

37 (a) Berger, R.; Duff, K.; Leighton, J. L. J. Am. Chem. Soc. 2004, 126, 5686 - 5687.

(b) Friestad, G. K.; Korapala, C. S.; Ding, H. J. Org. Chem. 2006, 71, 281 - 289.

${ }^{38}$ Yeagley, A. A.; Chruma, J. J. Org. Lett. 2007, 9, 2879 - 2882.

${ }^{39}$ Burger, E. C.; Tunge, J. A. J. Am. Chem. Soc. 2006, 128, $10002-10003$.

${ }^{40}$ For examples of bimetallic catalyst systems for decarboxylation - coupling reactions, see: (a) Goossen, L. J.; Deng, G.; Levy, L. M. Science, 2006, 313, 662 664. (b) Goossen, L. J.; Rodriguez, N.; Melzer, B.; Linder, C.; Deng, G.; Levy, L. M. J. Am. Chem. Soc. 2007, 129, $4824-4833$.

${ }^{41} \mathrm{~A}$ recently developed palladium-catalyzed decarboxylation - coupling reaction without the need for a bimetallic catalytic system: Arroyave, F. A.; Reynolds, J. R. Org. Lett. 2010, 12, $1328-1331$.

42 Myers, A. G.; Tanaka, D.; Mannion, M. R. J. Am. Chem. Soc. 2002, 124, 11250 11251.

43 (a) Tanaka, D.; Myers, A. G. Org. Lett. 2004, 6, 433. (b) Goossen, L. J.; Zimmerman, B.; Knauber, T. Bielstein J. Org. Chem. 2010, 6. (c) Maehara, A.; Tsurugi, H.; Satoh, T.; Miura, M. Org. Lett. 2008, 10, 1159 - 1162. (d) Hu, P.; Kan, 
J.; Su, W.; Hong, M. Org. Lett. 2009, 11, 2341 - 2344. (e) Tanaka, D.; Romeril, S. P.; Myers, A. G. J. Am. Chem. Soc. 2005, 127, 10323 - 10333.

44 Nokami, J.; Watanabe, H.; Mandai, T.; Kawada, M.; Tsuji, J. Tetrahedron Lett. 1989, 30, $4829-4832$.

45 (a) Nokami, J.; Mandai, T.; Watanabe, H.; Ohyama, H.; Tsuji, J. J. Am. Chem. Soc. 1989, 111, 4126. (b) Nokami, J.; Konishi, H.; Matsura, H. Chem. Lett. 1991, 2023 2026. (c) Lou, S.; Westbrook, J. A.; Schaus, S. E. J. Am. Chem. Soc. 2004, 126, 11440 $-11441$.

46 Recently reported bimetallic $\mathrm{Cu} / \mathrm{Pd}$ transformation in the synthesis of unsymmetrical biaryls using decarboxylation-coupling reaction: Gooßen, L. J.; Rodriguez, N.; Lange, P. P.; Linder, C. Angew. Chem. Int. Ed. 2010, 49, 1111 1114.

47 (a) Moon, J.; Jang, M.; Lee, S. J. Org. Chem. 2009, 74, 1403 - 1406. (b) Kim, H.; Lee, P. H. Adv. Synth. Catal. 2009, 351, 2827 - 2832.

48 (a) Tietze, L. F.; Beifuss, U. Angew. Chem. Int. Ed. 1993, 32, 131 - 312. (b) Bunce, R. A.; Tetrahedron, 1995, 48, 13103 - 13159. (c) Patil, N. T.; Yamamoto, Y. Top. Organomet. Chem. 2006, 19, 91 - 113.

49 Moon, J.; Jeong, M.; Nam, H.; Ju, J.; Moon, J. H.; Jung, H. M.; Lee, S. Org. Lett. 2008, 10, $945-948$.

50 Marsden, J. A.; Haley, M. M; In Metal Catalyzed Cross-Coupling Reactions, $2^{\text {nd }}$ ed.; de Meijere, A.; Diederich, F.; Eds.; Wiley-VCH: Weinheim, 2004; Chapter 6. 
51 Pi, S. -F.; Tang, B. -X.; Li, J. -H.; Liu, Y. -L; Liang, Y. Org. Lett. 2009, 11, 2309 2312.

52 Shim, J.-G.; Nakamura, H.; Yamamoto, Y. J. Org. Chem. 1998, 63, 8470 - 8474.

53 Patil, N. T.; Huo, Z.; Yamamoto, Y. J. Org. Chem. 2006, 71, 6991 - 6995.

${ }^{54}$ Liégault, B.; Renaud, J.-L.; Bruneau, C. Chem. Soc. Rev. 2008, 37, 290 - 299.

55 (a) Legros, J. Y.; Fiaud, J. C. Tetrahedron Lett. 1992, 33, 2509 - 2510. (b)

Legros, J. Y.; Toffano, M.; Fiaud, J.-C. Tetrahedron. 1995, 51, 3235 - 3246.

${ }^{56}$ Baird, J. M.; Kern, J. R.; Lee, G. R.; Morgan, D. J.; Sparacino, M. L. J. Org. Chem. 1991, 56, $1928-1933$.

57 Kuwano, R.; Kondo, Y.; Matsuyama, Y. J. Am. Chem. Soc. 2003, 125, $12104-$ 12105.

${ }^{58}$ Kuwano, R.; Kusano, H. Org. Lett. 2008, 10, 1979 - 1982.

${ }^{59}$ (a) Greene, T. W., Wuts, P. G. M. Protective Groups in Organic Synthesis, 3rd ed.; John Wiley and Sons: New York, 1999. (b) Iversen, T.; Bundle, D. R. J. Chem. Soc., Chem. Commun. 1981, 1240 - 1241. (c) Poon, K. W. C.; Dudley, G. B. J. Org. Chem. 2006, 71, $3923-3927$.

60 Torregrosa, R. R. P.; Ariyarathna, Y.; Chattopadhyay, K.; Tunge, J. A. J. Am. Chem. Soc. 2010, 132, 9280 - 9282.

${ }^{61}$ Zhang, W.-W.; Zhang, X.-G.; Li, J.-H. J. Org. Chem. 2010, 75, 5259 - 5264. 


\section{Chapter 2. Microwaves in Organic Synthesis}

\subsection{Introduction to Microwaves in Organic Synthesis}

Microwave technology first saw its beginnings with the development of the cavity magnetron by Randall and Booth during World War II. ${ }^{1}$ This novel device was not patented until 1946, however, following research on high-powered radars for the Raytheon Company by American engineer, Percy Spencer. ${ }^{2}$ Though utilized for various industrial practices starting in the 1950s, applications in research laboratories were limited due to preconceived notions that linked microwave effects solely to interactions with water molecules. In 1986, the first reports of microwaveassisted organic syntheses were independently described by Gedye and Giguere/Majetich in which a variety of transformations, including hydrolysis, esterification, oxidation and Diels-Alder reactions, were performed in organic solvents (Scheme 2.1). ${ }^{3}$ These observations were especially pioneering as the microwave conditions efficiently reproduced or surpassed yields acquired using conventional heating conditions. 
Scheme 2.1 Initial reports on microwave-assisted (MW) organic reactions.

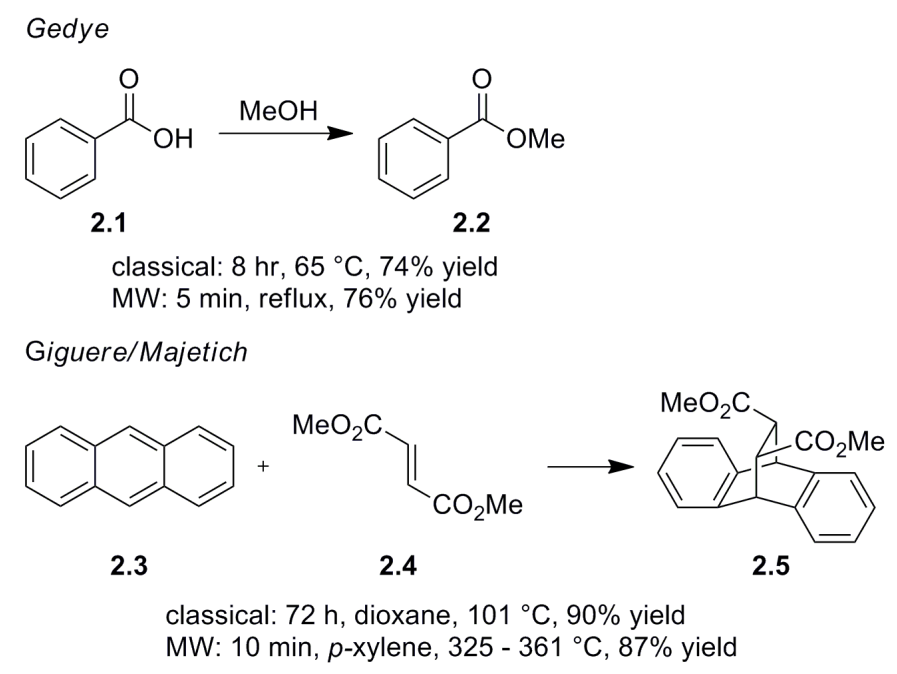

Over 60 years since the initial use of microwave irradiation, researchers have made strides in harnessing and improving the technique for chemical synthesis as evidence by nearly 2500 publications and reviews.4,5 Microwave heating possesses several advantages over conventional thermal heating including drastically reduced reactions times and increased solvent reflux temperatures when using a sealed reaction vessel. The development of commercial research microwave reactors (controlled microwave synthesis) has beneficially increased reproducibility of transformations, provided controlled temperature and power parameters, and decreased side product formation while often increasing yields. Overall, microwave irradiation has proven to be an efficient source of heat for organic reaction systems and has since been applied to a wide range of transformations including transition metal-catalyzed reactions (vide infra), reductions, oxidations, multi-component reactions, and solid-phase synthesis. ${ }^{2}$ 


\subsection{A Brief and Simplified Summary of Microwave Theory}

The microwave frequency range of 0.3 to $300 \mathrm{GHz}$ is located between infrared radiation and radio waves on the electromagnetic spectrum. In order to circumvent possible interference with telecommunication frequencies, most domestic and industrial microwave instruments have a standard operating frequency of $2.45 \mathrm{GHz}^{6,7}$ Unlike classic thermal heating (example: oil bath) which relies on heating the external vessel prior to heating the reaction contents, microwave irradiation provides a more efficient source of internal heat from energy generated by the molecules within the reaction mixture (Figure 2.1).

Figure 2.1 Temperature gradients of microwave vs. oil-bath heating after $60 \mathrm{sec}$.; microwave-heated vial (left) and thermally-heated by oil-bath vial (right). ${ }^{6,8}$

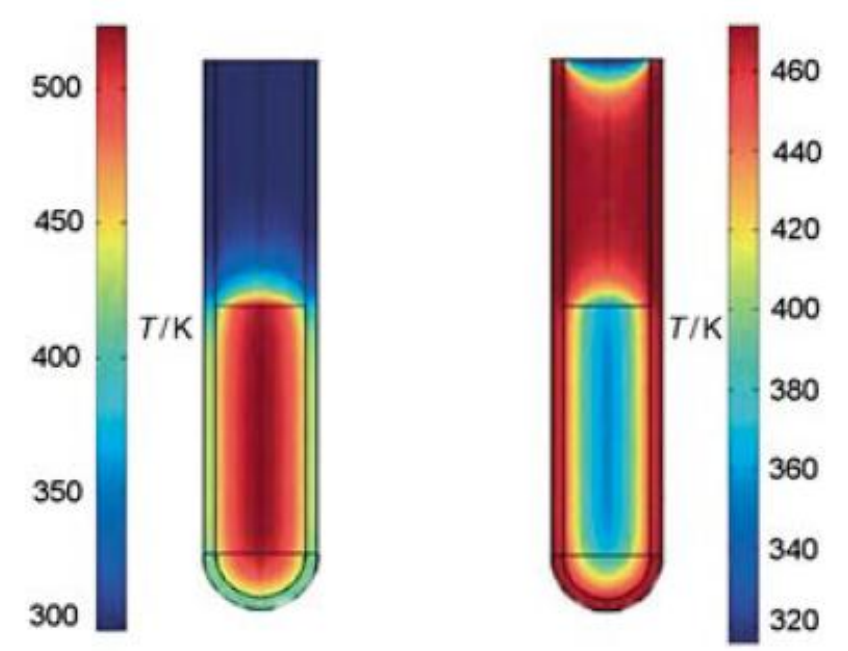

${ }^{*}$ Reproduced with kind permission from Springer Science+Business Media B.V.

Microwave irradiation utilizes a dielectric heating effect characteristic of some liquids and solids that subsequently generates internal heat from applied electromagnetic energy. This effect is controlled by two mechanisms - dipolar polarization (molecules in the reaction mixture with a permanent dipole) and ionic 
conduction (charge particles in the sample) - and is largely dependent on the ability of the reaction medium to absorb the applied microwave energy. Dipoles or ions, which typically freely rotate and oscillate in random orientations in the absence of an electric field, are aligned to a highly polarizing applied field upon irradiation at microwave frequencies and continually realign upon oscillation of the field. Through this process, molecular friction and collisions produce energy that is released as heat into the reaction mixture. $6,7,9,10$

Some solvents are particularly superior reaction mediums for microwave heating due to their ability to efficiently absorb microwave energy and dissipate it as heat. In systems that result in no dispersion of heat from an applied electromagnetic field, molecules are effectively able to adjust to electric field fluctuations because they rotate naturally at these frequencies (1 $\mathrm{MHz}$ to $1 \mathrm{GHz})$. However, at the frequency of $2.45 \mathrm{GHz}$ typically employed by most microwave reactors, the solvent dipole rotations lag behind the oscillating electric field resulting in a displacement difference, $(\delta)$, between the current in an irradiated sample and the applied field. The tangent loss factor, $\tan (\delta)$, is defined by this difference and is also a characteristic indicator of effective reaction mediums for microwave heating. In turn, solvents with high $\tan (\delta)$ values are required in order to achieve rapid heating for microwave reactions. As seen in Table 2.1, effective microwave reaction solvents have higher $\tan (\delta)$ values. For example, ethylene glycol is an efficient microwave solvent with a reported $\tan (\delta)$ of 1.350 in 
comparison to hexanes, a poorly microwave-absorbing solvent with a tan $(\delta)$ of only 0.020. Noteworthy, typical microwave vessels are made from microwave transparent borosilicate glass or Teflon with a $\tan (\delta)<0.01 .6,7,9,10$

Table 2.1 Tangent loss factors $(\tan (\delta))$ of selected solvents at $2.45 \mathrm{GHz}$ and $20{ }^{\circ} \mathrm{C} .6,11$

\begin{tabular}{cc|cc}
\hline Solvent & $\tan \delta$ & Solvent & $\tan \delta$ \\
\hline Ethylene glycol & 1.350 & 1,2-Dichloroethane & 0.127 \\
Ethanol & 0.941 & Water & 0.123 \\
DMSO & 0.825 & Chloroform & 0.091 \\
Methanol & 0.659 & Acetonitrile & 0.062 \\
1,2-Dichlorobenzene & 0.280 & Tetrahydrofuran & 0.047 \\
NMP & 0.275 & Dichloromethane & 0.042 \\
Acetic Acid & 0.174 & Toluene & 0.040 \\
DMF & 0.161 & Hexane & 0.020
\end{tabular}

An additional important characteristic of microwave heating is the ability for the solvent to superheat, or heat above its boiling point under atmospheric conditions without physically boiling, when subjected to irradiation in a sealed vessel. In fact, this capability has often been attributed as support for the continually debated idea of "non-thermal microwave effects", which claim product yields and purity from microwave-accelerated reactions are inherently different than identical conditions from thermally heated reactions. The certainty of this theory continues to be studied and ultimately requires additional research to fully disclose the possibility of these effects concerning organic reactions. $6,7,9,10$ 


\subsection{Transition Metal Catalysis: Carbon-Carbon Bond-Formation}

Transition metal-catalyzed reactions are one of the most studied and reported microwave-accelerated organic transformations. Many metal-catalyzed carbon-carbon bond-forming reactions require heating by conventional methods for extended lengths of time, often hours to days. The innovation of microwave heating has revolutionized the field by reducing these extensive reaction times to mere minutes or even seconds.

Specifically, palladium-catalyzed reactions comprise the majority of reported microwave-promoted transformations. The Heck, Sonogashira, ${ }^{12}$ Stille, ${ }^{13}$ and Suzuki ${ }^{14}$ protocols are four major carbon-carbon bond-forming reactions that have greatly benefited from microwave irradiation. Of these transformations, the Heck reaction has been the focus of a considerable influx of reports and will be discussed further in Section 2.4 (page 41). Highly enantioselective microwave-promoted asymmetric allylic alkylations have also been recently reported. ${ }^{15}$ For example, Hallberg and co-workers reported a highly enantioselective microwave-promoted palladium-catalyzed allylic alkylation of malonate nucleophiles (Scheme 2.2). ${ }^{15 a}$

Scheme 2.2 MW heated palladium-catalyzed asymmetric allylic alkylation.
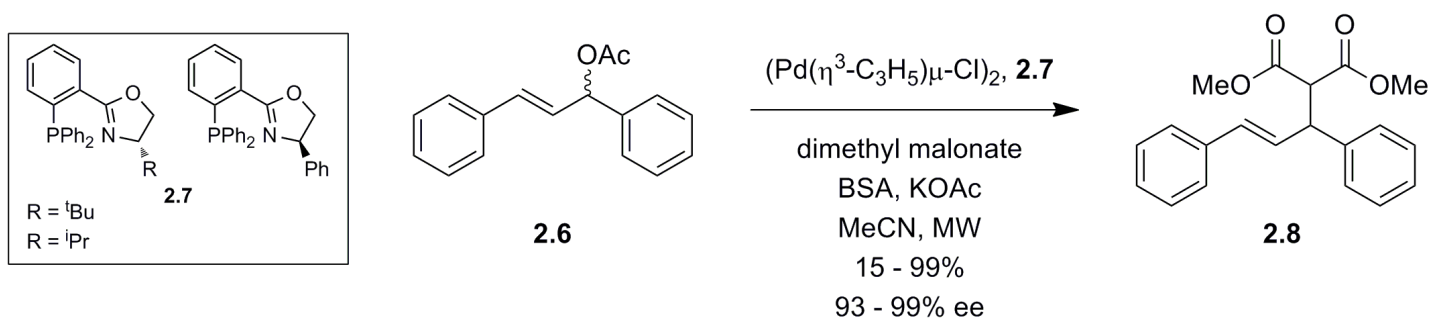

2.8 
Beyond reduced reaction times, recent breakthroughs in microwavepromoted synthesis have broadened the reaction scope of palladium-catalyzed carbon-carbon bond-forming transformations. For example, aryl chlorides have been increasingly implemented in microwave-irradiated palladium-catalyzed coupling reactions. ${ }^{16}$ Typically a poorly reactive coupling partner in conventional heating applications, this is an especially attractive innovation as aryl chlorides may be implemented in chemoselective coupling reactions. Additionally, these substrates are readily available and inexpensive compared to their bromide and iodide counterparts. Huang and coworkers recently reported a palladium-catalyzed Sonogashira coupling of aryl chlorides utilizing microwave heating (Scheme 2.3).17 The reaction scope included the successful coupling of electron-neutral, -deficient and -rich aryl chlorides with phenyl acetylene in moderate to high yields. Furthermore, the authors discovered the bimetallic $\mathrm{Pd} / \mathrm{Cu}$ pathway characteristic of Sonogashira reactions was unnecessary for their method and subsequently eliminated Glaser homocoupling of the alkyne moiety by removing copper from the reaction. The method was successfully applied to Heck, Suzuki and BuchwaldHartwig couplings of aryl chlorides. 
Scheme 2.3 Palladium-catalyzed coupling of aryl chlorides utilizing MW heating

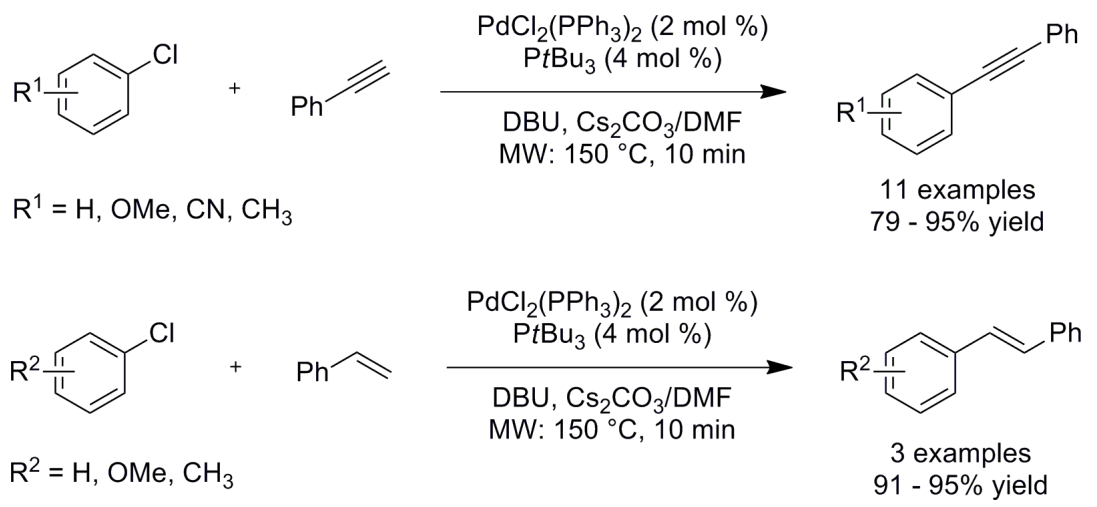

Recently, microwave-promoted olefin metathesis has gained increasing popularity. ${ }^{18}$ Thermal olefin metathesis reaction conditions can range from ambient to reflux temperatures for extended periods of time in order to achieve complete conversion. ${ }^{19}$ However, recent reports on microwave-accelerated olefin metathesis have reduced reaction times to minutes or even seconds upon subjection to microwave irradiation. ${ }^{20}$ In 2000, Varray and coworkers reported the first microwave-promoted olefin ring-closing metathesis (RCM) reaction in the synthesis of cyclic amino acid derivatives using PEG as a polymeric support (Scheme 2.4).21 The ruthenium-catalyzed reactions were heated in a domestic microwave oven, reducing reaction times from 24 hours to 10 minutes. Microwave heating has also been successfully applied to olefin cross-metathesis (CM) reactions ${ }^{22}$ and other carbon-carbon bond-forming processes catalyzed by copper, ${ }^{23}$ cobalt, $^{24}$ and nickel. 25 
Scheme 2.4 Initial report of MW-promoted olefin metathesis.

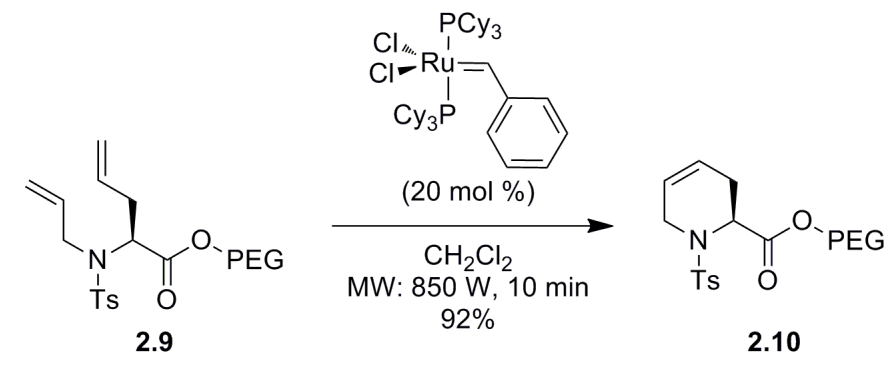

\subsection{Microwave-Assisted Heck Reactions}

The Heck reaction has been extensively optimized under microwave conditions. The first report of microwave irradiated Heck reactions emanated from Larhed and Hallberg in 1996 where the authors described the coupling of aryl iodides, aryl bromides and aryl triflates with various olefins (Scheme 2.5). ${ }^{26}$ The primary goal of this study was to determine a reduction in reaction time with microwave heating. Therefore, the reported conditions remained identical to thermal Heck reaction conditions as to retain an accurate comparison between the two methods. The intermolecular coupling products were furnished in moderate to high yields with substantially reduced reactions times compared to the corresponding conventionally heated examples. 
Scheme 2.5 MW-assisted Heck reaction.

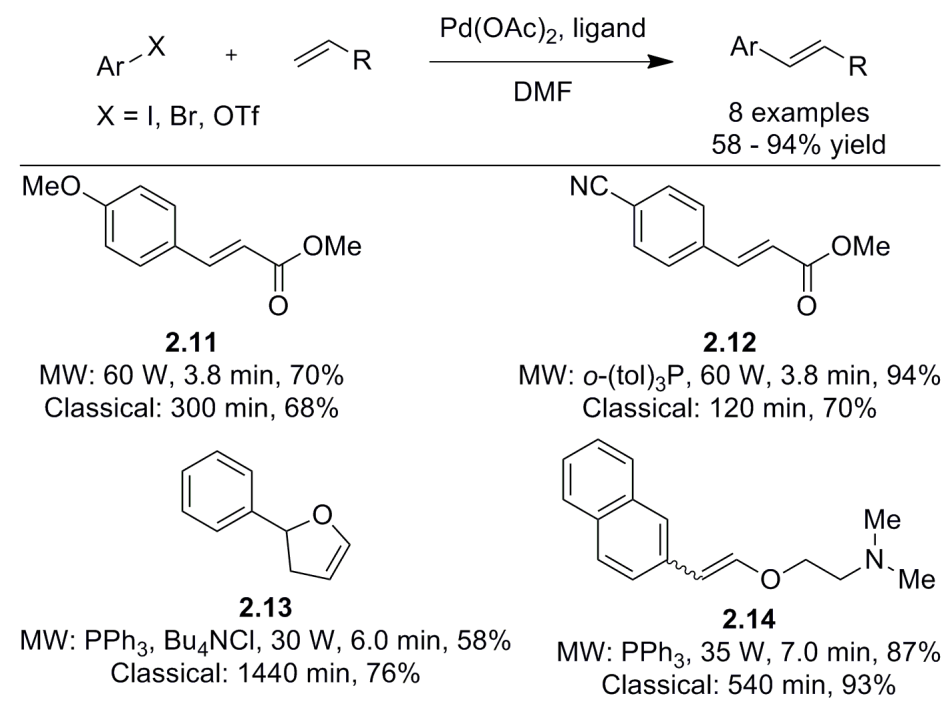

Aqueous microwave-assisted Heck reactions have also been reported, offering an additional "green" Heck reaction alternative. Wang et. al. described a rapid microwave-irradiated Heck reaction in water using tetrabutylammonium bromide as a phase transfer catalyst. ${ }^{27}$ Villemine and co-workers have reported a $\mathrm{H}_{2} \mathrm{O} / \mathrm{MeCN}$ protocol using hydrophilic ligands that lead to rapid Heck reactions with microwave heating. ${ }^{28}$ In 2004, Botella and co-workers described a microwavepromoted intermolecular Heck reaction in water catalyzed by an oxime-derivated palladacycle that resulted in the mono- and biarylation of $\alpha, \beta$-unsaturated carbonyls with aryl iodides. ${ }^{29}$

The introduction of polar ionic liquids into Heck reaction conditions has also been described, offering a green alternative to other highly microwave absorbing organic solvents. Larhed et. al. reported a microwave-promoted Heck arylation using ionic liquid 1-butyl-3-methylimidazolium hexafluorophosphate $\left(\mathrm{bmimPF}_{6}\right.$ ) 
and $\mathrm{PdCl}_{2}$, a system that was stable to the requisite high temperatures (Scheme 2.6)..$^{30}$ Aryl bromides typically required conditions of $220{ }^{\circ} \mathrm{C}$ for 20 minutes. However, the reaction with iodobenzene resulted in a 95\% yield in just 5 minutes at $180^{\circ} \mathrm{C}$. In support of the author's assertion that the ionic liquid/-catalyst system truly represented a green alternative, the recyclability of the system was tested. Bromobenzene and butyl acrylate were irradiated in the presence of $\mathrm{PdCl}_{2}$ and bmimPF $_{6}$ for 20 minutes at $180{ }^{\circ} \mathrm{C}$. The catalytic system successfully underwent 5 cycles without loss in isolated product yield.

Scheme 2.6 Heck arylation in ionic liquid.

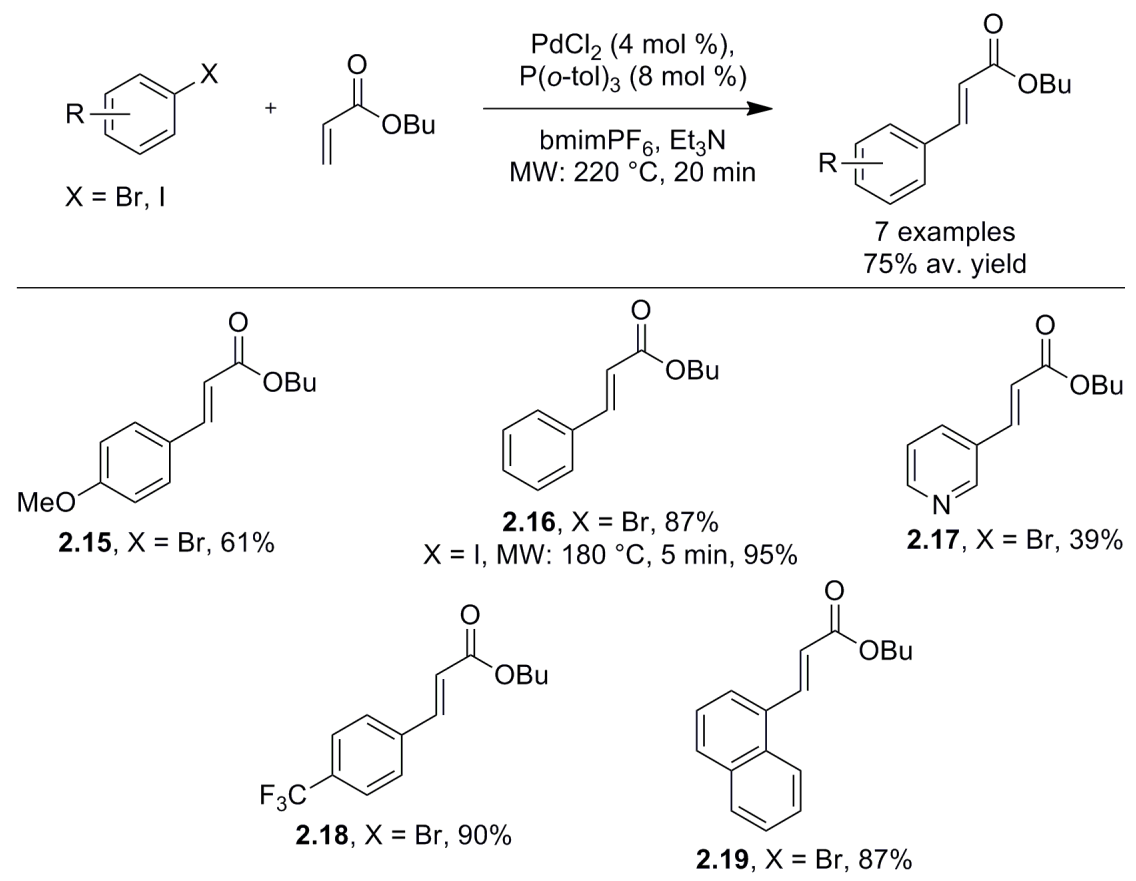

There are limited examples in the literature concerning the efficient use of microwave irradiation with tandem palladium-catalyzed transformations and in particular, regarding sequential palladium-catalyzed reactions and the Heck 
reaction. ${ }^{31}$ Leadbeater et. al. recently reported a microwave-promoted double Heck reaction in the synthesis of unsymmetric stilbene derivatives. ${ }^{32}$ In 2005, Larhed and coworkers reported a rapid palladium-mediated one-pot epoxy-ketone rearrangement - Heck arylation utilizing microwave heating (Scheme 2.7). ${ }^{33}$ A variety of electron-rich, electron-deficient, and electron-neutral bromobenzene moieties successfully underwent the transformation resulting in modest isolated yields that often surpassed those derived from classical heating conditions, though modification of solvent and base were required. For example, the electron-rich para-methoxybromobenzene underwent the transformation to form $\mathbf{2 . 2 1}$ in 58\% yield and required 75\% aqueous PEG. However, the corresponding conventionally heated reaction resulted in no conversion to product.

Scheme 2.7 One-pot MW-promoted isomerization-Heck reaction.

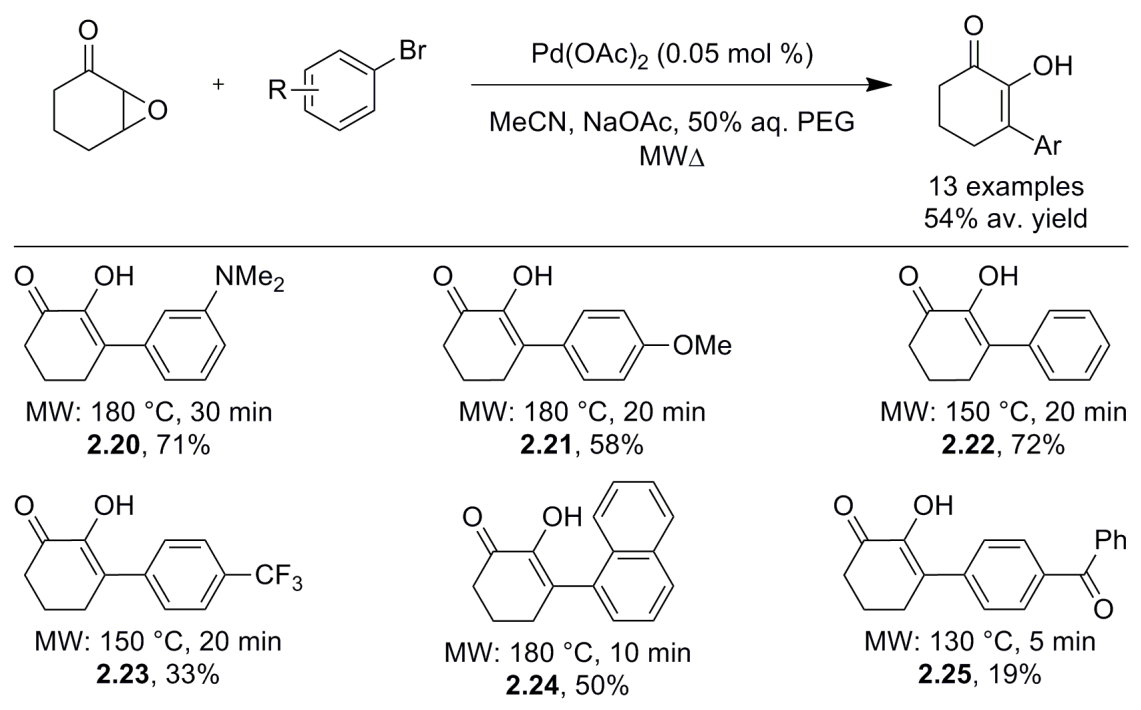

Since Larhed's initial report, microwave irradiation has been applied to a variety $^{34}$ of other Heck reactions including intramolecular spirocyclizations, ${ }^{35}$ 
intramolecular reductive cyclizations, ${ }^{36}$ regioselective cyclizations in the synthesis of indoloquinoline moieties, ${ }^{37}$ synthesis of azaindoles, ${ }^{38}$ and application in ultra-low palladium catalyst concentration Heck coupling reactions. ${ }^{39}$

\subsection{Conclusion}

The use of microwave heating has proved increasingly advantageous for transition metal-mediated carbon-carbon bond-forming reactions. Dramatic reduction in reaction times, reduced side-product formation, and increased yields have been reported in association with microwave irradiation. Extensive research efforts are still necessary, however, in order to verify the possibility of microwavespecific effects and related occurrences. Although recent advances in microwave heating have generated instances of efficient Heck coupling reactions, there are relatively few examples that couple this powerful method with other palladiumcatalyzed carbon-carbon bond-forming processes in one reaction vessel. The development of such methods would further broaden the scope of domino-Heck reactions involved in multiple carbon-carbon bond-forming steps. Our efforts to address this issue will be the focus of Chapter 3 . 


\subsection{References}

1 (a) Harvey, A. F. Microwave Engineering, Academic Press, New York, 1963. (b) Lovell, B; Notes Rec. R. Soc. Lond. 2004, 58, 283 - 294.

2 Mingos, D. M. P, in Microwave Assisted Organic Synthesis; Tierney, J. P.; Lidstrom, P., Eds. Blackwell: Oxford, 2005.

${ }^{3}$ (a) Gedye, R.; Smith, F.; Westaway, K.; Ali, H.; Baldisera, L.; Laberge, L.; Rousell, J. Tetrahedron Lett. 1986, 27, 279 - 282. (b) Giguere, R. J.; Bray, T. L.; Duncan, S. M.; Majetich, G. Tetrahedron Lett. 1986, 27, 4945 - 4948.

${ }^{4}$ General organic synthesis: a) Abramovitch, R. A. Org. Prep. Proced. Int. 1991, 23, 685 - 711. b) Caddick, S. Tetrahedron 1995, 51, 10403 - 10432. c) Lidstrom, P.; Tierney, J.; Wathey, B.; Westman, J. Tetrahedron 2001, 57, 9225 - 9283.; for technical reviews, see: d) Nüchter, M.; Ondruschka, B.; Bonrath, W.; Gum, A. Green Chem. 2004, 6, 128 - 141. e) Nüchter, M.; Müller, U.; Ondruschka, B.; Tied, A.; Lautenschläger, W. Chem. Eng. Technol. 2003, 26, 1207 - 1216.

5 D. Adam, Nature 2003, 421, 571 - 572.

${ }^{6}$ Kappe, C. O. Angew. Chem. Int. Ed. 2004, 43, 6250 - 6284.

${ }^{7}$ Kappe, C. O. Chem. Soc. Rev. 2008, 37, 1127 - 1139.

8 Schanche, J.-S. Mol. Diversity 2003, 7, 293 - 300.

${ }^{9}$ Mingos, D. M. P.; Baghurst, D. R. Chem. Soc. Rev. 1991, 20, 1 - 47.

10 Larhed, M.; Moberg, C.; Hallberg, A. Acc. Chem. Res. 2002, 35, 717 - 727. 
${ }^{11}$ Kappe, C. 0.; Stadler, A. Microwaves in Organic and Medicinal Chmeistry, WileyVCH, Weinheim, 2005.

${ }^{12}$ A selection of recent MW-promoted Sonogashira couplings: (a) Erdélyi, M.; Gogoll, A. J. Org. Chem. 2001, 603, 4165 - 4169. (b) Erdélyi, M.; Langer, V.; Karlén, A.; Gogoll, A. New. J. Chem. 2002, 26, 834 - 843. (c) Miljanić, O. S.; Vollhardt, K. P. C.; Whitener, G. D. Synlett, 2003, 29 - 34. (d) Petricci, E.; Radi, M.; Corelli, F.; Botta, M. Tetrahedron Lett. 2003, 44, 9181 - 9184. (e) Leadbeater, N. E.; Marco, M.; Tominack, B. J. Org. Lett. 2003, 5, $3919-3922$.

${ }^{13}$ A selection of recent MW-promoted Stille couplings: (a) Larhed, M.; Hallberg, A. J. Org. Chem. 1996, 61, 9582 - 9584. (b) Larhed, M.; Lindeberg, G.; Hallberg, A. Tetrahedron Lett. 1996, 37, 8219 - 8222. (c) Appukkuttan, P.; Husain, M.; Gupta, R. K.; Parmar, V. S.; Van der Eycken, E. Synlett 2006, 10, 1491 - 1495. (d) Hodgson, D. M.; Chung, Y. K.; Nuzzo, I.; Freixas, G.; Kulikiewicz, K. K.; Cleator, E.; Paris, J. -M. J. Am. Chem. Soc. 2007, 129, 4456 - 4462. (e) Jeon, S. L.; Kim, J. K.; Son, J. B.; Kim, B. T.; Jeong, I. H. J. Fluor. Chem. 2007, 128, 153 - 157.

14 A selection of recent MW-promoted Suzuki couplings: (a) Sharma, A. K.; Gowdahalli, K.; Krzeminski, J.; Amin, S. J. Org. Chem. 2007, 72, 8987 - 8989. (b) Leadbeater, N. E.; Marco, M. Org. Lett. 2002, 4, 2973 - 2976. (c) Leadbeater, N. E.; Marco, M. Angew. Chem. Int. Ed. 2003, 115, 1445 - 1447. (d) Navarro, O.; Kaur, H.; Mahjoor, P.; Nolan, S. P. J. Org. Chem. 2004, 69, 3173 - 3180. (e) Yan, J.; Zhu, M.; Zhou, Z. Eur. J. Org. Chem. 2006, 9, 2060 - 2062. 
15 (a) Kaiser, N. F. K.; Bremberg, U.; Larhed, M.; Moberg, C.; Hallberg, A. J. Organomet. Chem. 2000, 603, 2 - 5. (b) Bremberg, U.; Lutsenko, S.; Kaiser, N. -F. K.; Larhed, M.; Hallberg, A. Synthesis 2000, 1004 - 1008. (c) Trost, B. M.; Andersen, N. G. J. Am. Chem. Soc. 2002, 124, 14320 - 14321.

16 (a) Kalek, M.; Stawinski, J. Tetrahedron, 2009, 65, 10406 - 10412. (b) Arvela, R. K.; Leadbeater, N. E. Org. Lett. 2005, 11, 2101 - 2104. (c) Harmata, M.; Hong, X.; Ghosh, S. K. Tetrahedron Lett. 2004, 45, 5233 - 5236. (d) Maes, B. U. W.; Loone, K. T. G.; Hostyn, S.; Diels, G.; Rombouts, G. Tetrahedron 2004, 60, 11559 - 11564.

17 Huang, H.; Liu, H.; Jiang, H.; Chen, K. J. Org. Chem. 2008, 73, 6037 - 6040.

18 (a) Coquerel, Y.; Rodriguez, J. Eur. J. Org. Chem. 2008, 1125 - 1132. (b) Aitken, S. G.; Abell, A. D. Aust. J. Chem. 2005, 58, 3 - 13.

19 Connon, S. J.; Blechert, S. Angew. Chem. Int. Ed. 2003, 42, 1900 - 1923.

20 (a) Mayo, K. G.; Nearhoof, E. H.; Kiddle, J. J. Org. Lett. 2002, 4, 1567 - 1570 . (b) Garbacia, S.; Desai, B.; Lavastre, O.; Kappe, C. O. J. Org. Chem. 2003, 68, 9136 - 9139. (c) Yang, C.; Murray, W. V.; Wilson, L. J. Tetrahedron Lett. 2003,44, 1783 - 1786. (d) Grigg, R.; Martin, W.; Morrisa, J.; Sridharana, Vt. Tetrahedron Lett. 2003, 44, 4899 4901. (e) Balan, D.; Adolfsson, H. Tetrahedron Lett. 2004, 45, 3089 - 3092.

21 Varray, S.; Gauzy, C.; Lamaty, F.; Lazaro, R.; Martinez, J. J. Org. Chem. 2000, 65, $6787-6790$.

${ }^{22}$ (a) Salim, S. S.; Bellingham, R. K.; Brown, R. C. D. Eur. J. Org. Chem. 2006, 47, 800 806. (b) Castagnolo, D.; Renzulli, M. L.; Galletti, E.; Corelli, F.; Botta, M. Tetrahedron: 
Asymmetry 2005, 16, 2893 - 2896. (c) Bargigia, F. C.; Murray, W. V. J. Org. Chem. 2005, 70, $9636-9639$.

23 (a) Wu, Y. -J.; He, H., L’Heureux, A. Tetrahedron Lett. 2003, 44, 4217 - 4218. (b) Lange, J. H. M.; Hofmeyer, L. J. F.; Hout, F. A. S.; Osnabrug, S. J. M.; Verveer, P. C.; Kruse, C. G.; Feenstra, R. W. Tetrahedron Lett. 2002, 43, 1101 - 1104.

${ }^{24}$ Enquist, P. -A.; Nilsson, P.; Larhed, M. Org. Lett. 2003, 5, 4875 - 4878.

${ }^{25}$ Lipshutz, B. H.; Frieman, B. Tetrahedron 2004, 60, 1309 - 1316.

${ }^{26}$ Larhed, M.; Hallberg, A. J. Org. Chem. 1996, 61, 9582 - 9584.

27 Wang, J. X.; Hu, Z.; Wei, B. G.; Bai, L. J. Chem. Res., Synop. 2000, 10, 484 - 485.

28 Villemin, D.; Nechab, B. J. Chem. Res., Synop. 2000, 9, 429 - 431.

${ }^{29}$ Botella, L.; Najera, C. Tetrahedron Lett. 2004, 45, 1833 - 1836.

30 Vallin, K. S. A.; Emilsson, P.; Larhed, M.; Hallberg, A. J. Org. Chem. 2002, 67, 6243 6246.

31 A recent report of domino allylstannylation/Heck cyclization: Cvengroš, J.; Schütte, J.; Schlörer, N.; Neudörfl, J.; Schmalz, H. -G. Angew. Chem. Int. Ed. 2009, 48, $6148-6151$.

32 Kormos, C. M.; Leadbeater, N. E. J. Org. Chem. 2008, 73, 3854 - 3858.

${ }^{33}$ Svennebring, A.; Garg, N.; Nilsson, P.; Hallber, A.; Larhed, M. J. Org. Chem. 2005, 70, $4720-4725$.

${ }^{34}$ For review of recent microwave accelerated Pd reactions including the Heck reaction: Kappe, C. O.; Dallinger, D. Mol. Divers. 2009, 13, 71 - 193. 
35 Svennebring, A.; Nilsson, P.; Larhed, M. J. Org. Chem., 2007, 72, 5851 - 5854.

36 Donets, P.A.; Van der Eycken, E.V. Org. Lett., 2007, 9, 3017 - 3020.

37 Hostyn, S.; Maes, B.U.W.; Van Baelen, G.; Gulevskaya, A.; Meyers,C.; Smits, K. Tetrahedron, 2006, 62, 4676 - 4684.

${ }^{38}$ Lachance, N.; April, M.; Joly, M. A. Synthesis 2005, 2571 - 2577.

${ }^{39}$ Arvela, R. K.; Leadbeater, N. E. J. Org. Chem. 2005, 70, 1786 - 1790. 


\section{Chapter 3. Tandem Decarboxylative Allylation-Heck Cyclization}

\subsection{Introduction}

As previously discussed in Chapter 1, the palladium-catalyzed decarboxylative alkylation of allyl diphenylglycinate imines recently reported by our group employs mild and essentially neutral reaction conditions for the generation of $\alpha$-imino anion nucleophiles. This method has been utilized in the rapid synthesis of homoallylic imines, which serve as useful precursors for azaheterocycles and alkaloids (Scheme 3.1). ${ }^{1}$ Moreover, the decarboxylative allylation proceeds in the absence of toxic by-products.

Scheme 3.1 Decarboxylative allylation of diphenylglycinate imines.

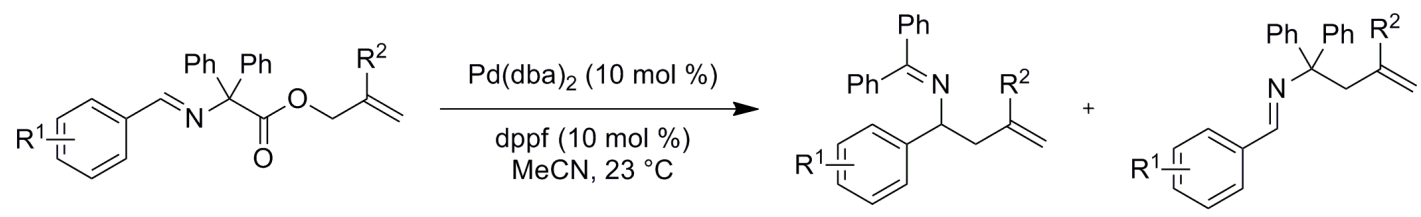

A unique characteristic inherent to palladium-catalyzed transformations, such as the decarboxylative allylation of allyl diphenylglycinate imines, is the potential to couple them in tandem with other powerful carbon-carbon bondforming reactions. Instances of tandem palladium-mediated decarboxylation and carbon-carbon coupling reactions have previously been reported, ${ }^{2}$ however there are relatively few examples that successfully undergo this series of reactions from only one starting material. We reasoned that the palladium-catalyzed decarboxylative allylation of $o$-halodiphenylglycinate imines could be coupled to an 
intramolecular Heck cyclization to rapidly generate functionalized 1-iminoindanes, a structural motif recently identified as both a unique platform for ventures in diversity-oriented synthesis ${ }^{3}$ and for the construction of patented atypical antipsychotic agents (Scheme 3.2). ${ }^{4}$ To increase the scope of the reaction, a number of $o$-haloaryl aldehydes of varying electronic properties were employed.

Scheme 3.2 Proposed synthetic route.

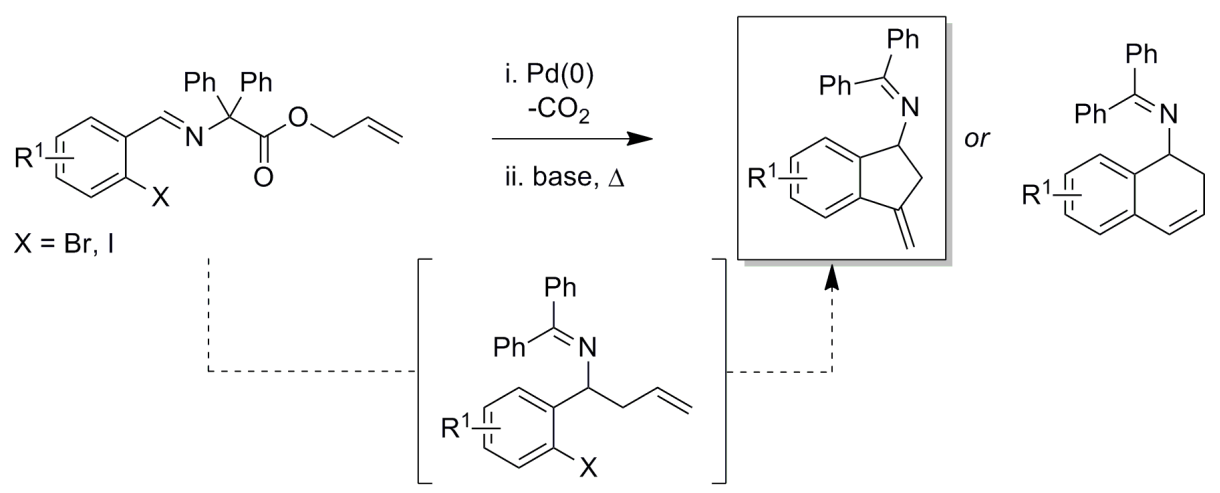

\subsection{Synthesis of Allyl Diphenylglycinate Imines}

Our studies began with the selection of the appropriate $o$-haloaldimine to probe a tandem decarboxylative allylation-Heck cyclization process. Based on known C-X reactivity common to palladium-catalyzed oxidative addition in which I $\sim 0 \mathrm{Tf}>\mathrm{Br}>>\mathrm{Cl},{ }^{5}$ o-iodobenzaldimine 3.1a was chosen for our initial investigations. Allyl diphenylglycinate 3.6, synthesized from commercially-available diphenylglycine following our previously reported protocol, ${ }^{1}$ was subjected to imine condensation in the presence of $o$-iodobenzaldehyde to furnish 3.1a in acceptable isolated yield and high purity (Scheme 3.3). 
Scheme 3.3 Synthesis of $o$-iodobenzaldimine 3.1.

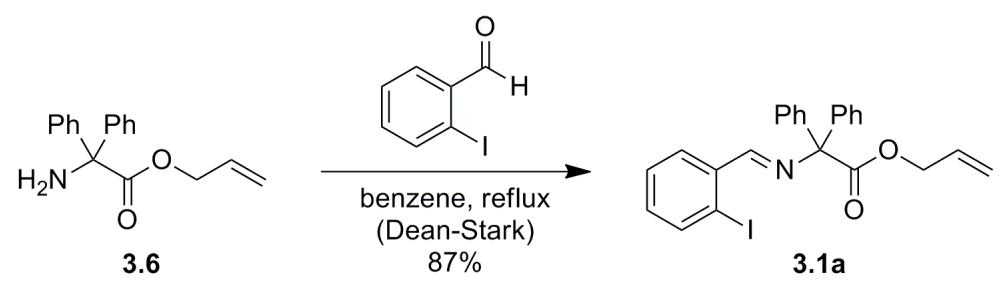

\subsection{Initial Decarboxylative Allylation - Heck Cyclization Studies}

Imine 3.1a was subjected to our standard decarboxylative allylation conditions $\left(10 \mathrm{~mol} \% \mathrm{Pd}(\mathrm{dba})_{2}\right.$, dppf, DMF, $\left.20^{\circ} \mathrm{C}\right)$. After one hour, complete conversion to the expected homoallylic imine $\mathbf{3 . 3}$ was observed. The desired homoallylic imine was the sole regioisomer of the decarboxylative allylation, as observed by ${ }^{1} \mathrm{H}$ NMR analysis of the unpurified reaction mixture. It is noteworthy that the cyclized product 3.4 was detected in a 1:10 ratio with homoallylic imine 3.3. This result was particularly interesting as the Heck cyclization occurred in the absence of exogenous heat or base. Encouraged by these results, the reaction mixture was then subjected to standard Heck reaction conditions ${ }^{6}$ and the 3methylenyl-1-iminoindane $\mathbf{3 . 4}$ was furnished in 78\% isolated yield. The structure of the cyclized product was further confirmed by X-ray crystallographic analysis (Figure 3.1). The observed selectivity was interesting, as standard Heck reaction selectivity for terminal olefins predominantly dictates that substitution occurs at the least substituted olefinic carbon. In consideration of Baldwin's rules of ring closures, the formation of either a 5-exo-trig or 6-endo-trig product could be 
favored. ${ }^{7}$ In our case, the substitution occurred at the more substituted carbon resulting in a 5-membered ring, exclusively.

Scheme 3.4 Two-step decarboxylative allylation-Heck cascade.

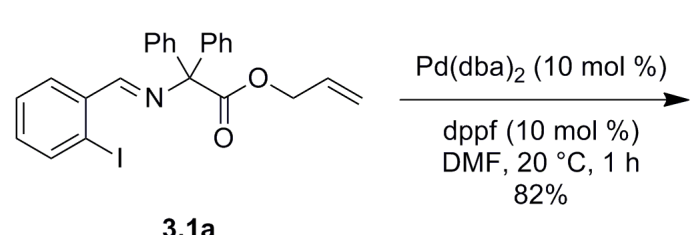

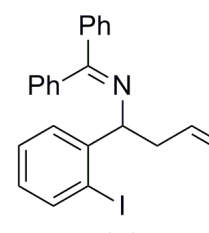

3.3

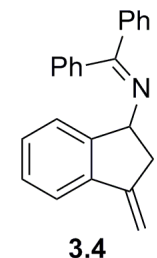

3.4

$\mathrm{Pd}(\mathrm{dba})_{2}(10 \mathrm{~mol} \%) \uparrow$

dppf $(10 \mathrm{~mol} \%)$

$\mathrm{Et}_{3} \mathrm{~N}, 110^{\circ} \mathrm{C}, 1 \mathrm{~h}$

$78 \%$

Figure 3.1 X-ray crystallographic analysis of 3.4.

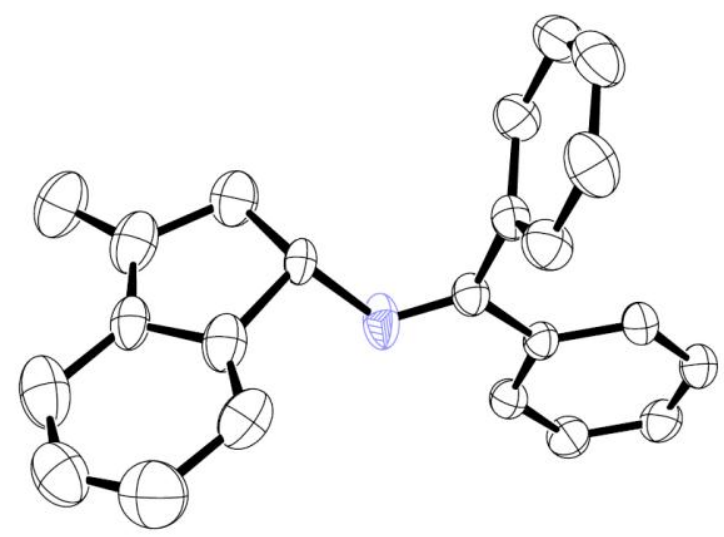

\subsection{Optimization of Decarboxylative Allylation-Heck Cyclization}

Encouraged by this success, we sought to optimize the reaction conditions for the conventionally-heated two-step process into one reaction vessel. Initial optimization studies employed $10 \mathrm{~mol} \%$ of $\mathrm{Pd}(\mathrm{dba})_{2} / \mathrm{dppf}$ and furnished $3.3 \mathrm{in}$ excellent isolated yields. However, coelution of the dibenzylidene-acetone (dba) ligand during chromatography compromised the ultimate purity of the product. 
Accordingly, tetrakis(triphenylphosphine)palladium(0) was evaluated and gratifyingly, provided rapid decarboxylative allylation and subsequent Heck cyclization without introducing intractable purification issues (Table 3.1). Unfortunately, an additional isomerized product $\mathbf{3 . 5}$ was cogenerated in unpredictable ratios. Surprisingly, this enamine side product was remarkably stable to standard flash chromatography. Formation of enamine $\mathbf{3 . 5}$ may be attributed to the production of an ephemeral palladium hydride species that can isomerize the double bond to the more substituted position via a series of addition - elimination events. ${ }^{8}$ We investigated the use of tetrabutylammonium chloride ${ }^{9}$ to reduce this undesired alkene internalization, but it did not have an appreciable effect on the reaction rate or alkene isomer ratios.

Table 3.1 Optimization studies of thermally heated one-pot reaction.

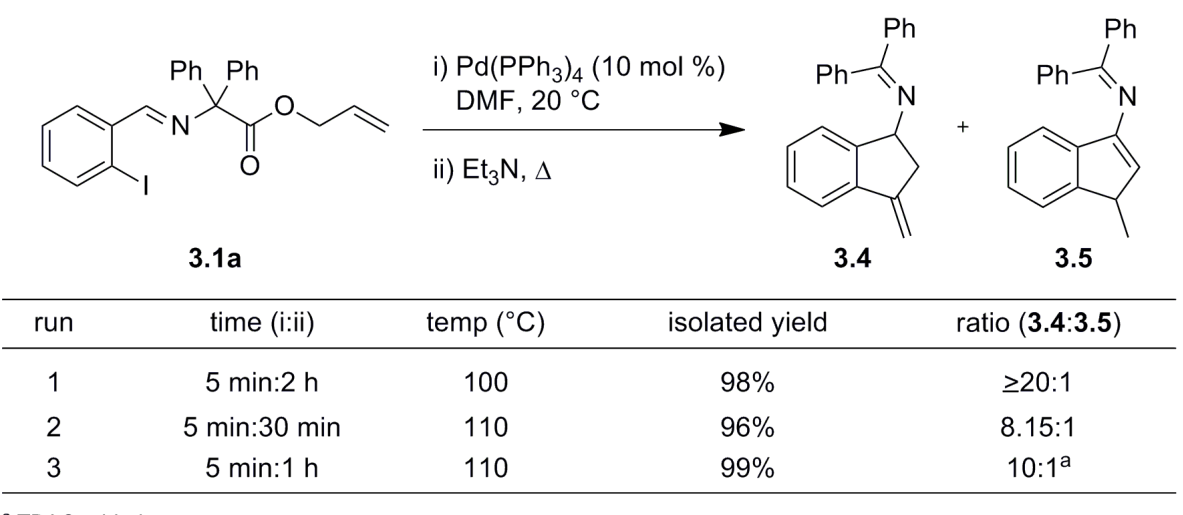

a TBAC added.

In an attempt to reduce reaction times and possibly inhibit isomer formation, microwave irradiation was utilized for the Heck cyclization. Microwave heating was found to accelerate the reaction, but the isomer ratio was nevertheless highly variable. We next investigated a variety of additives to enhance the selectivity of the 
microwave-promoted Heck reaction (Table 3.2).10 To this end, a variety of tetraalkylammonium salts were employed. As observed previously with the conventionally-heated reactions, these additives did not have an appreciable effect on the alkene isomer ratio. Alternatively, silver(I) sulfate successfully inhibited olefin internalization and furnished $\mathbf{3 . 4}$ in excellent isolated yield. Other silver salts (entries 6-8) completely inhibited the initial decarboxylative allylation, even after subjection to microwave heating. This result was similar to our previous observations of inhibition of decarboxylative allylation at room temperature with $\geq 10 \mathrm{~mol} \%$ of other Lewis acids such as $\mathrm{LiCl}, \mathrm{ZnCl}_{2}$ or $\mathrm{Sc}(\mathrm{OTf})_{3} .{ }^{1}$ The addition of $\mathrm{Tl}_{2} \mathrm{CO}_{3}$ (entry 9) furnished an improved isomer ratio, but a decreased isolated yield. ${ }^{11}$ In 2008, Van Vranken and coworkers reported the crucial need for an insoluble base in their tandem carbene insertion-Heck cyclization protocol, resulting in complete inhibition of alkene migration in $\alpha, \beta$-unsaturated esters. ${ }^{12}$ This result was in agreement to Jeffery's previous studies of increased yields and regioselectivity for Heck reactions using insoluble bases. ${ }^{13}$ Accordingly, $\mathrm{Et}_{3} \mathrm{~N}$ was replaced with $\mathrm{K}_{2} \mathrm{CO}_{3}$, affording a surprisingly poor selectivity ratio (entry 10 ). Though various conditions were explored in an effort to increase yields while maintaining high selectivity, optimized conditions for the two-step one-pot decarboxylative allylation-Heck reaction cascade are summarized in entry 5 , which provided excellent regioselectivity for $\mathbf{3 . 4}$ and high isolated yields. 
Table 3.2 Optimization studies of microwave-promoted one-pot reaction.

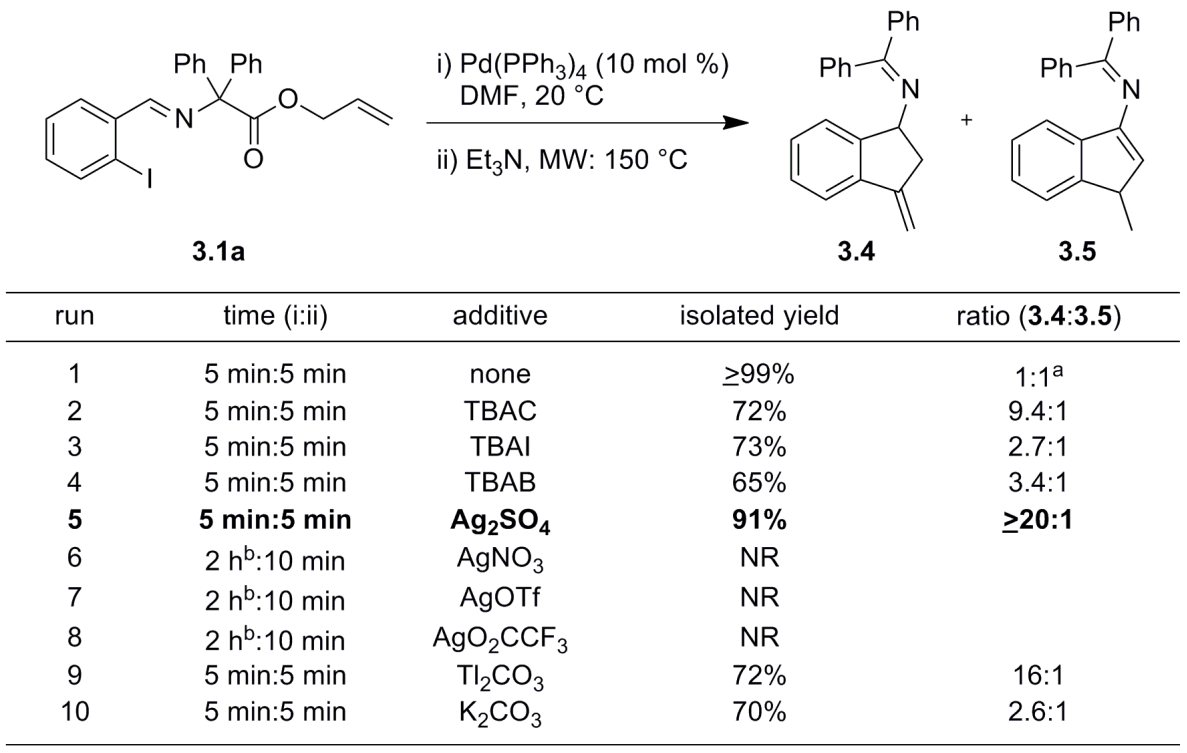

${ }^{a}$ This represents an average ratio; specific ratios per run were highly variable. ${ }^{b}$ No conversion to homoallylic imine; subjection to Heck reaction conditions after $2 \mathrm{~h}$ led to complete decomposition of 3.1. ${ }^{\mathrm{c}} 2$ equiv of $\mathrm{K}_{2} \mathrm{CO}_{3}$ instead of $\mathrm{Et}_{3} \mathrm{~N} . \mathrm{NR}=$ no reaction. $\mathrm{TBAC}=$ tetrabutylammonium chloride. $\mathrm{TBAI}=$ tetrabutylammonium iodide. TBAB = tetra-

butylammonium bromide.

\subsection{Evaluation of Substrate Scope - Synthesis of Functionalized Imines}

With optimized conditions identified for the two-step one-pot reaction (see entry 5, Table 3.2), the substrate scope was evaluated next through variation of the imine moiety. Synthesis of starting imines 3.1 proved facile via condensation of allyl diphenylglycine (3.6) with a variety of commercially available aryl and heteroaryl aldehydes (Table 3.3). 
Table 3.3 Synthesis of imines 3.1.

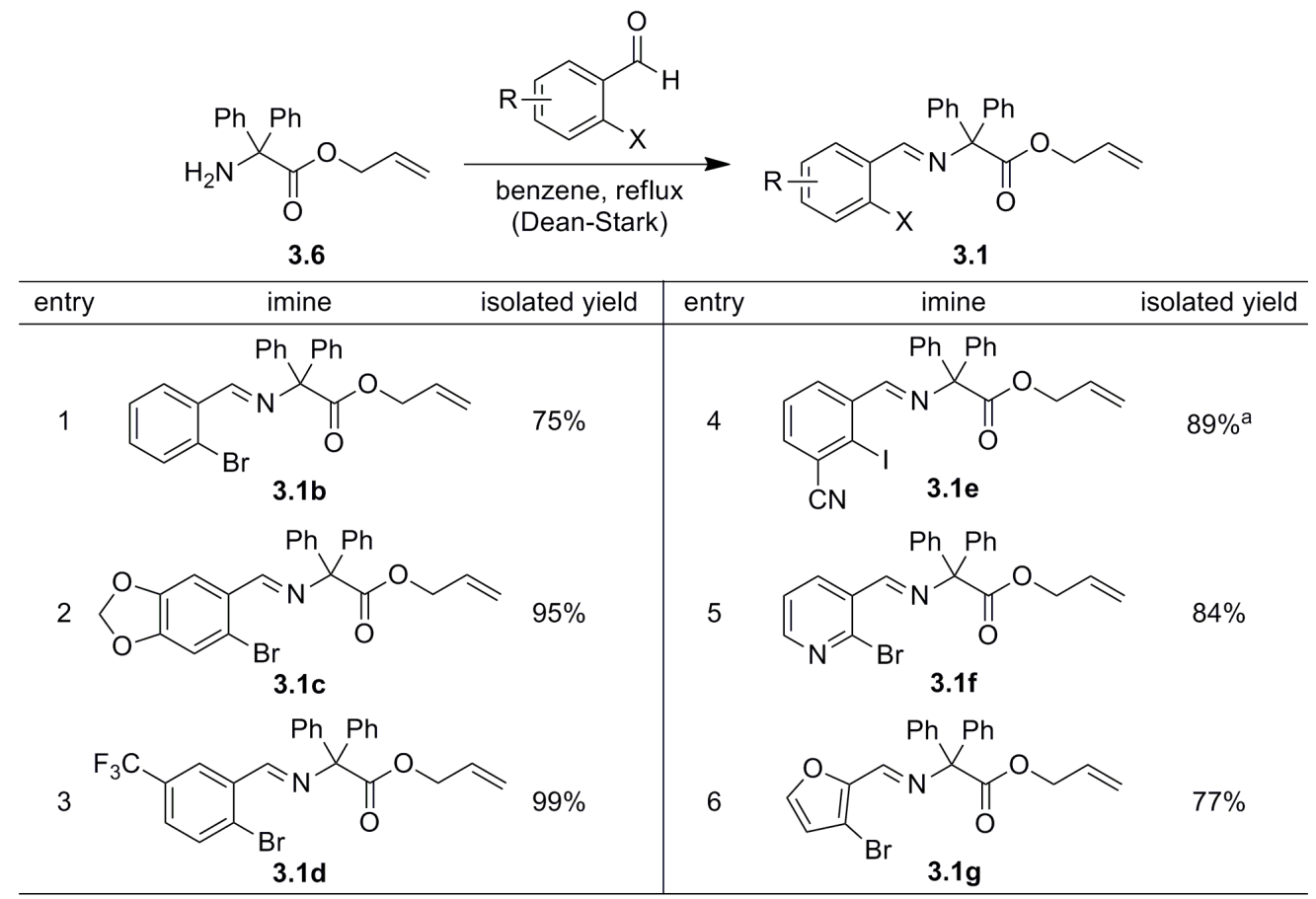

a Imine 3.1e prepared as a 4.6:1 ratio of o-iodo- and o-bromobenzaldimine.

\subsection{Evaluation of Substrate Scope - Subjection of Functionalized Imines to One-Pot Reaction}

The imine substrates $\mathbf{3 . 1}$ successfully underwent the tandem carbon-carbon bond-formations and electronic trends were apparent depending on the nature of the imine moiety (Table 3.4). Electron-deficient $o$-halobenzaldimines provided superior yields versus electron-rich counterparts (compare entries 4 and 5). Regrettably, electron-rich furanyl bromide 3.1g did not undergo the Heck cyclization and halted at the homoallylic imine as a 9.3:1 mixture of regioisomers (entry 8). However, electron-deficient 3.1f converted to the Heck cyclized product 3.4e in a moderate isolated yield, showcasing the applicability of this method 
toward heterocyclic substrates. These results are also in accord with our previous studies on decarboxylative allylation and the accepted mechanism of the Heck reaction. ${ }^{14}$ The combination of all reagents at the initial decarboxylation stage, followed by immediate microwave heating, successfully promoted the transformation, although at lower isolated yields in comparison to the stepwise addition of base after completion of the decarboxylative allylation step (entry 2). Additionally, the use of silver(I) sulfate successfully inhibited isomer formation in all examples provided.

Table 3.4 MW-promoted tandem-decarboxylative allylation-Heck cyclization.

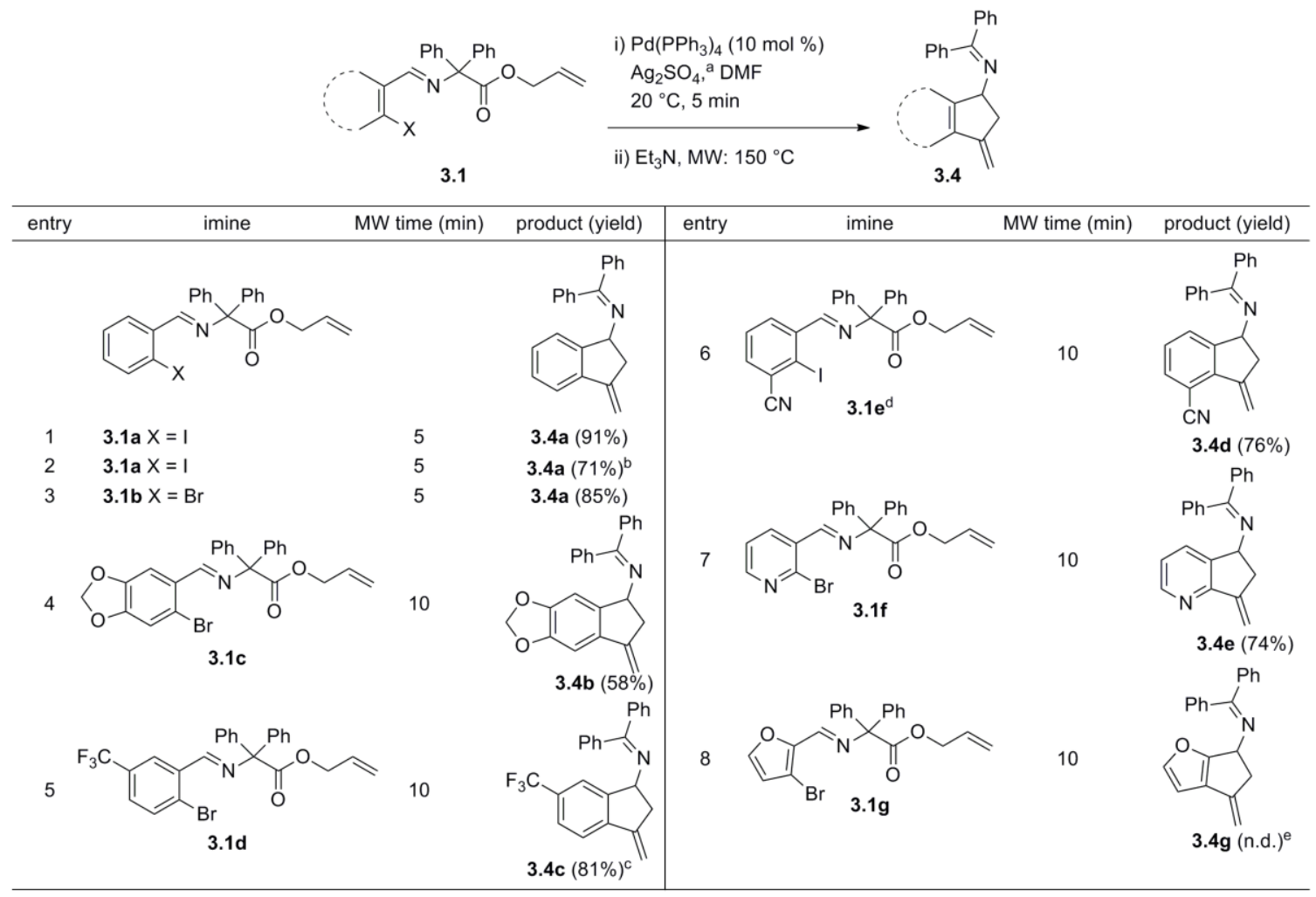

a 1.0 equiv of $\mathrm{Ag}_{2} \mathrm{SO}_{4}$ added to inhibit double bond migration. ${ }^{\mathrm{b}} \mathrm{Et}_{3} \mathrm{~N}$ added prior to decarboxylative allylation. ${ }^{\mathrm{c}} \mathrm{Ag}_{2} \mathrm{SO}_{4}$ was omitted. ${ }^{\mathrm{d}}$ Compound $3.1 \mathrm{e}$ was a $4.6: 1$ ratio of aryl iodide and aryl bromide. ${ }^{e} 100 \%$ conversion to homoallylic imine as a 9.3:1 ratio of regioisomers; no cyclized product (3.4f) was observed. 


\subsection{Evaluation of Substrate Scope - Functionalized Terminal Olefin Synthesis}

The external olefin of imine 3.1 allowed for additional diversity in evaluation of the substrate scope for our two-step one-pot decarboxylative allylation-Heck cyclization. This substrate diversification was achieved by microwave-accelerated olefin cross-metathesis either prior to or after imine formation. ${ }^{15}$ Initial optimization studies to determine the most effective catalyst loading, temperature and reaction time employed methyl acrylate as the coupling partner with Cbzprotected allyl diphenylglycinate 3.7 (Table 3.5). Optimal conditions for the transformation were ascertained using 5 mol \% Grubbs second-generation catalyst (3.10) and microwave heating for only 10 minutes as seen in entry 6. Attempts to reduce catalyst loading any further resulted in decreased isolated yields (entry 7). An effort to employ the Grubbs-Hoveyda second-generation catalyst (3.11) also resulted in decreased yield of $\mathbf{3 . 9}$ (entry 8). It is noteworthy that the $Z$ isomer of $\mathbf{3 . 9}$ was observed in only minimal amounts during the course of the optimization studies; this olefin isomer was successfully separated from the more predominant $E$ isomer using flash column chromatography. This protocol was also amendable to other alkene coupling partners, most notably stilbene (vide infra). 
Table 3.5 Optimization of olefin metathesis reactions on imine 3.1.
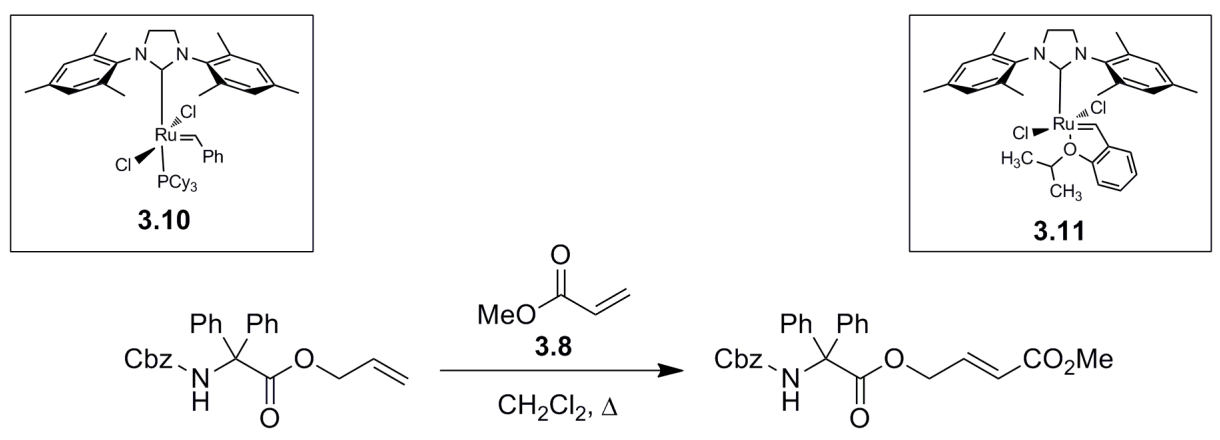

3.7

3.9

\begin{tabular}{ccccccc}
\hline entry & catalyst & loading $(\mathrm{mol} \%)$ & equiv of $\mathbf{3 . 8}$ & temp $\left({ }^{\circ} \mathrm{C}\right)$ & time & isolated yield \\
\hline 1 & 3.10 & 10 & 1.0 & 20 & $19 \mathrm{~h}$ & $\mathrm{NR}$ \\
2 & 3.10 & 10 & 1.0 & 40 & $19 \mathrm{~h}$ & $13 \%$ \\
3 & 3.10 & 5 & 10.0 & 40 & $48 \mathrm{~h}$ & $87 \%$ \\
4 & 3.10 & 5 & neat & 40 & $48 \mathrm{~h}$ & $52 \%$ \\
5 & 3.10 & 5 & neat & MW: 130 & $5 \mathrm{~min}$ & $\mathrm{NR}$ \\
$\mathbf{6}$ & $\mathbf{3 . 1 0}$ & $\mathbf{5}$ & $\mathbf{1 0 . 0}$ & MW: 90 & $\mathbf{5} \mathbf{\text { min }}$ & $\mathbf{9 6 \%}$ \\
7 & 3.10 & 3 & 10.0 & MW: 90 & $10 \mathrm{~min}$ & $\mathbf{7 2} \%$ \\
8 & 3.11 & 5 & 10.0 & MW: 90 & $5 \mathrm{~min}$ & $\mathbf{7 0} \%$
\end{tabular}

The deprotection of 3.9, following our previously reported strategy using TMS-I in methylene chloride, ${ }^{1}$ resulted in $87 \%$ yield of the amine, which was subsequently subjected to condensation with $o$-iodobenzaldehyde in refluxing benzene under Dean Stark conditions to furnish imine 3.12a in high isolated yield (Scheme 3.5).

Scheme 3.5 Deprotection of $\mathbf{3 . 9}$ followed by imine formation.<smiles>COC(=O)CCOC(=O)C(NC(C)(F)F)(c1ccccc1)c1ccccc1</smiles>

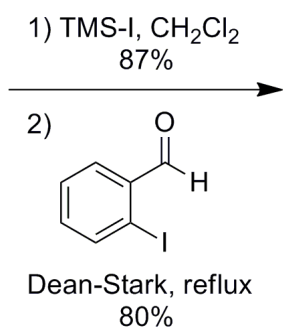<smiles>CC(=O)/C=C/COC(=O)C(/N=C/c1ccccc1I)(c1ccccc1)c1ccccc1</smiles>

As mentioned previously, the optimized protocol for olefin cross-metathesis prior to imine formation was also amendable to the reaction following imine 
formation. For example, subjection of alkene 3.1a and stilbene to Grubbs' secondgeneration catalyst (3.10) under microwave heating $\left(90^{\circ} \mathrm{C}, 10 \mathrm{~min}\right)$ rapidly afforded the corresponding imine 3.12b in high isolated yield (Scheme 3.6).

Scheme 3.6 Olefin cross-metathesis on imine 3.1a.

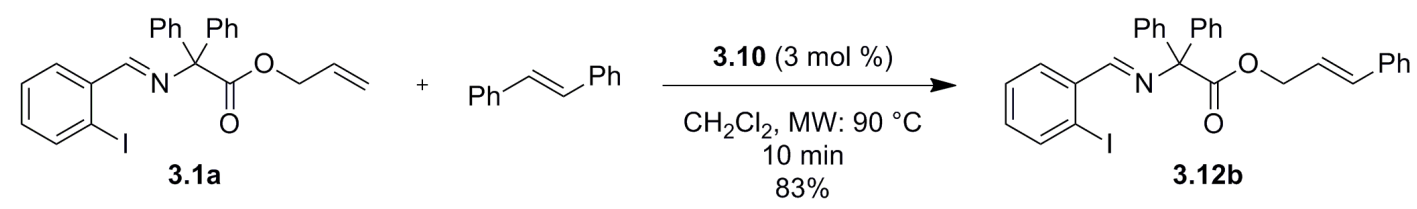

\subsection{Evaluation of Substrate Scope - Subjection of Functionalized Olefins to One-Pot Reaction Conditions}

The resultant esters were next subjected to our optimized tandem decarboxylative allylation-Heck cyclization conditions (Table 3.6). The isomer ratio for the reaction of imine $\mathbf{3 . 1 2 a}$ was highly variable, though combined yields were typically high (entry 1). Unlike imine 3.1a, the addition of $\mathrm{Ag}_{2} \mathrm{SO}_{4}$ did not suppress this isomerization. Surprisingly, the addition of $\mathrm{Tl}_{2} \mathrm{CO}_{3}$ resulted in the predominant formation of the internalized alkene 3.14a (entry 2). However, the preferential formation of the internalized olefin was unique to substrate 3.12a. The cinnamyl ester $\mathbf{3 . 1 2 b}$ and furanyl imine $3.12 \mathrm{c}$ consistently afforded the corresponding exomethylene products (entries 3 and 4). It should be noted that the electron-rich furanyl imine 3.12c successfully underwent the Heck cyclization in a high isolated yield. Although the transformation required a longer reaction time and the addition of $\mathrm{Ag}_{2} \mathrm{SO}_{4}$, this result was particularly noteworthy given that the 
related allyl ester 3.1g did not proceed past decarboxylative allylation following our standard reaction conditions (see Table 3.4, entry 8). This crucial use of the additive has also been observed in similar systems. In 2007, Young and Kerr noted a comparable reliance on $\mathrm{Ag}_{2} \mathrm{SO}_{4}$ for a related Heck cyclization in their total synthesis of nakadomarin A. ${ }^{16}$

Table 3.6 Tandem decarboxylative allylation-Heck cyclization of imine 3.12.

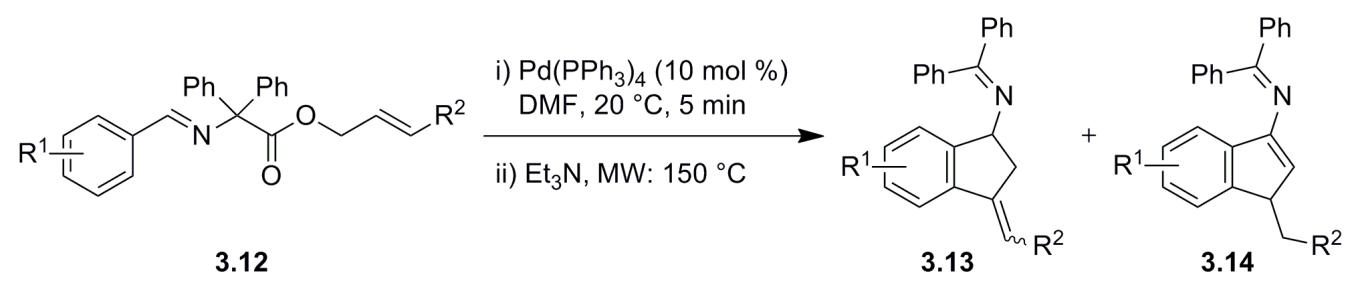

entry
a This represents an average ratio; specific ratios are highly variable sometimes with 3.13a predominating. ${ }^{\mathrm{b}} 2.0$ equiv of $\mathrm{Tl}_{2} \mathrm{CO}_{3}$ added.
${ }^{\circ}$ Decarboxylative allylation required 15 min. ${ }^{1.5}$ equiv of $\mathrm{Ag}_{2} \mathrm{O}_{4}$ added.

The geometry of 3.13 was determined by extensive 2D-NMR spectroscopic analysis (NOESY) to be predominantly the $E$-alkene. This result represents a formal anti- $\beta$-hydride elimination of the palladium(II) intermediate in the Heck cyclization. 
This is unusual as Heck reactions characteristically impose syn- $\beta$-hydride elimination achieved by a carbon-carbon bond rotation following migratory insertion (see Figure 3.2). ${ }^{13 a}$ However, there have been several reported examples that suggest the possibility of anti- $\beta$-hydride elimination. ${ }^{17}$ Possible mechanisms include either (1) epimerization through a $\pi$-allyl palladium intermediate, ${ }^{18}$ or (2) removal of a proton with a base from a benzylic palladium-intermediate in an antiperiplanar approach, which has been reported to occur in $\alpha, \beta$-unsaturated carbonyl and styrene systems. ${ }^{19}$ For example, Lautens and coworkers reported a high yielding synthesis of functionalized dihydronaphthalene substrates that exhibited a formal anti- $\beta$-hydride elimination. ${ }^{20}$ The authors attributed this phenomenon to hydrogen abstraction by the base to achieve trans-elimination.

Figure 3.2 Heck reaction mechanism.

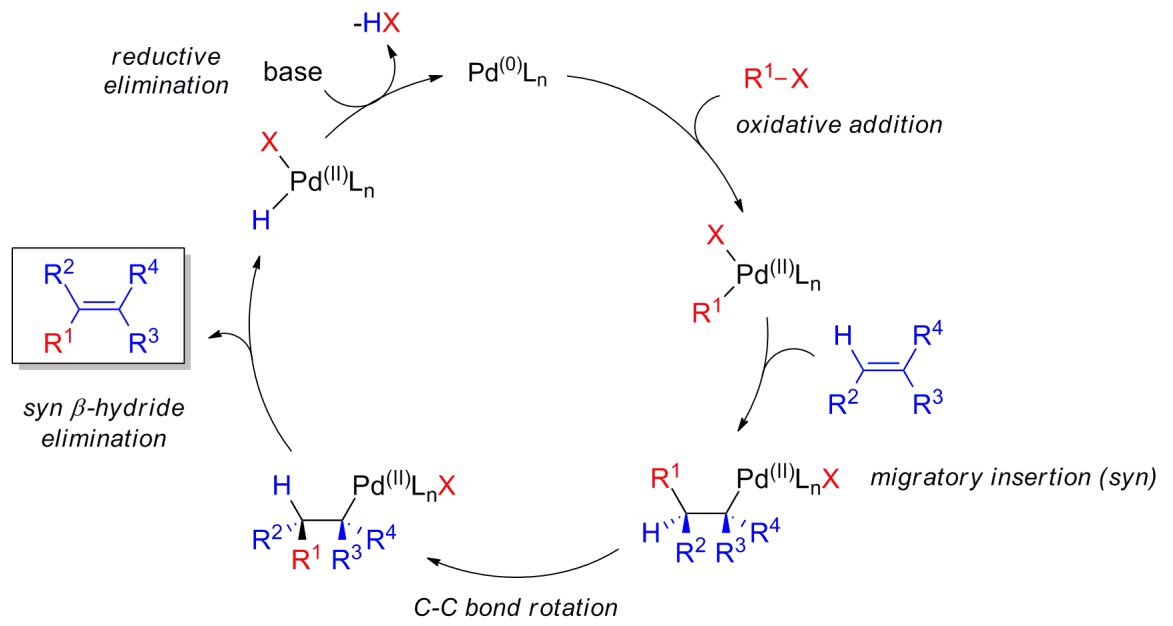

Our lab has recently reported a versatile palladium-catalyzed decarboxylative allylation in which the $\alpha$-imino anion is intercepted by activated olefins, followed by Heck cyclization (Scheme 3.7). ${ }^{21}$ Both arylidene malononitriles, 
alkyl malononitriles, and arylindene Meldrum's acid derivatives effectively underwent the transformation in moderate to high yields. Variation of the imine functionality produced results comparable to our previous decarboxylative allylation studies, in which electron-deficient and heteroaromatic substitution provided increased regioselectivity in comparison to their electron-donating counterparts. ${ }^{38}$ Furthermore, this intercepted decarboxylative allylation protocol could be coupled with an intramolecular Heck cyclization in the same reaction vessel to rapidly generate a complex organoamine framework, e.g. 3.16.22 This example demonstrates the potentially broad utility of coupling palladium-catalyzed decarboxylative allylations with microwave-assisted Heck cyclizations.

Scheme 3.7 Tandem decarboxylative allylation-interception-Heck cyclization.

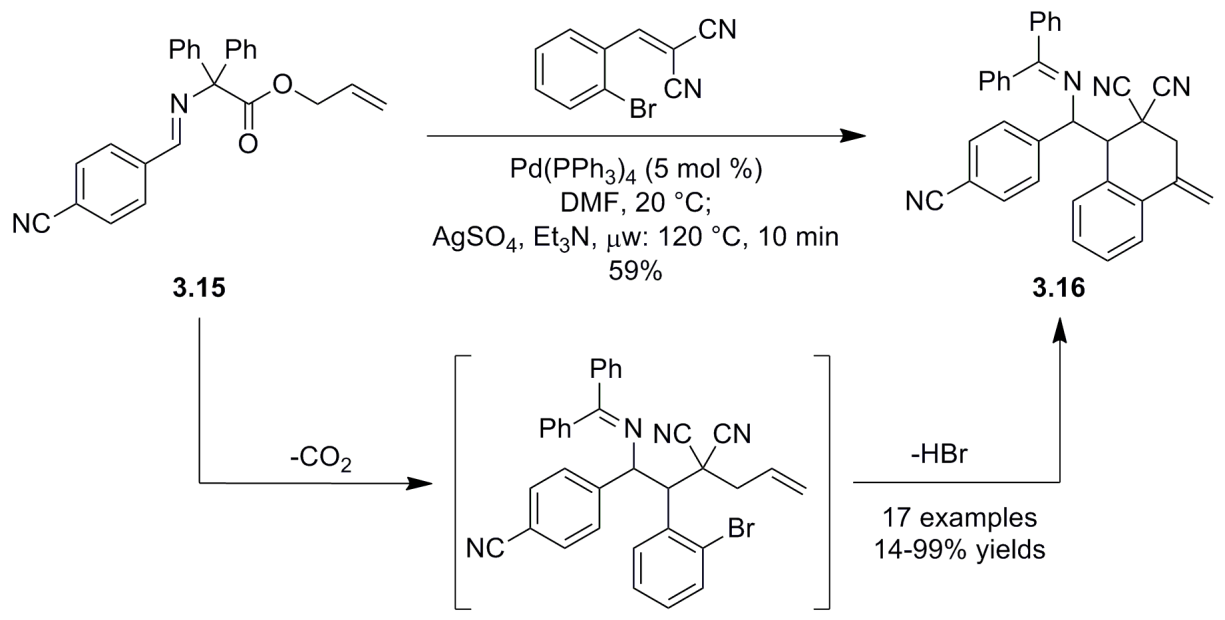

\subsection{Conclusion}

The tandem palladium-catalyzed decarboxylative allylation-Heck cyclization method described above has furnished a rapid pathway for the synthesis of complex 
polycyclic organoamines under relatively mild reaction conditions. The one-pot two-step cascade represents the first evidence that decarboxylative allylations can be coupled effectively to other powerful transition metal-mediated carbon-carbon bond-forming events in a single reaction vessel. 


\subsection{References}

1 Yeagley, A. A.; Chruma, J. J. Org. Lett. 2007, 9, 2879 - 2882.

${ }^{2}$ (a) Myers, A. G.; Tanaka, D.; Mannion, M. R. J. Am. Chem. Soc. 2002, 124, 11250 -

11251. (b) Tanaka, D.; Myers, A. G. Org. Lett. 2004, 6, 433 - 436. (c) Goossen, L. J.;

Paetzold, J. Angew. Chem. Int. Ed. 2004, 43, 1095 - 1098. (d) Maehara, A.; Tsurugi, H.; Satoh, T.; Miura, M. Org. Lett. 2008, 10, 1159 - 1162. (e) Hu, P.; Kan, J.; Su, W.; Hong, M. Org. Lett. 2009, 11, 2341 - 2344. (f) Tanaka, D.; Romeril, S. P.; Myers, A. G. J. Am .Chem. Soc. 2005, 127, 10323 - 10333.

${ }^{3}$ (a) Kesavan, S.; Panek, J. S.; Porco, J. A. Org. Lett. 2007, 9, 5203 - 5206. (b) Cvengroš, J.; Schütte, K.; Schlörer, N.; Neudörfl, J; Schmalz, H. -G. Angew. Chem. Int. Ed. 2009, 48, $6148-6151$.

${ }^{4}$ Graham, J. M.; Coughenour, L. L.; Barr, B. M.; Rock, D. L.; Nikam, S. S. Bioorg. Med. Chem. Lett.2008, 18, $489-493$.

${ }^{5}$ Jutand, A.; Mosleh, A. Organometallics 1995, 14, 1810 - 1817.

${ }^{6}$ (a) Heck, R. F. Acc. Chem. Res. 1979, 12, 146 - 151. (b) Mizoroki, T.; Mori, K.; Ozaki, A. Bull. Chem. Soc. Jpn. 1971, 44, 581. (c) Beletskaya, I. P.; Cheprakov, A. V. Chem. Rev. 2000, 100, 3009 - 3066. (d) Daves, G. D.; Hallberg, A. Chem. Rev. 1989, 89, 1433 144.

${ }^{7}$ Baldwin, J. E. J. Chem. Soc., Chem. Commun. 1976, $734-736$.

${ }^{8}$ (a) Abelman, M. M.; Oh, T.; Overman, L. E. J. Org. Chem. 1987, 52, 4130 - 4133. (b) Wheatley, B. M. M.; Keay, B. A. J. Org. Chem. 2007, 72, 7253 - 7259. (c) Reetz, M. T. 
Angew. Chem., Int. Ed. 1972, 11, 129 - 130. (d) Larock, R. C.; Gong, W. H. J. Org. Chem. 1989, 54, 2047 - 2050. (f) Jeffery, T. Synthesis 1987, $70-71$.

${ }^{9}$ Jeffery, T. Synthesis 1987, $70-71$.

10 (a) Jeffery, T. Tetrahedron Lett. 1985, 26, 2667 - 2670. (b) Jeffery, T. Tetrahedron Lett. 1990, 31, 6641 -6644. (c) Karabelas, K.; Westerlund, C.; Hallberg, A. J. Org. Chem. 1985, 50, $3896-3900$.

${ }^{11}$ Grigg, R.; Loganathan, V.; Santhakumar, V.; Sridharan, V.; Teasdale, A. Tetrahedron Lett. 1991, 32, $687-690$

12 Kudirka, R.; Van Vranken, D. L. J. Org. Chem. 2008, 73, 3585 - 3588.

13 (a) Jeffery, T. J. Chem. Soc., Chem. Commun. 1984, 19, 1287 - 1289. (b) Jeffery, T. Tetrahedron Lett. 1985, 26, 2667 - 2670. (c) Jeffery, T. Synth. Commun. 1988, 18, 77. 14 (a) Knowles, J. P.; Whiting, A. Org. Biomol. Chem. 2007, 5, 31 - 44. (b) Crisp, G. T. Chem. Soc. Rev. 1998, 27, 427 - 436.

15 (a) Schwab, P.; Grubbs, R. H.; Ziller, J. W. J. Am. Chem. Soc. 1996, 118, 100 - 110. (b) Schwab, P.; France, M. B.; Ziller, J. W.; Grubbs, R. H. Angew. Chem. Int. Ed. 1995, $34,2039-2041$.

${ }^{16}$ Young, I. S.; Kerr, M. A. J. Am. Chem. Soc. 2007, 129, 1465 - 1469.

17 (a) Takacs, J. M.; Lawson, E. C.; Clement, F. J. Am. Chem. Soc. 1997, 119, 5956 5957. (b) Maeda, K.; Farrington, E. J.; Galardon, E.; John, B. D.; Brown, J. M. Adv. Synth. Catal. 2002, 344, 104 - 109. (c) Bray, K. L.; Lloyd-Jones, G. C.; Muñoz, M. P.; Slatford, 
P. A.; Tan, E. H. P.; Tyler-Mahon, A. R.; Worthington, P. A. Chem. -Eur. J. 2006, 12, 8650 - 8663. (d) Hudlicky, T.; Olivo, H. F. J. Am. Chem. Soc. 1992, 114, 9694 - 9696.

18 Granberg, K. L.; Backvall, J. E. J. Am. Chem. Soc. 1992, 114, 6858 - 6863.

${ }^{19}$ Andersson, P. G.; Schab, S. Organometallics 1995, 14, 1 - 2.

${ }^{20}$ Lautens, M.; Fang, Y.-Q. Org. Lett. 2003, 5, 3679 - 3682.

${ }^{21}$ Yeagley, A. A.; Lowder, M. A.; Chruma, J. J. Org. Lett. 2009, 11, 4022 - 4025.

22 (a) Blaskó, G.; Murugesan, N.; Freyer, A. J.; Shamma, M.; Ansari, A. A.; Rahman, A.V. J. Am. Chem. Soc. 1982, 104, 2039 - 2041. (b) Stevens, R. V.; Pruitt, J. R. J. Chem. Soc., Chem. Commun. 1983, 1425. 


\section{Chapter 4. Decarboxylative Benzylation}

\subsection{Introduction}

Despite rapidly growing interest in the arena of palladium-catalyzed decarboxylative alkylations, ${ }^{1}$ the reaction scope remains generally limited to allylation of enolate nucleophiles with $\pi$-allyl palladium(II) species. This moiety is generated via insertion of a $\operatorname{Pd}(0)$ catalyst into an allyl ester or carbonate $\mathrm{C}-\mathrm{O}$ bond. Our group was inspired by recent reports that benzyl esters and carbonates were viable substrates for $\mathrm{Pd}(0)$-catalyzed nucleophilic alkylations. ${ }^{2}$ We envisioned advancing a similar strategy for the benzylation of $\alpha$-imino anions. We have ascertained general reaction conditions for the decarboxylative benzylation of benzyl diphenylglycinate imines $\mathbf{4 . 1}$ into the corresponding 1,2-diarylethyl imines 4.2 (Scheme 4.1). The reaction scope was evaluated through substitution of both the imine and ester functionalities.

Scheme 4.1 Decarboxylative benzylation of $\alpha$-imino anions.

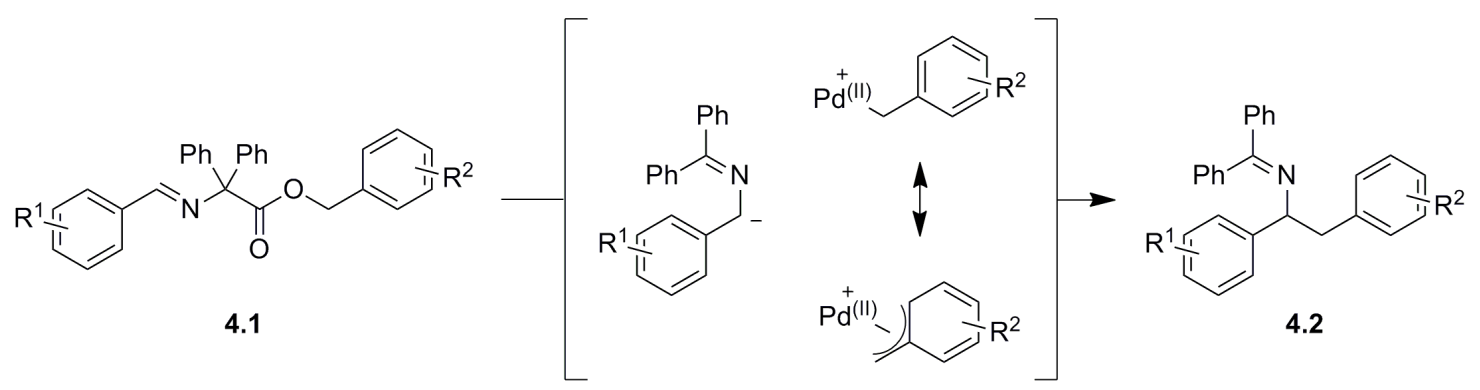




\subsection{Synthesis of Benzyl Diphenylglycinate Imine}

Our studies began with the selection of the appropriate imine 4.1 to begin the investigation for a decarboxylative benzylation process. Encouraged by a recent report by Kuwano in which the use of either electron-deficient or electron-rich aryl systems enhanced the insertion of palladium(0) into benzylic acetates, ${ }^{2 \mathrm{e}}$ we rationalized that incorporation of an electron-withdrawing group into the benzyl ester would facilitate insertion of palladium $(0)$ into the ester $\mathrm{C}$ - $\mathrm{O}$ bond of our system. $^{2}$ Based on our previous experience, ${ }^{3}$ we reasoned that electronwithdrawing substituents on the imine component would accelerate the decarboxylation and predispose the delocalized 2-azaallyl anion intermediate toward benzylation at the least substituted carbon. Accordingly, (4trifluoromethyl)benzyl ester 4.1a was selected for initial studies and synthesized on a gram scale in two reaction vessels from diphenylglycine (Scheme 4.2).

Scheme 4.2 Preparation of diphenylglycinate ester 4.1a.

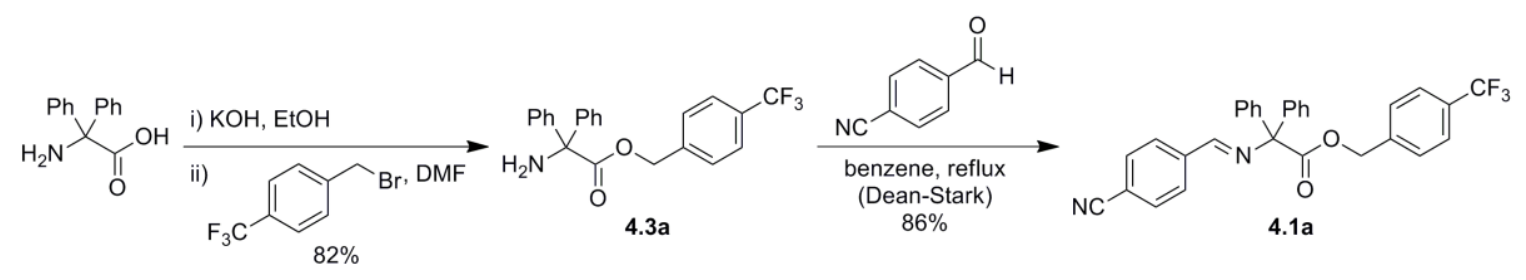

\subsection{Initial Decarboxylative Benzylation Studies and Optimization}

Initial reactions were heated conventionally with a variety of mono and bidenate ligands under an inert atmosphere. In accord with related studies by Kuwano and coworkers, ${ }^{2 e, 2 f}$ only bidentate ligands proved effective in catalyzing the 
decarboxylative benzylation (Table 4.1). Moreover, the bite angle of bidentate ligands appeared to demonstrate an impact on the reaction rate and relative percentage of side products generated. For example, the bite angles of relevant palladium(II) complexes include xanthphos $=108.1^{\circ}, \mathrm{dppf}=102.2^{\circ}$, and $\mathrm{BINAP}=$ $96.0^{\circ}$. A trend in isolated yield of the desired imine 4.2a was observed with increased yield corresponding to a decrease in bite angle, though no reaction was observed when dppe $\left(\right.$ dppe $\left.=86^{\circ}\right)$ was employed (entries 4-7). This may suggest successful conversion is reliant on the BINAP ligand's optimal bite angle. After an extensive screening of reaction conditions, the application of microwave irradiation provided optimal conditions and afforded the desired decarboxylative benzylation product 2a in high yield (entry 10). To our disappointment, $R$-BINAP did not confer any enantioselectivity for the transformation, as monitored by chiral HPLC analysis. It should be noted that the high ligand-to-palladium ratio ( $\sim 6.7$ vs. 2.0 for conventional heating) proved critical for the success of the microwave-promoted conditions. This high ligand-to-palladium ratio was presumably required to encourage the formation of the requisite palladium $(0)$ - ligand complex within the relatively short time frame of the reaction. Extensive efforts to test this hypothesis, however, have not been attempted. 
Table 4.1 Decarboxylative benzylation optimization conditions.

\begin{tabular}{cccccc} 
& & & \\
\hline
\end{tabular}

Starting material was isolated in examples where little to no reaction took place (entries 1-5, 11). In the cases of a successful decarboxylative benzylation, the majority of the remaining mass balance was predominantly attributed to the formation of side products emanating from decarboxylative protonation (4.4) and acetate addition in which the acetate from $\mathrm{Pd}(\mathrm{OAc})_{2}$ serves as a competitive nucleophile for the benzyl-palladium(II) intermediate (4.5) (Figure 4.1). Nonenantioselective and enantioselective examples of palladium-catalyzed decarboxylative protonation have been previously noted.4,5 For example, Stoltz and coworkers described an enantioselective decarboxylative protonation of racemic $\beta$ ketoesters. $^{5 a}$ Despite extensive experimentation, the authors were unable to identify the mechanism of protonation or the origin of the proton in 4.7. When deuterated formic acid was used, they observed only a maximum of $35 \%$ deuteriumincorporation indicating that the proton source may not solely originate from an 
acidic proton. Similarly, we have yet to unambiguously determine the proton source for production of benzylic imine 4.4.

Figure 4.1 Major side products for the decarboxylative benzylation of ester 4.1a.

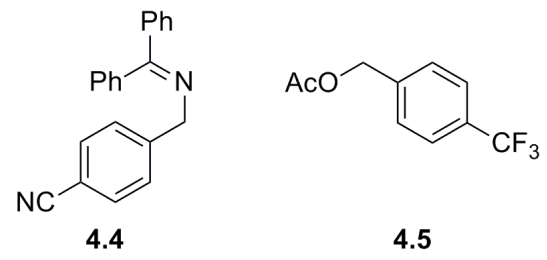

Scheme 4.3 Stoltz's enantioselective decarboxylative protonation of $\beta$-keto esters.

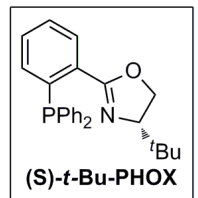

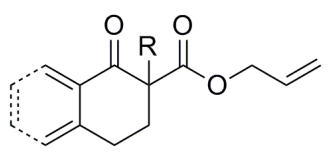

(士) 4.6

$\mathrm{R}=\mathrm{Me}$, allyl, $\mathrm{Bn}$
$\mathrm{Pd}(\mathrm{OAc})_{2}(10 \mathrm{~mol} \%)$ (S)-t-Bu-PHOX (12.5 mol \%)

$\mathrm{HCO}_{2} \mathrm{H}, p$-dioxane, 4 Å MS

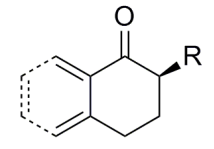

4.7

14 examples $62-99 \%$ yield $60-95 \%$ ee

\subsection{Evaluation of Reaction Scope - Synthesis for Ester and Imine Variation}

Encouraged by the results following our optimization studies on the decarboxylative benzylation of imine 4.1a, we next sought to evaluate the scope of the reaction. This was achieved by variation of both the ester and imine moieties on 4.1. In some instances concerning variation of the ester, the requisite benzyl bromide was not available. Therefore, synthesis of imine 4.1 was initiated with the preparation of the benzyl bromide from the corresponding commercially available aldehyde, followed by the formation of ester 4.3 to afford the substituted benzyl bromide (Scheme 4.4). The various benzyl diphenylglycinate amines 4.3 were next synthesized in high isolated yields from commercially-available diphenylglycine 
(Scheme 4.5). It is noteworthy that the synthesis of benzyl ester 4.3 was highly selective for mono-benzylation at the carboxylic acid rather than benzylation of both the acid and amine functionalities; $\mathrm{N}, \mathrm{O}$-bisallylation is a common side product ( $\sim 20 \%$ yield $)$ in the formation of allyl diphenylglycinate using allyl bromide.

Scheme 4.4 Preparation of benzyl bromide substrates.

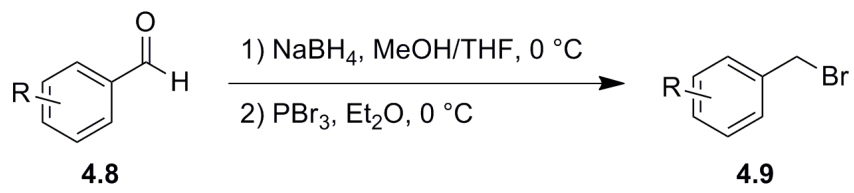

Scheme 4.5 Synthesis of benzyl diphenylglycinate amine 4.3.

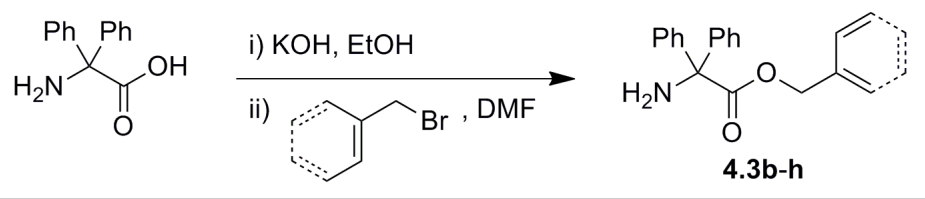<smiles>NC(C(=O)OCc1ccccc1)(c1ccccc1)c1ccccc1</smiles>

$4.3 b$

$86 \%$
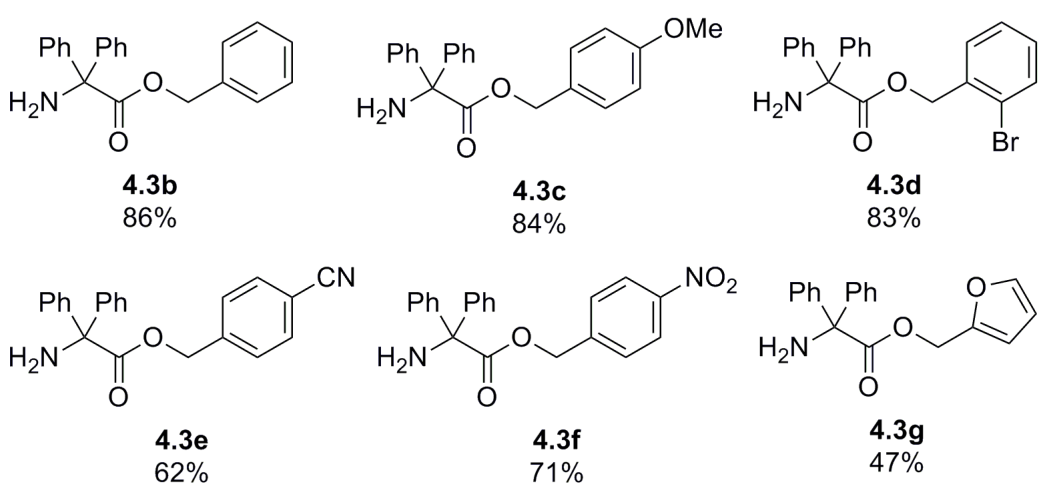

$62 \%$
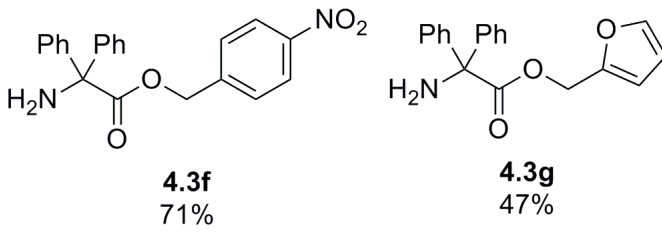

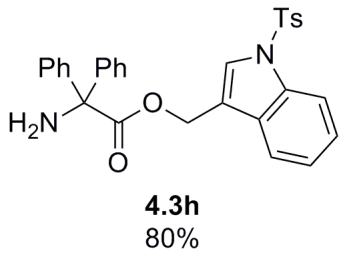

To focus on the impact of the benzyl ester, we first used the same imine moiety for our initial optimization studies. Accordingly, amines $\mathbf{4 . 3 a - h}$ were subjected to imine condensation with para-cyanobenzaldehyde to afford the 
corresponding imines 4.1a-h in moderate to high isolated yields (Scheme 4.6). To facilitate investigations concerning the impact of the imine moiety, we sought to condense amine 4.3 with a variety of aromatic and heteroaromatic aldehydes. Amine 4.3b was selected due to the neutral electronic character of the benzyl ester and subsequently furnished a variety of aryl and heteroaryl imines 4.3i-r in moderate to high isolated yields (Scheme 4.7). It should be emphasized that previous studies to generate benzyl palladium(II) species from benzyl acetates have noted limited success with unsubstituted benzyl esters. ${ }^{6}$ Thus, benzyl esters 4.3i-r represent a real challenge to our decarboxylative benzylation reaction conditions. We were gratified that a majority of the synthesized imines 4.1 were readily isolated in spectroscopically pure form as crystalline products.

Scheme 4.6 Imine condensation to furnish imines 4.1a-h.

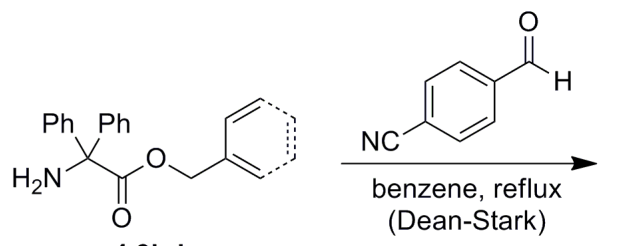

4.3b-h
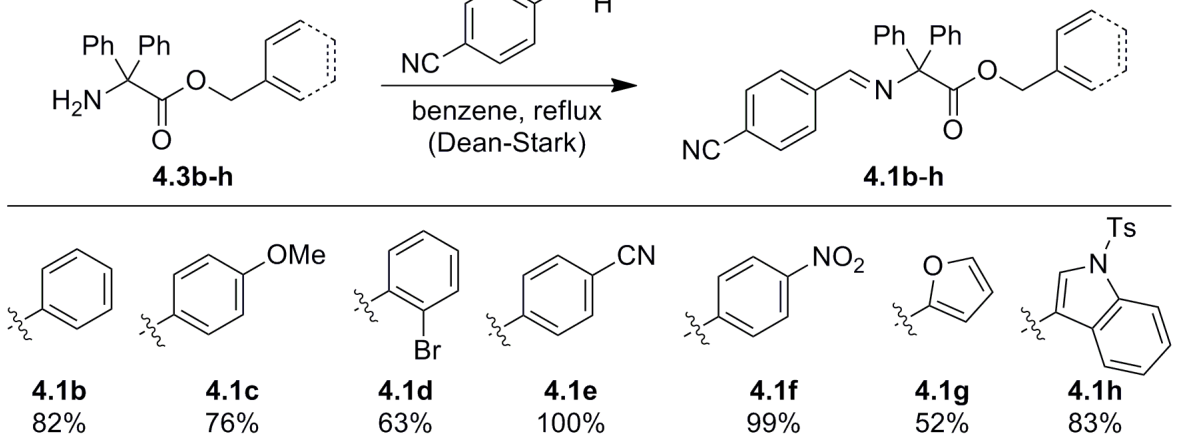
Scheme 4.7 Imine condensation to furnish imines 4.1i-r.

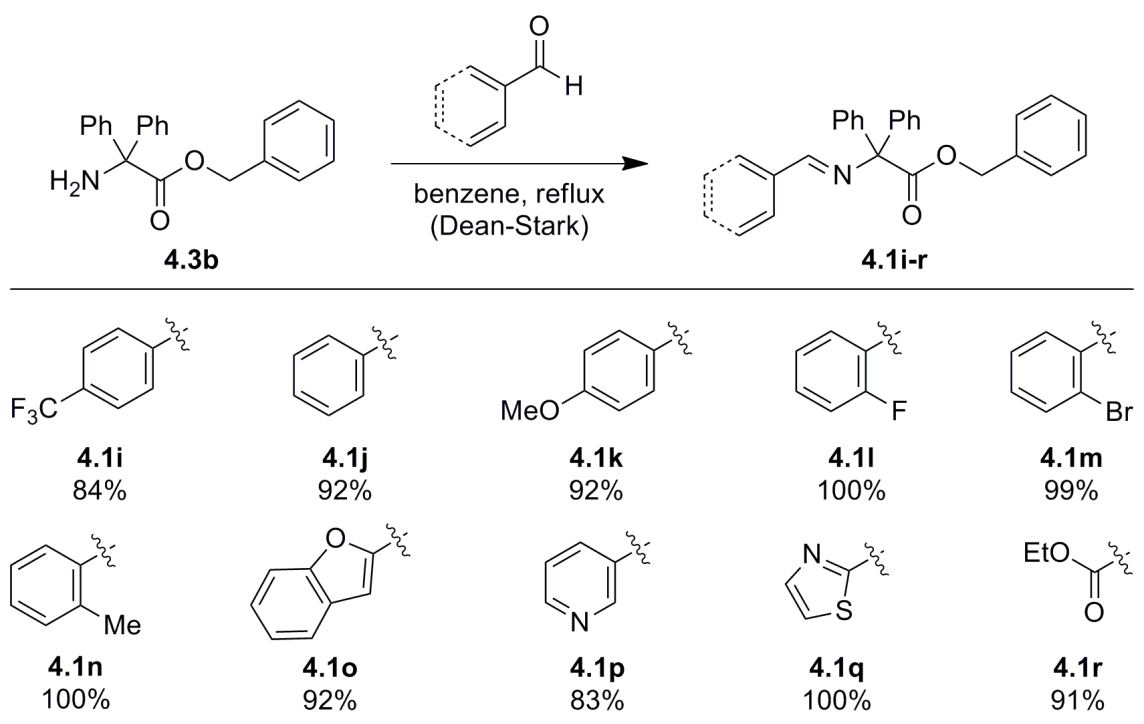

\subsection{Evaluation of Substrate Scope - Subjection of Functionalized Imines to Decarboxylative Benzylation}

A variety of aryl and heteroaryl imines 4.1 were subjected to our optimized decarboxylative benzylation conditions to afford the corresponding products 4.2 in moderate yields (Table 4.2). While ideal reaction temperatures/times were substrate specific, heating to $150{ }^{\circ} \mathrm{C}$ for as little as 5 minutes afforded complete conversion of $\alpha$-imino ester 4.1a and typically provided moderate to high conversion for all other substrates investigated. The electronic composition of the benzyl ester significantly impacted product distribution. Electron-withdrawing groups were observed to reduce the preference for the desired imine 4.2 (entries 18). For example, 4-methoxybenzyl ester 4.1c afforded $85 \%$ of the desired product 4.2c, whereas 4-nitrobenzyl ester 4.1f was converted almost exclusively to the side 
product 4.4 (entry 3 vs. entry 6). Heteroaromatic benzyl esters proved to be viable substrates for the decarboxylative benzylation (entries 7 and 8), suggesting potential application toward the synthesis of 2 -aryl- $\beta$-carboline alkaloid analogues, ${ }^{7}$ which will be the focus of Section 4.6. To the best of our knowledge, this represented the first example of the formation of a catalytically-relevant palladium(II)-3-methyleneindole species via insertion into the corresponding ester. Furthermore, it is the first example of an indole participating in a palladiumcatalyzed decarboxylative alkylation. Following our publication, Tunge and coworkers noted a similar reactivity for the palladium-catalyzed decarboxylative coupling of indole propioliates, as previously discussed in Chapter 1, Section 1.8. The reaction of 2-furanyl ester $\mathbf{4 . 1 9}$ was especially intriguing as alkylation was identified by ${ }^{1} \mathrm{H}$ NMR to also occur at the more substituted carbon center (Figure 4.2). This observation supports the proposition that heteroaryl esters proceed via an $\eta^{3} \pi$-benzyl palladium(II) intermediate (vide infra). Our microwave-assisted decarboxylative benzylation condition remain the best yields reported for the palladium-catalyzed formation and nucleophilic alkylation of benzyl palladium(II) species from simple benzyl esters, e.g. products $4.2 \mathrm{~b}$ and $\mathbf{4 . 2 i}-\mathbf{r}$.

Figure 4.2 Isomer of decarboxylative benzylation product 4.2g.

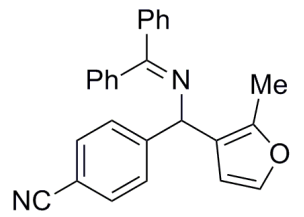


The imine moiety was also tolerant to variation, though increasing the size and electron-releasing capacity of the ortho substituent dramatically impacted the corresponding isolated yields (entries 12-14). Additionally, the electronic characteristic of the imine moiety matched our earlier observations for decarboxylative allylation. ${ }^{3 a}$ It is noteworthy that heteroaryl imines 2-benzofuranyl 4.10, 3-pyridyl 4.1p, and 2-thiazolyl 4.1q successfully underwent the transformation in moderate to good yields (entries 15-17). Moreover, $\alpha$-imino ester 4.1r was converted to protected phenylalanine 4.2r, a transformation that only required higher catalyst and ligand loading (10 mol \% $\mathrm{Pd}(\mathrm{OAc})_{2}$ and $40 \mathrm{~mol} \% \mathrm{rac}$ BINAP), a necessity specific to this substrate. 
Table 4.2 Substrate scope for palladium-catalyzed decarboxylative benzylation of ester 4.1.

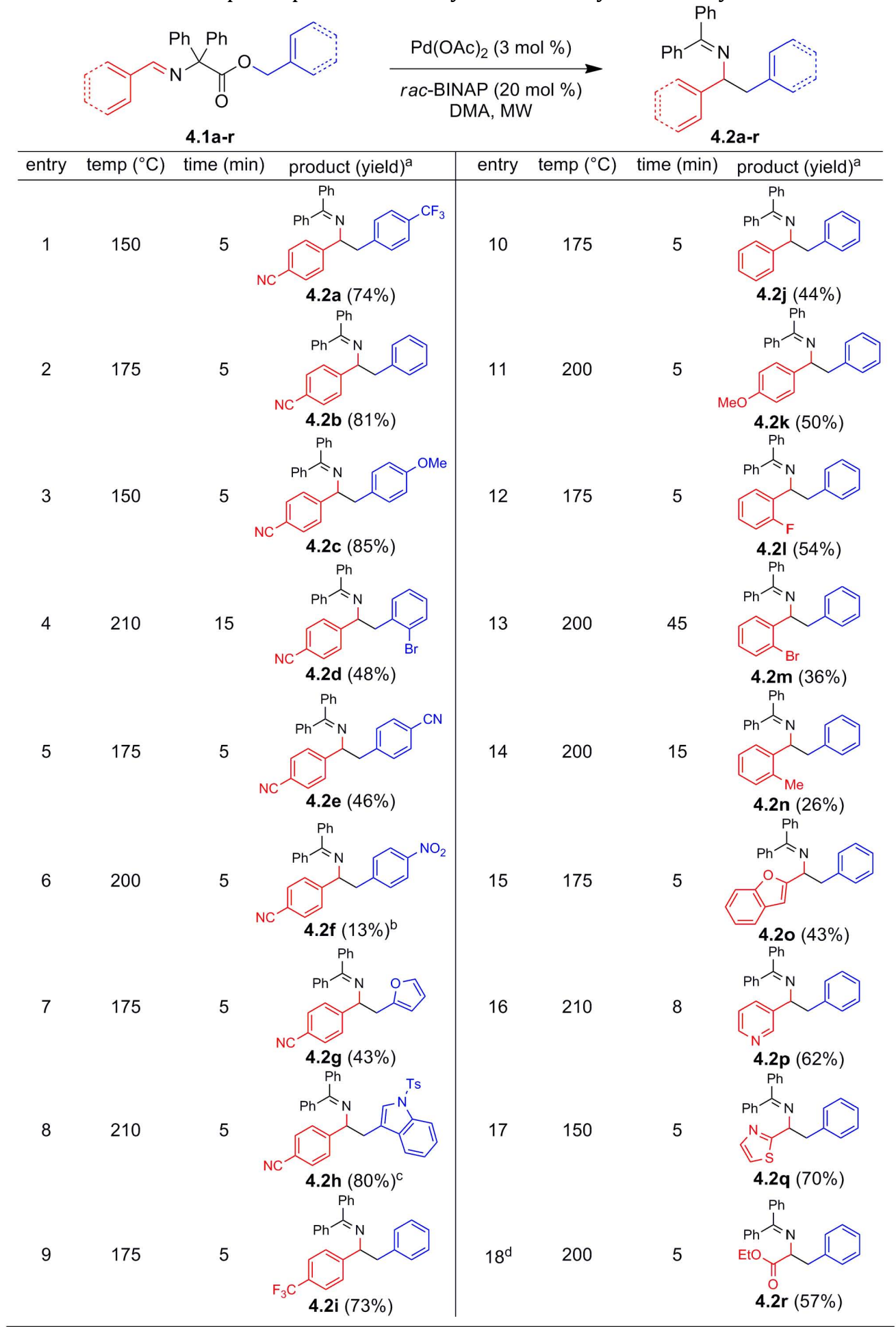

${ }^{a}$ Isolated yield after chromatographic purification; reaction conditions: imine (100 mg), $\mathrm{Pd}(\mathrm{OAc})_{2}(3 \mathrm{~mol} \%)$, rac-BINAP $(20 \mathrm{~mol} \%)$ in DMA $(0.1 \mathrm{M})$. The remaining mass balance was predominantly the protonation and acetaylation side products. ${ }^{b}$ Determined by ${ }^{1} \mathrm{H}$ NMR spectroscopy of an inseperable mixture of $4.2 \mathrm{f}$ and $4.4{ }^{\circ}{ }^{\mathrm{C}}$ Reaction conditions: imine $(300 \mathrm{mg}, 0.500 \mathrm{mmol}), \mathrm{Pd}(\mathrm{OAc})_{2}(3 \mathrm{~mol}$ $\%)$, rac-BINAP $(20 \mathrm{~mol} \%)$ in DMA $(0.1 \mathrm{M}) .{ }^{\mathrm{d}}$ Reaction conditions: Pd(OAc) 2 (10 mol \%), rac-BINAP (40 mol \%) in DMA $(0.1 \mathrm{M})$. 
The mechanism for the palladium-catalyzed decarboxylative benzylation of imino ester 4.1 is currently undetermined, though a preliminary mechanistic explanation is proposed in Figure 4.3. The active palladium(0) catalyst is generated following reduction of $\mathrm{Pd}(\mathrm{OAc})_{2}$ with BINAP. Oxidative insertion of palladium into the ester C-O bond of $\mathbf{4 . 1}$ forms an ephemeral palladium(II)-carboxylate species I that undergoes relatively irreversible decarboxylation to furnish the 2-azaallyl palladium(II) intermediate II. This intermediate is in equilibrium with the $\eta^{1}$ complex III and the tight-ion pair $\pi$-benzylpalladium(II): $\alpha$-imino anion species IV. Reductive elimination (from III) or regioselective nucleophilic attack (from IV) then regenerates the palladium(0) catalyst with concomitant formation of homobenzylic imine 4.2.

Figure 4.3 Possible mechanism for decarboxylative benzylation.

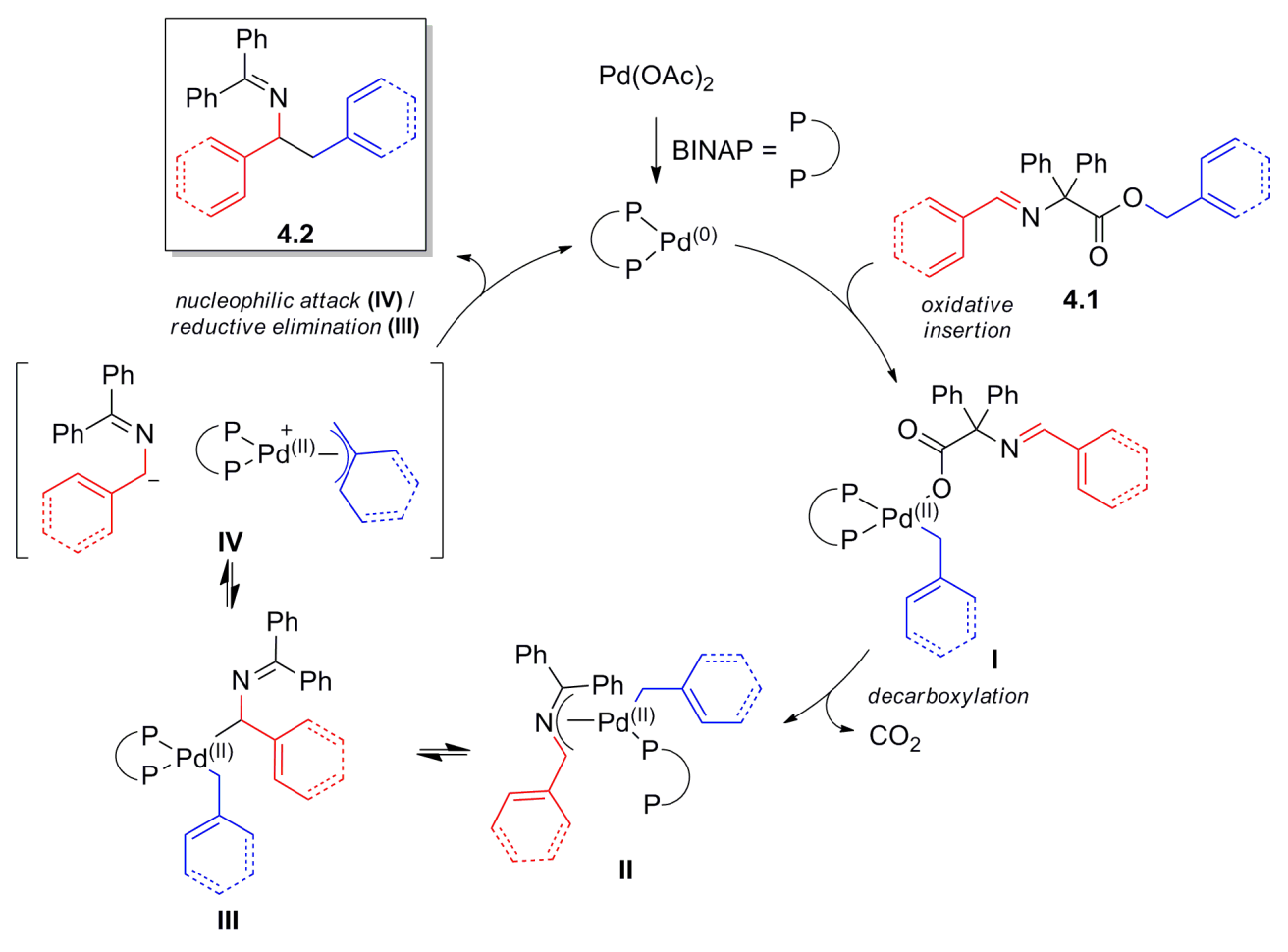




\subsection{Application: Synthesis of a $\beta$-Carboline Scaffold}

As previously mentioned in Section $\mathbf{4 . 5}$, the palladium-catalyzed decarboxylative benzylation of heteroaromatic imine $4.1 \mathrm{~h}$ suggests potential application toward the synthesis of 2 -aryl- $\beta$-carboline alkaloid analogues. Inspired by a large family of naturally-occurring tryptophan derivatives found in plants and animals, $\beta$-carboline analogues have recently regained attention for their diverse biological activity, including both anti-tumor, ${ }^{8}$ anti-HIV potential, ${ }^{9}$ antimicrobial ${ }^{10}$ and broad spectrum pharmaceutical properties. They have also been found to possess significant neurological activity. The ethyl ester of $\beta$-carboline-3-carboxylic acid $\left(\beta\right.$-BCC, Figure 4.4, $\left.\mathrm{R}^{1}=\mathrm{CO}_{2} \mathrm{Et}, \mathrm{R}^{2}=\mathrm{H}\right)$ has been determined to possess a high affinity for the benzodiazepine receptor, which has been linked to significant effects in the central nervous system. ${ }^{11}$ Methods for the synthesis of functionalized $\beta$ carbolines have predominantly focused on condensation of tryptophan with an aldehyde followed by a Pictet-Spengler cyclization, or through formation of the amide derivative of tryptophan followed by a Bischler-Naperalski reaction (Scheme 4.8). ${ }^{12}$ Following these strategies, derivatization of $\beta$-carboline scaffolds at the 2 position ( $\mathrm{R}^{1}$ in Figure 4.4) has been limited to functionalities readily derived from a carboxylic acid (Figure 4.4). Accordingly, there remains a significant void in all $\beta$ carboline structure-activity relationship studies for compounds possessing 2 -aryl substituents. Similarly, diversification of the indole ring beyond alkylation/amidation of the nitrogen is absent in the literature. 
Figure 4.4 $\beta$-Carboline scaffold.

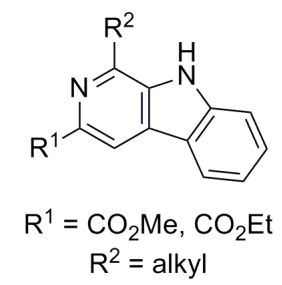

Scheme 4.8 Methods for synthesis of $\beta$-carboline scaffold.

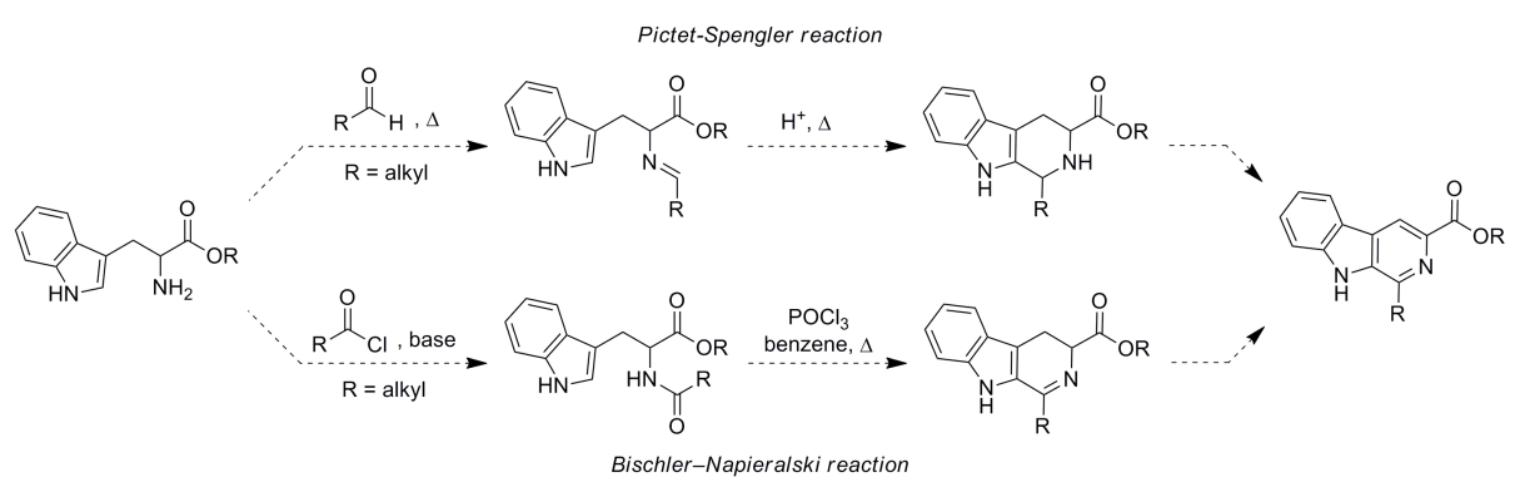

\subsection{Synthesis of a 2-Aryl- $\beta$-Carboline: The Pictet-Spengler Reaction}

Our initial aim was to utilize the Pictet-Spengler cyclization, ${ }^{13}$ a classical method for the synthesis of $\beta$-carboline or isoquinone alkaloid cores. We envisioned the use of $\mathbf{4 . 2 h}$, generated from our decarboxylative benzylation reaction (vide supra), which after global deprotection to furnish imine 4.10, could serve as a potential starting point toward the synthesis of 2 -aryl- $\beta$-carboline derivatives (Scheme 4.9). Condensation with a variety of aryl aldehydes would then afford a collection of imines $\mathbf{4 . 1 1}$ and thus a variety of unique 2-aryl- $\beta$-carboline analogues following Pictet-Spengler cyclization and oxidation/aromatization. 
Scheme 4.9 Retrosynthetic analysis of 2-aryl- $\beta$-carbolines via Pictet-Spengler cyclization.

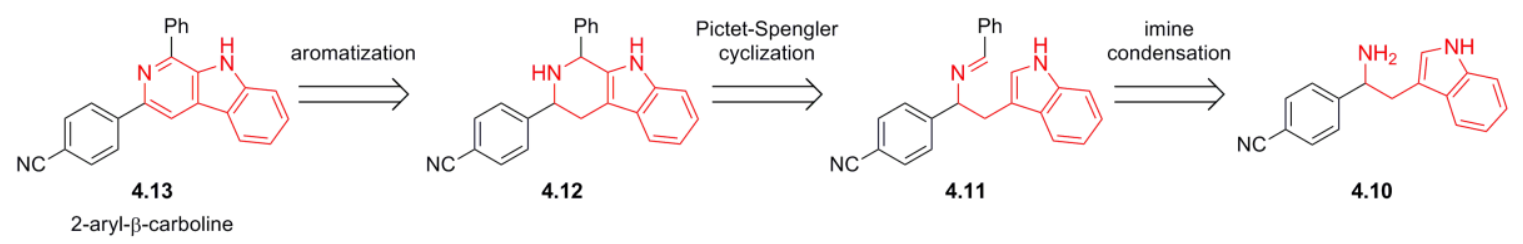

Our investigation began with multiple attempts to hydrolyze the benzophenone imine and tosyl protecting groups of imine $\mathbf{4 . 2 h}$ to furnish amine 4.10. Regrettably, extensive experimental efforts to cleave the tosyl moiety from either amine $\mathbf{4 . 1 4}$ or imine $\mathbf{4 . 2 \mathrm { h }}$ resulted in complicated reaction mixtures and irreproducibility (Scheme 4.10). We ascertained that removal of both protecting groups concomitantly and product isolation may be problematic due to the high polarity of the resulting amine $\mathbf{4 . 1 0}$ and the dramatic loss in molecular weight.

Scheme 4.10 Deprotection of diphenyl moiety from imine $\mathbf{4 . 2 h}$.

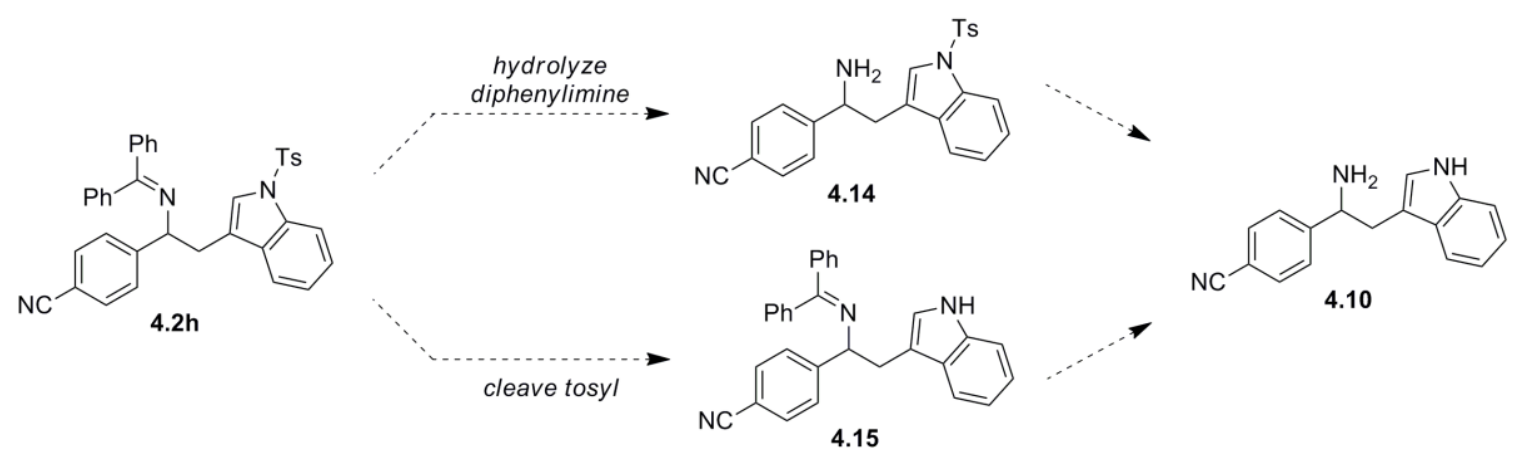

A new strategy was then devised to (1) maintain a favorable mass balance in an attempt to synthesize a Pictet-Spengler precursor and (2) assist with the removal of the tosyl moiety. To this end, imine $\mathbf{4 . 2 h}$ was subjected to $1 \mathrm{M} \mathrm{HCl}$ in $\mathrm{THF}$, followed by imine condensation to afford imine 4.16 in moderate isolated yield (Scheme 4.11). Disappointingly, the tosyl protecting group could not be cleaved 
from imines 4.16 under various conditions. Due to the inability to cleave the tosyl moiety, imine 4.16a was subjected to standard Pictet-Spengler cyclization reaction conditions (Scheme 4.12). To our disappointment, the reactions only resulted in, at best, recovered starting material. The reaction was also attempted with amine $\mathbf{4 . 1 4}$ in the presence of benzaldehyde, in which the imine would be formed in situ, however this resulted in no reaction and re-isolation of starting material.

Scheme 4.11 Synthesis of imine 4.16.

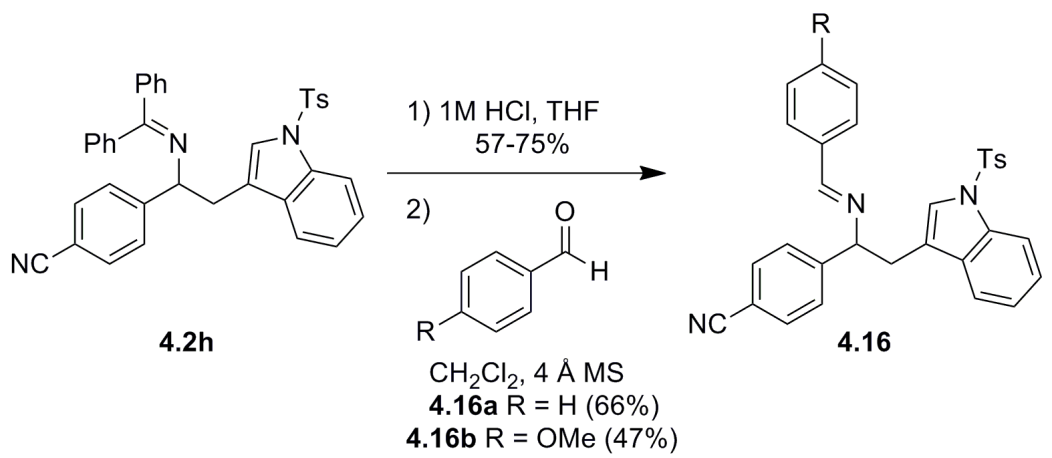

Scheme 4.12 Attempts at Pictet-Spengler cyclization.

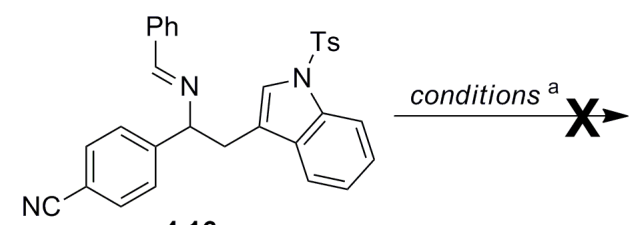

4.16a

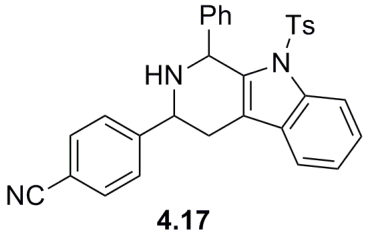

a Method $\mathrm{A}$ : $\mathrm{Ac}_{2} \mathrm{O}$, pyridine, rt; Method $\mathrm{B}: \mathrm{AcOH}, 0^{\circ} \mathrm{C} \rightarrow 60^{\circ} \mathrm{C}$; Method $\mathrm{C}: \mathrm{TFA}, \mathrm{CH}_{2} \mathrm{Cl}_{2}, 0^{\circ} \mathrm{C} \rightarrow \mathrm{rt}$

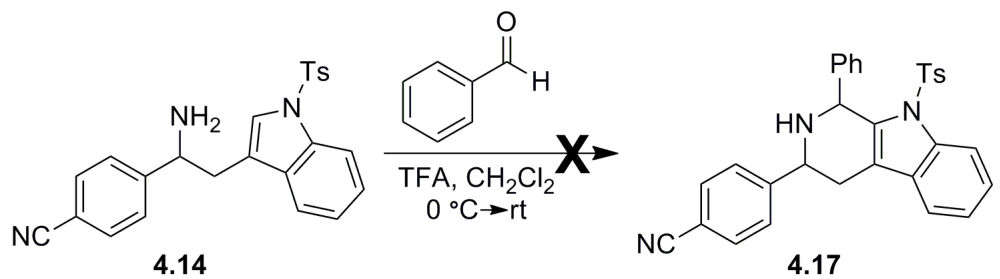

In a final attempt to utilize this cyclization manifold for the synthesis of a $\beta$ carboline scaffold, imines $\mathbf{4 . 1 8}$ and $\mathbf{4 . 2 0}$ were synthesized with altered and more 
labile indole protecting groups. When subjected to our optimized palladiumcatalyzed decarboxylative benzylation conditions, neither imine successfully converted to their respective 1,2-diarylethyl imine products 4.19 and 4.21 (Scheme 4.13). The Boc protecting group of imine 4.18 was most likely cleaved under the high temperature achieved via microwave irradiation, resulting in a complicated mixture of products. The reaction of imine $\mathbf{4 . 2 0}$ also resulted in a complicated reaction mixture following microwave irradiation. The synthesis of the nonprotected indole imine $\mathbf{4 . 2 2}$ was also attempted, but ultimately failed (Figure 4.5). After extensive screening of reaction conditions and protecting group strategies, it was determined that a Pictet-Spengler cyclization strategy did not represent a promising approach toward the 2-aryl- $\beta$-carboline scaffold from the $\mathbf{4 . 2 h}$ core.

Scheme 4.13 Decarboxylative benzylation of imines 4.18 and 4.20 .
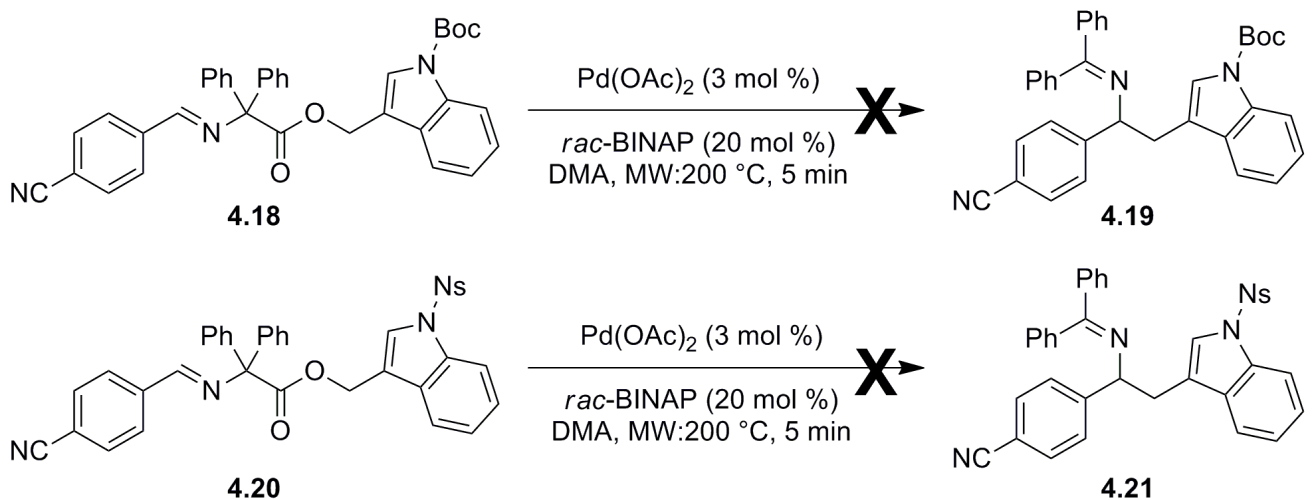<smiles>N#Cc1ccc(C(Cc2cn(N)c3ccccc23)N=C(c2ccccc2)c2ccccc2)cc1</smiles>

Figure 4.5 Deprotected imine 4.22.<smiles>N#Cc1ccc(/C=N/C(=O)C(OCc2c[nH]c3ccccc23)c2ccccc2)cc1</smiles> 


\subsection{Synthesis of a $\beta$-Carboline Scaffold: the Bischler-Napieralski Reaction}

After extensive, yet unsuccessful, experimentation toward the synthesis of a 2-aryl- $\beta$-carboline analogue via a Pictet-Spengler cyclization (vide supra), alternative strategies were sought to achieve the desired cyclization. A related transformation to the Pictet-Spengler cyclization, the Bischler-Napieralski reaction has been utilized widely in the synthesis of $\beta$-carboline derivatives and related alkaloids. ${ }^{14}$ We envisioned a pathway that would utilize the same precursor $\mathbf{4 . 2 h}$ derived from our previous palladium-catalyzed decarboxylative benzylation studies (Scheme 4.14).

Scheme 4.14 Retrosynthesis of 2-aryl- $\beta$-carbolines via Bischler-Napieralski cyclization.

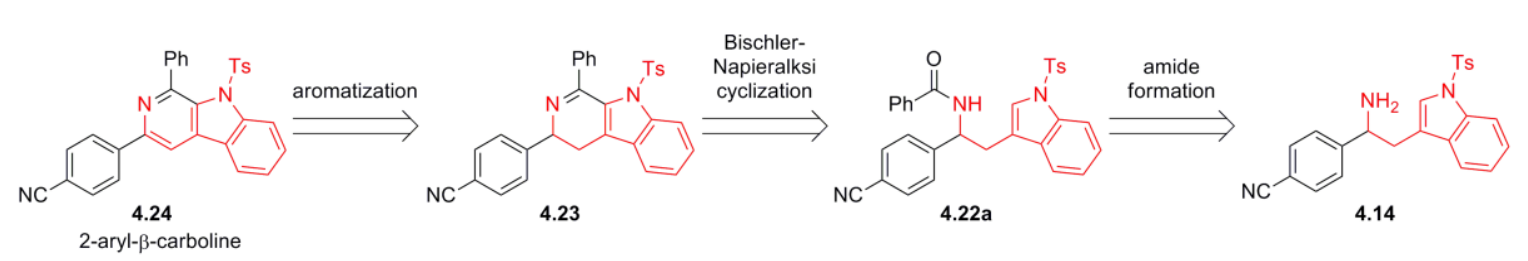

Treatment of amine $\mathbf{4 . 1 4}$ with benzoyl chloride or para-methoxybenzoyl chloride, DMAP, and DIPEA in THF afforded amides 4.22a and 4.22b, respectively, in respectable isolated yields (Scheme 4.15). The amides were then subjected to the Bischeler-Napieralski reaction utilizing various activating conditions (Table 4.3).15 Gratifyingly, the treatment of amide 4.22a with $\mathrm{POCl}_{3} / \mathrm{P}_{2} \mathrm{O}_{5}$ in refluxing benzene or toluene furnished the expected cyclized product 4.23 , albeit in low isolated yield (entries 1 and 2). Slight alterations in the reaction conditions, namely exclusion of phosphorous pentaoxide, provided the fully oxidized analogue 4.24 in 35\% yield from amide $\mathbf{4 . 2 2 a}$ (entry 3). The dihydropyridine $\mathbf{4 . 2 3}$ also readily 
oxidized to furnish the desired 2-aryl- $\beta$-carboline analogue $\mathbf{4 . 2 4}$ in $44 \%$ isolated yield upon treatment with sulfur in refluxing xylenes (Scheme 4.16).16 Precedent exists for microwave-accelerated Bischler-Napieralski reactions. ${ }^{17}$ Accordingly, a mixture of amide 4.22a and $\mathrm{POCl}_{3}$ in benzene was heated via microwave irradiation, resulting in an intractable complex mixture (entry 4). Surprisingly, electron-rich amide 4.22b proved resistant to Bischler-Naperalski cyclization reaction conditions (entries 5 and 6).

Scheme 4.15 Synthesis of Bischler-Napieralski precursor 4.22.<smiles>Cn1cc(CC(N)c2ccc(C#N)cc2)c2ccccc21</smiles>

4.14<smiles>[R]c1ccc(C(=O)Cl)cc1</smiles>

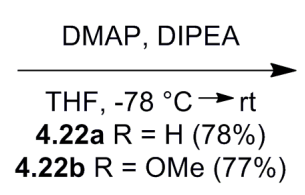

4.22b R = OMe (77\%)<smiles>[R]c1ccc(C(=O)NC(Cc2cn([Y5])c3ccccc23)c2ccc([R])cc2)cc1</smiles>

Table 4.3 Bischler-Napieralski reaction.

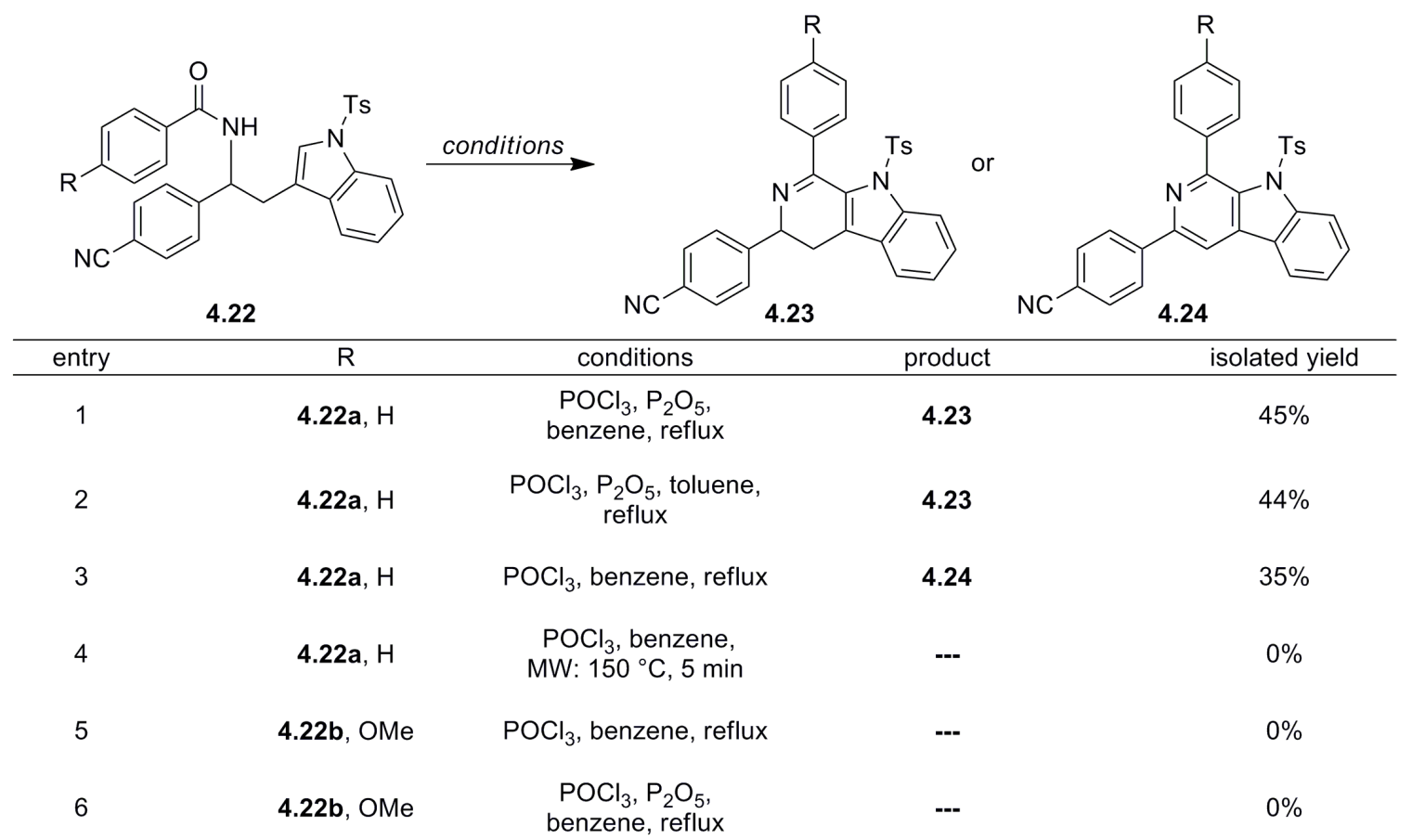


Scheme 4.16 Oxidation of imine 4.23.

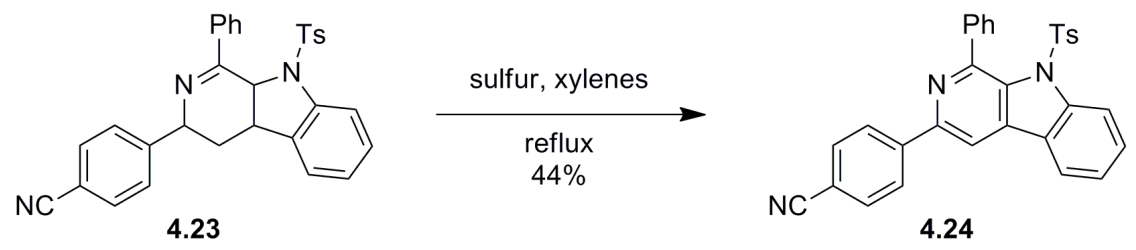

Gratifyingly, we successfully synthesized the first member of what is hoped to be a small library of 2-aryl- $\beta$-carbolines 4.24 utilizing our decarboxylative benzylation protocol followed by a Bischler-Napieralski cyclization. A thorough investigation regarding reaction scope and generality of the method would be beneficial, in addition to further optimization studies. This synthesis provides a unique application of the palladium-catalyzed decarboxylative benzylation reaction developed within our lab and furnishes the first example of a 2-aryl substituted $\beta$ carboline derivative.

\subsection{Conclusion}

In summary, we have reported general reaction conditions for the palladiumcatalyzed decarboxylative benzylation of benzyl diphenylglycinate imines promoted by microwave heating. To the best of our knowledge, this research represents the first example of a palladium-catalyzed decarboxylative benzylation involving a nonenolate carbon-centered nucleophile. Moreover, our results represent the most successful examples of formation and derivatization of simple $\pi$-benzyl palladium(II) species from nonsubstituted ("electron-neutral") benzyl esters. This transformation has expanded the reaction scope of our previously identified 
palladium-catalyzed decarboxylative generation and derivatization of semistabilized $\alpha$-imino anions. Moreover, we have demonstrated a unique application of our methodology toward the successful synthesis of a 2 -aryl- $\beta$-carboline scaffold. 


\subsection{References}

${ }^{1}$ For reviews on palladium-catalyzed decarboxylative allylic alkylations, see: (a) Weaver, J. D.; Recio, A.; Grenning, A. J.; Tunge, J. A. Chem. Rev. 2011, 111, 1846 - 913. (b) Trost, B. M.; Van Vranken, D. L. Chem. Rev. 1996, 96, 395. (c) Tunge, J. A.; Burger, E. C. Eur. J. Org. Chem. 2005, 9, 1715 - 1726.

2 (a) Legros, J.-Y.; Fiaud, J.-C. Tetrahedron Lett. 1992, 33, 2509 - 2510. (b) Boutros, A.; Legros, J.-Y.; Fiaud, J.-C. Tetrahedron Lett. 1999, 40, 7329 - 7332. (c) Legros, J.-Y.; Toffano, M.; Fiaud, J.-C. Tetrahedron 1995, 51, 3235 - 3246. (d) Legros, J.-Y.; Primault, G.; Toffano, M.; Rivie`re, M.-A.; Fiaud, J.-C. Org. Lett. 2000, 2, 433 - 436. (e) Kuwano, R.; Kondo, Y.; Matsuyama, Y. J. Am. Chem. Soc. 2003, 125, 12104 - 12105. (f) Kuwano, R.; Yokogi, M. Org. Lett. 2005, 7, 945 - 947. (g) Kuwano, R.; Kondo, Y.; Shirahama, T. Org. Lett. 2005, 7, 2973 - 2975. (h) Kuwano, R.; Yokogi, M. Chem. Commun. 2005, 5899 - 5901. (i) Narahashi, H.; Shimizu, I.; Yamamoto, A. J. Organomet. Chem. 2008, 693, 283 - 296. (j) Miller, K. J.; Abu-Omar, M. M. Eur. J. Org. Chem. 2003, 1294 - 1299. (k) Kuwano, R. Synthesis 2009, 1049 - 1061. (l) Lie'gault, B.; Renaud, J.-L.; Bruneau, C. Chem. Soc. Rev. 2008, 37, 290 - 299.

${ }^{3}$ (a) Yeagley, A. A.; Chruma, J. J. Org. Lett. 2007, 9, 2879 - 2882. (b) Fields, W. H.; Khan, A. K.; Sabat, M.; Chruma, J. J. Org. Lett. 2008, 10, 5131 - 5134.

${ }^{4}$ Nonenantioselective decarboxylative protonation examples: (a) Mandai, T.; Imaji, M.; Takada, H.; Kawata, M.; Nokami, J.; Tsuji, J. J. Org. Chem. 1989, 54, 5395 - 5397.

(b) Tsuji, J.; Nisar, M.; Shimizu, I. J. Org. Chem. 1985, 50, 3416 - 3417. (c) 
Gowrisankar, S.; Kim, K. H.; Kim, S. H.; Kim, J. N. Tetrahedron Lett. 2008, 49, 6241 6244. (d) Kim, J. M.; Kim, S. H.; Lee, H. S.; Kim, J. N. Tetrahedron Lett. 2009, 50, 1734 $-1737$.

${ }^{5}$ Enantioselective decarboxylative protonation examples: (a) Mohr, J. T.; Nishimata, T.; Behenna, D. C.; Stoltz, B. M. J. Am. Chem. Soc. 2006, 128, 11348 - 11349. (b) Marinescu, S. C.; Nishimata, T.; Mohr, J. T.; Stoltz, B. M. Org. Lett. 2008, 10, 1039 1042.

${ }^{6}$ (a) Torregrosa, R. R. P.; Ariyarathna, Y.; Chattopadhyay, K.; Tunge, J. A. J. Am. Chem. Soc. 2010, 132, 9280 - 9282. (b) Kuwano, R.; Kondo, Y.; Shirahama, T. Org. Lett. 2005, 7, $2973-2975$.

7 (a) Ohmoto, T.; Koike, K. The Alkaloids; Brossi, A.; Ed.; Academic Press: San Diego, 1989; Vol. 36, pp 135 - 150. (b) Love, B. E. Org. Prep. Proced. Int. 1996, $28,1$.

${ }^{8}$ (a) Cao, R. et al. Eur. J. Med. Chem. 2010, 45, 2503 - 2515. (b) Guan, H. et al. Eur. J. Med. Chem. 2006, 41, 1167 - 1179.

${ }_{9}^{9}$ Brahmbhatt, K. G. et al. Bioorg. Med. Chem. Lett. 2010, 20, 4416 - 4419.

${ }^{10}$ Y. Iinuma, S. Kozawa, H. Ishiyama, M. Tsuda, E. Fukushi, J. Kawabata, J. Nat. Prod. 2005, 68, $1109-1110$.

${ }^{11}$ Nielsen, M.; Bræstrup, C. Nature. 1980, 286, 606 - 607.

12 (a) Snyder, H. R.; Hansch, C. H.; Katz, L.; Parmerter, S. M.; Spaeth, E. C. J. Am. Chem. Soc., 1948, 70, 219 - 221. (b) Brahmbhatt, K. G.; Ahmed, N.; Sabde, S; Mitra, D.; Singh, I. P.; Bhutani, K. K. Bioorg. Med. Chem. 2010, 20, 4416 - 4419. (c) Cox, E. D.; Cook, J. 
M. Chem. Rev. 1995, 95, 1797 - 1842. (d) Singh, V.; Hutait, S.; Biswas, S.; Batra, S. Eur. J. Org. Chem. 2010, $531-539$.

13 (a) Pictet, A.; Spengler, T. Berichte der deutschen chemischen Gesellschaft, 1911, 2030 - 2036. (b) Whaley, W. M.; Govindachari, T. R. In Organic Reactions; Adams, R., Ed.; John Wiley \& Sons: New York, 1951; Vol. 6, pp 151 - 206. (c) Cox, E. D.; Cook, J. M. Chem. Rev. 1995, 95, 1797 - 1842.

14 (a) Bischler, A.; Napieralski, B. Chem. Ber. 1893, 26, 1891 - 1903. (b) Whaley, W. M.; Govindachari, T. R. The Preparation of 3,4-Dihydroisoquinolines and Related Compounds by the Bischler-Napieralski Reaction. Adams, R., Ed.; Organic Reactions; John Wiley and Sons: New York, 1951; Vol. VI, pp 74 - 150. (c) Butin, A. V.; Pilipenko, A. S.; Milich, A. A.; Finko, A. V. Chem. Heterocycl. Compd. 2009, 45, 613 - 614.

15 (a) Bergmeier, S. C.; Seth, P. P. J. Org. Chem. 1999, 64, 3237 - 3243. (b) Nicoletti, M.; O'Hagan, D.; Slawin, A. M. Z. J. Chem. Soc. Perkin Trans. 1, 2002, 116 - 121.

16 (a) Zhao, M.; Bi, L.; Wang, W.; Wang, C.; Baudy-Floc'h, M.; Ju, J.; Peng, S. Bioorg. Med. Chem. 2006, 14, 6998 - 7010. (b) Cao, R.; Chen, H.; Peng, W.; Ma, Y.; Hou, X.; Guan, H.; Liu, X.; Xu, A. Eur. J. Org. Chem. 2005, 40, 991 - 1001. (c) Tonin, L. T. D.; Panice, M. R.; Nakamura, C. V.;Rocha, K. J. P.; Oliveira dos Santos, A.; Ueda-Nakamura, T.; Ferreira da Costa, W.; Sarragiotto, M. H. Biomed. Pharmacother. 2008, 16, 9660 9667. 
17 (a) Pal, B.; Jaisankar, P.; Giri, V. S. Synthetic Commun. 2003, 33, 2339 - 2348. (b)

Kennedy, J. P.; Breininger, M. L.; Lindsley, C. W. Tetrahedron Lett. 2009, 50, 7067 7069. (c) Awuah, E.; Capretta, A. J. Org. Chem. 2010, 75, 5627 - 5634. 


\section{Chapter 5. Conclusions}

\subsection{Future Extensions}

The synthesis of a 2-aryl- $\beta$-carboline scaffold through the successful application of our palladium-catalyzed decarboxylative benzylation of benzyl diphenylglycinate imines has prompted the need to investigate the generality and scope of this transformation. Three distinct regions for the diversification of amide 4.22 can be envisioned prior to the Bischler-Napieralski cyclization (Scheme 5.1). In general, the functional group tolerance and electronic requirements of each region would need to be investigated. Region A contains a nitrile group that is accessible for additional modifications following the palladium-catalyzed decarboxylative benzylation. Alternatively, Region A can be altered by starting from a different imine precursor prior to decarboxylative benzylation; our previous studies have demonstrated that heteroaromatic moieties successfully undergo the transformation and may be substituted for Region A. The electronic character and corresponding tolerance of aryl/heteroaryl functionality in Region B should be further evaluated, as our current studies are limited to the unsubstituted benzoyl and para-methoxylbenzoyl moieties. Region C contains a $N$-tosyl group that may be cleaved and replaced by an alkyl moiety; this functionality has been reported to be essential for enhanced anti-HIV activity in the $\beta$-carboline alkaloid N9-butylharmine

(Figure 5.1). ${ }^{1}$ The indole ring of Region $\mathrm{C}$ could also be modified prior to decarboxylative benzylation to produce more complex $\beta$-carboline scaffolds. This 
represents one of the strategic advantages to approaching the $\beta$-carboline scaffold via a decarboxylative benzylation manifold instead of the more traditional approaches starting from tryptophan imines; a diversity of 3-bromomethyleneindoles are significantly more synthetically-accessible than the corresponding tryptophan analogs.

Studies are also necessary to optimize the individual reaction conditions following decarboxylative benzylation, as isolated yields are currently moderate, at best. Biological testing against various pathogens (e.g., protozoan-based diseases) ${ }^{2}$ and cancer $^{3}$ so as to determine the activity profile for synthesized $\beta$-carboline derivatives would further bolster the application of our method toward the synthesis of biologically active natural products analogues based on this privileged platform.

Scheme 5.1 Diversification of $\mathbf{4 . 2 2}$.
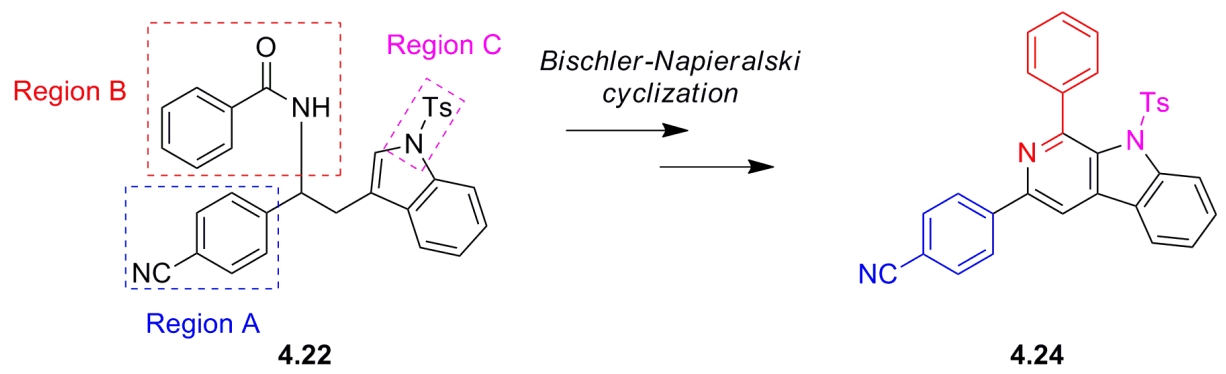

Figure 5.1 N9-Butylharmine.

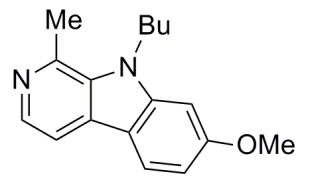




\subsection{Final Conclusions}

In summary, the palladium-catalyzed decarboxylative alkylation of allyl and benzyl diphenylglycinate imines provides two rapid and mild methods for the synthesis of complex polycyclic amines. Carbon dioxide serves as a readily-removed and relatively non-toxic stoichiometric side product as well as a thermodynamic driving force. Furthermore, the palladium-catalyzed generation of both the nucleophile and electrophile from a single allyl or benzyl diphenylglycinate imine precursor represents a particularly efficient approach toward complex polycyclic amines. Lastly, the incorporation of microwave irradiation into our reaction conditions affords drastically reduced reaction times for both transformations.

In the first method, a one-pot tandem decarboxylative allylation-Heck cyclization cascade of allyl diphenylglycinate imines promoted by microwave irradiation furnished a diverse range of 1-iminoindane scaffolds. A collection of aryl and heteroaryl imine functionalities successfully underwent the tandem reaction cascade. In accord with our previous decarboxylative allylation studies, electrondeficient $o$-halobenzaldimines provided superior yields and rates versus the electron-rich counterparts. The use of $\mathrm{Ag}_{2} \mathrm{SO}_{4}$ successfully inhibited formation of a highly variable regioisomer of the Heck reaction for a majority of substrates. Furthermore, microwave-promoted olefin cross-metathesis was utilized in the diversification of the allyl ester to rapidly afford the corresponding imines in high isolated yields. Upon treatment with our optimized reaction conditions, the cyclized products were isolated in moderate to high yields with preferential formation of the 
exomethylene products, exclusively. Interestingly, 2D-NMR spectroscopic analysis of these products elucidated the preferential formation of the $E$ olefin isomer, thus representing a formal anti- $\beta$-hydride elimination of the palladium(II) intermediate in the Heck cyclization.

In the second method, general reaction conditions for a microwavepromoted palladium-catalyzed decarboxylative benzylation of benzyl diphenylglycinate imines were ascertained. Heterocyclic functionalities, e.g. furan, indole, thiazole, and pyridine, on either the imine or ester groups were well tolerated under the reaction conditions. The electronic composition of the benzyl ester significantly impacted the product distribution, with electron-withdrawing groups reducing preference for the desired 1,2-diarylethyl imines. To the best of our knowledge, the successful decarboxylative benzylation of the indole ester moiety represents the first example of the formation of a catalytically relevant palladium(II)-3-methylindole species via insertion into the corresponding ester. It also is the first example of an indole participating in a palladium-catalyzed decarboxylative alkylation. Moreover, the size of the ortho substituent on the imine moiety dramatically impacted the corresponding isolated yields in which an overall decreasing trend in yield was observed with increasing size of the ortho moiety. Lastly, this method was successfully applied toward the synthesis of a 2-aryl- $\beta$ carboline alkaloid analogue by means of the Bischler-Napieralski cyclization, thus representing access to a new variation on this renowned privileged scaffold. 
The tandem decarboxylative allylation-Heck cyclization cascade has provided proof-of-principle evidence that palladium-catalyzed decarboxylative allylations are tolerant to multiple bond-forming events in one reaction vessel. Furthermore, given the broad substrate scope and utility of the Tsuji-Trost decarboxylative allylation manifold, our evidence supporting extension to benzyl esters is expected to have a significant impact. The decarboxylative benzylation of diphenylglycinate imines has furnished a supplementary and viable pathway for the diversification of semi-stabilized $\alpha$-imino anions under relatively neutral reaction conditions. Overall, this work has provided new methods that further define the reaction scope for palladium-catalyzed decarboxylative alkylation. 


\subsection{References}

${ }^{1}$ (a) Brahmbhatt, K. G.; Ahmed, N.; Sabde, S; Mitra, D.; Singh, I. P.; Bhutani, K. K. Bioorg. Med. Chem. 2010, 20, 4416 - 4419. (b) Ishida, J.; Wang, H. K.; Oyama, M.; Cosentino, M. L.; Hu, C. Q.; Lee, K. H. J. Nat. Prod. 2001, 64, 958 - 960.

2 (a) Cavin, J. C.; Krassner, S. M.; Rodriguez, E. J. Ethnopharmacol. 1987, 19, 89 - 94. (b) Mishra, B. B.; Singh, R. K.; Srivastava, A.; Tripathi, V. J.; Tiwari, V. K. Mini-Rev. Med. Chem. 2009, 9, 107 - 123. (c) Valdez, R. H.; Tonin, L. T. D.; Ueda-Nakamura, T.; Benedito Prado Dias Filho a,c, José Andrés Morgado-Diazd, Sarragiotto, M. H.; Nakamura, C. V. Acta Tropica, 2009, 110, 7 - 14.

${ }^{3}$ (a) García, M. D.; Wilson, A. J.; Emmerson, D. P. J.; Jenkins, P. R.; Mahale. S.;

Chaudhuri, B. Org. Biomol. Chem., 2006, 4, 4478 - 4484. (b) Zhao, M; Bi, L.; Wang, W.; Wang, C.; Baudy-Floc'h, M.; Ju, J.; Peng, S. Bioorg. Med. Chem. 2006, 14, 6998 - 7010. (c) Abe, N.; Nakakita, Y.; Nakamura, T.; Enoki, N.; Uchida, H.; Takeo, S.; Munekata, M. J. Antibiot. 1993, 46, 1672 - 1677. (d) Rao, K. N.; Venkatachalam, S. R. Bioorg. Med. Chem. 1999, 7, $1105-1110$. 


\section{Chapter 6. Experimentals}

\subsection{Materials and Methods}

All non-aqueous reactions were carried out in flame-dried glassware under argon or nitrogen atmosphere with dry solvents and magnetic stirring, unless otherwise stated. All argon or nitrogen was purified by passage through Drierite and an Oxiclear deoxygenation column. Anhydrous dichloromethane $\left(\mathrm{CH}_{2} \mathrm{Cl}_{2}\right)$, benzene $(\mathrm{PhH})$, toluene $\left(\mathrm{PhCH}_{3}\right)$, dimethyl formamide (DMF), tetrahydrofuran (THF), and 1, 4-dioxanes were used as received. Triethylamine $\left(\mathrm{Et}_{3} \mathrm{~N}\right)$ was distilled and further dried over potassium hydroxide. All other chemicals were used as received. Microwave reactions were conducted in a CEM Explorer-Discover microwave reactor at $300 \mathrm{~W}$ for the specified time and temperature using the Chem Driver Explorer Application program. Reaction progress was monitored by analytical thin layer chromatography (TLC) using $250 \mu \mathrm{m}$ thick Partisil K6F $60 \AA$ precoated silica gel plates (Whatman), with the exception of imine $\mathbf{5}$ formations (monitored by ${ }^{1} \mathrm{H}$ NMR spectroscopy by means of reaction aliquots) and Heck cyclization 3 formations (monitored by HPLC/MS). Developed TLCs were analyzed by UV light $(254 \mathrm{~nm})$, ninhydrin stain, and/or potassium permanganate stain. All flash chromatography was performed with indicated solvents and Dynamic Adsorbents 230-400 mesh or Purasil (Whatman) $60 \AA$ 230-400 mesh silica gel. Radial chromatography was performed using a Harrison Research Chromatotron (Model 7924T) 133 with pre-scraped silica rotor plates purchased from Analtech. 
All yields refer to chromatographically and spectroscopically pure compounds, unless otherwise noted.

Melting points were determined using a Mel-Temp apparatus (Electrothermal) and are uncorrected. Infrared spectra were obtained from a Nicolet Avatar 330 FT-IR (Thermo) and reported in $\mathrm{cm}^{-1}(\% \mathrm{~T}) .{ }^{1} \mathrm{H}$ NMR and ${ }^{13} \mathrm{C}$ NMR was recorded on a Varian MercuryPlus 300 (75) or Varian UnityNova 500 (125) at $300 \mathrm{~K}$, as indicated. Chemical shifts are reported in ppm $(\delta)$ values relative to the solvent residual peak $\left(\mathrm{CHCl}_{3}\right)$ as standard: $\delta 7.26$ for ${ }^{1} \mathrm{H}$ NMR and $\delta 77.0$ for ${ }^{13} \mathrm{C}$ NMR. High resolution mass spectra obtained from the Mass Spectrometry Laboratory at the University of Illinois, Urbana-Champaign or William Myers at the University of Richmond (UR). Unless otherwise noted, the following experimentals describe conditions for the highest yielding reactions described in the text.

\subsection{Experimentals for Chapter 3 - Tandem Decarboxylative Heck Cyclization}

General procedure for imine formation (3.1).

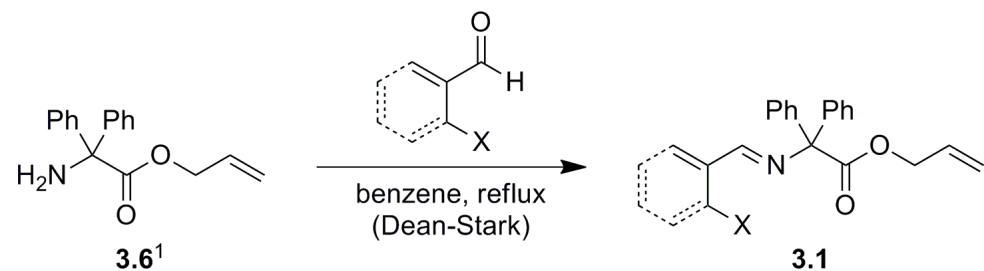

To a flame-dried flask flushed with nitrogen and equipped with a Dean-Stark trap was added amine (3.6, 1 equiv $)^{1}$ and aldehyde (0.95 equiv) dissolved in $\mathrm{PhH}(0.1$

\footnotetext{
1 Yeagley, A. A.; Chruma, J. J. Org. Lett. 2007, 9, 2879 - 2882.
} 
M). The reaction mixture was heated to reflux and stirred at that temperature until completion. Reaction progress was monitored by ${ }^{1} \mathrm{H}$ NMR spectroscopic analysis of concentrated reaction aliquots. Following concentration in vacuo, the imine product was purified by flash chromatography with the indicated eluent or by recrystallization from the indicated solvent.

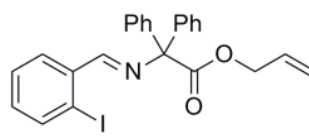

\section{o-Allyl-2-(4-iodobenzylideneamino)-2,2-diphenylacetate}

(3.1a). $25 \mathrm{~h}$, Recrystallization: hot hexanes, further purification of mother liquor by flash chromatography, Eluent: $3 \% \mathrm{EtOAc} /$ hexanes with $1 \% \mathrm{Et}_{3} \mathrm{~N}$; white solid $(1.73 \mathrm{~g}$, 3.59 mmol, 87\%): $\mathrm{mp} 85-86{ }^{\circ} \mathrm{C} ; \mathrm{R}_{\mathrm{f}}=0.37\left(5 \% \mathrm{EtOAc} / \mathrm{hexanes}\right.$ with $\left.1 \% \mathrm{Et}_{3} \mathrm{~N}\right)$; IR ( $\mathrm{NaCl}$, film) 3059 (w), 1733 (s), 1635 (m), 1199 (s); ${ }^{1} \mathrm{H}$ NMR ( $\mathrm{CDCl}_{3}, 500 \mathrm{MHz}$ ) $\delta$ $8.22(\mathrm{dd}, \mathrm{J}=6.0,1.8 \mathrm{~Hz}, 1 \mathrm{H}), 8.05(\mathrm{~s}, 1 \mathrm{H}), 7.82(\mathrm{~J}=\mathrm{dd}, 7.0,0.9 \mathrm{~Hz}, 1 \mathrm{H}), 7.53-7.28(\mathrm{~m}$, 12H), 5.88 (ddt, J = 16.9, 10.5, $5.5 \mathrm{~Hz}, 1 \mathrm{H}), 5.21-5.15(\mathrm{~m}, 2 \mathrm{H}), 4.73(\mathrm{td}, \mathrm{J}=2.5,1.5 \mathrm{~Hz}$, 2H); ${ }^{13} \mathrm{C}$ NMR $\left(\mathrm{CDCl}_{3}, 125 \mathrm{MHz}\right) \delta 171.6,167.0,141.9,139.5,137.2,132.3,131.5$, 129.3, 129.1, 128.4, 128.1, 127.7, 118.4, 100.9, 79.8, 66.3; HRMS (ESI+) m/z $482.0612\left[(\mathrm{M}+\mathrm{H})^{+}\right.$; calculated mass for $\left.\mathrm{C}_{24} \mathrm{H}_{21} \mathrm{NO}_{2} \mathrm{I}^{+}: 482.0617 \mathrm{amu}\right]$.

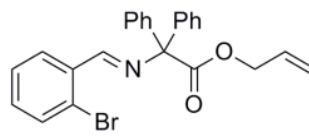

O-Allyl-2-(4-bromobenzylideneamino)-2,2-diphenylacetate (3.1b).

$27 \mathrm{~h}$, Recrystallization: hot hexanes; white solid (0.826 g, $1.90 \mathrm{mmol}, 75 \%): \mathrm{mp} 81-84{ }^{\circ} \mathrm{C} ; \mathrm{R}_{\mathrm{f}}$ = $0.35(5 \% \mathrm{EtOAc} /$ hexanes with 1\% Et 3 N); IR (NaCl, film) 3060 (m), 1735 (s), $1636(\mathrm{~m})$, 
$1199(\mathrm{~s}) ;{ }^{1} \mathrm{H} \mathrm{NMR}\left(\mathrm{CDCl}_{3}, 500 \mathrm{MHz}\right) \delta 8.28(\mathrm{dd}, \mathrm{J}=6.0,1.8 \mathrm{~Hz}, 1 \mathrm{H}), 8.27(\mathrm{~s}, 1 \mathrm{H}), 7.52(\mathrm{dd}, \mathrm{J}=$ 6.9, 1.2 Hz, 1H), 7.49-7.27 (m, 12H), 5.87 (ddt J = 17.2, 10.5, $5.5 \mathrm{~Hz}, 1 \mathrm{H}), 5.20-5.15(\mathrm{~m}, 2 \mathrm{H})$, $4.72(\mathrm{td}, \mathrm{J}=5.5,1.5 \mathrm{~Hz}, 2 \mathrm{H}) ;{ }^{13} \mathrm{C} \mathrm{NMR}\left(\mathrm{CDCl}_{3}, 125 \mathrm{MHz}\right) \delta$ 171.6, 162.7, 142.0, 134.8, 132.9, 132.1, 131.4, 129.2, 129.1, 128.0, 127.7, 127.6, 125.8, 118.4, 79.9, 66.3; HRMS (ESI+) m/z 434.0776 [(M+H)+; calculated mass for $\left.\mathrm{C}_{24} \mathrm{H}_{21} \mathrm{NO}_{2} \mathrm{Br}^{+}: 434.0756 \mathrm{amu}\right]$.

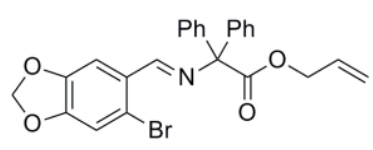

\section{[(6-Bromo-benzo[1,3]dioxol-5-ylmethylene)}

amino]diphenylacetic acid allyl ester (3.1c). 24 h, Eluent: gradient $5 \% \rightarrow 20 \%$ EtOAc/hexanes with 1\% Et 3 N; pale yellow solid (0.585 g, 1.22 mmol, 95\%): mp 87$92{ }^{\circ} \mathrm{C} ; \mathrm{R}_{\mathrm{f}}=0.37$ (5\% EtOAc/hexanes with $1 \% \mathrm{Et}_{3} \mathrm{~N}$ ); IR (NaCl, film) $2916(\mathrm{~m}), 1733$ (s), $1627(\mathrm{~m}), 1249(\mathrm{~s}) ;{ }^{1} \mathrm{H} \mathrm{NMR}\left(\mathrm{CDCl}_{3}, 500 \mathrm{MHz}\right) \delta 8.19$ (s, 1H), $7.81(\mathrm{~s}, 1 \mathrm{H}), 7.43-$ $7.31(\mathrm{~m}, 10 \mathrm{H}), 6.96(\mathrm{~s}, 1 \mathrm{H}), 6.02(\mathrm{~s}, 2 \mathrm{H}), 5.92-5.84(\mathrm{~m}, 1 \mathrm{H}), 5.23-5.15(\mathrm{~m}, 2 \mathrm{H}), 4.72$ $(\mathrm{dt}, \mathrm{J}=5.5,1.5 \mathrm{~Hz}, 2 \mathrm{H}) ;{ }^{13} \mathrm{C} \mathrm{NMR}\left(\mathrm{CDCl}_{3}, 125 \mathrm{MHz}\right) \delta 171.8,162.0,150.8,147.8$, 142.2, 131.5, 129.2, 128.0, 127.7, 118.3, 112.5, 107.9, 102.2, 79.6, 66.2; HRMS (ESI+) $\mathrm{m} / \mathrm{z} 478.0637$ [(M+H)+; calculated mass for $\left.\mathrm{C}_{25} \mathrm{H}_{21} \mathrm{NO}_{4} \mathrm{Br}^{+}: 478.0654 \mathrm{amu}\right]$.

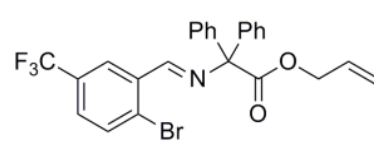

\section{[(2-Bromo-5-trifluoromethyl-benzylidene)-}

amino]diphenylacetic acid allyl ester (3.1d). $22.5 \mathrm{~h}$, Eluent: $2 \% \mathrm{Et}_{2} \mathrm{O} /$ pentane with $1 \% \mathrm{Et}_{3} \mathrm{~N}$; orange oil $(0.513 \mathrm{~g}, 1.21 \mathrm{mmol}, 99 \%): \mathrm{R}_{\mathrm{f}}=0.49$ (5\% EtOAc/hexanes with 1\% $\mathrm{Et}_{3} \mathrm{~N}$ ); IR (NaCl, film) 3063 (m), 1736 (s), 1640 (m), 1328 (s), 1172 (s); ${ }^{1} \mathrm{H}$ 
$\operatorname{NMR}\left(\mathrm{CDCl}_{3}, 500 \mathrm{MHz}\right) \delta 8.54(\mathrm{~s}, 1 \mathrm{H}), 8.31(\mathrm{~s}, 1 \mathrm{H}), 7.67(\mathrm{~d}, \mathrm{~J}=8.4 \mathrm{~Hz}, 2 \mathrm{H}), 7.54-7.34$ (m, 10H), 5.95-5.82 (m, 1H), 5.24-5.16 (m, 2H), $4.74(\mathrm{dt}, \mathrm{J}=1.4,5.4 \mathrm{~Hz}, 2 \mathrm{H}) ;{ }^{13} \mathrm{C} \mathrm{NMR}$ $\left(\mathrm{CDCl}_{3}, 125 \mathrm{MHz}\right) \delta 171.3,161.7,141.7,135.6,133.7,131.4,130.5\left(\mathrm{q}, \mathrm{J}_{\mathrm{CF}}=33.3 \mathrm{~Hz}\right)$, 129.2, 128.32, 128.30, 128.2, 127.9, 125.98, 125.95, 124.7 (q, JCF $=273.0 \mathrm{~Hz}), 118.5$, 80.1, 66.4; HRMS (ESI+) $\mathrm{m} / \mathrm{z} \quad 502.0646 \quad\left[(\mathrm{M}+\mathrm{H})^{+}\right.$; calculated mass for $\left.\mathrm{C}_{25} \mathrm{H}_{20} \mathrm{NO}_{2} \mathrm{BrF}_{3}^{+}: 502.0629 \mathrm{amu}\right]$.

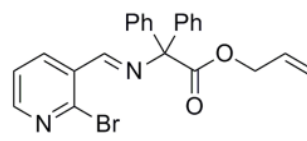

\section{[(2-Bromo-pyridin-3-ylmethylene)-amino]diphenylacetic}

acid allyl ester (3.1f). $23 \mathrm{~h}$, Eluent: 15\% EtOAc/pentane with 1\% $\mathrm{Et}_{3} \mathrm{~N}$; yellow solid (0.553 g, $1.27 \mathrm{mmol}, 84 \%): \mathrm{mp} 85-95{ }^{\circ} \mathrm{C} ; \mathrm{R}_{\mathrm{f}}=0.21(10 \%$ EtOAc/hexanes with $1 \%$ Et ${ }_{3} \mathrm{~N}$ ); IR (NaCl, film) 3059 (m), 1734 (s), 1637 (m), 1200 (s), 934 (m); ${ }^{1} \mathrm{H}$ NMR $\left(\mathrm{CDCl}_{3}, 500 \mathrm{MHz}\right) \delta 8.53(\mathrm{dd}, \mathrm{J}=2.07,7.69 \mathrm{~Hz}, 1 \mathrm{H}), 8.41(\mathrm{dd}, \mathrm{J}=2.1,4.7 \mathrm{~Hz}, 1 \mathrm{H}), 8.17$ (s, 1H), 7.38-7.33 (m, 11H), 5.90-5.83 (m, 1H), 5.20-5.16 (m, 1H), $4.72(\mathrm{dt}, \mathrm{J}=1.5$, 5.5, 2H); ${ }^{13} \mathrm{C}$ NMR $\left(\mathrm{CDCl}_{3}, 125 \mathrm{MHz}\right) \delta 171.2,161.3,151.8,144.4,141.5,137.2,132.2$, 131.3, 129.1, 128.1, 127.9, 127.5, 123.2, 118.5; HRMS (ESI+) m/z 435.0728 [(M+H)+; calculated mass for $\left.\mathrm{C}_{23} \mathrm{H}_{20} \mathrm{~N}_{2} \mathrm{O}_{2} \mathrm{Br}^{+}: 435.0708 \mathrm{amu}\right]$.

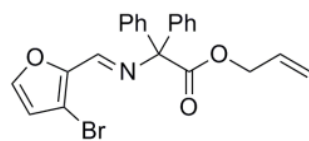

\section{E-Allyl 2-((3-bromofuran-2-yl)methyleneamino)-2,2-}

diphenylacetate (3.1g). 21 h, Eluent: gradient $0 \rightarrow 10 \%$ EtOAc/hexanes with $2 \%$ $\mathrm{Et}_{3} \mathrm{~N}$; yellow oil (0.138 g, $\left.0.325 \mathrm{mmol}, 77 \%\right): \mathrm{R}_{\mathrm{f}}=0.20$ (20\% EtOAc/hexanes); IR 
( $\mathrm{NaCl}$, film) 3060 (m), 3024 (w), 2926 (w), 1735 (s), 1685 (w), 1637 (s), $1598(w)$, 1568 (w), 1488 (s), 1447 (m), 1390 (m), 1347 (m), $1271(\mathrm{~m}), 1198$ (s), $1084(\mathrm{~m})$, 1064 (m), 1032 (m), 986 (s), 933 (m), 886 (m), 820 (m), 753 (m), 700 (s) 681 (m), $665(\mathrm{w}), 605(\mathrm{~m}) ;{ }^{1} \mathrm{H}$ NMR $\left(500 \mathrm{MHz}, \mathrm{CDCl}_{3}\right) \delta 7.73(\mathrm{~s}, 1 \mathrm{H}), 7.53(\mathrm{~d}, J=1.9,1 \mathrm{H}), 7.42-$ $7.28(\mathrm{~m}, 10 \mathrm{H}), 6.54(\mathrm{~d}, J=1.9,1 \mathrm{H}), 5.87(\mathrm{ddt}, J=5.5,10.9,17.1,1 \mathrm{H}), 5.21-5.14(\mathrm{~m}$, $2 \mathrm{H}), 4.71(\mathrm{dt}, J=1.4,5.5,2 \mathrm{H}) ;{ }^{13} \mathrm{C}$ NMR $\left(125 \mathrm{MHz}, \mathrm{CDCl}_{3}\right) \delta 171.4,149.7,147.8$, 145.3, 141.6, 131.5, 129.3, 128.1, 127.8, 118.5, 115.6, 106.8, 79.9, 66.4; HRMS (ESI+) m/z 424.0541 [(M+H)+; calculated mass for $\left.\mathrm{C}_{24} \mathrm{H}_{21} \mathrm{NO}_{5} \mathrm{Br}^{+}: 424.0548 \mathrm{amu}\right]$.

General Procedure for tandem reaction in formation of polycyclic imine (3.4).

To a flame-dried CEM IntelliVent microwave tube capped with a rubber septum and charged with $10 \mathrm{~mol} \% \mathrm{Pd}\left(\mathrm{PPh}_{3}\right)_{4}$ was added by syringe a solution of imine 3.1 in DMF (0.1 M). The reaction mixture was stirred at $\mathrm{rt}$ for $5 \mathrm{~min} .{ }^{2} \mathrm{Next}, \mathrm{Et}_{3} \mathrm{~N}$ was added (2 equiv) by syringe, the septum was replaced with a CEM IntelliVent cap, and the reaction mixture was heated via microwave irradiation $(300 \mathrm{~W})$ for the specified time and temperature using a CEM Explorer-Discover microwave reactor. Reaction temperature and temperature-time profile were monitored using an IR probe and the ChemDriver Explorer Application program. The resulting mixture was filtered through Celite and azeotropically concentrated in vacuo with $\mathrm{PhCH}_{3}$. The reaction was purified by flash chromatography with the indicated eluent

\footnotetext{
${ }^{2}$ In early studies, the reaction mixtures were submitted to three freeze-pump-thaw cycles (syringe needle) prior to addition of $\mathrm{Et}_{3} \mathrm{~N}$. Further studies revealed that this precaution does not dramatically impact the results of the two step-one pot process, and it has since been excluded.
} 


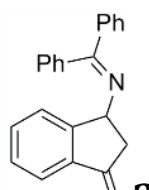

3-Methylene-diphenylimineindan (3.4a). $\mu \mathrm{w}$ time: $5 \mathrm{~min}, \mu \mathrm{w}$ temperature: $150{ }^{\circ} \mathrm{C}$; Eluent: gradient $0 \rightarrow 5 \%$ EtOAc/hexanes with $1 \% \mathrm{Et}_{3} \mathrm{~N}$; orange crystals (0.024 g, $0.076 \mathrm{mmol}, 85 \%): \mathrm{mp} 130-136{ }^{\circ} \mathrm{C} ; \mathrm{R}_{\mathrm{f}}=0.50$ (5\% EtOAc/hexanes with 1\% Et ${ }_{3} \mathrm{~N}$ ); IR (NaCl, film) 3059 (w), 1615 (m), 1446 (m), 1286 (m); ${ }^{1} \mathrm{H}$ NMR $\left(\mathrm{CDCl}_{3}, 500 \mathrm{MHz}\right) \delta$ 7.68-7.16 (m, 14H), $5.46(\mathrm{~s}, 1 \mathrm{H}), 5.04(\mathrm{~s}, 1 \mathrm{H}), 4.98(\mathrm{t}, \mathrm{J}=6.8 \mathrm{~Hz}$, 1H), 2.96-2.94 (m, 2H); ${ }^{13} \mathrm{C} \mathrm{NMR}\left(\mathrm{CDCl}_{3}, 125 \mathrm{MHz}\right) \delta 168.6,148.0,140.6,130.1$, 128.8, 128.6, 128.57, 128.1, 127.9, 127.6, 124.9, 120.7, 103.1, 64.3, 41.1; HRMS (ESI+) m/z 310.1595 [(M+H)+; calculated mass for $\left.\mathrm{C}_{23} \mathrm{H}_{20} \mathrm{~N}^{+}: 310.1596 \mathrm{amu}\right]$.

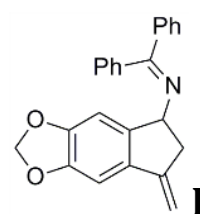

\section{Benzhydrylidene-(7-methylene-6,7-dihydro-5H-indeno[5,6-}

d][1,3]dioxol-5-yl)-amine (3.4b). $\mu \mathrm{w}$ time: $10 \mathrm{~min}, \mu \mathrm{w}$ temperature: $150{ }^{\circ} \mathrm{C}$; Eluent: gradient $5 \rightarrow 10 \%$ EtOAc/hexanes with $1 \% \mathrm{Et}_{3} \mathrm{~N}$; red-orange oil $(0.013 \mathrm{~g}$, $0.037 \mathrm{mmol}, 58 \%): \mathrm{R}_{\mathrm{f}}=0.48\left(5 \%\right.$ EtOAc/hexanes with $\left.1 \% \mathrm{Et}_{3} \mathrm{~N}\right) ; \mathrm{IR}(\mathrm{NaCl}$, film) 2920 (w), 1615 (w), 1472 (s); ${ }^{1} \mathrm{H} \mathrm{NMR}\left(\mathrm{CDCl}_{3}, 500 \mathrm{MHz}\right) \delta$ 7.65-7.24 (m, 10H), 6.92 $(\mathrm{s}, 1 \mathrm{H}), 6.58(\mathrm{~s}, 1 \mathrm{H}), 5.95(\mathrm{~d}, \mathrm{~J}=3.4 \mathrm{~Hz}, 2 \mathrm{H}), 5.23(\mathrm{~s}, 1 \mathrm{H}), 4.89(\mathrm{~s}, 1 \mathrm{H}), 4.85(\mathrm{t}, \mathrm{J}=6.6$ $\mathrm{H}, 1 \mathrm{H}), 2.92(\mathrm{dt}, \mathrm{J}=6.6,2.0 \mathrm{~Hz}, 2 \mathrm{H}) ;{ }^{13} \mathrm{C} \mathrm{NMR}\left(\mathrm{CDCl}_{3}, 125 \mathrm{MHz}\right) \delta 168.8,148.9,148.3$, $147.9,142.4,139.8,137.2,135.1,132.7,130.4,130.3,128.94,128.86,128.7,128.5$, 
128.3, 128.1, 105.1, 101.5, 101.0, 100.9, 64.1, 41.7; HRMS (ESI+) m/z 354.1484 $\left[(\mathrm{M}+\mathrm{H})^{+}\right.$; calculated mass for $\left.\mathrm{C}_{24} \mathrm{H}_{20} \mathrm{NO}_{2}{ }^{+}: 354.1494 \mathrm{amu}\right]$.

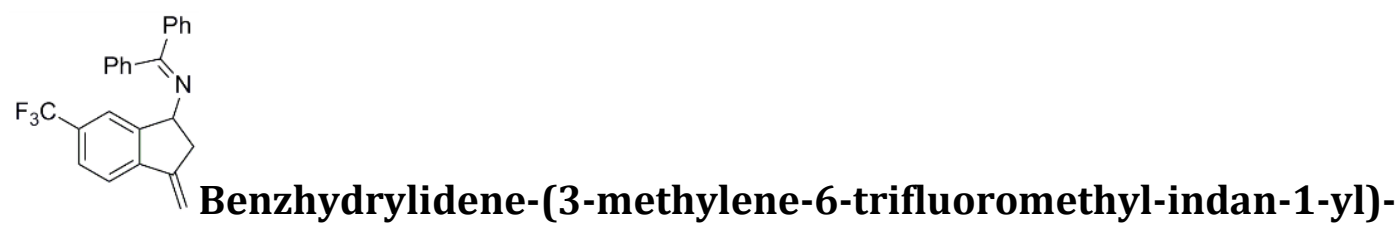

amine (3.4c). $\mu \mathrm{w}$ time: $10 \mathrm{~min}, \mu \mathrm{w}$ temperature: $150{ }^{\circ} \mathrm{C}$; Eluent: gradient $5 \rightarrow 10 \%$ EtOAc/hexanes with 1\% $\mathrm{Et}_{3} \mathrm{~N}$; red crystals (0.025 g, 0.066 mmol, 78\%): mp 124$128^{\circ} \mathrm{C} ; \mathrm{R}_{\mathrm{f}}=0.51\left(3 \%\right.$ EtOAc/hexanes with $\left.1 \% \mathrm{Et}_{3} \mathrm{~N}\right) ; \mathrm{IR}(\mathrm{NaCl}$, film) $3060(\mathrm{w}), 1617$ (m), $1322(\mathrm{~s}), 1122(\mathrm{~s}) ;{ }^{1} \mathrm{H}$ NMR $\left(\mathrm{CDCl}_{3}, 500 \mathrm{MHz}\right) \delta$ 7.87-7.28 (m, 13H), $5.57(\mathrm{~s}, 1 \mathrm{H})$, $5.16(\mathrm{~s}, 1 \mathrm{H}), 4.97(\mathrm{t}, \mathrm{J}=7.0 \mathrm{~Hz}, 1 \mathrm{H}), 2.98(\mathrm{dt}, \mathrm{J}=7.0,2.2 \mathrm{~Hz}, 2 \mathrm{H}) ;{ }^{13} \mathrm{C} \mathrm{NMR}\left(\mathrm{CDCl}_{3}, 125\right.$ MHz) $\delta 148.2,146.7 .144 .0,139.4,136.7,130.4,130.1,128.8,128.7,128.3,128.1$, 127.8, 124.9 (q, J $\left.\mathrm{JFF}_{\mathrm{F}}=232.0 \mathrm{~Hz}\right), 121.0,105.8,63.9,41.1$; HRMS (ESI+) m/z 378.1465 $\left[(\mathrm{M}+\mathrm{H})^{+}\right.$; calculated mass for $\left.\mathrm{C}_{24} \mathrm{H}_{19} \mathrm{NF}_{3}{ }^{+}: 378.1470 \mathrm{amu}\right]$.

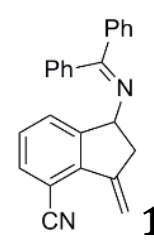

1-(Benzhydrylidene-amino)-3-methylene-indan-4-carbonitrile (3.4d). 2-Iodo-3-methylbenzonitrile $(2.037 \mathrm{~g}, 8.38 \mathrm{mmol}), \mathrm{N}$-bromosuccinimide $(1.594 \mathrm{~g}$, $8.96 \mathrm{mmol}$ ), and benzoyl peroxide (106 $\mathrm{mg}, 0.44 \mathrm{mmol})$ were combined in $\mathrm{CCl}_{4}(17$ $\mathrm{mL})$ and the stirred mixture was heated to reflux $\left(85^{\circ} \mathrm{C}\right)$ for $22 \mathrm{~h}$. The resulting warm red slurry was filtered through a glass frit and the filtrate was concentrated in 
vacuo to a white solid. Purification by flash chromatography (gradient $15 \% \rightarrow 20 \%$ EtOAc/hexanes) afforded $1.175 \mathrm{~g}$ of a $3.9: 1$ mixture of $o$-iodo- and $o$ bromobenzylbromide, respectively, as a white solid plus $861 \mathrm{mg}$ of recovered starting material. ${ }^{1} \mathrm{H} \mathrm{NMR}\left(\mathrm{CDCl}_{3}, 500 \mathrm{MHz}\right) \delta 7.69(\mathrm{dd}, \mathrm{J}=7.8,1.6 \mathrm{~Hz}, 1 \mathrm{H}), 7.66(\mathrm{dd}$, $\mathrm{J}=7.7,1.7 \mathrm{~Hz}, 3.9 \mathrm{H}), 7.62(\mathrm{dd}, \mathrm{J}=7.7,1.6 \mathrm{~Hz}, 1 \mathrm{H}), 7.53(\mathrm{dd}, \mathrm{J}=7.7,1.7 \mathrm{~Hz}, 3.9 \mathrm{H}), 7.46$ (ps t, J = 7.7 Hz, 3.9H), 7.43 (ps t, J = 7.7 Hz, 1H), $4.62(\mathrm{~s}, 7.8 \mathrm{H}), 4.61(\mathrm{~s}, 2 \mathrm{H})$.

The resulting mixture of benzylbromides $(1.175 \mathrm{~g}, 3.76 \mathrm{mmol}$ ) was dissolved in DMSO $(12.0 \mathrm{~mL})$, followed by the addition of $\mathrm{NaHCO}_{3}(810 \mathrm{mg}, 9.64 \mathrm{mmol})$ and stirring at $\mathrm{rt}$ for $48 \mathrm{~h}$ (an additional $565 \mathrm{mg} \mathrm{NaHCO} 3$ was added after $24 \mathrm{~h}$ ), then 100 ${ }^{\circ} \mathrm{C}$ for $15 \mathrm{~min}$. After cooling to rt, the mixture was diluted with $\mathrm{H}_{2} \mathrm{O}(30 \mathrm{~mL})$ and extracted with EtOAc $(2 \times 30 \mathrm{~mL})$. The combined organic extracted was washed sequentially with $1 \mathrm{M} \mathrm{HCl}(3 \times 20 \mathrm{~mL})$ and brine $(2 \times 20 \mathrm{~mL})$, dried (Na2SO4), filtered, and concentrated in vacuo to a tan-white solid (853 mg, 84\%). Freshly prepared IBX ${ }^{3}$ was added to a stirred solution of the resulting benzyl alcohols (519 mg, 1.98 mmol) in DMSO (4 mL), and the stirred mixture was heated to $65{ }^{\circ} \mathrm{C}$ for $40 \mathrm{~min}$. After cooling to rt, the reaction mixture was diluted with EtOAc (20 mL) and $\mathrm{H}_{2} \mathrm{O}$ (15 $\mathrm{mL})$ and filtered through a glass frit. The resulting organic layer was washed with brine $(3 \times 10 \mathrm{~mL})$, dried $\left(\mathrm{Na}_{2} \mathrm{SO}_{4}\right)$, filtered, and concentrated in vacuo to $505 \mathrm{mg}$ (98\%) of a white solid. ${ }^{1} \mathrm{H} \mathrm{NMR}\left(\mathrm{CDCl}_{3}, 300 \mathrm{MHz}\right) \delta 10.38(\mathrm{~d}, \mathrm{~J}=0.8 \mathrm{~Hz}, 1 \mathrm{H}), 10.11(\mathrm{~d}$, $J=0.8 \mathrm{~Hz}, 3.9 \mathrm{H}), 8.12(\mathrm{dd}, \mathrm{J}=7.8,1.8 \mathrm{~Hz}, 1 \mathrm{H}), 8.04(\mathrm{dd}, \mathrm{J}=7.8,1.8 \mathrm{~Hz}, 3.9 \mathrm{H}), 7.89$

\footnotetext{
${ }^{3}$ Frigerio, M.; Santagostino, M.; Sputore, S. J. Org. Chem. 1999, 64, 4537 - 4538.
} 
(dd, J = 7.7, $1.8 \mathrm{~Hz}, 1 \mathrm{H}$ ), 7.83 (dd, J = 7.6, $1.8 \mathrm{~Hz}, 3.9 \mathrm{H}), 7.60$ (td, J = 7.7, $0.7 \mathrm{~Hz}, 3.9 \mathrm{H}$ ), $7.59(\mathrm{td}, \mathrm{J}=7.7,0.8 \mathrm{~Hz}, 1 \mathrm{H})$.

The resulting 3.9:1 mixture of $o$-iodo- and $o$-bromobenzaldehyde, respectively, was condensed with amine 3.6 following our standard procedures (14.5 h, Eluent: 20\% EtOAc/hexanes) to afford imine $\mathbf{1 e}$ as a $4.6: 1$ ratio of $o$-iodo- and $o$ bromobenzaldimine, respectively (yellow honey, $555 \mathrm{mg}, 1.11 \mathrm{mmol}$, 89\%). This mixture was carried directly onto decarboxylative allylation-Heck cyclization following our optimized protocol ( 1 equiv $\mathrm{Ag}_{2} \mathrm{SO}_{4} ; \mu \mathrm{w}$ time: $5 \mathrm{~min}, \mu \mathrm{w}$ temperature: $150{ }^{\circ} \mathrm{C}$, Eluent: gradient $5 \rightarrow 10 \rightarrow 20 \% \mathrm{EtOAc} /$ hexanes with $1 \% \mathrm{Et}_{3} \mathrm{~N}$ ) to afford indane 3.4d as a glassy yellow foam $(0.57 \mathrm{mmol}, 76 \%): \mathrm{R}_{\mathrm{f}}=0.38(10 \% \mathrm{EtOAc} /$ hexanes with 1\% Et3N); IR (NaCl, film) 3057 (w), $2226(\mathrm{~m}), 1616(\mathrm{~m}) ;{ }^{1} \mathrm{H}$ NMR (CDCl $\left.3,500 \mathrm{MHz}\right)$ $\delta$ 7.68-7.64 (m, 2H), 7.58-7.25 (m, 11H), $6.33(\mathrm{t}, \mathrm{J}=2.3 \mathrm{~Hz}, 1 \mathrm{H}), 5.40(\mathrm{t}, \mathrm{J}=2.0 \mathrm{~Hz}$, $1 \mathrm{H}), 4.93(\mathrm{t}, \mathrm{J}=7.1 \mathrm{~Hz}, 1 \mathrm{H}), 3.07-2.91(\mathrm{~m}, 2 \mathrm{H}) ;{ }^{13} \mathrm{C} \mathrm{NMR}\left(\mathrm{CDCl}_{3}, 125 \mathrm{MHz}\right) \delta 169.8$, $149.8,144.9,141.2,139.3,136.6,132.8,130.4,129.6,128.75,128.68,128.4,128.12$, 127.7, 118.0, 109.8, 105.3, 95.3, 63.1, 41.8; HRMS (ES+) $m / z 335.1539\left[(\mathrm{M}+\mathrm{H})^{+}\right.$; calc'd for $\mathrm{C}_{24} \mathrm{H}_{19} \mathrm{~N}_{2}+$ : 335.1548].

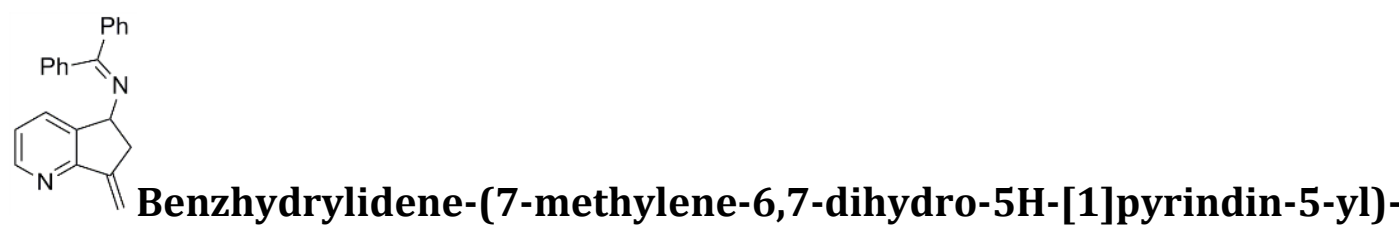

amine (3.4e). $\mu \mathrm{w}$ time: $10 \mathrm{~min}, \mu \mathrm{w}$ temperature: $150{ }^{\circ} \mathrm{C}$; Eluent: gradient $3 \rightarrow 15 \%$ 
EtOAc/pentane with $1 \% \mathrm{Et}_{3} \mathrm{~N}$; orange solid (0.012 g, $0.064 \mathrm{mmol}$ ): $\mathrm{mp} 73-78{ }^{\circ} \mathrm{C}$; $\mathrm{R}_{\mathrm{f}}$ $=0.13(3 \%$ EtOAc/hexanes with 1\% Et 3 N); IR (NaCl, film) 2919 (w), 1616 (m), 1572 (m); ${ }^{1} \mathrm{H}$ NMR $\left(\mathrm{CDCl}_{3}, 300 \mathrm{MHz}\right) \delta 8.52-8.51(\mathrm{~m}, 1 \mathrm{H}), 7.66-7.14(\mathrm{~m}, 15 \mathrm{H}), 6.00(\mathrm{~s}, 1 \mathrm{H})$,

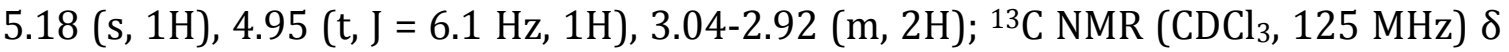
$169.3,158.8,149.5,146.4,141.1,139.3,136.7,133.1,130.3,128.7,128.7,127.7$ 122.9, 106.8, 62.0, 39.1; HRMS (ESI+) m/z 311.1539 [(M+H)+; calculated mass for $\left.\mathrm{C}_{22} \mathrm{H}_{19} \mathrm{~N}_{2}{ }^{+}: 311.1548 \mathrm{amu}\right]$.

\section{"All-in-One" Decarboxylative Allylation-Heck Cyclization}

To a CEM IntelliVent microwave tube was added imine $\mathbf{3 . 1 a}$ (30 mg, $0.062 \mathrm{mmol}, 1$ equiv), $\mathrm{Pd}\left(\mathrm{PPh}_{3}\right)_{4}(7 \mathrm{mg}, 6.2 \mu \mathrm{mol}, 10 \mathrm{~mol} \%), \mathrm{Ag}_{2} \mathrm{SO}_{4}(19 \mathrm{mg}, 0.062 \mathrm{mmol}, 1$ equiv), $\mathrm{Et}_{3} \mathrm{~N}(0.02 \mathrm{~mL}, 0.125 \mathrm{mmol}, 2$ equiv), and DMF (0.1 M). The tube was sealed with a CEM IntelliVent cap and the reaction mixture was heated via microwave irradiation (300W) to $150{ }^{\circ} \mathrm{C}$ for 5 min using a CEM Explorer-Discover microwave reactor. Reaction temperature and temperature-time profile were monitored using an IR probe and the ChemDriver Explorer Application program. The reaction mixture was cooled to rt, filtered through Celite and concentrated azeotropically in vacuo with $\mathrm{PhCH}_{3}$. Purification by flash chromatography $\left(0 \rightarrow 3 \%\right.$ EtOAc/hexanes with $\left.1 \% \mathrm{Et}_{3} \mathrm{~N}\right)$ afforded analytically pure $(\geq 95 \%)$ 1-iminoindane $\mathbf{3 . 1 a}$ as an orange solid (14 mg, $0.044 \mathrm{mmol}, 71 \%)$. 
General procedure for olefin metathesis in formation of imine (3.12).

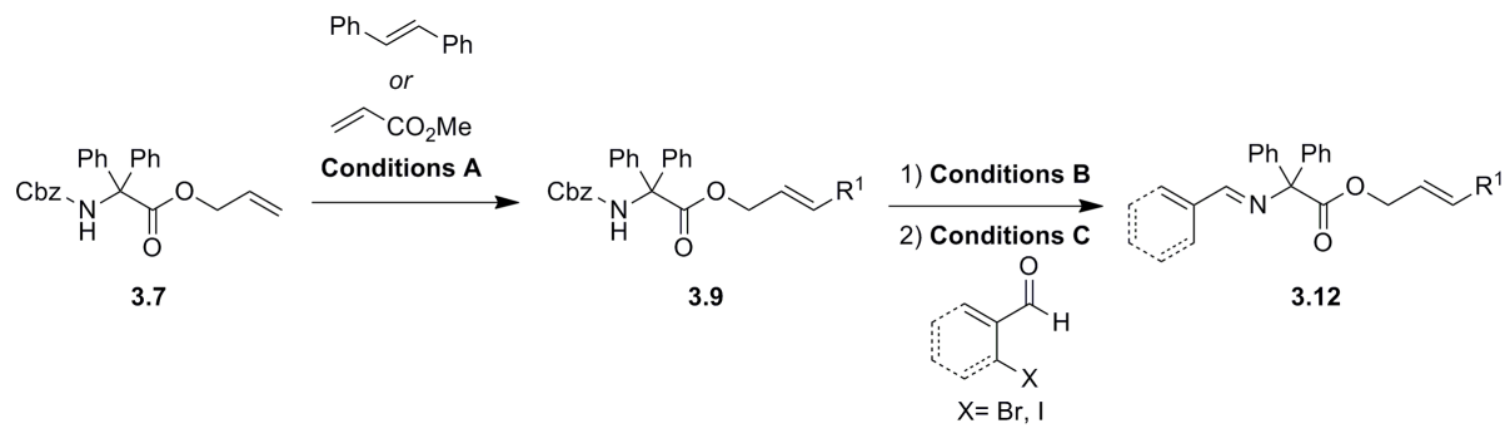

Conditions A: Allyl ester 3.7 (1.0 equiv), coupling alkene (5 - 10.0 equiv), Grubbs' $2^{\text {nd }}$ generation catalyst $(0.05 \text { equiv })^{4}$ and $\mathrm{CH}_{2} \mathrm{Cl}_{2}(0.1 \mathrm{M})$ were combined with a magnetic stir bar in a sealed CEM Intellevent microwave tube. The reaction mixture was subjected to microwave irradiation $(300 \mathrm{~W})$ for $10 \mathrm{~min}$ at $90{ }^{\circ} \mathrm{C}$. Reaction temperature and temperature-time profile were monitored using an IR probe and the ChemDriver Explorer Application program. The resulting mixture was then concentrated in vacuo and purified by flash chromatography with the indicated eluent furnishing 3.9.

Conditions B: To a solution of 3.9 (1.0 equiv) in $\mathrm{CH}_{2} \mathrm{Cl}_{2}(0.1 \mathrm{M})$ was added slowly via syringe TMSI (2.0 equiv). The reaction mixture stirred at $\mathrm{rt}$ for $2 \mathrm{~h}$, was quenched with $\mathrm{MeOH}$ and concentrated in vacuo. The resulting product was dissolved in $30 \%$ aqueous $\mathrm{AcOH}$ and extracted with ether until the yellow color disappeared. The organic layer was re-extracted with fresh $30 \%$ aqueous AcOH after each original extraction. The combined aqueous layer was then neutralized

${ }^{4}$ (a) Schwab, P.; France, M. B.; Ziller, J. W.; Grubbs, R. H. Angew. Chem. Int. Ed. 1995, 34, 2039-2041.

(b) Schwab, P.; Grubbs, R. H.; Ziller, J. W. J. Am. Chem. Soc. 1996, 118, 100-110. 
with $2 \mathrm{~N} \mathrm{NaOH}$ and extracted with ether, dried with $\mathrm{MgSO}_{4}$, filtered and concentrated in vacuo to provide the deprotected amine.

Conditions C: To a flame-dried flask flushed with nitrogen and equipped with a Dean-Stark trap was added the deprotected amine (1 equiv) and aldehyde (0.95 equiv) dissolved in $\mathrm{PhH}(0.1 \mathrm{M})$. The reaction mixture was heated to reflux and stirred at that temperature until completion. Reaction progress was monitored by ${ }^{1} \mathrm{H}$ NMR spectroscopic analysis of concentrated reaction aliquots. The concentrated reaction mixture was purified by flash chromatography with the indicated eluent or by recrystallization from the indicated solvent to afford imine $\mathbf{3 . 1 2}$.

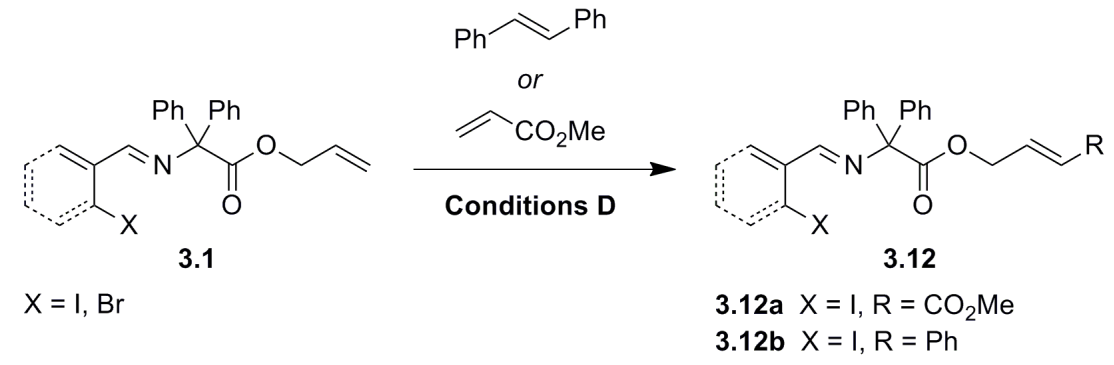

Conditions D: 3.1 (1.0 equiv), coupling alkene (5-10.0 equiv), Grubbs' 2nd generation catalyst $(0.05 \text { equiv })^{4}$ and $\mathrm{CH}_{2} \mathrm{Cl}_{2}(0.1 \mathrm{M})$ were combined with a stir bar in a sealed CEM Intellevent microwave tube. The reaction mixture was subjected to microwave irradiation $(300 \mathrm{~W})$ for $10 \mathrm{~min}$ at $90{ }^{\circ} \mathrm{C}$. Reaction temperature and temperature-time profile were monitored using an IR probe and ChemDriver Explorer Application program. Concentration in vacuo and purification by gradient flash chromatography with the indicated eluent afforded the desired imines 3.12. 
${ }_{\mathrm{H}}^{\mathrm{Cbz}} \mathrm{C}_{\mathrm{O}}^{\mathrm{Ph}} \mathrm{T}_{\mathrm{CO}}^{\mathrm{Ph}}$

\section{4-(2-Benzyloxycarbonylamino-2,2-diphenyl-acetoxy)-but-}

2-enoic acid methyl ester (3.9a). Conditions A; Eluent: $5 \rightarrow 40 \%$ EtOAc/hexanes, off-white crystals $(0.224 \mathrm{~g}, 0.488 \mathrm{mmol}, 84 \%): \mathrm{mp} 99-101{ }^{\circ} \mathrm{C} ; \mathrm{R}_{\mathrm{f}}=0.10(10 \%$ EtOAc/hexanes); IR (NaCl, film) 3408 (s), 3063 (s), 1724 (s), 1255 (s); ${ }^{1} \mathrm{H}$ NMR $\left(\mathrm{CDCl}_{3}, 300 \mathrm{MHz}\right) \delta 7.45-7.34(\mathrm{~m}, 15 \mathrm{H}), 6.80(\mathrm{dt}, \mathrm{J}=15.8,4.4 \mathrm{~Hz}, 1 \mathrm{H}), 6.50(\mathrm{~s}, 1 \mathrm{H})$,

$5.68(\mathrm{~d}, 1 \mathrm{H}), 5.05(\mathrm{~s}, 2 \mathrm{H}), 4.80(\mathrm{~s}, 2 \mathrm{H}), 3.71(\mathrm{~s}, 3 \mathrm{H}) ;{ }^{13} \mathrm{C} \mathrm{NMR}\left(\mathrm{CDCl}_{3}, 125 \mathrm{MHz}\right) \delta$ 171.0, 166.0, 140.3, 139.0, 128.3, 122.0, 69.6, 66.9, 64.2, 51.7; HRMS (ESI+) m/z $460.1755\left[(\mathrm{M}+\mathrm{H})^{+}\right.$; calculated mass for $\left.\mathrm{C}_{27} \mathrm{H}_{26} \mathrm{NO}_{6}{ }^{+}: 460.1760 \mathrm{amu}\right]$.

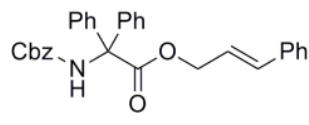

\section{Benzyloxycarbonylamino-diphenyl-acetic acid 3-phenyl-allyl}

ester (3.9b). Conditions A; Eluent: gradient $5 \rightarrow 20 \%$ EtOAc/hexanes, orange oil (0.245 g, 0.512 mmol, 92\%): IR (NaCl, film) 3408 (s), 3061 (s), 1731 (s), 1254 (s); ${ }^{1} \mathrm{H}$ NMR $\left(\mathrm{CDCl}_{3}, 300 \mathrm{MHz}\right) \delta$ 7.50-7.67 (m, 20H), $6.61(\mathrm{~s}, 1 \mathrm{H}), 6.47$ (d, J = $\left.15.9 \mathrm{~Hz}\right), 6.13$ $(\mathrm{dt}, \mathrm{J}=6.1,1 \mathrm{H}), 5.03(\mathrm{~s}, 2 \mathrm{H}), 4.85(\mathrm{~s}, 2 \mathrm{H}) ;{ }^{13} \mathrm{C} \mathrm{NMR}\left(\mathrm{CDCl}_{3}, 125 \mathrm{MHz}\right) \delta 171.5,139.2$, 136.0, 134.4, 128.6, 128.5, 128.2, 128.1, 128.01, 127.97, 126.6, 122.0, 69.7, 66.8; HRMS (ESI+) m/z 478.2000 [(M+H)+; calculated mass for C31H28NO4+: 478.2018 $\mathrm{amu}]$. 


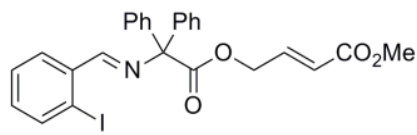

\section{4-\{2-[(2-Iodo-benzylidene)-amino]-2,2-diphenyl-}

acetoxy\}-but-2-enoic acid methyl ester (3.12a). Conditions B, $(0.224 \mathrm{~g}, 0.689$ mmol, 91\%); Conditions C; Eluent: $0 \% \rightarrow 20 \%$ EtOAc/Pentane with $1 \% \mathrm{Et}_{3} \mathrm{~N}$, yellow oil $(0.459 \mathrm{~g}, 0.852 \mathrm{mmol}, 77 \%): \mathrm{R}_{\mathrm{f}}=0.13\left(3 \% \mathrm{EtOAc} /\right.$ hexanes with $\left.1 \% \mathrm{Et}_{3} \mathrm{~N}\right)$; IR ( $\mathrm{NaCl}$, film) $3060(\mathrm{w}), 1727$ (s), $1636(\mathrm{~m}), 1583$ (w), 1277 (s); ${ }^{1} \mathrm{H}$ NMR $\left(\mathrm{CDCl}_{3}, 500\right.$ MHz) $\delta 8.24(\mathrm{dd}, \mathrm{J}=4.8,1.7,1 \mathrm{H}), 8.06(\mathrm{~s}, 1 \mathrm{H}), 7.82(\mathrm{dd}, \mathrm{J}=7.9,1.1,1 \mathrm{H}), 7.46-7.34$ (m, 10H), $7.12(\mathrm{dt}, \mathrm{J}=7.4,1.8 \mathrm{~Hz}, 1 \mathrm{H}), 6.91(\mathrm{dt}, \mathrm{J}=15.8,4.3 \mathrm{~Hz}, 1 \mathrm{H}), 5.80(\mathrm{dt}, \mathrm{J}=15.8$, $2.0 \mathrm{~Hz}, 2 \mathrm{H}), 4.90(\mathrm{dd}, \mathrm{J}=4.3,2.0 \mathrm{~Hz}, 2 \mathrm{H}), 3.71(\mathrm{~s}, 3 \mathrm{H}) ;{ }^{13} \mathrm{C} \mathrm{NMR}\left(\mathrm{CDCl}^{3}, 125 \mathrm{MHz}\right) \delta$ $171.4,167.3,166.1,141.5,140.8,139.6,137.0,132.5,129.3,129.1,128.5,128.2$, 128.0, 121.9, 101.1, 79.8, 63.7, 51.7; HRMS (ESI+) m/z 540.0675 [(M+H)+; calculated mass for $\left.\mathrm{C}_{26} \mathrm{H}_{23} \mathrm{NO}_{4} \mathrm{I}^{+}: 540.0672 \mathrm{amu}\right]$.

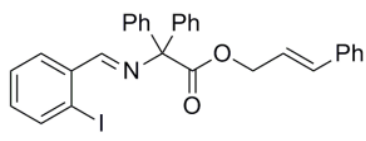

[(2-Iodo-benzylidene)-amino]-diphenyl-acetic acid 3-

phenyl-allyl ester (3.12b). Conditions B; Eluent: gradient $10 \rightarrow 40 \%$ EtOAc/hexanes with $1 \% \mathrm{Et}_{3} \mathrm{~N}$ : (0.033 g, $\left.0.100 \mathrm{mmol}, 51 \%\right)$; Conditions C; Eluent: gradient $0 \% \rightarrow 5 \%$ EtOAc/hexanes with 1\% Et $3 \mathrm{~N}$, orange oil (0.108 g, $0.194 \mathrm{mmol}, 36 \%$ ) or, Conditions D; Eluent: $10 \% \mathrm{EtOAc} /$ hexanes with $1 \% \mathrm{Et}_{3} \mathrm{~N}$ : orange oil $(0.0252 \mathrm{~g}, 0.045 \mathrm{mmol}$, 83\%): $\mathrm{R}_{\mathrm{f}}=0.49\left(5 \%\right.$ EtoAc/hexanes with $\left.1 \% \mathrm{Et}_{3} \mathrm{~N}\right) ; \mathrm{IR}(\mathrm{NaCl}$, film) $3059(\mathrm{w}), 1732$ (s), $1198(\mathrm{~s}) ;{ }^{1} \mathrm{H} \mathrm{NMR}\left(\mathrm{CDCl}_{3}, 500 \mathrm{MHz}\right) \delta 8.24(\mathrm{dd}, \mathrm{J}=$ 7.7-1.4 Hz, 1H), $8.09(\mathrm{~s}, 1 \mathrm{H})$, $7.83(\mathrm{~d}, \mathrm{~J}=7.9 \mathrm{~Hz}, 1 \mathrm{H}), 7.54-7.09(\mathrm{~m}, 16 \mathrm{H}), 6.54(\mathrm{dd}, \mathrm{J}=15.9,0.8 \mathrm{~Hz}, 1 \mathrm{H}), 6.26(\mathrm{dt}, \mathrm{J}$ 
$=15.9,5.9,1 \mathrm{H}), 4.91(\mathrm{~d}, \mathrm{~J}=5.9 \mathrm{~Hz}, 2 \mathrm{H}) ;{ }^{13} \mathrm{C} \mathrm{NMR}(\mathrm{CDCl} 3,125 \mathrm{MHz}) \delta 171.8,167.0$, 141.9, 139.5, 137.2, 136.2, 133.9, 132.4, 129.3, 129.2, 128.6, 128.5, 128.1, 128.0, 127.8, 126.6, 122.6, 101.0, 79.9, 66.2; HRMS (ESI+) m/z 558.0928 [(M+H)+; calculated mass for $\left.\mathrm{C}_{30} \mathrm{H}_{25} \mathrm{NO}_{2} \mathrm{I}^{+}: 558.0930 \mathrm{amu}\right]$.

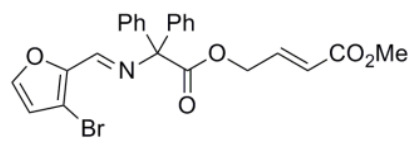

\section{E-Methyl 4-(2-((E)-(3-bromofuran-2-}

yl)methyleneamino)-2,2-diphenylacetoxy)but-2-enoate (3.12c). Conditions $B$, (0.203 g, $0.624 \mathrm{mmol}, 77 \%)$; Conditions C; $23.5 \mathrm{hrs}$, Eluent: gradient $3 \rightarrow 10 \%$ EtOAc/hexanes, yellow oil $(0.200 \mathrm{~g}, 0.415 \mathrm{mmol}, 73 \%): \mathrm{R}_{\mathrm{f}}=0.29(36 \%$ EtOAc,/hexanes); IR (NaCl, film) 3060 (m), 3025 (m), 2950 (m), 1727 (s), 1643 (m), 1487 (m), 1446 (m), 1278 (s), 1196 (s), 1023 (s), 754 (s), 701 (s); ${ }^{1} \mathrm{H}$ NMR (500 $\left.\mathrm{MHz}, \mathrm{CDCl}_{3}\right) \delta 7.70(\mathrm{~s}, 1 \mathrm{H}), 7.53(\mathrm{~d}, J=1.9,1 \mathrm{H}), 7.42-7.31(\mathrm{~m}, 10 \mathrm{H}), 6.87(\mathrm{dt}, J=4.4$, $15.8,1 \mathrm{H}), 6.54(\mathrm{dd}, J=0.7,1.9,1 \mathrm{H}), 5.77(\mathrm{dt}, J=2.0,15.7,1 \mathrm{H}), 4.86(\mathrm{dd}, J=2.0,4.4$, 2H), 3.69 (s, 3H); ${ }^{13} \mathrm{C} \mathrm{NMR}\left(126 \mathrm{MHz}, \mathrm{CDCl}_{3}\right) \delta 171.2,166.2,149.8,147.7,145.4$, 141.1, 140.7, 129.3, 128.4, 128.2, 128.1, 128.0, 127.8, 122.0, 115.6, 107.0, 80.0, 77.4, 77.1, 76.9, 63.8, 51.7; HRMS (ESI+) m/z $482.0619\left[(\mathrm{M}+\mathrm{H})^{+}\right.$; calculated mass for $\left.\mathrm{C}_{24} \mathrm{H}_{21} \mathrm{NO}_{5} \mathrm{Br}^{+}: 482.0603 \mathrm{amu}\right]$.

General Procedure for tandem reaction in formation of polycyclic imine (3.13). To a flame-dried CEM IntelliVent microwave tube capped with a rubber septum and charged with $10 \mathrm{~mol} \% \mathrm{Pd}\left(\mathrm{PPh}_{3}\right)_{4}$ was added by syringe a solution of imine 3.12 in 
DMF (0.1M). The reaction mixture was stirred at $\mathrm{rt}$ for 5 min. ${ }^{2} \mathrm{Next}, \mathrm{Et}_{3} \mathrm{~N}$ (2 equiv) was added by syringe, the septum was replaced with a CEM IntelliVent cap, and the reaction mixture was subjected to microwave irradiation $(300 \mathrm{~W})$ for the specified time and temperature using a CEM Explorer-Discover microwave reactor. Reaction temperature and temperature-time profile were monitored using an IR probe and the ChemDriver Explorer Application program. The resulting mixture was filtered through Celite and azeotropically concentrated in vacuo with $\mathrm{PhCH}_{3}$. The reaction was purified by flash chromatography with the indicated eluent.

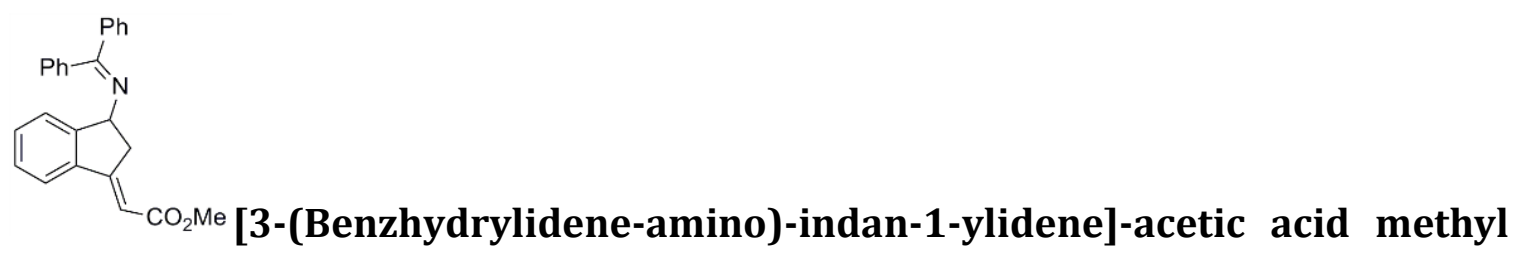
ester and [3-(Benzhydrylidene-amino)-1H-inden-1-yl]-acetic acid methyl ester (3.13a). $\mu \mathrm{w}$ time: $10 \mathrm{~min}, \mu \mathrm{w}$ temperature: $150{ }^{\circ} \mathrm{C}$; Eluent: gradient $0 \% \rightarrow 3 \%$ EtOAc/hexanes with $1 \% \mathrm{Et}_{3} \mathrm{~N}$ : pale yellow oil $(0.0153 \mathrm{~g}, 0.042 \mathrm{mmol}, 76 \%): \mathrm{R}_{\mathrm{f}}=$ 0.25 (3\% EtOAc/hexanes with 1\% Et 3 N); IR (NaCl, film) 3058 (w), 1706 (s), 1641 (m), $1163(\mathrm{~s}) ;{ }^{1} \mathrm{H} \mathrm{NMR}\left(\mathrm{CDCl}_{3}, 500 \mathrm{MHz}\right) \delta 7.82-7.24(\mathrm{~m}, 15 \mathrm{H}$, overlap with solvent), $6.33(\mathrm{~s}, 1 \mathrm{H}), 4.99$ (dd, J = 7.4, $4.3 \mathrm{~Hz}, 1 \mathrm{H}), 3.76(\mathrm{~s}, 3 \mathrm{H}), ;{ }^{13} \mathrm{C} \mathrm{NMR}\left(\mathrm{CDCl}_{3}, 125 \mathrm{MHz}\right) \delta$ 169.1, 167.8, 160.4, 150.4, 139.6, 136.8, 131.2, 130.2, 128.8, 127.9, 125.5, 121.7, 107.8, 105.6, 64.3, 51.1, 40.7; HRMS (ESI+) m/z 368.1646 [(M+H)+; calculated mass for $\mathrm{C}_{25} \mathrm{H}_{22} \mathrm{NO}_{2}+$ : $\left.368.1651 \mathrm{amu}\right]$. 


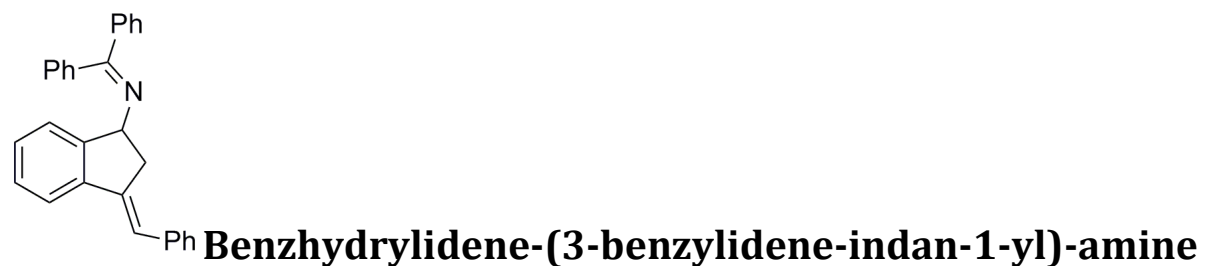

(3.13b). $\mu \mathrm{W}$ time: $10 \mathrm{~min}, \mu \mathrm{w}$ temperature: $150{ }^{\circ} \mathrm{C}$; , Eluent: gradient $0 \% \rightarrow 5 \%$ EtOAc/hexanes with $1 \% \mathrm{Et}_{3} \mathrm{~N}$ : orange oil (0.020 g, $\left.0.051 \mathrm{mmol}, 81 \%\right): \mathrm{R}_{\mathrm{f}}=0.72(5 \% \mathrm{EtOAc} / \mathrm{hexanes}$ with 1\% Et ${ }_{3} \mathrm{~N}$ ); IR (NaCl, film) 3023 (w), 1659 (w), 1278 (w); ${ }^{1} \mathrm{H}$ NMR $\left(\mathrm{CDCl}_{3}, 300\right.$ MHz) $\delta 7.83-7.17(\mathrm{~m}, 19 \mathrm{H}), 6.98(\mathrm{~s}, 1 \mathrm{H}), 5.06(\mathrm{t}, \mathrm{J}=6.5 \mathrm{~Hz}, 1 \mathrm{H}), 3.29(\mathrm{dd}, \mathrm{J}=6.6,2.29$ $\mathrm{Hz}, 2 \mathrm{H}) ;{ }^{13} \mathrm{C} \mathrm{NMR}\left(\mathrm{CDCl}_{3}, 75 \mathrm{MHz}\right) \delta 169.0,147.0,142.4,141.8,139.9,138.3,137.0$, $130.4,130.3,129.2,129.0,128.9,128.7,128.6,128.5,128.3,128.1,128.07,126.7$ 125.1, 120.6, 119.8; ; HRMS (ESI+) m/z 386.1915 [(M+H)+; calculated mass for $\left.\mathrm{C}_{29} \mathrm{H}_{24} \mathrm{~N}^{+}: 386.1909 \mathrm{amu}\right]$.

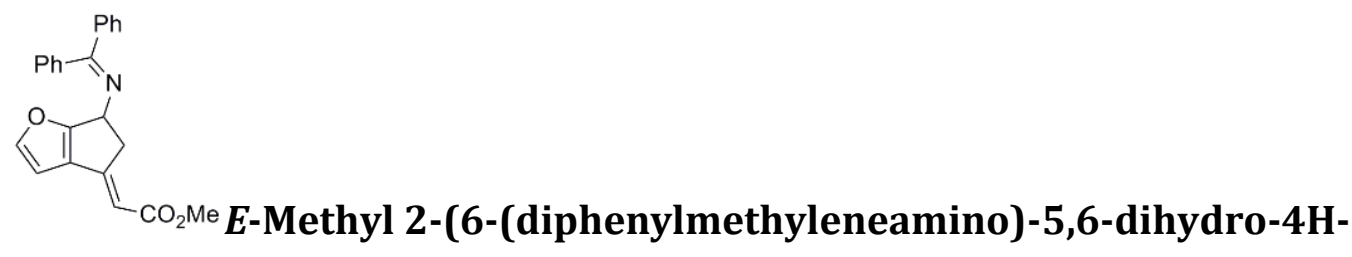

cyclopenta[b]furan-4-ylidene)acetate (3.13c). $\mu \mathrm{w}$ time: $30 \mathrm{~min}, \mu \mathrm{w}$ temperature: $150{ }^{\circ} \mathrm{C}$; Eluent: $10 \%$ EtOAc/hexanes, yellow oil (0.028 g, $\left.0.0783 \mathrm{mmol}, 88 \%\right): \mathrm{R}_{\mathrm{f}}=$ 0.52 (36\% EtOAc/hexanes); IR (NaCl, film) 2923 (s), 2852 (m), 1709 (m), 1639 (m), $1446(\mathrm{~m}), 1341(\mathrm{~m}), 1170(\mathrm{~m}), 696.77(\mathrm{~m}) ;{ }^{1} \mathrm{H}$ NMR (500 MHz, $\left.\mathrm{CDCl}_{3}\right) \delta$ 7.65-7.27 $(\mathrm{m}, 9 \mathrm{H}), 6.44(\mathrm{~d}, J=2.0,1 \mathrm{H}), 5.85(\mathrm{t}, J=2.1,1 \mathrm{H}), 4.89(\mathrm{dd}, J=1.7,6.4,1 \mathrm{H}), 3.82$ (ddd, $J=2.0,6.5,18.5,1 \mathrm{H}), 3.72(\mathrm{~s}, 3 \mathrm{H}), 3.63-3.57(\mathrm{~m}, 1 \mathrm{H}) ;{ }^{13} \mathrm{C} \mathrm{NMR}\left(126 \mathrm{MHz}, \mathrm{CDCl}_{3}\right) \delta$ $170.5,169.8,167.9,152.8,149.2,139.4,136.4,132.4,130.4,130.1,128.8,128.6$ 
128.3, 128.2, 128.1, 106.2, 105.1, 77.3, 77.0, 76.8, 58.3, 50.9, 46.3; HRMS (ESI+) m/z $358.1426\left[(\mathrm{M}+\mathrm{H})^{+}\right.$; calculated mass for $\left.\mathrm{C}_{23} \mathrm{H}_{20} \mathrm{NO}_{3}{ }^{+}: 358.1443 \mathrm{amu}\right]$.

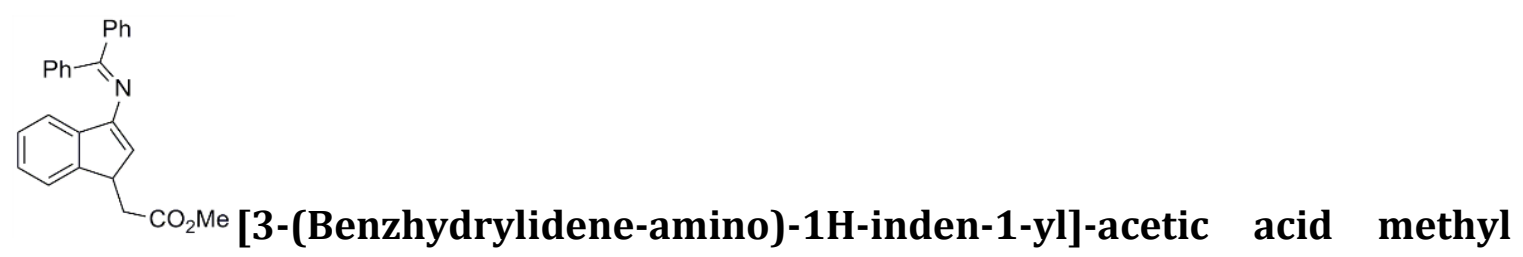

ester (3.14a). $\mu \mathrm{w}$ time: $10 \mathrm{~min}, \mu \mathrm{w}$ temperature: $150{ }^{\circ} \mathrm{C}$; Eluent: gradient $0 \% \rightarrow 5 \%$ EtOAc/Pentane: pale yellow oil $(0.0153 \mathrm{~g}, 0.042 \mathrm{mmol}, 76 \%): \mathrm{R}_{\mathrm{f}}=0.25(3 \%$ EtOAc/hexanes with 1\% Et ${ }_{3} \mathrm{~N}$ ); IR (NaCl, film) 3058 (w), 1706 (s), 1641 (m), 1163 (s); ${ }^{1} \mathrm{H} \mathrm{NMR}\left(\mathrm{CDCl}_{3}, 500 \mathrm{MHz}\right) \delta$ 7.84-7.82 (d, J = 7.2 Hz, 2H), 7.50-7.16 (m, 15H), $5.26(\mathrm{~s}, 1 \mathrm{H}), 3.74(\mathrm{~m}, 1 \mathrm{H}), 3.70(\mathrm{~s}, 3 \mathrm{H}) ;{ }^{13} \mathrm{C} \mathrm{NMR}\left(\mathrm{CDCl}_{3}, 125 \mathrm{MHz}\right) \delta 173.0,170.0$, $151.1,146.0,142.4,138.9,136.2,130.9,129.4,128.8,128.3,128.2,127.8,126.9$, 125.4, 122.8, 119.4, 117.1, 51.6, 43.6, 36.5; HRMS (ESI+) m/z $368.1646\left[(\mathrm{M}+\mathrm{H})^{+}\right.$; calculated mass for $\left.\mathrm{C}_{25} \mathrm{H}_{22} \mathrm{NO}_{2}+: 368.1651 \mathrm{amu}\right]$.

\subsection{Experimentals for Chapter 4 - Decarboxylative Benzylation}

Preparation of benzyl bromide substrates.

$$
\text { 2) } \mathrm{PBr}_{3}, \mathrm{Et}_{2} \mathrm{O}, 0^{\circ} \mathrm{C}
$$


All benzyl bromides used for esterification are known compounds previously described in the literature. ${ }^{5}$ The requisite benzyl bromides were either purchased commercially or used as received or prepared from the corresponding benzyl aldehyde following a reported procedure. ${ }^{6}$ Briefly, to a solution of the requisite aldehyde (1.0 equiv) in 2:1 MeOH/THF at $0{ }^{\circ} \mathrm{C}(1 \mathrm{M})$, was added $\mathrm{NaBH}_{4}$ (2.0 equiv.); reaction progress was monitored by TLC. Upon completion, the reaction mixture was concentrated in vacuo. The residue was dissolved in ether $(100 \mathrm{~mL})$ and quenched with $1 \mathrm{~N} \mathrm{HCl}$. The resulting aqueous phase was extracted with $\mathrm{Et}_{2} \mathrm{O}$ $(3 \times 100 \mathrm{~mL})$ and the combined organic layers were rinsed with water $(100 \mathrm{~mL})$, dried $\left(\mathrm{Mg}_{2} \mathrm{SO}_{4}\right)$, filtered and concentrated to afford the corresponding benzyl alcohol. The alcohol (1.0 equiv.) was then dissolved in $\mathrm{Et}_{2} \mathrm{O}(0.3 \mathrm{M})$ and cooled to 0 ${ }^{\circ} \mathrm{C}$ under $\mathrm{N}_{2}$. $\mathrm{PBr}_{3}$ (1.9 equiv.) was slowly added via syringe and the reaction mixture was allowed to warm gradually to ambient temperature with stirring overnight. Upon completion, as determined by TLC, the reaction mixture was slowly pipetted into a vigorously stirring solution of ice water. The organic layer was sequentially washed with saturated $\mathrm{NaHCO}_{3}$ and brine, dried $\left(\mathrm{Mg}_{2} \mathrm{SO}_{4}\right)$, filtered and concentrated in vacuo to afford the corresponding benzyl bromide. The resulting bromides were used without further purification.

\footnotetext{
5 (a) Khartulyari, A. S.; Kapur, M.; Maier, M. E. Org. Lett. 2006, 8, 5833-5836. (b) Lee, J. C.; Hwang, E. Y. Synth. Commun. 2004, 34, 2959-2963. (c) Dallacker, F.; Kornfeld, F.; Lipp, M. Monatsh. Chem. 1960, 91, 688-93. (d) Bassoli, A.; Borgonovo, G.; Busnelli, G.; Morini, G.; Merlini, L. Eur. J. Org. Chem. 2005, 2518-2525. (e) Bower, J. F.; Szeto, P.; Gallagher, T. Org. Biomol. Chem. 2007, 5, 143-150.

${ }^{6}$ Bower, J. F.; Szeto, P.; Gallagher, T. Org. Biomol. Chem. 2007, 5, 143-150.
} 
General procedure for the preparation of diphenylglycinate ester amines (4.3).

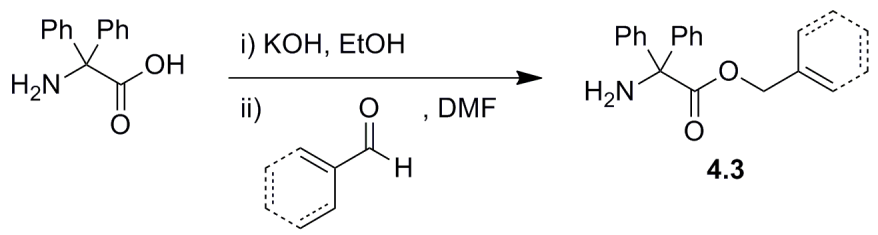

Diphenylglycine (1.0 equiv.) and KOH (1.1 equiv.) were combined in ethanol $(0.1 \mathrm{M})$ and the mixture was stirred at room temperature until near complete dissolution of solids. The reaction mixture was concentrated in vacuo to afford a white solid which was dissolved in DMF (0.1 M). The corresponding benzyl bromide (1.1 equiv.) was added at room temperature and the reaction mixture stirred. Upon completion as determined by TLC, the reaction mixture was quenched with saturated $\mathrm{NaHCO}_{3}(200 \mathrm{~mL})$ and extracted with ethyl acetate $(3 \times 100 \mathrm{~mL})$. The combined organic layers were washed with brine $(200 \mathrm{~mL})$, dried $\left(\mathrm{Mg}_{2} \mathrm{SO}_{4}\right)$, filtered and concentrated in vacuo. The residue was purified using flash column chromatography (10\% EtOAc/hexanes until least polar spots eluted, then $25 \%$ EtOAc/hexanes with 1\% triethylamine to elute desired ester 4.3).

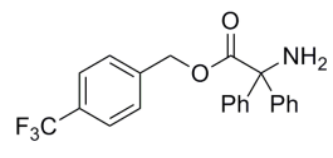

4-(Trifluoromethyl)benzyl 2-amino-2,2-diphenylacetate

(4.3a). White solid (1.04 g, $2.99 \mathrm{mmol}, 66 \%): \mathrm{mp}=54-56{ }^{\circ} \mathrm{C}$; $\mathrm{R}_{\mathrm{f}}=0.21(10 \%$ EtOAc/Hexanes); IR (NaCl, film) 3386, 3060, 1731, 1599, 1215; ${ }^{1} \mathrm{H}$ NMR $\left(\mathrm{CDCl}_{3}, 300\right.$ MHz) $\delta 7.54(\mathrm{~d}, J=8.1 \mathrm{~Hz}, 2 \mathrm{H}), 7.39-7.24(\mathrm{~m}, 12 \mathrm{H}), 5.28(\mathrm{~s}, 2 \mathrm{H}), 2.31(\mathrm{br} \mathrm{s}, 2 \mathrm{H}) ;{ }^{13} \mathrm{C}$ $\operatorname{NMR}\left(\mathrm{CDCl}_{3}, 75 \mathrm{MHz}\right) \delta 174.5,143.4,139.3,130.3\left(\mathrm{q}, J_{C-F}=32.7 \mathrm{~Hz}\right), 128.1,127.8$, 
$127.64,127.57,125.40,125.35,123.9\left(\mathrm{q}, J_{C-F}=272.5 \mathrm{~Hz}\right), 68.5,66.4 ;{ }^{19} \mathrm{~F}$ NMR $\left(\mathrm{CDCl}_{3}\right.$, $282 \mathrm{MHz}) \delta$-63.3; HRMS (ESI+) $\mathrm{m} / \mathrm{z} 386.1369\left[(\mathrm{M}+\mathrm{H})^{+}\right.$; calculated mass for $\left.\mathrm{C}_{22} \mathrm{H}_{19} \mathrm{~F}_{3} \mathrm{NO}_{2}+386.1368 \mathrm{amu}\right]$.

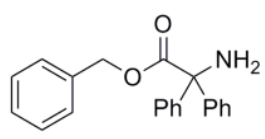

Benzyl 2-amino-2,2-diphenylacetate (4.3b). White solid (3.12 g, $9.86 \mathrm{mmol}, 86 \%): \mathrm{mp}=54-56^{\circ} \mathrm{C} ; \mathrm{R}_{\mathrm{f}}=0.15(10 \%$ EtOAc/Hexanes$) ; \mathrm{IR}(\mathrm{NaCl}$, film $)$ 3386, 3061, 1731, 1599, 1215; ${ }^{1} \mathrm{H}$ NMR ( $\left.\mathrm{CDCl}_{3}, 500 \mathrm{MHz}\right) \delta$ 7.39-7.19 (m, 15H), 5.24 (s, 2H), 2.31 (br s, 2H); ${ }^{13} \mathrm{C} \mathrm{NMR}\left(\mathrm{CDCl}_{3}, 75 \mathrm{MHz}\right) \delta$ 174.6, 143.6, 135.3, 128.4, 128.2, 128.1, 128.0, 127.6, 127.5, 68.4, 67.5; HRMS (ESI+) m/z $318.1489\left[(\mathrm{M}+\mathrm{H})^{+}\right.$; calculated mass for $\left.\mathrm{C}_{21} \mathrm{H}_{20} \mathrm{NO}_{2}{ }^{+}: 318.1494 \mathrm{amu}\right]$.

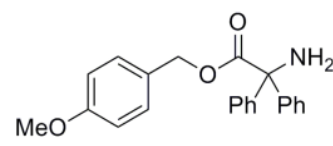

4-Methoxybenzyl 2-amino-2,2-diphenylacetate

(4.3c).

Yellow solid (0.654 g, $1.88 \mathrm{mmol}, 84 \%): \mathrm{mp}=42-44{ }^{\circ} \mathrm{C} ; \mathrm{R}_{\mathrm{f}}=0.21(10 \%$

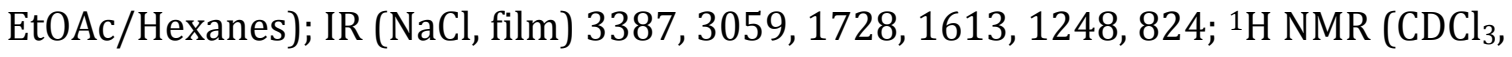
$500 \mathrm{MHz}) \delta 7.36-7.26(\mathrm{~m}, 10 \mathrm{H}), 7.17(\mathrm{~d}, J=8.7 \mathrm{~Hz}, 2 \mathrm{H}), 6.84(\mathrm{~d}, J=8.7 \mathrm{~Hz}, 2 \mathrm{H}), 5.17$ (s, 2H), $3.80(\mathrm{~s}, 3 \mathrm{H}), 2.25$ (br s, 2H); ${ }^{13} \mathrm{C} \mathrm{NMR}\left(\mathrm{CDCl}_{3}, 125 \mathrm{MHz}\right) \delta 174.7,159.5,143.6$, 129.9, 128.0, 127.6, 127.4, 113.8, 68.4, 67.4, 55.3; HRMS (ESI+) m/z 348.1601 $\left[(\mathrm{M}+\mathrm{H})^{+}\right.$; calculated mass for $\left.\mathrm{C}_{22} \mathrm{H}_{22} \mathrm{NO}_{3}{ }^{+}: 348.1600 \mathrm{amu}\right]$. 


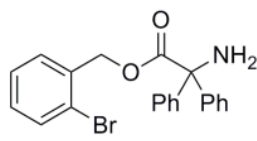

2-Bromobenzyl 2-amino-2,2-diphenylacetate (4.3d). White solid (3.34 g, $8.42 \mathrm{mmol}, 83 \%): \mathrm{mp}=58-60{ }^{\circ} \mathrm{C} ; \mathrm{R}_{\mathrm{f}}=0.29$ (20\% EtOAc/Hexanes); IR ( $\mathrm{NaCl}$, film) 3059, 1733, 1493, 1213, 752; ${ }^{1} \mathrm{H}$ NMR $\left(\mathrm{CDCl}_{3}, 500 \mathrm{MHz}\right) \delta 7.53(\mathrm{dd}, J=7.8,1.4$ $\mathrm{Hz}, 1 \mathrm{H}), 7.41-7.40(\mathrm{~m}, 4 \mathrm{H}), 7.34-7.28(\mathrm{~m}, 6 \mathrm{H}), 7.17$ (dtd, $J=17.2,7.5,1.6 \mathrm{~Hz}, 2 \mathrm{H})$, 7.09 (dd, $J=7.5,1.8 \mathrm{~Hz}, 1 \mathrm{H}), 5.31(\mathrm{~s}, 2 \mathrm{H}), 2.35(\mathrm{br} \mathrm{s}, 2 \mathrm{H}) ;{ }^{13} \mathrm{C} \mathrm{NMR}\left(\mathrm{CDCl}_{3}, 125 \mathrm{MHz}\right)$ $\delta 174.4,143.5,134.7,132.7,129.64,129.60,128.1,127.64,127.55,127.4,123.1$, 68.6, 67.0; HRMS (ESI+) m/z $396.0600\left[(\mathrm{M}+\mathrm{H})^{+}\right.$; calculated mass for $\mathrm{C}_{21} \mathrm{H}_{19} \mathrm{BrNO}_{2}{ }^{+}$: $396.0599 \mathrm{amu}]$.

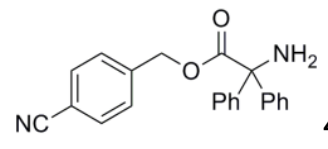

4-Cyanobenzyl 2-amino-2,2-diphenylacetate (4.3e). White solid (0.467 g, $1.36 \mathrm{mmol}, 62 \%): \mathrm{mp}=114-116^{\circ} \mathrm{C} ; \mathrm{R}_{\mathrm{f}}=0.25$ (25\% EtOAc/Hexanes); IR (NaCl, film) 3387, 3059, 1733, 1216, 821; ${ }^{1} \mathrm{H}$ NMR $\left(\mathrm{CDCl}_{3}, 300 \mathrm{MHz}\right) \delta 7.57$ (d, $J=$ $8.5 \mathrm{~Hz}, 2 \mathrm{H}), 7.38-7.30(\mathrm{~m}, 10 \mathrm{H}), 7.20(\mathrm{~d}, J=8.6 \mathrm{~Hz}, 2 \mathrm{H}), 5.26(\mathrm{~s}, 2 \mathrm{H}), 2.33(\mathrm{br} \mathrm{s}, 2 \mathrm{H})$; ${ }^{13} \mathrm{C}$ NMR $\left(\mathrm{CDCl}_{3}, 75 \mathrm{MHz}\right) \delta 174.3,143.2,140.6,132.2,128.4,128.2,127.9,127.7$, 127.6, 118.5, 111.9, 68.6, 66.1; HRMS (ESI+) m/z $343.1448\left[(\mathrm{M}+\mathrm{H})^{+}\right.$; calculated mass for $\mathrm{C}_{22} \mathrm{H}_{19} \mathrm{~N}_{2} \mathrm{O}_{2}+$ : $\left.343.1447 \mathrm{amu}\right]$.

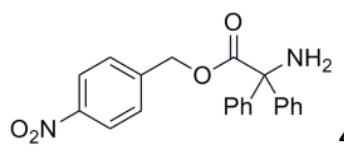

4-Nitrobenzyl 2-amino-2,2-diphenylacetate (4.3f). Yellow solid (1.03 g, $2.85 \mathrm{mmol}, 71 \%$ ): $\mathrm{mp}=78-80{ }^{\circ} \mathrm{C} ; \mathrm{R}_{\mathrm{f}}=0.21$ (20\% EtOAc/Hexanes); IR 
$\left(\mathrm{NaCl}\right.$, film) $3386,3059,1731,1248,825 ;{ }^{1} \mathrm{H} \mathrm{NMR}\left(\mathrm{CDCl}_{3}, 300 \mathrm{MHz}\right) \delta 8.11(\mathrm{~d}, J=8.6$ $\mathrm{Hz}, 2 \mathrm{H}), 7.41-7.28(\mathrm{~m}, 10 \mathrm{H}), 7.24(\mathrm{~d}, J=8.1 \mathrm{~Hz}, 2 \mathrm{H}), 5.31(\mathrm{~s}, 2 \mathrm{H}), 2.33(\mathrm{br} \mathrm{s}, 2 \mathrm{H}) ;{ }^{13} \mathrm{C}$ $\operatorname{NMR}\left(\mathrm{CDCl}_{3}, 75 \mathrm{MHz}\right) \delta 174.3,147.5,143.2,142.6,128.2,127.9,127.7,127.5,123.6$, 68.6, 65.7; HRMS (ESI+) m/z $363.1344\left[(\mathrm{M}+\mathrm{H})^{+}\right.$; calculated mass for $\mathrm{C}_{22} \mathrm{H}_{19} \mathrm{~N}_{2} \mathrm{O}_{4}{ }^{+}$: $363.1345 \mathrm{amu}]$.

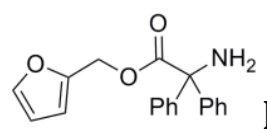

Furan-2-ylmethyl 2-amino-2,2-diphenylacetate (4.3g). Orange oil (1.605 g, 5.22 mmol, 47\%): $\mathrm{R}_{\mathrm{f}}=0.55$ (25\% EtOAc/Hexanes); IR (NaCl, film) 3386, 3059, 1732, 1447, 1194, 749; ${ }^{1} \mathrm{H} \mathrm{NMR}\left(\mathrm{CDCl}_{3}, 500 \mathrm{MHz}\right) \delta$ 7.404-7.398 (m, 1H) 7.35$7.27(\mathrm{~m}, 10 \mathrm{H}), 6.38(\mathrm{~d}, J=3.3 \mathrm{~Hz}, 1 \mathrm{H}), 6.35(\mathrm{dd}, J=3.2,1.9 \mathrm{~Hz}, 1 \mathrm{H}), 5.19(\mathrm{~s}, 2 \mathrm{H}), 2.33$ (br s, 2H); ${ }^{13} \mathrm{C}$ NMR $\left(\mathrm{CDCl}_{3}, 125 \mathrm{MHz}\right) \delta 174.5,148.9,143.4,143.2,128.0,127.5$, 127.45, 110.0, 110.5, 68.4, 59.1; HRMS (ESI+) m/z 308.1284 [(M+H)+; calculated mass for $\left.\mathrm{C}_{19} \mathrm{H}_{17} \mathrm{NO}_{3}{ }^{+}: 308.1287 \mathrm{amu}\right]$.

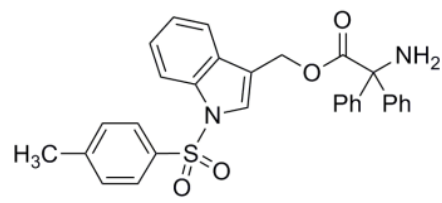

\section{(1-Tosyl-1H-indol-3-yl)methyl 2-amino-2,2-}

diphenylacetate (4.3h). Orange oil $(0.565 \mathrm{~g}, 1.11 \mathrm{mmol}, 80 \%): \mathrm{R}_{\mathrm{f}}=0.35(25 \%$ EtOAc/Hexanes); IR (NaCl, film) 3387, 3059, 1731, 1447, 910, 747; ${ }^{1} \mathrm{H}$ NMR ( $\mathrm{CDCl}_{3}$, $500 \mathrm{MHz}) \delta 7.97(\mathrm{~d}, J=8.4 \mathrm{~Hz}, 1 \mathrm{H}), 7.73(\mathrm{~d}, J=8.4 \mathrm{~Hz}, 2 \mathrm{H}), 7.52(\mathrm{~s}, 1 \mathrm{H}), 7.33-7.14(\mathrm{~m}$, $14 \mathrm{H}), 5.34(\mathrm{~s}, 2 \mathrm{H}), 2.32(\mathrm{~s}, 3 \mathrm{H}), 2.26(\mathrm{br} \mathrm{s}, 2 \mathrm{H}) ;{ }^{13} \mathrm{C} \mathrm{NMR}\left(\mathrm{CDCl}_{3}, 125 \mathrm{MHz}\right) \delta 174.6$, 
$145.0,143.3,134.91,134.87,129.8,129.2,128.0,127.4,126.7,125.7,124.9,123.3$ 119.7, 116.7, 113.4, 68.4, 59.2, 21.5; HRMS (ESI+) m/z 511.1682 [(M+H)+; calculated mass for $\left.\mathrm{C}_{30} \mathrm{H}_{27} \mathrm{~N}_{2} \mathrm{O}_{4} \mathrm{~S}^{+}: 511.1692 \mathrm{amu}\right]$.

General procedure for the preparation of diphenylglycinate imines (4.1).
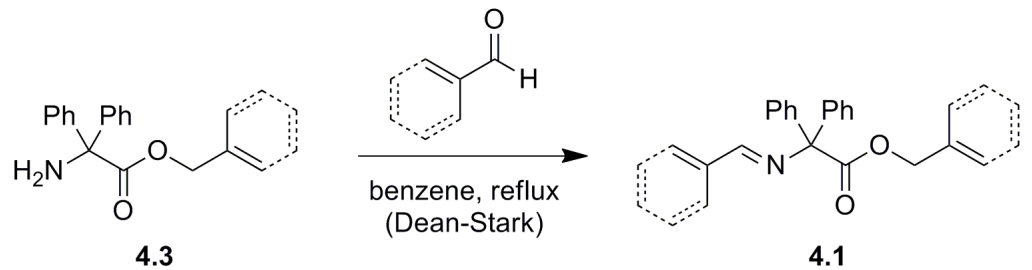

To a round bottom flask equipped with a Dean-Stark trap and reflux condenser was added amine (4.3, 1 equiv.) and aldehyde (0.95 equiv.) dissolved in $\mathrm{PhH}(0.1 \mathrm{M})$. The reaction mixture was heated to reflux and stirred at that temperature. Upon completion, as determined by ${ }^{1} \mathrm{H}$ NMR spectroscopic analysis of an aliquot, the solvent was removed in vacuo. The reaction residue was purified by triteration from $\mathrm{CH}_{2} \mathrm{Cl}_{2}$ and hexanes, unless otherwise noted.

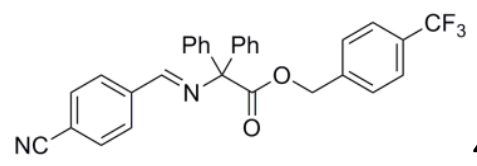

\section{4-(Trifluoromethyl)benzyl 2-(4-}

cyanobenzylideneamino)-2,2-diphenylacetate (4.1a). White solid (1.15 g, 2.30 mmol, 86\%): $\mathrm{mp}=100-101{ }^{\circ} \mathrm{C} ; \mathrm{R}_{\mathrm{f}}=0.42(15 \%$ EtOAc/Hexanes); IR (NaCl, film) 3062, 1736, 1446, 1216, 971, 755; ${ }^{1} \mathrm{H}$ NMR $\left(\mathrm{CDCl}_{3}, 500 \mathrm{MHz}\right) \delta 7.90(\mathrm{~d}, J=8.2 \mathrm{~Hz}$, 2H), $7.86(\mathrm{~s}, 1 \mathrm{H}), 7.71(\mathrm{~d}, J=8.1 \mathrm{~Hz}, 2 \mathrm{H}), 7.51(\mathrm{~d}, J=8.0 \mathrm{~Hz}, 2 \mathrm{H}), 7.35(\mathrm{~s}, 9 \mathrm{H}), 7.22(\mathrm{~d}$, 
$J=8.0 \mathrm{~Hz}, 2 \mathrm{H}), 5.28(\mathrm{~s}, 2 \mathrm{H}) ;{ }^{13} \mathrm{C} \mathrm{NMR}\left(\mathrm{CDCl}_{3}, 125 \mathrm{MHz}\right) \delta 171.2,161.7,141.4,139.8$ $139.3,132.3,130.2\left(\mathrm{q}, J_{C-F}=32.9 \mathrm{~Hz}\right), 129.2,129.0,128.1,127.9,127.7,125.3\left(\mathrm{q}, J_{C-F}\right.$ $=3.1 \mathrm{~Hz}), 123.9\left(\mathrm{q}, J_{C-F}=272.4 \mathrm{~Hz}\right), 116.42\left(\mathrm{q}, J_{C-F}=507 \mathrm{~Hz}\right), 79.7,66.4 ;{ }^{19} \mathrm{~F}$ NMR $\left(\mathrm{CDCl}_{3}, 282 \mathrm{MHz}\right) \delta$-63.4; HRMS (ESI+) m/z 499.1644 [(M+H)+; calculated mass for $\left.\mathrm{C}_{30} \mathrm{H}_{22} \mathrm{~F}_{3} \mathrm{~N}_{2} \mathrm{O}_{2}{ }^{+}: 499.1633 \mathrm{amu}\right]$.

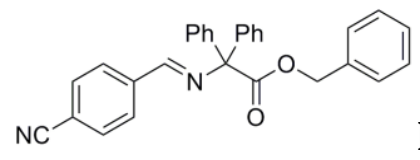

\section{Benzyl 2-(4-cyanobenzylideneamino)-2,2-}

diphenylacetate (4.1b). White solid (0.487 g, $1.13 \mathrm{mmol}, 82 \%)$ : $\mathrm{mp}=124-125^{\circ} \mathrm{C}$; $\mathrm{R}_{\mathrm{f}}=0.51$ (15\% EtOAc/Hexanes); IR (NaCl, film) 3061, 1736, 1492, 1217, 699; ${ }^{1} \mathrm{H}$ $\operatorname{NMR}\left(\mathrm{CDCl}_{3}, 500 \mathrm{MHz}\right) \delta 7.89(\mathrm{~d}, J=8.4 \mathrm{~Hz}, 2 \mathrm{H}), 7.87(\mathrm{~s}, 1 \mathrm{H}), 7.70(\mathrm{~d}, J=8.4 \mathrm{~Hz}, 2 \mathrm{H})$, 7.36-7.25 (m, 13H), 7.18-7.16 (m, 2H), $5.24(\mathrm{~s}, 2 \mathrm{H}) ;{ }^{13} \mathrm{C}$ NMR $\left(\mathrm{CDCl}_{3}, 125 \mathrm{MHz}\right)$ $\delta 171.3,161.6,141.7,140.0,135.3,132.3,129.2,129.1,128.4,128.2,128.1,127.9$, 127.8, 118.5, 114.3, 79.7, 67.5; HRMS (ESI+) m/z 431.1749 [(M+H)+; calculated mass for $\left.\mathrm{C}_{29} \mathrm{H}_{23} \mathrm{~N}_{2} \mathrm{O}_{2}{ }^{+}: 431.1760 \mathrm{amu}\right]$.

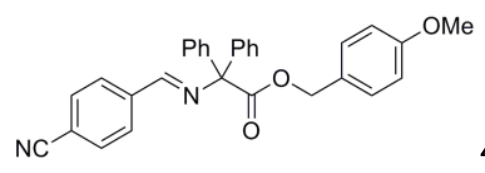

\section{4-Methoxybenzyl 2-(4-cyanobenzylideneamino)-2,2-}

diphenylacetate (4.1c). Off-white solid (0.550 g, $1.19 \mathrm{mmol}, 76 \%): \mathrm{mp}=107-109$ ${ }^{\circ} \mathrm{C} ; \mathrm{R}_{\mathrm{f}}=0.33$ (15\% EtOAc/Hexanes); IR (NaCl, film) 2360, 1731, 1515, 1218, 700; ${ }^{1} \mathrm{H}$ NMR $\left(\mathrm{CDCl}_{3}, 300 \mathrm{MHz}\right) \delta 7.88(\mathrm{~d}, J=7.3 \mathrm{~Hz}, 2 \mathrm{H}), 7.86(\mathrm{~s}, 1 \mathrm{H}), 7.70(\mathrm{~d}, J=7.3 \mathrm{~Hz}, 2 \mathrm{H})$, 
$7.32(\mathrm{~s}, 10 \mathrm{H}), 7.14(\mathrm{~d}, J=8.3 \mathrm{~Hz}, 2 \mathrm{H}), 6.80(\mathrm{~d}, J=8.4 \mathrm{~Hz}, 2 \mathrm{H}), 5.17(\mathrm{~s}, 2 \mathrm{H}), 3.80(\mathrm{~s}$, 3H); ${ }^{13} \mathrm{C}$ NMR $\left(\mathrm{CDCl}_{3}, 75 \mathrm{MHz}\right) \delta 171.4,161.5,159.5,141.8,140.0,132.3,129.9$, 129.2, 129.0, 128.0, 127.7, 127.5, 118.5, 114.2, 113.7, 79.7, 67.4, 55.3; HRMS (ESI+) $\mathrm{m} / \mathrm{z} 461.1849\left[(\mathrm{M}+\mathrm{H})^{+}\right.$; calculated mass for $\left.\mathrm{C}_{30} \mathrm{H}_{25} \mathrm{~N}_{2} \mathrm{O}_{3}{ }^{+}: 461.1865 \mathrm{amu}\right]$.

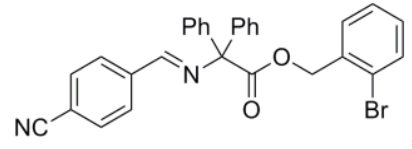

\section{2-Bromobenzyl 2-(4-cyanobenzylideneamino)-2,2-}

diphenylacetate (4.1d). Crude product purified using flash column chromatography (10-20\% EtOAc/hexanes) and required additional purification using radial chromatography (1-10\% EtOAc/hexanes). White solid (0.443 g, 0.87 mmol, 63\%): $\mathrm{mp}=107-108{ }^{\circ} \mathrm{C} ; \mathrm{R}_{\mathrm{f}}=0.37(10 \%$ EtOAc/Hexanes); IR $(\mathrm{NaCl}$, film $)$ 3060, 1738, 1196, 752; ${ }^{1} \mathrm{H} \mathrm{NMR}\left(\mathrm{CDCl}_{3}, 500 \mathrm{MHz}\right) \delta 7.92(\mathrm{~d}, J=3.8 \mathrm{~Hz}, 2 \mathrm{H}), 7.91(\mathrm{~s}$, $1 \mathrm{H}), 7.70(\mathrm{~d}, J=8.4 \mathrm{~Hz}, 2 \mathrm{H}), 7.52-7.50(\mathrm{~m}, 1 \mathrm{H}), 7.39-7.33(\mathrm{~m}, 10 \mathrm{H}), 7.16-7.13(\mathrm{~m}$, 2H), 7.07-7.05 (m, 1H), $5.30(\mathrm{~s}, 2 \mathrm{H}) ;{ }^{13} \mathrm{C}$ NMR $\left(\mathrm{CDCl}_{3}, 125 \mathrm{MHz}\right) \delta 171.1,161.8$, $141.7,140.0,134.7,132.6,132.3,129.6,129.4,129.3,129.1,128.1,127.9,127.3$ 122.9, 118.5, 114.3, 79.8, 67.0; HRMS (ESI+) m/z 509.0865 [(M+H)+; calculated mass for $\left.\mathrm{C}_{29} \mathrm{H}_{22} \mathrm{BrN}_{2} \mathrm{O}_{2}{ }^{+}: 509.0865 \mathrm{amu}\right]$.

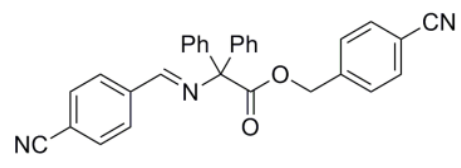

4-Cyanobenzyl 2-(4-cyanobenzylideneamino)-2,2-

diphenylacetate (4.1e). Crude product needed no further purification. Reaction 
residue concentrated in vacuo. White solid $(0.422 \mathrm{~g}, 0.926 \mathrm{mmol}, 100 \%): \mathrm{mp}=152-$ $154{ }^{\circ} \mathrm{C} ; \mathrm{R}_{\mathrm{f}}=0.18$ (15\% EtOAc/Hexanes); IR (NaCl, film) 3059, 1738, 1218, 701; ${ }^{1} \mathrm{H}$ $\operatorname{NMR}\left(\mathrm{CDCl}_{3}, 500 \mathrm{MHz}\right) \delta 7.91(\mathrm{~d}, J=8.4 \mathrm{~Hz}, 2 \mathrm{H}), 7.86(\mathrm{~s}, 1 \mathrm{H}), 7.71(\mathrm{~d}, J=8.3 \mathrm{~Hz}, 2 \mathrm{H})$, $7.53(\mathrm{~d}, J=8.4 \mathrm{~Hz}, 2 \mathrm{H}), 7.36(\mathrm{~s}, 10 \mathrm{H}), 7.17(\mathrm{~d}, J=8.6 \mathrm{~Hz}, 2 \mathrm{H}), 5.27(\mathrm{~s}, 2 \mathrm{H}) ;{ }^{13} \mathrm{C} \mathrm{NMR}$ $\left(\mathrm{CDCl}_{3}, 125 \mathrm{MHz}\right) \delta 171.2,161.8,141.2,140.6,139.8,132.4,132.2,129.2,129.1$, 128.2, 128.1, 127.8, 118.44, 118.40, 114.4, 111.9, 79.8, 66.1; HRMS (ESI+) m/z $456.1699\left[(\mathrm{M}+\mathrm{H})^{+}\right.$; calculated mass for $\left.\mathrm{C}_{30} \mathrm{H}_{22} \mathrm{~N}_{3} \mathrm{O}_{2}+456.1712 \mathrm{amu}\right]$.

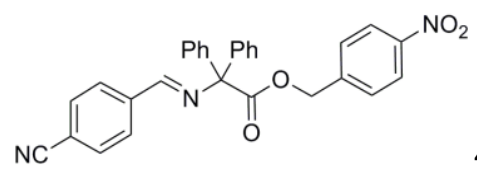

\section{4-Nitrobenzyl 2-(4-cyanobenzylideneamino)-2,2-}

diphenylacetate (4.1f). Crude product needed no further purification. Reaction residue concentrated in vacuo. Orange solid (0.623 g, $1.31 \mathrm{mmol}, 99 \%): \mathrm{mp}=127$ $129^{\circ} \mathrm{C} ; \mathrm{R}_{\mathrm{f}}=0.20$ (15\% EtOAc/Hexanes); IR (NaCl, film) 3060, 1739, 1347, 1195, 701; ${ }^{1} \mathrm{H}$ NMR $\left(\mathrm{CDCl}_{3}, 300 \mathrm{MHz}\right) \delta 8.09(\mathrm{~d}, J=8.6 \mathrm{~Hz}, 2 \mathrm{H}), 7.92(\mathrm{~d}, J=8.2 \mathrm{~Hz}, 2 \mathrm{H}), 7.87$ (s, 1H), $7.71(\mathrm{~d}, J=8.2 \mathrm{~Hz}, 2 \mathrm{H}), 7.37(\mathrm{~s}, 10 \mathrm{H}), 7.22(\mathrm{~d}, J=8.5 \mathrm{~Hz}, 2 \mathrm{H}), 5.32(\mathrm{~s}, 2 \mathrm{H}) ;{ }^{13} \mathrm{C}$ NMR $\left(\mathrm{CDCl}_{3}, 75 \mathrm{MHz}\right) \delta 171.2,161.8,147.5,142.6,141.2,139.8,132.4,129.2,129.1$, 128.2, 128.1, 127.8, 123.6, 118.4, 114.4, 79.8, 65.8; HRMS (ESI+) m/z 476.1625 $\left[(\mathrm{M}+\mathrm{H})^{+}\right.$; calculated mass for $\left.\mathrm{C}_{29} \mathrm{H}_{22} \mathrm{~N}_{3} \mathrm{O}_{4}^{+}: 476.1610 \mathrm{amu}\right]$. 


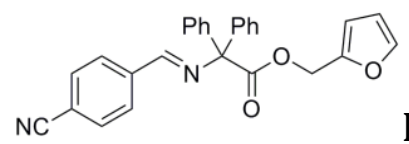

\section{Furan-2-ylmethyl 2-(4-cyanobenzylideneamino)-2,2-}

diphenylacetate (4.1g). White solid (0.321 g, $0.764 \mathrm{mmol}, 52 \%): \mathrm{mp}=128-130$ ${ }^{\circ} \mathrm{C} ; \mathrm{R}_{\mathrm{f}}=0.30$ (10\% EtOAc/Hexanes); IR (NaCl, film) 3059, 2360, 1736, 1226, 700; ${ }^{1} \mathrm{H}$ NMR $\left(\mathrm{CDCl}_{3}, 500 \mathrm{MHz}\right) \delta 7.90(\mathrm{~d}, J=8.4 \mathrm{~Hz}, 2 \mathrm{H}), 7.86(\mathrm{~s}, 1 \mathrm{H}), 7.70(\mathrm{~d}, J=8.3 \mathrm{~Hz}, 2 \mathrm{H})$, $7.38(\mathrm{dd}, J=1.8,0.9 \mathrm{~Hz}, 1 \mathrm{H}), 7.34-7.28(\mathrm{~m}, 10 \mathrm{H}), 6.38-6.34(\mathrm{~m}, 1 \mathrm{H}), 5.19(\mathrm{~s}, 2 \mathrm{H}) ;{ }^{13} \mathrm{C}$ NMR $\left(\mathrm{CDCl}_{3}, 125 \mathrm{MHz}\right) \delta 171.2,161.5,148.9,143.1,141.6,140.0,132.3,129.11$, 129.07, 128.05, 127.9, 127.8, 118.5, 114.2, 111.1, 110.5, 79.6, 59.3; HRMS (ESI+) $\mathrm{m} / \mathrm{z} 421.1540\left[(\mathrm{M}+\mathrm{H})^{+}\right.$; calculated mass for $\left.\mathrm{C}_{27} \mathrm{H}_{21} \mathrm{~N}_{2} \mathrm{O}_{3}{ }^{+}: 421.1552 \mathrm{amu}\right]$.

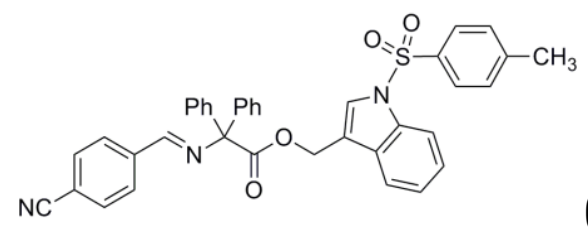

(1-Tosyl-1H-indol-3-yl)methyl-2-(4-

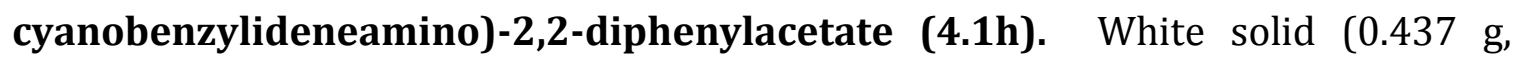
$0.701 \mathrm{mmol}, 83 \%): \mathrm{mp}=173-175{ }^{\circ} \mathrm{C} ; \mathrm{R}_{\mathrm{f}}=0.12(10 \%$ EtOAc $/$ Hexanes $) ; \mathrm{IR}(\mathrm{NaCl}$, film) 3059, 1733, 1174, 701; ${ }^{1} \mathrm{H}$ NMR $\left(\mathrm{CDCl}_{3}, 300 \mathrm{MHz}\right) \delta 7.93(\mathrm{~d}, J=8.3 \mathrm{~Hz}, 1 \mathrm{H})$, 7.79-7.64 (m, 6H), $7.50(\mathrm{~s}, 1 \mathrm{H}), 7.31-7.25(\mathrm{~m}, 12 \mathrm{H}), 7.17(\mathrm{~d}, J=8.4 \mathrm{~Hz}, 2 \mathrm{H}), 7.06(\mathrm{t}, J$ $=7.1 \mathrm{~Hz}, 1 \mathrm{H}), 5.34(\mathrm{~s}, 2 \mathrm{H}), 2.31(\mathrm{~s}, 3 \mathrm{H}) ;{ }^{13} \mathrm{C} \mathrm{NMR}\left(\mathrm{CDCl}_{3}, 125 \mathrm{MHz}\right) \delta 171.4,161.5$, $145.1,141.6,139.8,135.0,132.3,129.9,129.0,128.1,127.8,126.8,125.7,125.0$ 123.3, 119.8, 118.5, 116.7, 114.2, 113.5, 79.7, 59.5, 21.6; HRMS (ESI+) m/z 624.1959 $\left[(\mathrm{M}+\mathrm{H})^{+}\right.$; calculated mass for $\left.\mathrm{C}_{38} \mathrm{H}_{30} \mathrm{~N}_{3} \mathrm{O}_{4} \mathrm{~S}^{+}: 624.1957 \mathrm{amu}\right]$. 


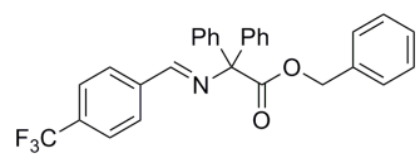

\section{Benzyl 2,2-diphenyl-2-(4-}

(trifluoromethyl)benzylideneamino)acetate (4.1i). White solid (0.915 g, 1.93 mmol, 84\%): $\mathrm{mp}=101-103{ }^{\circ} \mathrm{C} ; \mathrm{R}_{\mathrm{f}}=0.53(10 \%$ EtOAc/Hexanes $) ; \mathrm{IR}(\mathrm{NaCl}$, film $)$ 3062, 1737, 1017, 754; ${ }^{1} \mathrm{H} \mathrm{NMR}\left(\mathrm{CDCl}_{3}, 300 \mathrm{MHz}\right) \delta 7.91$ (d, $\left.J=7.6 \mathrm{~Hz}, 2 \mathrm{H}\right), 7.90$ (s, 1H), $7.67(\mathrm{~d}, J=8.2 \mathrm{~Hz}, 2 \mathrm{H}), 7.38-7.17(\mathrm{~m}, 15 \mathrm{H}), 5.24(\mathrm{~s}, 2 \mathrm{H}) ;{ }^{13} \mathrm{C} \mathrm{NMR}\left(\mathrm{CDCl}_{3}, 75\right.$ MHz) $\delta 171.5,161.9,141.9,139.3,135.4,132.8,132.6\left(q, J_{C-F}=32.2 \mathrm{~Hz}\right), 129.2$, $128.9,128.4,128.1,128.0,127.9,127.7,125.5,125.4,123.9\left(\mathrm{q}, J_{C-F}=247.7 \mathrm{~Hz}\right)$, 122.1, 79.6, 67.4; ${ }^{19} \mathrm{~F}$ NMR ( $\left.\mathrm{CDCl}_{3}, 282 \mathrm{MHz}\right) \delta$-63.5; HRMS (ESI+) m/z 474.1672 $\left[(\mathrm{M}+\mathrm{H})^{+}\right.$; calculated mass for $\left.\mathrm{C}_{29} \mathrm{H}_{23} \mathrm{~F}_{3} \mathrm{NO}_{2}+474.1669 \mathrm{amu}\right]$.

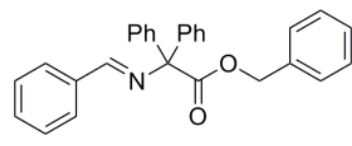

\section{Benzyl 2-(benzylideneamino)-2,2-diphenylacetate (4.1j).}

White solid (0.418 g, $1.03 \mathrm{mmol}, 92 \%): \mathrm{mp}=83-84{ }^{\circ} \mathrm{C} ; \mathrm{R}_{\mathrm{f}}=0.56(10 \%$ EtOAc/Hexanes); IR (NaCl, film) 3061, 1735, 1492, 755, 695; ${ }^{1} \mathrm{H}$ NMR $\left(\mathrm{CDCl}_{3}, 500\right.$ MHz) $\delta 7.90(\mathrm{~s}, 1 \mathrm{H}), 7.82(\mathrm{dd}, J=7.8,1.8 \mathrm{~Hz}, 2 \mathrm{H}), 7.47-7.20(\mathrm{~m}, 18 \mathrm{H}), 5.26(\mathrm{~s}, 2 \mathrm{H})$; ${ }^{13} \mathrm{C}$ NMR $\left(\mathrm{CDCl}_{3}, 125 \mathrm{MHz}\right) \delta 171.9,163.9,142.3,136.3,135.6,131.1,129.2,128.7$, 128.5, 128.3, 128.0, 127.9, 127.8, 127.5, 79.4, 67.2; HRMS (ESI+) m/z 406.1801 $\left[(\mathrm{M}+\mathrm{H})^{+}\right.$; calculated mass for $\left.\mathrm{C}_{28} \mathrm{H}_{24} \mathrm{NO}_{2}{ }^{+}: 406.1807 \mathrm{amu}\right]$. 


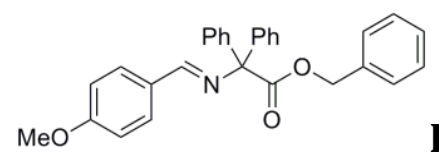

\section{Benzyl 2-(4-methoxybenzylideneamino)-2,2-}

diphenylacetate (4.1k). White solid $(0.441 \mathrm{~g}, 1.01 \mathrm{mmol}, 92 \%): \mathrm{mp}=92-94{ }^{\circ} \mathrm{C} ; \mathrm{R}_{\mathrm{f}}$ $=0.36$ (10\% EtOAc/Hexanes); IR (NaCl, film) 3032, 2837, 1735, 1308, 699; ${ }^{1} \mathrm{H}$ NMR $\left(\mathrm{CDCl}_{3}, 500 \mathrm{MHz}\right) \delta 7.84(\mathrm{~s}, 1 \mathrm{H}), 7.76(\mathrm{~d}, J=8.8 \mathrm{~Hz}, 2 \mathrm{H}), 7.40-7.20(\mathrm{~m}, 15 \mathrm{H}), 6.93(\mathrm{~d}, J$ $=8.8 \mathrm{~Hz}, 2 \mathrm{H}), 5.25(\mathrm{~s}, 2 \mathrm{H}), 3.85(\mathrm{~s}, 3 \mathrm{H}) ;{ }^{13} \mathrm{C} \mathrm{NMR}\left(\mathrm{CDCl}_{3}, 125 \mathrm{MHz}\right) \delta 172.1,162.5$, $161.9,142.5,135.6,130.3,129.4,129.2,128.3,128.0,127.9,127.8,127.4,113.8$ 79.2, 67.2, 55.4; HRMS (ESI+) $\mathrm{m} / \mathrm{z} 436.1912\left[(\mathrm{M}+\mathrm{H})^{+}\right.$; calculated mass for $\left.\mathrm{C}_{29} \mathrm{H}_{26} \mathrm{NO}_{3}{ }^{+}: 436.1913 \mathrm{amu}\right]$.

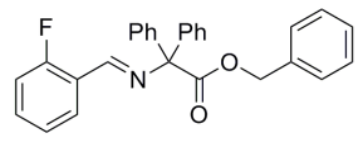

\section{Benzyl 2-(2-fluorobenzylideneamino)-2,2-diphenylacetate}

(4.11). Crude product needed no further purification. Reaction residue concentrated in vacuo. Off-white solid (0.494 g, $1.17 \mathrm{mmol}, 100 \%): \mathrm{mp}=75-78{ }^{\circ} \mathrm{C}$; $\mathrm{R}_{\mathrm{f}}=0.51$ (10\% EtOAc/Hexanes); IR (NaCl, film) 3063, 1737, 1216, 1028, 698; ${ }^{1} \mathrm{H}$ $\mathrm{NMR}\left(\mathrm{CDCl}_{3}, 500 \mathrm{MHz}\right) \delta 8.27(\mathrm{dt}, J=7.6,1.8 \mathrm{~Hz}, 1 \mathrm{H}), 8.24(\mathrm{~s}, 1 \mathrm{H}), 7.44-7.19(\mathrm{~m}, 17$ H), $7.04(\mathrm{ddd}, J=10.4,8.3,1.0 \mathrm{~Hz}, 1 \mathrm{H}), 5.26(\mathrm{~s}, 2 \mathrm{H}) ;{ }^{13} \mathrm{C} \mathrm{NMR}\left(\mathrm{CDCl}_{3}, 125 \mathrm{MHz}\right)$ $\delta 171.7,162.5\left(\mathrm{~d}, J_{C-F}=253.0 \mathrm{~Hz}\right), 156.90,156.86,142.1,135.5,132.7\left(\mathrm{~d}, J_{C-F}=8.4\right.$ $\mathrm{Hz}), 129.3,128.4,128.0,127.8,127.7,124.3,115.7\left(\mathrm{~d}, J_{C-F}=20.7 \mathrm{~Hz}\right), 79.8,67.4 ;{ }^{19} \mathrm{~F}$ NMR ( $\left.\mathrm{CDCl}_{3}, 282 \mathrm{MHz}\right) \delta$-122.0; HRMS (ESI+) m/z 424.1703 [(M+H)+; calculated mass for $\left.\mathrm{C}_{28} \mathrm{H}_{23} \mathrm{FNO}_{2}{ }^{+}: 424.1713 \mathrm{amu}\right]$. 


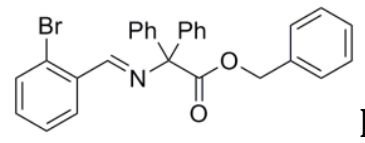

\section{Benzyl 2-(2-bromobenzylideneamino)-2,2-diphenylacetate}

(4.1m). Crude product purified using flash column chromatography (10-15\% EtOAc/hexanes). Yellow solid (0.726 g, $1.50 \mathrm{mmol}, 99 \%): \mathrm{mp}=54-58^{\circ} \mathrm{C} ; \mathrm{R}_{\mathrm{f}}=0.53$ (10\% EtOAc/Hexanes); IR (NaCl, film) 3060, 1736, 1167, 701; ${ }^{1} \mathrm{H}$ NMR $\left(\mathrm{CDCl}_{3}, 500\right.$ MHz) $\delta 8.30(\mathrm{~s}, 1 \mathrm{H}), 8.28(\mathrm{dd}, J=7.8,1.8 \mathrm{~Hz}, 1 \mathrm{H}), 7.53(\mathrm{dd}, J=8.0,1.2 \mathrm{~Hz}, 1 \mathrm{H}), 7.41-$ $7.21(\mathrm{~m}, 17 \mathrm{H}), 5.28(\mathrm{~s}, 2 \mathrm{H}) ;{ }^{13} \mathrm{C} \mathrm{NMR}\left(\mathrm{CDCl}_{3}, 125 \mathrm{MHz}\right) \delta$ 171.7, 162.8, 141.9, 135.5, 134.8, 132.9, 132.1, 129.2, 129.1, 128.3, 128.0, 127.8, 127.6, 127.5, 125.8, 79.8, 67.4; HRMS (ESI+) m/z $484.0905\left[(\mathrm{M}+\mathrm{H})^{+}\right.$; calculated mass for $\mathrm{C}_{28} \mathrm{H}_{23} \mathrm{NO}_{2}{ }^{+}: 484.0912$ $\mathrm{amu}]$.

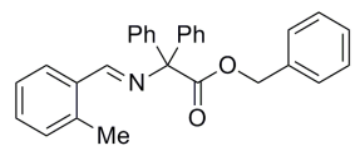

\section{Benzyl 2-(2-methylbenzylideneamino)-2,2-diphenylacetate}

(4.1n). Crude product purified using flash column chromatography $(0-15 \%$ EtOAc/hexanes) followed by additional purification using radial chromatography (1-10\% Et0Ac/hexanes). Yellow solid (0.726 g, $1.73 \mathrm{mmol}, 100 \%): \mathrm{mp}=44-48{ }^{\circ} \mathrm{C}$; $\mathrm{R}_{\mathrm{f}}=0.59$ (10\% EtOAc/Hexanes); IR (NaCl, film) 3060, 1736, 1167, 701; ${ }^{1} \mathrm{H}$ NMR $\left(\mathrm{CDCl}_{3}, 500 \mathrm{MHz}\right) \delta 8.23(\mathrm{~s}, 1 \mathrm{H}), 8.04(\mathrm{~d}, J=7.6 \mathrm{~Hz}, 1 \mathrm{H}), 7.43-7.22(\mathrm{~m}, 17 \mathrm{H}), 7.17(\mathrm{~d}, J$ $=7.4 \mathrm{~Hz}, 1 \mathrm{H}), 5.27(\mathrm{~s}, 2 \mathrm{H}), 2.30(\mathrm{~s}, 3 \mathrm{H}) ;{ }^{13} \mathrm{C} \mathrm{NMR}\left(\mathrm{CDCl}_{3}, 125 \mathrm{MHz}\right) \delta 171.9,162.7$, $142.5,138.2,135.5,134.3,130.7,130.5,129.2,128.3,128.1,128.0,127.9,127.8$ 127.5, 126.1, 79.9, 67.3, 19.3; HRMS (ESI+) m/z 420.1960 [(M+H)+; calculated mass for $\left.\mathrm{C}_{29} \mathrm{H}_{26} \mathrm{NO}_{2}+420.1964 \mathrm{amu}\right]$. 


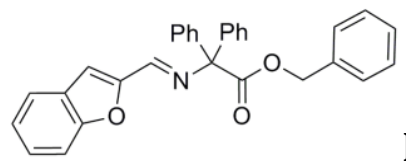

\section{Benzyl 2-(benzofuran-2-ylmethyleneamino)-2,2-}

diphenylacetate (4.10). White solid (0.813 g, $1.83 \mathrm{mmol}, 92 \%)$ : $\mathrm{mp}=134-136{ }^{\circ} \mathrm{C}$; $\mathrm{R}_{\mathrm{f}}=0.44$ (10\% EtOAc/Hexanes); IR (NaCl, film) 3061, 1735, 1198, 699; ${ }^{1} \mathrm{H}$ NMR $\left(\mathrm{CDCl}_{3}, 500 \mathrm{MHz}\right) \delta 7.79(\mathrm{~s}, 1 \mathrm{H}), 7.62-7.59(\mathrm{~m}, 2 \mathrm{H}), 7.41-7.20(\mathrm{~m}, 17 \mathrm{H}), 7.08(\mathrm{~d}, J=$ $0.9 \mathrm{~Hz}, 1 \mathrm{H}), 5.26(\mathrm{~s}, 2 \mathrm{H}) ;{ }^{13} \mathrm{C} \mathrm{NMR}\left(\mathrm{CDCl}_{3}, 125 \mathrm{MHz}\right) \delta 171.5,155.7,152.8,141.5$, 135.5, 129.4, 128.4, 128.1, 128.0, 127.75, 127.70, 126.7, 123.3, 122.1, 112.4, 112.2, 79.9, 67.5; HRMS (ESI+) m/z $446.1768\left[(\mathrm{M}+\mathrm{H})^{+}\right.$; calculated mass for $\mathrm{C}_{30} \mathrm{H}_{24} \mathrm{NO}_{3}{ }^{+}$: $446.1756 \mathrm{amu}]$.

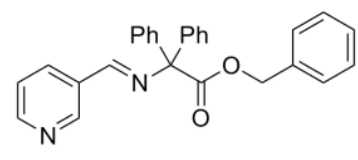

\section{Benzyl 2,2-diphenyl-2-(pyridin-3-}

ylmethyleneamino)acetate (4.1p). White solid $(0.570 \mathrm{~g}, 1.40 \mathrm{mmol}, 83 \%): \mathrm{mp}=$ $88-90{ }^{\circ} \mathrm{C} ; \mathrm{R}_{\mathrm{f}}=0.07$ (10\% EtOAc/Hexanes); IR (NaCl, film) 3032, 1736, 1196, 698; ${ }^{1} \mathrm{H}$ $\operatorname{NMR}\left(\mathrm{CDCl}_{3}, 500 \mathrm{MHz}\right) \delta 8.83(\mathrm{~d}, J=2.0 \mathrm{~Hz}, 1 \mathrm{H}), 8.67(\mathrm{dd}, J=4.8,1.7 \mathrm{~Hz}, 1 \mathrm{H}), 8.26$ (td, $J=7.9,1.9 \mathrm{~Hz}, 1 \mathrm{H}), 7.91(\mathrm{~s}, 1 \mathrm{H}), 7.38-7.18(\mathrm{~m}, 16 \mathrm{H}), 5.25(\mathrm{~s}, 2 \mathrm{H}) ;{ }^{13} \mathrm{C}$ NMR $\left(\mathrm{CDCl}_{3}, 125 \mathrm{MHz}\right) \delta 171.5,160.7,151.9,150.7,141.9,135.4,134.9,131.8,129.2$, 128.4, 128.1, 128.0, 127.9, 127.7, 123.6, 79.6, 67.4; HRMS (ESI+) m/z 407.1747 $\left[(\mathrm{M}+\mathrm{H})^{+}\right.$; calculated mass for $\left.\mathrm{C}_{27} \mathrm{H}_{23} \mathrm{~N}_{2} \mathrm{O}_{2}+407.1760 \mathrm{amu}\right]$. 


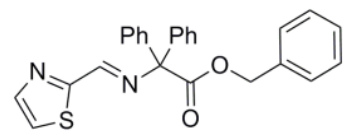

\section{Benzyl 2,2-diphenyl-2-(thiazol-2-ylmethyleneamino)acetate}

(4.1q). Crude product needed no further purification. Reaction residue concentrated in vacuo. Orange solid (0.454 g, $1.10 \mathrm{mmol}, 100 \%): \mathrm{mp}=57-60^{\circ} \mathrm{C} ; \mathrm{R}_{\mathrm{f}}$ $=0.65$ (10\% EtOAc/Hexanes); IR (NaCl, film) 3033, 1736, 1322, 1217, 698; ${ }^{1} \mathrm{H}$ NMR $\left(\mathrm{CDCl}_{3}, 500 \mathrm{MHz}\right) \delta 8.02(\mathrm{~s}, 1 \mathrm{H}), 7.91(\mathrm{~d}, J=3.2 \mathrm{~Hz}, 1 \mathrm{H}), 7.46(\mathrm{~d}, J=3.1 \mathrm{~Hz}, 1 \mathrm{H}), 7.37-$ $7.28(\mathrm{~m}, 13 \mathrm{H}), 7.23-7.20(\mathrm{~m}, 2 \mathrm{H}), 5.26(\mathrm{~s}, 2 \mathrm{H}) ;{ }^{13} \mathrm{C} \mathrm{NMR}\left(\mathrm{CDCl}_{3}, 125 \mathrm{MHz}\right) \delta$ 171.0, 167.6, 157.1, 144.2, 141.1, 135.3, 129.2, 128.3, 128.1, 128.06, 127.9, 127.8, 122.2, 79.7, 67.5; HRMS (ESI+) m/z $413.1329\left[(\mathrm{M}+\mathrm{H})^{+}\right.$; calculated mass for $\mathrm{C}_{25} \mathrm{H}_{21} \mathrm{~N}_{2} \mathrm{O}_{2} \mathrm{~S}^{+}$: $413.1324 \mathrm{amu}]$.

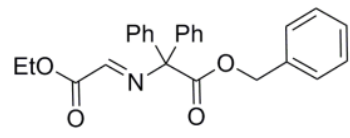

\section{Benzyl 2-(2-ethoxy-2-oxoethylideneamino)-2,2-}

diphenylacetate (4.1r). To flask equipped with a Dean-Starke trap was added benzyl diphenylglycinate (6b, 1 equiv.) dissolved in $\mathrm{PhCH}_{3}(0.1 \mathrm{M})$ and a $0.1 \mathrm{M}$ solution of ethyl glyoxylate in $\mathrm{PhCH}_{3}$ (5.0 equiv.). The reaction mixture was heated to reflux and stirred at that temperature overnight until completion, as determined by ${ }^{1} \mathrm{H}$ NMR analysis of reaction aliquots. The solvent was removed in vacuo and the residue was purified by flash column chromatography (15\% Et0Ac/hexanes) to afford a clear colorless oil $(0.592 \mathrm{~g}, 1.48 \mathrm{mmol}, 91 \%): \mathrm{R}_{\mathrm{f}}=0.26(10 \%$ EtOAc/Hexanes); IR (NaCl, film) 3061, 1739, 698; ${ }^{1} \mathrm{H} \mathrm{NMR}\left(\mathrm{CDCl}_{3}, 300 \mathrm{MHz}\right) \delta 7.40-$ $7.19(\mathrm{~m}, 15 \mathrm{H}), 5.25(\mathrm{~s}, 2 \mathrm{H}), 4.35(\mathrm{q}, J=7.1 \mathrm{~Hz}, 2 \mathrm{H}), 1.36(\mathrm{t}, J=7.1 \mathrm{~Hz}, 3 \mathrm{H}) ;{ }^{13} \mathrm{C} \mathrm{NMR}$ 
$\left(\mathrm{CDCl}_{3}, 125 \mathrm{MHz}\right) \delta 170.3,163.3,156.1,140.3,135.2,129.2,128.4,128.2,128.1$, 128.0, 127.6, 127.5, 80.2, 67.7, 61.9, 14.1; HRMS (ESI+) m/z 402.1696 [(M+H)+; calculated mass for $\left.\mathrm{C}_{25} \mathrm{H}_{24} \mathrm{NO}_{4}+: 402.1705 \mathrm{amu}\right]$.

General procedure for palladium-catalyzed decarboxylative benzylation reaction.

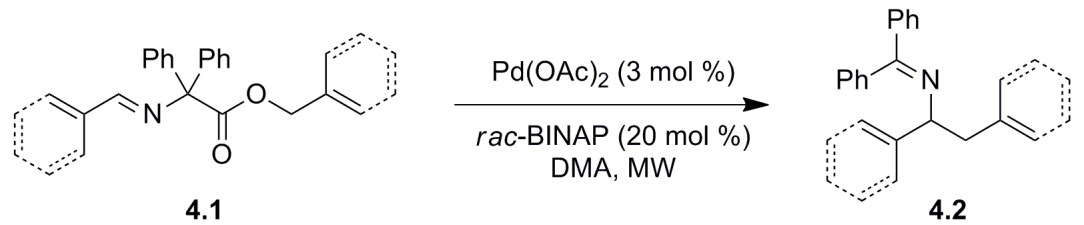

An oven-dried CEM Intellivent microwave tube capped with an Intellivent Teflon cap was charged with 4.1 (1.0 equiv.), $\mathrm{Pd}(\mathrm{OAc})_{2}$ (0.03 equiv.), and rac-BINAP (0.20 equiv.) in DMA (0.1 M). The reaction mixture was deoxygenated by subjection to three consecutive freeze-pump-thaw cycles followed by addition of nitrogen. The reaction mixture was then subjected to microwave irradiation $(300 \mathrm{~W})$ for the specified time and temperature using a CEM Explorer-Discover microwave reactor. Reaction temperature and temperature-time profile were monitored using the ChemDriver Explorer Application program. Upon completion, the reaction was purified by means of flash chromatography or filtration through a short silica gel plug followed by radial chromatography to afford the desired product 4.2. 


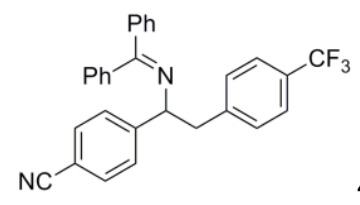

\section{4-(1-(Diphenylmethyleneamino)-2-(4}

(trifluoromethyl)phenyl)ethyl)benzonitrile (4.2a). Reaction temperature, time: $150{ }^{\circ} \mathrm{C}, 5 \mathrm{~min}$. Yellow solid (52.9 mg, $\left.0.116 \mathrm{mmol}, 74 \%\right): \mathrm{mp}=144-146^{\circ} \mathrm{C} ; \mathrm{R}_{\mathrm{f}}=0.40$

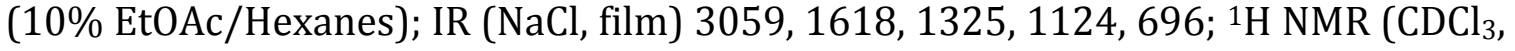
$500 \mathrm{MHz}) \delta 7.61(\mathrm{t}, J=8.0 \mathrm{~Hz}, 4 \mathrm{H}), 7.47-7.28(\mathrm{~m}, 10 \mathrm{H}), 7.07(\mathrm{~d}, J=8.0 \mathrm{~Hz}, 2 \mathrm{H}), 6.51$ (d, $J=6.9 \mathrm{~Hz}, 2 \mathrm{H}), 4.59$ (dd, $J=8.7,4.5 \mathrm{~Hz}, 1 \mathrm{H}), 3.23(\mathrm{dd}, J=13.1,8.7 \mathrm{~Hz}, 1 \mathrm{H}), 3.07$ (dd, $J=13.1,4.5 \mathrm{~Hz}, 1 \mathrm{H}) ;{ }^{13} \mathrm{C} \mathrm{NMR}\left(\mathrm{CDCl}_{3}, 125 \mathrm{MHz}\right) \delta 168.3,149.3,142.4,139.1$, $136.1,132.3,130.4,130.1,129.0$ (q, $\left.J_{C-F}=31.6 \mathrm{~Hz}\right), 128.5,128.46,128.3,128.1$, $127.9,127.1,126.4\left(\mathrm{q}, J_{C-F}=272.2 \mathrm{~Hz}\right), 125.04,125.01,118.9,110.9,67.8,45.7 ;{ }^{19} \mathrm{~F}$ NMR $\left(\mathrm{CDCl}_{3}, 282 \mathrm{MHz}\right) \delta$-63.1; HRMS (ESI+) m/z 455.1717 [(M+H)+; calculated mass for $\left.\mathrm{C}_{29} \mathrm{H}_{22} \mathrm{~F}_{3} \mathrm{~N}_{2}+: 455.1735 \mathrm{amu}\right]$.

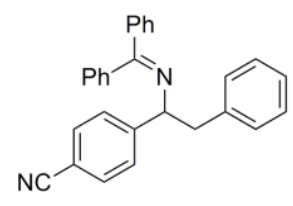

\section{4-(1-(Diphenylmethyleneamino)-2-phenylethyl)benzonitrile}

(4.2b). Reaction temperature, time: $175^{\circ} \mathrm{C}, 5 \mathrm{~min}$. Yellow solid $(71.9 \mathrm{mg}, 0.186$ mmol, 81\%): $\mathrm{mp}=42-46^{\circ} \mathrm{C} ; \mathrm{R}_{\mathrm{f}}=0.43(10 \% \mathrm{EtOAc} /$ Hexanes); IR (NaCl, film) 3060, 2919, 1624, 1001, 697; ${ }^{1} \mathrm{H}$ NMR $\left(\mathrm{CDCl}_{3}, 500 \mathrm{MHz}\right) \delta$ 7.67-7.65 (m, 2H), $7.60(\mathrm{~d}, J=$ $8.2 \mathrm{~Hz}, 2 \mathrm{H}), 7.48(\mathrm{~d}, J=8.4 \mathrm{~Hz}, 2 \mathrm{H}), 7.42-7.30(\mathrm{~m}, 6 \mathrm{H}), 7.21-7.19(\mathrm{~m}, 3 \mathrm{H}), 6.97$ (dd, $J$ $=6.6,2.7 \mathrm{~Hz}, 2 \mathrm{H}), 6.55(\mathrm{~d}, J=6.8 \mathrm{~Hz}, 2 \mathrm{H}), 4.60(\mathrm{dd}, J=8.6,4.8 \mathrm{~Hz}, 1 \mathrm{H}), 3.21(\mathrm{dd}, J=$ 13.1, $8.6 \mathrm{~Hz}, 1 \mathrm{H}), 3.05(\mathrm{dd}, J=13.1,4.8 \mathrm{~Hz}, 1 \mathrm{H}) ;{ }^{13} \mathrm{C} \mathrm{NMR}\left(\mathrm{CDCl}_{3}, 125 \mathrm{MHz}\right) \delta 167.8$, 
149.7, 139.3, 138.1, 136.4, 132.1, 130.1, 129.8, 128.5, 128.2, 128.17, 128.1, 128.0, 127.9, 127.2, 126.2, 119.0, 110.5, 68.2, 45.9; HRMS (ESI+) m/z 387.1855 [(M+H)+; calculated mass for $\left.\mathrm{C}_{28} \mathrm{H}_{23} \mathrm{~N}_{2}+387.1861 \mathrm{amu}\right]$.

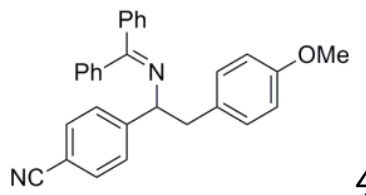

4-(1-(Diphenylmethyleneamino)-2-(4-

methoxyphenyl)ethyl)benzonitrile (4.2c). Reaction temperature, time: $150{ }^{\circ} \mathrm{C}, 5$ min. Off-white oil (78.8 mg, $0.189 \mathrm{mmol}, 85 \%): \mathrm{R}_{\mathrm{f}}=0.33$ (10\% EtOAc/Hexanes); IR $\left(\mathrm{NaCl}\right.$, film) 3058, 2915, 1445, 1177, 1035; ${ }^{1} \mathrm{H} \mathrm{NMR}\left(\mathrm{CDCl}_{3}, 300 \mathrm{MHz}\right) \delta 7.67$ (dd, $J=$ 8.1, 1.6 Hz, 2H), $7.59(\mathrm{~d}, J=8.3 \mathrm{~Hz}, 2 \mathrm{H}), 7.47-7.31(\mathrm{~m}, 8 \mathrm{H}), 6.88(\mathrm{~d}, J=8.7 \mathrm{~Hz}, 2 \mathrm{H})$, $6.74(\mathrm{~d}, J=8.7 \mathrm{~Hz}, 2 \mathrm{H}), 6.63(\mathrm{~d}, J=6.5 \mathrm{~Hz}, 2 \mathrm{H}), 4.57(\mathrm{dd}, J=8.2,5.1 \mathrm{~Hz}, 1 \mathrm{H}), 3.78(\mathrm{~s}$, 3H), $3.15(\mathrm{dd}, J=13.2,8.3 \mathrm{~Hz}, 1 \mathrm{H}), 2.99(\mathrm{dd}, J=13.2,5.1 \mathrm{~Hz}, 1 \mathrm{H}) ;{ }^{13} \mathrm{C} \mathrm{NMR}\left(\mathrm{CDCl}_{3}, 75\right.$ MHz) $\delta 167.7,158.1,149.8,139.3,136.4,132.1,130.6,130.2,130.1,128.4,128.2$, 128.0, 127.9, 127.2, 119.0, 113.4, 110.4, 68.3, 55.1, 45.0; HRMS (ESI+) m/z 417.1970 [(M+H)+; calculated mass for $\left.\mathrm{C}_{29} \mathrm{H}_{25} \mathrm{~N}_{2} \mathrm{O}^{+}: 417.1967 \mathrm{amu}\right]$.

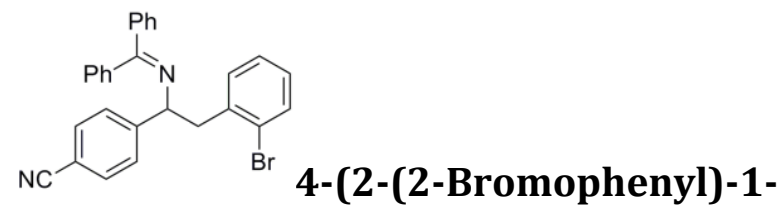

(diphenylmethyleneamino)ethyl)benzonitrile (4.2d).

Reaction temperature, time: $210{ }^{\circ} \mathrm{C}, 15 \mathrm{~min}$. Clear colorless oil $(44.4 \mathrm{mg}, 0.095$ mmol, 48\%): $\mathrm{R}_{\mathrm{f}}=0.44$ (10\% EtOAc/Hexanes); IR (NaCl, film) 3057, 2927, 1624, 
1287,$1028 ;{ }^{1} \mathrm{H} \mathrm{NMR}\left(\mathrm{CDCl}_{3}, 500 \mathrm{MHz}\right) \delta 7.66(\mathrm{dd}, J=8.4,1.4 \mathrm{~Hz}, 2 \mathrm{H}), 7.61(\mathrm{~d}, J=8.4$ $\mathrm{Hz}, 2 \mathrm{H}$ ), 7.55 (d, $J=8.2 \mathrm{~Hz}, 2 \mathrm{H}$ ), 7.45 (d, $J=8.0 \mathrm{~Hz}, 1 \mathrm{H}$ ), 7.42-7.26 (m, 7H), 7.10 (ddd, $J=30.9,12.1,8.1 \mathrm{~Hz}, 3 \mathrm{H}), 6.44(\mathrm{~d}, J=5.2 \mathrm{~Hz}, 2 \mathrm{H}), 4.83(\mathrm{dd}, J=8.7,4.6 \mathrm{~Hz}, 1 \mathrm{H}), 3.27$ (dd, $J=13.1,4.6 \mathrm{~Hz}, 1 \mathrm{H}), 3.22(\mathrm{dd}, J=13.1,8.8 \mathrm{~Hz}, 1 \mathrm{H}) ;{ }^{13} \mathrm{C} \mathrm{NMR}\left(\mathrm{CDCl}_{3}, 125 \mathrm{MHz}\right)$ $\delta 168.5,149.7,139.2,137.5,136.2,132.6,132.2,130.2,128.5,128.2,128.18,128.1$, 128.0, 127.7, 127.1, 127.0, 125.2, 119.1, 110.5, 65.0, 45.8; HRMS (ESI+) m/z 465.0963 [(M+H)+; calculated mass for $\left.\mathrm{C}_{28} \mathrm{H}_{22} \mathrm{BrN}_{2}+465.0966 \mathrm{amu}\right]$.

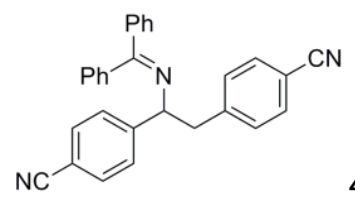

\section{4,4'-(1-(Diphenylmethyleneamino)ethane-1,2-}

diyl)dibenzonitrile (4.2e). Reaction temperature, time: $175^{\circ} \mathrm{C}, 5 \mathrm{~min}$. White solid (43.3 mg, $0.105 \mathrm{mmol}, 46 \%): \mathrm{mp}=62-64{ }^{\circ} \mathrm{C} ; \mathrm{R}_{\mathrm{f}}=0.17$ (10\% EtOAc $/$ Hexanes); IR

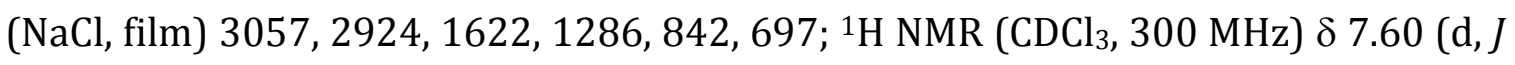
$=8.4 \mathrm{~Hz}, 4 \mathrm{H}), 7.50-7.30(\mathrm{~m}, 10 \mathrm{H}), 7.08(\mathrm{~d}, J=8.1 \mathrm{~Hz}, 2 \mathrm{H}), 6.54(\mathrm{~d}, J=6.9 \mathrm{~Hz}, 2 \mathrm{H})$, $4.59(\mathrm{dd}, J=8.6,4.5 \mathrm{~Hz}, 1 \mathrm{H}), 3.25(\mathrm{dd}, J=13.0,8.7 \mathrm{~Hz}, 1 \mathrm{H}), 3.07$ (dd, $J=13.0,4.5 \mathrm{~Hz}$, 1H); ${ }^{13} \mathrm{C} \mathrm{NMR}\left(\mathrm{CDCl}_{3}, 125 \mathrm{MHz}\right) \delta 168.6,149.0,144.0,138.9,136.1,132.4,131.9$, 130.6, 128.6, 128.5, 128.4, 128.2. 127.8, 127.1, 118.90, 118.87, 111.0, 110.2, 67.4, 46.0; HRMS (ESI+) m/z 412.1816 [(M+H)+; calculated mass for $\mathrm{C}_{29} \mathrm{H}_{22} \mathrm{~N}_{3}+$ : $412.1814 \mathrm{amu}]$. 


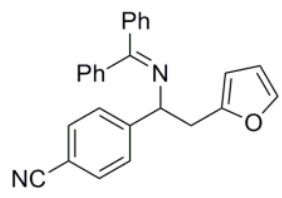

\section{4-(1-(Diphenylmethyleneamino)-2-(furan-2-}

yl)ethyl)benzonitrile (4.2g). Reaction temperature, time: $175^{\circ} \mathrm{C}, 5 \mathrm{~min}$. Yellow oil (39.9 mg, 0.106 mmol, 43\%): $\mathrm{R}_{\mathrm{f}}=0.43$ (10\% EtOAc/Hexanes); IR (NaCl, film) 3057, $1623,1290,837,697 ;{ }^{1} \mathrm{H} \mathrm{NMR}\left(\mathrm{CDCl}_{3}, 500 \mathrm{MHz}\right) \delta 7.65-7.63(\mathrm{~m}, 2 \mathrm{H}), 7.59(\mathrm{~d}, J=8.3$ $\mathrm{Hz}, 2 \mathrm{H}), 7.45(\mathrm{~d}, J=8.2 \mathrm{~Hz}, 2 \mathrm{H}), 7.42-7.32(\mathrm{~m}, 6 \mathrm{H}), 7.24(\mathrm{dd}, J=1.8,0.8 \mathrm{~Hz}, 1 \mathrm{H}), 6.74$ (dd, $J=8.0,1.3 \mathrm{~Hz}, 2 \mathrm{H}), 6.23(\mathrm{dd}, J=3.1,1.9 \mathrm{~Hz}, 1 \mathrm{H}), 5.92(\mathrm{~d}, J=3.1 \mathrm{~Hz}, 1 \mathrm{H}), 4.72(\mathrm{dd}$, $J=8.6,4.8 \mathrm{~Hz}, 1 \mathrm{H}), 3.23(\mathrm{dd}, J=14.6,8.6 \mathrm{~Hz}, 1 \mathrm{H}), 3.07(\mathrm{dd}, J=14.6,4.8 \mathrm{~Hz}, 1 \mathrm{H}) ;{ }^{13} \mathrm{C}$ NMR $\left(\mathrm{CDCl}_{3}, 125 \mathrm{MHz}\right) \delta 168.4,152.1,149.4,141.1,139.4,136.3,132.2,130.2$, 128.6, 128.5, 128.3, 128.0, 127.8, 127.3, 119.0, 110.7, 110.4, 107.5, 65.4, 37.9; HRMS (ESI+) m/z $377.1648\left[(\mathrm{M}+\mathrm{H})^{+}\right.$; calculated mass for $\mathrm{C}_{26} \mathrm{H}_{21} \mathrm{~N}_{2} \mathrm{O}^{+}$: $\left.377.1654 \mathrm{amu}\right]$.

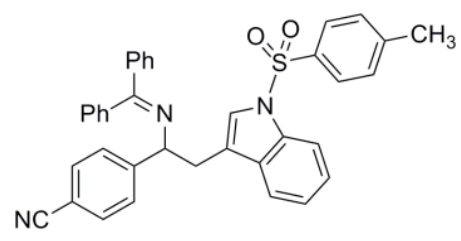

\section{4-(1-(Diphenylmethyleneamino)-2-(1-tosyl-1H-indol-}

3-yl)ethyl)benzonitrile (4.2h). Reaction temperature, time: $210{ }^{\circ} \mathrm{C}, 5 \mathrm{~min}$. Pale yellow solid (58.0 mg, $0.100 \mathrm{mmol}, 60 \%): \mathrm{mp}=158-160{ }^{\circ} \mathrm{C} ; \mathrm{R}_{\mathrm{f}}=0.16(10 \%$ EtOAc/Hexanes); IR (NaCl, film) 3055, 1607, 1446, 1173, 700; ${ }^{1} \mathrm{H}$ NMR $\left(\mathrm{CDCl}_{3}, 500\right.$ MHz) $\delta 7.96(\mathrm{~d}, J=8.33 \mathrm{~Hz}, 1 \mathrm{H}), 7.61-7.56(\mathrm{~m}, 4 \mathrm{H}), 7.51(\mathrm{~d}, J=8.4 \mathrm{~Hz}, 2 \mathrm{H}), 7.46-7.35$ (m, 5H), 7.28-7.23 (m, 1-3H, overlap with solvent peak), $7.15(\mathrm{~s}, 1 \mathrm{H}), 7.07-6.98(\mathrm{~m}$, $4 \mathrm{H}), 6.91(\mathrm{~d}, J=8.0 \mathrm{~Hz}, 2 \mathrm{H}), 6.27(\mathrm{~s}, 2 \mathrm{H}), 4.69(\mathrm{dd}, J=8.3,5.1 \mathrm{~Hz}, 1 \mathrm{H}), 3.19$ (dd, $J=$ 
14.1, 8.4 Hz, 1H), $3.06(\mathrm{dd}, J=14.9,5.1 \mathrm{~Hz}, 1 \mathrm{H}) ;{ }^{13} \mathrm{C} \mathrm{NMR}\left(\mathrm{CDCl}_{3}, 125 \mathrm{MHz}\right) \delta 168.2$, 149.5, 144.7, 139.2, 135.7, 135.0, 134.8, 132.1, 130.7, 130.4, 129.6, 128.5, 128.1, $128.06,127.8,126.9,126.5,124.5,124.1,122.9,119.2,118.9,118.8,113.5,110.6$ 65.3, 35.0, 21.4; HRMS (ESI+) $\mathrm{m} / \mathrm{z} 580.2056\left[(\mathrm{M}+\mathrm{H})^{+}\right.$; calculated mass for $\left.\mathrm{C}_{37} \mathrm{H}_{30} \mathrm{~N}_{3} \mathrm{O}_{2} \mathrm{~S}^{+}: 580.2059 \mathrm{amu}\right]$.

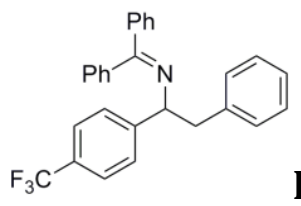

Diphenylmethylene-2-phenyl-1-(4-

(trifluoromethyl)phenyl)ethanamine (4.2i). Reaction temperature, time: $175{ }^{\circ} \mathrm{C}$, 5 min. Yellow oil (67.2 mg, $0.156 \mathrm{mmol}, 73 \%): \mathrm{R}_{\mathrm{f}}=0.73$ (10\% EtOAc/Hexanes); IR $\left(\mathrm{NaCl}\right.$, film) $3061,1618,1325,1124,697 ;{ }^{1} \mathrm{H} \mathrm{NMR}\left(\mathrm{CDCl}_{3}, 500 \mathrm{MHz}\right) \delta 7.68(\mathrm{~d}, J=8.1$ $\mathrm{Hz}, 2 \mathrm{H}), 7.61(\mathrm{~d}, J=8.1 \mathrm{~Hz}, 2 \mathrm{H}), 7.53(\mathrm{~d}, J=8.1 \mathrm{~Hz}, 2 \mathrm{H}), 7.43-7.31(\mathrm{~m}, 6 \mathrm{H}), 7.24-7.21$ $(\mathrm{m}, 3 \mathrm{H}), 7.04(\mathrm{~d}, J=5.5 \mathrm{~Hz}, 2 \mathrm{H}), 6.56(\mathrm{~d}, J=6.1 \mathrm{~Hz}, 2 \mathrm{H}), 4.64(\mathrm{dd}, J=8.8,4.5 \mathrm{~Hz}, 1 \mathrm{H})$, $3.28(\mathrm{dd}, J=13.0,8.9 \mathrm{~Hz}, 1 \mathrm{H}), 3.10(\mathrm{dd}, J=13.1,4.5 \mathrm{~Hz}, 1 \mathrm{H}) ;{ }^{13} \mathrm{C} \mathrm{NMR}\left(\mathrm{CDCl}_{3}, 125\right.$ MHz) $\delta 167.5,148.4,139.5,138.6,136.6,130.0,129.8,128.7$ (q, $\left.J_{C-F}=25.3 \mathrm{~Hz}\right)$, $128.5,128.1,128.08,128.0,127.4,127.3,126.2,125.3,125.2,124.3\left(\mathrm{q}, J_{C-F}=271.7\right.$ $\mathrm{Hz}), 68.2,46.0 ;{ }^{19} \mathrm{~F} \mathrm{NMR}\left(\mathrm{CDCl}_{3}, 282 \mathrm{MHz}\right) \delta$-63.0; HRMS (ESI+) m/z 430.1780 [(M+H)+; calculated mass for $\left.\mathrm{C}_{28} \mathrm{H}_{23} \mathrm{~F}_{3} \mathrm{~N}^{+}: 430.1783 \mathrm{amu}\right]$. 


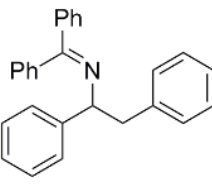

\section{Diphenylmethylene-1,2-diphenylethanamine (4.2j).}

Reaction temperature, time: $175^{\circ} \mathrm{C}, 5 \mathrm{~min}$. Clear colorless oil (41.9 mg, $0.116 \mathrm{mmol}$, 44\%); Characteristic data agree with reported values. ${ }^{7}{ }^{1} \mathrm{H} \mathrm{NMR}\left(\mathrm{CDCl}_{3}, 500 \mathrm{MHz}\right) \delta$ $7.65(\mathrm{~d}, J=6.9 \mathrm{~Hz}, 2 \mathrm{H}), 7.41-7.19(\mathrm{~m}, 14 \mathrm{H}), 7.04(\mathrm{~d}, J=5.7 \mathrm{~Hz}, 2 \mathrm{H}), 6.54(\mathrm{~d}, J=3.5 \mathrm{~Hz}$, $2 \mathrm{H}), 4.57(\mathrm{dd}, J=8.8,4.0 \mathrm{~Hz}, 1 \mathrm{H}), 3.28(\mathrm{dd}, J=12.8,9.2 \mathrm{~Hz}, 1 \mathrm{H}), 3.10(\mathrm{dd}, J=13.0,4.0$ $\mathrm{Hz}, 1 \mathrm{H})$.

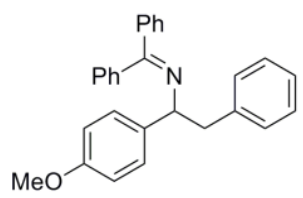

\section{Diphenylmethylene-1-(4-methoxyphenyl)-2-}

phenylethanamine (4.2k). Reaction temperature, time: $200^{\circ} \mathrm{C}, 5 \mathrm{~min}$. Clear oil (45.7 mg, 0.117 mmol, 50\%): $\mathrm{R}_{\mathrm{f}}=0.55$ (10\% EtOAc/Hexanes); IR (NaCl, film) 3059, $1611,1246,1035,697 ;{ }^{1} \mathrm{H}$ NMR $\left(\mathrm{CDCl}_{3}, 500 \mathrm{MHz}\right) \delta 7.63(\mathrm{~d}, J=7.1 \mathrm{~Hz}, 2 \mathrm{H}), 7.38-$ $7.17(\mathrm{~m}, 11 \mathrm{H}), 7.02(\mathrm{dd}, J=7.4,1.5 \mathrm{~Hz}, 2 \mathrm{H}), 6.88(\mathrm{~d}, J=8.6 \mathrm{~Hz}, 2 \mathrm{H}), 6.54(\mathrm{~d}, J=6.1 \mathrm{~Hz}$, 2H), $4.51(\mathrm{dd}, J=9.0,4.4 \mathrm{~Hz}, 1 \mathrm{H}), 3.82(\mathrm{~s}, 3 \mathrm{H}), 3.25(\mathrm{dd}, J=13.0,9.0 \mathrm{~Hz}, 1 \mathrm{H}), 3.07$ $(\mathrm{dd}, J=13.0,4.4 \mathrm{~Hz}, 1 \mathrm{H}) ;{ }^{13} \mathrm{C} \mathrm{NMR}\left(\mathrm{CDCl}_{3}, 125 \mathrm{MHz}\right) \delta 166.3,158.3,139.8,139.3$, 136.9, 136.6, 129.9, 129.7, 128.4, 128.1, 127.9, 127.89, 127.86, 127.5, 125.9, 113.6, 67.9, 55.2, 46.1; HRMS (ESI+) m/z $391.2008\left[(\mathrm{M}+\mathrm{H})^{+}\right.$; calculated mass for $\left.\mathrm{C}_{28} \mathrm{H}_{26} \mathrm{NO}^{+}: 392.2014 \mathrm{amu}\right]$.

\footnotetext{
${ }^{7}$ Cainelli, G.; Giacomini, D.; Trere, A.; Boyl, P. P. J. Org. Chem. 1996, 61, 5134-5139.
} 


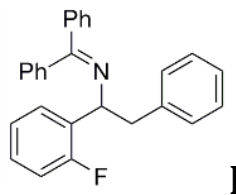

\section{Diphenylmethylene-1-(2-fluorophenyl)-2-phenylethanamine}

(4.21). Reaction temperature, time: $175^{\circ} \mathrm{C}, 5 \mathrm{~min}$. Pale yellow oil $(49.2 \mathrm{mg}, 0.130$ mmol, 54\%): $\mathrm{R}_{\mathrm{f}}=0.72$ (10\% EtOAc/Hexanes); IR (NaCl, film) 3060, 1488, 1226, 696; ${ }^{1} \mathrm{H} \mathrm{NMR}\left(\mathrm{CDCl}_{3}, 500 \mathrm{MHz}\right) \delta 7.80(\mathrm{dt}, J=7.4,1.4 \mathrm{~Hz}, 1 \mathrm{H}), 7.67-7.65(\mathrm{~m}, 2 \mathrm{H}), 7.40-7.14$ (m, 11H), $7.05(\mathrm{dd}, J=7.4,1.8 \mathrm{~Hz}, 2 \mathrm{H}), 6.98(\mathrm{ddd}, J=10.3,8.1,1.1 \mathrm{~Hz}, 1 \mathrm{H}), 6.51(\mathrm{~d}, J=$ $7.2 \mathrm{~Hz}, 2 \mathrm{H}), 4.95(\mathrm{dd}, J=8.9,4.1 \mathrm{~Hz}, 1 \mathrm{H}), 3.21(\mathrm{dd}, J=13.1,8.9 \mathrm{~Hz}, 1 \mathrm{H}), 3.13$ (dd, $J=$ 13.1, $4.1 \mathrm{~Hz}, 1 \mathrm{H}) ;{ }^{13} \mathrm{C} \mathrm{NMR}\left(\mathrm{CDCl}_{3}, 125 \mathrm{MHz}\right) \delta 167.8,164.1$ (d, $\left.J_{C-F}=245.2 \mathrm{~Hz}\right)$, 139.8, 139.1, 136.6, 131.7, 131.6, 129.9, 129.0, 128.6, 128.4 (d, $\left.J_{C-F}=133.4 \mathrm{~Hz}\right)$, $128.0,127.9,127.4,126.0,124.1,115.1\left(\mathrm{~d}, J_{C-F}=22.2 \mathrm{~Hz}\right), 61.1,44.9 ;{ }^{19} \mathrm{~F} \mathrm{NMR}\left(\mathrm{CDCl}_{3}\right.$, $282 \mathrm{MHz}) \delta$-120.1; HRMS (ESI+] m/z $380.1804[(\mathrm{M}+\mathrm{H})+$; calculated mass for $\left.\mathrm{C}_{27} \mathrm{H}_{23} \mathrm{FN}+: 380.1815 \mathrm{amu}\right]$.

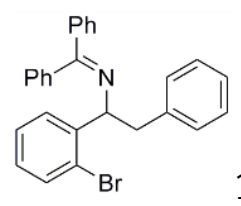

\section{1-(2-Bromophenyl)-N-(diphenylmethylene)-2-phenylethanamine}

(4.2m). Reaction temperature, time: $200{ }^{\circ} \mathrm{C}, 45 \mathrm{~min}$. Yellow oil $(34.1 \mathrm{mg}, 0.077$ mmol, 36\%): $R_{f}=0.74$ (10\% EtOAc/Hexanes); IR (NaCl, film) 3060, 1623, 1022, 696; ${ }^{1} \mathrm{H} \mathrm{NMR}\left(\mathrm{CDCl}_{3}, 500 \mathrm{MHz}\right) \delta 7.98(\mathrm{dd}, J=7.8,1.7 \mathrm{~Hz}, 1 \mathrm{H}), 7.67(\mathrm{dd}, J=8.4,1.4 \mathrm{~Hz}$, 2H), $7.51(\mathrm{dd}, J=8.0,1.2 \mathrm{~Hz}, 1 \mathrm{H}), 7.41-7.10(\mathrm{~m}, 13 \mathrm{H}), 6.43(\mathrm{~d}, J=6.9 \mathrm{~Hz}, 2 \mathrm{H}), 5.02$ (dd, $J=9.3,3.3 \mathrm{~Hz}, 1 \mathrm{H}$ ), 3.13 (dd, $J=13.1,3.3 \mathrm{~Hz}, 1 \mathrm{H}$ ), 3.06 (dd, $J=13.1,9.3 \mathrm{~Hz}, 1 \mathrm{H}$ ); ${ }^{13} \mathrm{C} \mathrm{NMR}\left(\mathrm{CDCl}_{3}, 125 \mathrm{MHz}\right) \delta 167.9,143.8,139.7,139.1,136.7,132.5,129.8,129.6$, 
128.6, 128.0, 127.96, 127.6, 127.4, 126.0, 122.3, 66.8, 44.9; HRMS (ESI+) m/z $440.1016\left[(\mathrm{M}+\mathrm{H})^{+}\right.$; calculated mass for $\mathrm{C}_{27} \mathrm{H}_{23} \mathrm{BrN}^{+}$: $\left.440.1014 \mathrm{amu}\right]$.

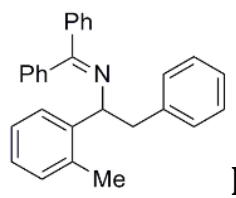

\section{Diphenylmethylene-2-phenyl-1-tolylethanamine (4.2n).}

Reaction temperature, time: $200^{\circ} \mathrm{C}, 15 \mathrm{~min}$. Cloudy oil (23.2 mg, $\left.0.062 \mathrm{mmol}, 26 \%\right)$ : $\mathrm{R}_{\mathrm{f}}=0.71$ (10\% EtOAc/Hexanes); IR (NaCl, film) 3060, 1623, 1288, 696; ${ }^{1} \mathrm{H}$ NMR $\left(\mathrm{CDCl}_{3}, 500 \mathrm{MHz}\right) \delta 7.89(\mathrm{~d}, J=7.0 \mathrm{~Hz}, 1 \mathrm{H}), 7.66(\mathrm{~d}, J=6.9 \mathrm{~Hz}, 2 \mathrm{H}), 7.39-7.02(\mathrm{~m}$, $14 \mathrm{H}), 6.52(\mathrm{~d}, J=7.0 \mathrm{~Hz}, 2 \mathrm{H}), 4.76(\mathrm{dd}, J=8.8,4.2 \mathrm{~Hz}, 1 \mathrm{H}), 3.21(\mathrm{dd}, J=13.1,8.8 \mathrm{~Hz}$, 1H), $3.02(\mathrm{dd}, J=13.1,4.2 \mathrm{~Hz}, 1 \mathrm{H}) ;{ }^{13} \mathrm{C} \mathrm{NMR}\left(\mathrm{CDCl}_{3}, 125 \mathrm{MHz}\right) \delta 166.7,143.2,139.8$, $139.5,137.3,134.1,130.0,129.7,129.67,128.5,128.0,127.98,127.9,127.6,127.4$, 126.2, 126.16, 125.9, 64.5, 45.7, 18.9; HRMS (ESI+) m/z $376.2067\left[(\mathrm{M}+\mathrm{H})^{+}\right.$; calculated mass for $\left.\mathrm{C}_{28} \mathrm{H}_{26} \mathrm{~N}^{+}: 376.2065 \mathrm{amu}\right]$.

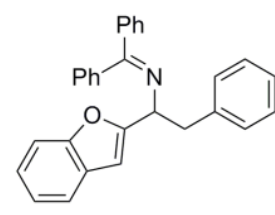

\section{1-(Benzofuran-2-yl)-N-(diphenylmethylene)-2-}

phenylethanamine (4.20). Reaction temperature, time: $200^{\circ} \mathrm{C}, 15$ min. Cloudy oil (40.6 mg, $0.101 \mathrm{mmol}, 43 \%): \mathrm{R}_{\mathrm{f}}=0.61(10 \% \mathrm{EtOAc} /$ Hexanes); IR (NaCl, film) 3059, 1660, 1278, 696; ${ }^{1} \mathrm{H}$ NMR $\left(\mathrm{CDCl}_{3}, 500 \mathrm{MHz}\right) \delta 7.85(\mathrm{~d}, J=7.3 \mathrm{~Hz}, 1 \mathrm{H}), 7.66(\mathrm{~d}, J=7.7$ $\mathrm{Hz}, 2 \mathrm{H}), 7.64-7.51(\mathrm{~m}, 2 \mathrm{H}), 7.42-7.21(\mathrm{~m}, 11 \mathrm{H}), 7.12(\mathrm{~d}, J=7.5 \mathrm{~Hz}, 2 \mathrm{H}), 6.61(\mathrm{~s}, 2 \mathrm{H})$, $4.83(\mathrm{dd}, J=9.3,4.0 \mathrm{~Hz}, 1 \mathrm{H}), 3.44(\mathrm{dd}, J=13.1,4.0 \mathrm{~Hz}, 1 \mathrm{H}), 3.37$ (dd, $J=13.1,9.4 \mathrm{~Hz}$, 
1H); ${ }^{13} \mathrm{C}$ NMR $\left(\mathrm{CDCl}_{3}, 125 \mathrm{MHz}\right) \delta 169.6,159.2,154.7,139.5,138.3,136.2,132.4$, $130.1,130.0,129.9,128.7,128.4,128.2,128.2,128.1,128.0,127.5,126.2,123.5$, 122.5, 120.7, 111.1, 102.5, 62.7, 41.7; HRMS (ESI+) m/z 402.1857 [(M+H)+; calculated mass for $\left.\mathrm{C}_{28} \mathrm{H}_{24} \mathrm{NO}^{+}: 402.1858 \mathrm{amu}\right]$.

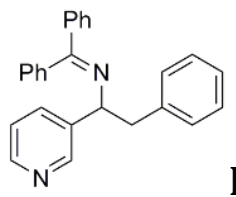

\section{Diphenylmethylene-2-phenyl-1-(pyridin-3-yl)ethanamine (4.2p).}

Reaction temperature, time: $210{ }^{\circ} \mathrm{C}, 8 \mathrm{~min}$. Yellow solid $(57.4 \mathrm{mg}, 0.158 \mathrm{mmol}$, 62\%): $\mathrm{mp}=68-71{ }^{\circ} \mathrm{C} ; \mathrm{R}_{\mathrm{f}}=0.11(10 \%$ EtOAc/Hexanes); IR (NaCl, film) 3058, 1624, 1286, 697; ${ }^{1} \mathrm{H} \mathrm{NMR}\left(\mathrm{CDCl}_{3}, 300 \mathrm{MHz}\right) \delta 8.49(\mathrm{dd}, J=4.8,1.7 \mathrm{~Hz}, 1 \mathrm{H}), 8.47(\mathrm{~d}, J=2.0$ $\mathrm{Hz}, 1 \mathrm{H}), 7.79(\mathrm{td}, J=7.9,1.8 \mathrm{~Hz}, 1 \mathrm{H}), 7.64(\mathrm{dd}, J=8.1,1.6 \mathrm{~Hz}, 2 \mathrm{H}), 7.41-7.17(\mathrm{~m}$, $10 \mathrm{H}), 7.01-6.98(\mathrm{~m}, 2 \mathrm{H}), 6.55(\mathrm{~d}, J=6.8 \mathrm{~Hz}, 2 \mathrm{H}), 4.58(\mathrm{dd}, J=8.7,4.8 \mathrm{~Hz}, 1 \mathrm{H}), 3.26$ $(\mathrm{dd}, J=13.0,8.7 \mathrm{~Hz}, 1 \mathrm{H}), 3.06(\mathrm{dd}, J=13.0,4.8 \mathrm{~Hz}, 1 \mathrm{H}) ;{ }^{13} \mathrm{C} \mathrm{NMR}\left(\mathrm{CDCl}_{3}, 75 \mathrm{MHz}\right)$ $\delta 167.6,148.7,148.3,139.7,139.4,138.4,136.5,134.8,130.0,129.8,128.4,128.2$, 128.1, 127.9, 127.2, 126.2, 123.4, 66.1, 45.8; HRMS (ESI+) m/z 363.1849 [(M+H)+; calculated mass for $\left.\mathrm{C}_{26} \mathrm{H}_{23} \mathrm{~N}_{2}+363.1861 \mathrm{amu}\right]$.

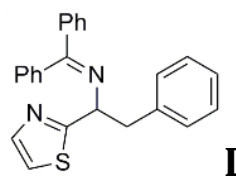

\section{Diphenylmethylene-2-phenyl-1-(thiazol-2-yl)ethanamine (2q).}

Reaction temperature, time: $150{ }^{\circ} \mathrm{C}, 5 \mathrm{~min}$. Yellow solid $(62.9 \mathrm{mg}, 0.171 \mathrm{mmol}$, 70\%): $\mathrm{mp}=82-84{ }^{\circ} \mathrm{C} ; \mathrm{R}_{\mathrm{f}}=0.28(10 \%$ EtOAc/Hexanes); IR (NaCl, film) 3060, 1625, 
1286, 696; ${ }^{1} \mathrm{H} \mathrm{NMR}\left(\mathrm{CDCl}_{3}, 500 \mathrm{MHz}\right) \delta 7.78(\mathrm{~d}, J=3.2 \mathrm{~Hz}, 1 \mathrm{H}), 7.71-7.68(\mathrm{~m}, 2 \mathrm{H})$, 7.44-7.21 (m, 10H), 7.10-7.08 (m, 2H), 6.42 (br s, 2H), 5.02 (dd, $J=9.6,3.3 \mathrm{~Hz}, 1 \mathrm{H}$ ), $3.44(\mathrm{dd}, J=13.1,3.3 \mathrm{~Hz}, 1 \mathrm{H}), 3.26(\mathrm{dd}, J=13.1,9.7 \mathrm{~Hz}, 1 \mathrm{H}) ;{ }^{13} \mathrm{C} \mathrm{NMR}\left(\mathrm{CDCl}_{3}, 125\right.$ MHz) $\delta 174.3,169.7,142.2,139.1,137.9,135.7,130.3,130.1,128.7,128.2,128.1$, 128.0, 127.2, 126.3, 118.6, 66.3, 44.7; HRMS (ESI+) m/z $369.1422\left[(\mathrm{M}+\mathrm{H})^{+}\right.$; calculated mass for $\left.\mathrm{C}_{24} \mathrm{H}_{21} \mathrm{~N}_{2} \mathrm{~S}^{+}: 369.1425 \mathrm{amu}\right]$.

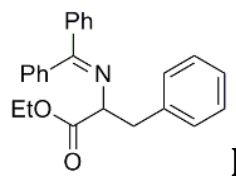

Ethyl 2-(diphenylmethyleneamino)-3-phenylpropanoate (2r).

Reaction temperature, time: $200{ }^{\circ} \mathrm{C}, 5 \mathrm{~min}$. Cloudy oil (50.3 mg, $0.141 \mathrm{mmol}, 57 \%$ );

Characteristic data agree with reported values. ${ }^{8}{ }^{1} \mathrm{H}$ NMR $\left(\mathrm{CDCl}_{3}, 300 \mathrm{MHz}\right) \delta 7.58(\mathrm{~d}$, $J=7.0 \mathrm{~Hz}, 2 \mathrm{H}), 7.49-7.16(\mathrm{~m}, 9 \mathrm{H}), 7.05-7.02(\mathrm{~m}, 2 \mathrm{H}), 6.60(\mathrm{~d}, J=5.5 \mathrm{~Hz}, 2 \mathrm{H}), 4.25-$ $4.13(\mathrm{~m}, 3 \mathrm{H}), 3.28(\mathrm{dd}, J=13.3,4.3 \mathrm{~Hz}, 1 \mathrm{H}), 3.18(\mathrm{dd}, J=13.2,9.3 \mathrm{~Hz}, 1 \mathrm{H}), 1.25(\mathrm{t}, J=$ 7.1 Hz, 3H).

\subsection{Experimentals for Chapter 4 - Synthesis of a 2-Aryl- $\beta$-Carboline}

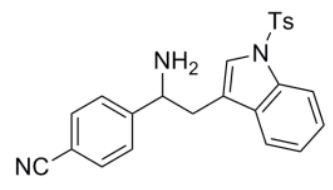

4-(1-amino-2-(1-tosyl-1H-indol-3-yl)ethyl)benzonitrile

(4.14). Imine 4.2h (1.0 equiv.) and $1 \mathrm{~N} \mathrm{HCl} \mathrm{(1.5} \mathrm{equiv.)} \mathrm{were} \mathrm{combined} \mathrm{in} \mathrm{THF} \mathrm{(0.1}$

8 O’Donnell, M. J.; Polt, R. L. J. Org. Chem. 1982, 47, 2663-2666. 
M) and the mixture was stirred at room temperature. The reaction progress was monitored by TLC. Upon completion, the reaction mixture was quenched with saturated $\mathrm{NaHCO}_{3}$. The resulting aqueous phase was extracted with EtOAc $(3 \times 100$ $\mathrm{mL}$ ) and the combined organic layers were rinsed with water $(100 \mathrm{~mL})$, dried $\left(\mathrm{Na}_{2} \mathrm{SO}_{4}\right)$, filtered and concentrated in vacuo. The resulting residue was purified by flash column chromatography $\left(0-5 \% \mathrm{MeOH} / \mathrm{CH}_{2} \mathrm{Cl}_{2}\right)$ to afford the amine product as a yellow oil (173.9 mg, $0.419 \mathrm{mmol}, 75 \%): \mathrm{R}_{\mathrm{f}}=0.45\left(5 \% \mathrm{MeOH} / \mathrm{CH}_{2} \mathrm{Cl}_{2}\right)$; IR $(\mathrm{NaCl}$, film) 3052, 2227, 1608, 1367, 1121, 911; ${ }^{1} \mathrm{H}$ NMR $\left(\mathrm{CDCl}_{3}, 300 \mathrm{MHz}\right) \delta 7.99(\mathrm{~d}, J=8.3$ Hz, 1H), 7.69 (d, J = 8.3 Hz, 2H), 7.52 (d, $J=8.1 \mathrm{~Hz}, 2 \mathrm{H}), 7.42-7.21$ (m, 8-9H, overlap with solvent peak), $4.34(\mathrm{t}, J=6.7 \mathrm{~Hz}, 1 \mathrm{H}), 2.98(\mathrm{~d}, J=1.9 \mathrm{~Hz}, 1 \mathrm{H}), 2.95(\mathrm{~d}, J=3.5 \mathrm{~Hz}$, 1H), 2.35 (s, 3H), $1.64(\mathrm{bs}, 2 \mathrm{H}) ;{ }^{13} \mathrm{C} \mathrm{NMR}\left(\mathrm{CDCl}_{3}, 75 \mathrm{MHz}\right) \delta$ 150.6, 145.0, 135.1, $132.2,130.5,129.8,127.2,126.7,124.9,124.2,123.2,119.2,118.8,113.8,110.9$ 55.3, 35.4, 21.6; HRMS (ESI+) m/z $416.1430\left[(\mathrm{M}+\mathrm{H})^{+}\right.$; calculated mass for $\left.\mathrm{C}_{24} \mathrm{H}_{22} \mathrm{~N}_{3} \mathrm{O}_{2} \mathrm{~S}^{+}: 416.1433 \mathrm{amu}\right]$.

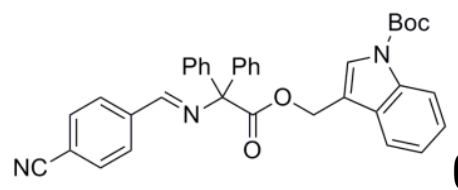

(E)-tert-butyl 3-((2-((4-cyanobenzylidene)amino)-2,2diphenylacetoxy)methyl)-1H-indole-1-carboxylate (4.17). Procedure mirrored the general procedure for the preparation of diphenylglycinate ester amines (4.3) and the general procedure for the preparation of diphenylglycinate imines (4.1); Red oil (184.5 mg, $0.324 \mathrm{mmol}, 99 \%): \mathrm{R}_{\mathrm{f}}=0.59$ (25\% EtOAc/hexanes); IR ( $\mathrm{NaCl}$, 
film) 3058, 2979, 2228, 1733, 1371, 1156, 911, 733; ${ }^{1} \mathrm{H}$ NMR $\left(\mathrm{CDCl}_{3}, 300 \mathrm{MHz}\right) \delta$ $8.13(\mathrm{~d}, J=8.3 \mathrm{~Hz}, 1 \mathrm{H}), 7.89-7.74(\mathrm{~m}, 3 \mathrm{H}), 7.66(\mathrm{~d}, J=8.3 \mathrm{~Hz}, 2 \mathrm{H}), 7.58(\mathrm{~s}, 1 \mathrm{H}), 7.42-$ $7.21(\mathrm{~m}, 11 \mathrm{H}), 7.08(\mathrm{t}, J=7.4 \mathrm{~Hz}, 1 \mathrm{H}), 5.39(\mathrm{~s}, 2 \mathrm{H}), 1.67(\mathrm{~s}, 9 \mathrm{H}) ;{ }^{13} \mathrm{C} \mathrm{NMR}\left(\mathrm{CDCl}_{3}, 75\right.$ MHz) $\delta 171.5,161.4,149.4,141.7,139.9,135.4,132.2,129.1,129.0,128.0,127.7$, $125.7,124.6,122.7,119.5,118.5,115.1,114.8,114.125,83.980,79.7,59.9,28.1$; HRMS (ESI+) m/z $570.2393\left[(\mathrm{M}+\mathrm{H})^{+}\right.$; calculated mass for $\mathrm{C}_{36} \mathrm{H}_{32} \mathrm{~N}_{3} \mathrm{O}_{4}{ }^{+}: 570.2393$ $\mathrm{amu}]$.

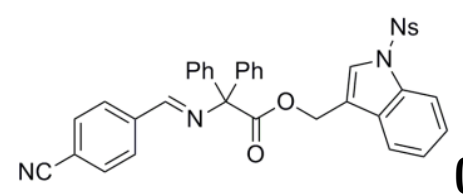

(E)-(1-((4-nitrophenyl)sulfonyl)-1H-indol-3-yl)methyl 2-((4-cyanobenzylidene)amino)-2,2-diphenylacetate (4.19). Procedure mirrored the general procedure for the preparation of diphenylglycinate ester amines (4.3) and the general procedure for the preparation of diphenylglycinate imines (4.1); Yellow solid (764.3 mg, $1.17 \mathrm{mmol}, 80 \%)$ : $\mathrm{mp}=174-176{ }^{\circ} \mathrm{C} ; \mathrm{R}_{\mathrm{f}}=0.27$ (25\% EtOAc/hexanes); IR (NaCl, film) 3105, 2228, 1732, 1532, 1120, 977, 908; ${ }^{1} \mathrm{H}$ $\operatorname{NMR}\left(\mathrm{CDCl}_{3}, 500 \mathrm{MHz}\right) \delta 8.18(\mathrm{~d}, J=8.8 \mathrm{~Hz}, 2 \mathrm{H}), 7.95(\mathrm{~d}, J=8.8 \mathrm{~Hz}, 3 \mathrm{H}), 7.83(\mathrm{~m}$, 3H), $7.69(\mathrm{~d}, J=8.2 \mathrm{~Hz}, 2 \mathrm{H}), 7.44(\mathrm{~s}, 1 \mathrm{H}), 7.39-7.20(\mathrm{~m}, 13 \mathrm{H}), 7.14(\mathrm{t}, J=7.6 \mathrm{~Hz}, 1 \mathrm{H})$, $5.35(\mathrm{~s}, 2 \mathrm{H}) ;{ }^{13} \mathrm{C} \mathrm{NMR}\left(\mathrm{CDCl}_{3}, 125 \mathrm{MHz}\right) \delta 171.3,161.5,150.5,142.8,141.3,139.7$, 134.9, 132.3, 129.2, 129.1, 127.9, 125.6, 125.2, 124.4, 124.1, 120.2, 118.6, 118.4, 114.3, 113.4, 79.7, 59.3; HRMS (ESI+) m/z 655.1646 [(M+H)+; calculated mass for $\left.\mathrm{C}_{37} \mathrm{H}_{27} \mathrm{~N}_{4} \mathrm{O}_{6} \mathrm{~S}^{+}: \mathrm{amu}\right]$. 


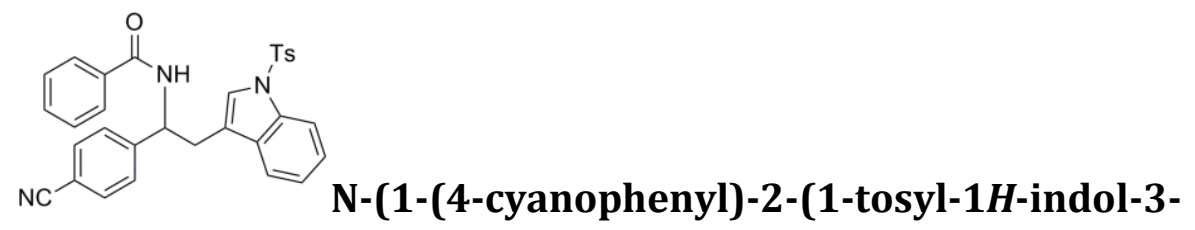

yl)ethyl)benzamide (4.22a). ). Benzoyl chloride (1.0 equiv.) and DMAP (0.1 equiv.) were combined in $\mathrm{THF}(0.1 \mathrm{M})$ and cooled to $-78{ }^{\circ} \mathrm{C}$. Amine 4.14 was dissolved in THF and added to the mixture, followed by DIPEA. The reaction stirred at $-78{ }^{\circ} \mathrm{C}$ and was allowed to gradually warm to ambient temperature with stirring overnight. Upon completion, as determined by TLC, the reaction mixture was quenched with $1 \mathrm{~N} \mathrm{HCl}$. The resulting aqueous phase was extracted with EtOAc $(3 \times 100 \mathrm{~mL})$ and the combined organic layers were rinsed with brine $(100 \mathrm{~mL})$, dried $\left(\mathrm{Na}_{2} \mathrm{SO}_{4}\right)$, filtered and concentrated in vacuo. The resulting residue was purified by triteration from $\mathrm{CH}_{2} \mathrm{Cl}_{2}$ and hexanes to afford the amide product as a white solid (159.2 mg, $0.306 \mathrm{mmol}, 73 \%): \mathrm{mp}=203-205{ }^{\circ} \mathrm{C} ; \mathrm{R}_{\mathrm{f}}=0.33(40 \%$ EtOAc/hexanes); IR (NaCl, film) 3256, 2229, 1633, 1534, 1277, 913; ${ }^{1} \mathrm{H}$ NMR $\left(\mathrm{CDCl}_{3}\right.$, $500 \mathrm{MHz}) \delta 7.99(\mathrm{dd}, J=8.3,0.6 \mathrm{~Hz}, 1 \mathrm{H}), 7.66(\mathrm{~d}, J=7.4 \mathrm{~Hz}, 2 \mathrm{H}), 7.59(\mathrm{~d}, J=8.3 \mathrm{~Hz}$, 2H), $7.52(\mathrm{~d}, J=8.1 \mathrm{~Hz}, 2 \mathrm{H}), 7.49-7.18(\mathrm{~m}, 8 \mathrm{H}), 7.09(\mathrm{~d}, J=8.5 \mathrm{~Hz}, 2 \mathrm{H}), 6.52(\mathrm{~d}, J=7.1$ $\mathrm{Hz}, 1 \mathrm{H}), 5.53(\mathrm{q}, J=7.0 \mathrm{~Hz}, 1 \mathrm{H}), 3.32(\mathrm{dd}, J=14.8,7.0 \mathrm{~Hz}, 1 \mathrm{H}), 3.23(\mathrm{dd}, J=14.8,7.1$ $\mathrm{Hz}, 1 \mathrm{H}), 2.30(\mathrm{~s}, 3 \mathrm{H}) ;{ }^{13} \mathrm{C} \mathrm{NMR}\left(\mathrm{CDCl}_{3}, 125 \mathrm{MHz}\right) \delta$ 166.9, 146.7, 145.1, 135.1, 134.9, 133.6, 132.5, 132.0, 130.4, 129.8, 128.7, 127.2, 126.9, 126.6, 125.2, 124.2, 123.5, 119.1, 118.6, 117.3, 113.9, 111.4, 53.3, 31.8, 21.6; HRMS (ESI+) m/z 520.1697 $\left[(\mathrm{M}+\mathrm{H})^{+} ;\right.$calculated mass for $\mathrm{C}_{31} \mathrm{H}_{26} \mathrm{~N}_{3} \mathrm{O}_{3} \mathrm{~S}^{+}: 520.1695$ 


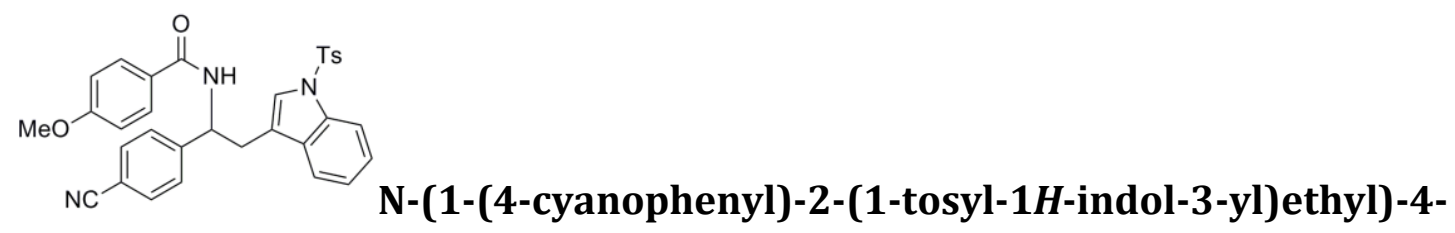

methoxybenzamide (4.22b). $p$-Anisoyl chloride (1.0 equiv.) and DMAP ( 0.1 equiv.) were combined in THF $(0.1 \mathrm{M})$ and cooled to $-78{ }^{\circ} \mathrm{C}$. Amine 4.14 was added, followed by DIPEA. The reaction stirred at $-78{ }^{\circ} \mathrm{C}$ and was allowed to gradually warm to ambient temperature with stirring overnight. Upon completion, as determined by TLC, the reaction mixture was quenched with $1 \mathrm{~N} \mathrm{HCl}$. The resulting aqueous phase was extracted with EtOAc $(3 \times 100 \mathrm{~mL})$ and the combined organic layers were rinsed with brine $(100 \mathrm{~mL})$, dried $\left(\mathrm{Na}_{2} \mathrm{SO}_{4}\right)$, filtered and concentrated in vacuo. The reaction residue was purified by triteration from $\mathrm{CH}_{2} \mathrm{Cl}_{2}$ and hexanes to afford the amide product as an off-white solid (140.8 $\mathrm{mg}, 0.256 \mathrm{mmol}, 77 \%): \mathrm{mp}=$ 217-219 ${ }^{\circ} \mathrm{C} ; \mathrm{R}_{\mathrm{f}}=0.22$ (40\% EtOAc/hexanes); IR (NaCl, film) 3342, 2227, 1633, 1369, 1172, 909; ${ }^{1} \mathrm{H}$ NMR $\left(\mathrm{CDCl}_{3}, 500 \mathrm{MHz}\right) \delta 7.98(\mathrm{~d}, J=8.3 \mathrm{~Hz}, 1 \mathrm{H}), 7.61$ (dd, $J=$ 21.9, $8.5 \mathrm{~Hz}, 4 \mathrm{H}), 7.51(\mathrm{~d}, J=8.2 \mathrm{~Hz}, 2 \mathrm{H}), 7.45(\mathrm{~d}, J=7.8 \mathrm{~Hz}, 1 \mathrm{H}), 7.36-7.18(\mathrm{~m}, 6 \mathrm{H}$, overlap with solvent), $7.10(\mathrm{~d}, J=8.3 \mathrm{~Hz}, 2 \mathrm{H}), 6.88(\mathrm{~d}, J=8.7 \mathrm{~Hz}, 2 \mathrm{H}), 6.46(\mathrm{~d}, J=6.9$ $\mathrm{Hz}, 1 \mathrm{H}), 5.51(\mathrm{q}, J=6.9 \mathrm{~Hz}, 1 \mathrm{H}), 3.84(\mathrm{~s}, 3 \mathrm{H}), 3.31(\mathrm{dd}, J=14.8,7.0 \mathrm{~Hz}, 1 \mathrm{H}), 3.21(\mathrm{dd}, J$ $=14.7,7.1 \mathrm{~Hz}, 1 \mathrm{H}), 2.31(\mathrm{~s}, 3 \mathrm{H}) ;{ }^{13} \mathrm{C} \mathrm{NMR}\left(\mathrm{CDCl}_{3}, 125 \mathrm{MHz}\right) \delta$ 166.4, 162.5, 146.9, $145.0,135.1,134.9,132.4,130.4,129.8,128.8,127.2,126.6,125.7,125.2,124.2$, 123.4, 119.2, 118.6, 117.3, 113.9, 113.7, 111.3, 55.5, 53.2, 31.8, 21.5; HRMS (ESI+) $\mathrm{m} / \mathrm{z} 550.1801\left[(\mathrm{M}+\mathrm{H})^{+}\right.$; calculated mass for $\left.\mathrm{C}_{32} \mathrm{H}_{28} \mathrm{~N}_{3} \mathrm{O}_{4} \mathrm{~S}^{+}: 550.1801 \mathrm{amu}\right]$. 


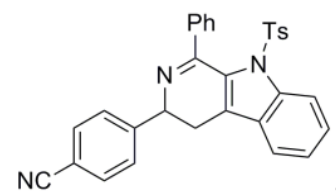

\section{4-(1-phenyl-9-tosyl-4,9-dihydro-3H-pyrido[3,4-b]indol-3-}

yl)benzonitrile (4.23). Amide 4.22a (1.0 equiv) and $\mathrm{P}_{2} \mathrm{O}_{5}$ (10 equiv.) were combined in anhydrous benzene $(0.05 \mathrm{M})$. $\mathrm{POCl}_{3}$ (10 equiv.) was slowly added via syringe and the reaction mixture was heated to reflux. The reaction progress was monitored by TLC. Upon completion, the reaction was cooled to ambient temperature and quenched with saturated $\mathrm{NaHCO}_{3}$. The resulting aqueous phase was extracted with EtOAc $(3 \times 100 \mathrm{~mL})$ and the combined organic layers were rinsed with brine $(100 \mathrm{~mL})$, dried $\left(\mathrm{Na}_{2} \mathrm{SO}_{4}\right)$, filtered and concentrated in vacuo. The reaction residue was purified by radial chromatography (15\%-25\% EtOAc/hexanes) to afford the desired product as a yellow oil $(22.6 \mathrm{mg}, 0.045 \mathrm{mmol}, 45 \%): \mathrm{R}_{\mathrm{f}}=0.36$ (25\% EtOAc/hexanes); IR (NaCl, film) 3061, 2924, 2227, 1596, 1373, 1174, 910; ${ }^{1} \mathrm{H}$ $\operatorname{NMR}\left(\mathrm{CDCl}_{3}, 500 \mathrm{MHz}\right) \delta 8.21(\mathrm{~d}, J=8.3 \mathrm{~Hz}, 1 \mathrm{H}), 7.92-7.87(\mathrm{~m}, 2 \mathrm{H}), 7.80(\mathrm{~d}, J=8.0$ $\mathrm{Hz}, 2 \mathrm{H}), 7.70(\mathrm{~d}, J=8.3 \mathrm{~Hz}, 2 \mathrm{H}), 7.53-7.42(\mathrm{~m}, 5 \mathrm{H}), 7.33(\mathrm{dd}, J=12.8,7.9 \mathrm{~Hz}, 3 \mathrm{H})$, $7.02(\mathrm{~d}, J=8.1 \mathrm{~Hz}, 2 \mathrm{H}), 4.59(\mathrm{dd}, J=15.7,5.6 \mathrm{~Hz}, 1 \mathrm{H}), 3.10(\mathrm{dd}, J=17.2,5.7 \mathrm{~Hz}, 1 \mathrm{H})$, $2.68(\mathrm{t}, J=16.5 \mathrm{~Hz}, 1 \mathrm{H}), 2.28(\mathrm{~s}, 3 \mathrm{H}) ;{ }^{13} \mathrm{C} \mathrm{NMR}\left(\mathrm{CDCl}_{3}, 125 \mathrm{MHz}\right) \delta 159.8,148.9$, 144.8, 139.8, 134.6, 132.5, 132.3, 129.6, 129.1, 129.1, 128.8, 128.1, 128.0, 126.9, 126.9, 125.2, 120.3, 119.0, 117.7, 110.8, 60.9, 28.4, 21.5; HRMS (ESI+) m/z 502.1591 $\left[(\mathrm{M}+\mathrm{H})^{+}\right.$; calculated mass for $\left.\mathrm{C}_{31} \mathrm{H}_{24} \mathrm{~N}_{3} \mathrm{O}_{2} \mathrm{~S}^{+}: 502.1589 \mathrm{amu}\right]$. 


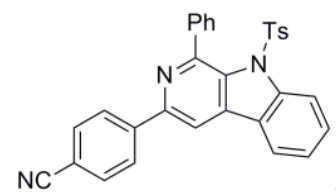

\section{4-(1-phenyl-9-tosyl-9H-pyrido[3,4-b]indol-3-yl)benzonitrile}

(4.13). Amide 4.22a (1.0 equiv) in $\mathrm{POCl}_{3}(0.5 \mathrm{M})$ was heated to reflux for one hour, after which anhydrous benzene $(0.1 \mathrm{M})$ was added and the reaction was again heated to reflux. The reaction progress was monitored by TLC. Upon completion, the reaction was cooled to ambient temperature and quenched with saturated $\mathrm{NaHCO}_{3}$. The resulting aqueous phase was extracted with EtOAc $(3 \times 100 \mathrm{~mL})$ and the combined organic layers were rinsed with brine $(100 \mathrm{~mL})$, dried $\left(\mathrm{Na}_{2} \mathrm{SO}_{4}\right)$, filtered and concentrated in vacuo. The reaction residue was purified by radial chromatography (15\%-25\% EtOAc/hexanes) to afford the desired product as a yellow oil (12.4 mg, $0.025 \mathrm{mmol}, 35 \%): \mathrm{R}_{\mathrm{f}}=0.38$ (25\% EtOAc/hexanes); IR (NaCl, film) 3062, 2922, 2227, 1610, 1374, 1172, 931; ${ }^{1} \mathrm{H}$ NMR $\left(\mathrm{CDCl}_{3}, 500 \mathrm{MHz}\right) \delta 8.34$ (d, $J=8.7 \mathrm{~Hz}, 2 \mathrm{H}), 8.28(\mathrm{~d}, J=8.3 \mathrm{~Hz}, 1 \mathrm{H}), 8.20(\mathrm{~d}, J=7.0 \mathrm{~Hz}, 2 \mathrm{H}), 8.02(\mathrm{~s}, 1 \mathrm{H}), 7.85(\mathrm{~d}, J$ $=8.2 \mathrm{~Hz}, 1 \mathrm{H}), 7.79(\mathrm{~d}, J=8.7 \mathrm{~Hz}, 2 \mathrm{H}), 7.63-7.40(\mathrm{~m}, 5 \mathrm{H}), 7.01(\mathrm{~d}, J=8.4 \mathrm{~Hz}, 2 \mathrm{H}), 6.84$ $(\mathrm{d}, J=8.0 \mathrm{~Hz}, 2 \mathrm{H}), 2.17(\mathrm{~s}, 3 \mathrm{H}) ;{ }^{13} \mathrm{C} \mathrm{NMR}\left(\mathrm{CDCl}_{3}, 125 \mathrm{MHz}\right) \delta 151.0,150.6,144.7$, $142.9,142.5,140.7,139.8,134.5,132.5,131.9,130.1,128.9,128.7,128.2,127.6$, 127.2, 126.9, 125.9, 125.9, 121.1, 119.6, 118.9, 112.3, 109.1, 21.5; HRMS (ESI+) m/z $500.1423\left[(\mathrm{M}+\mathrm{H})^{+}\right.$; calculated mass for $\left.\mathrm{C}_{31} \mathrm{H}_{22} \mathrm{~N}_{3} \mathrm{O}_{2} \mathrm{~S}^{+}: 500.1427 \mathrm{amu}\right]$. 
Appendix A.

NMR Spectra 

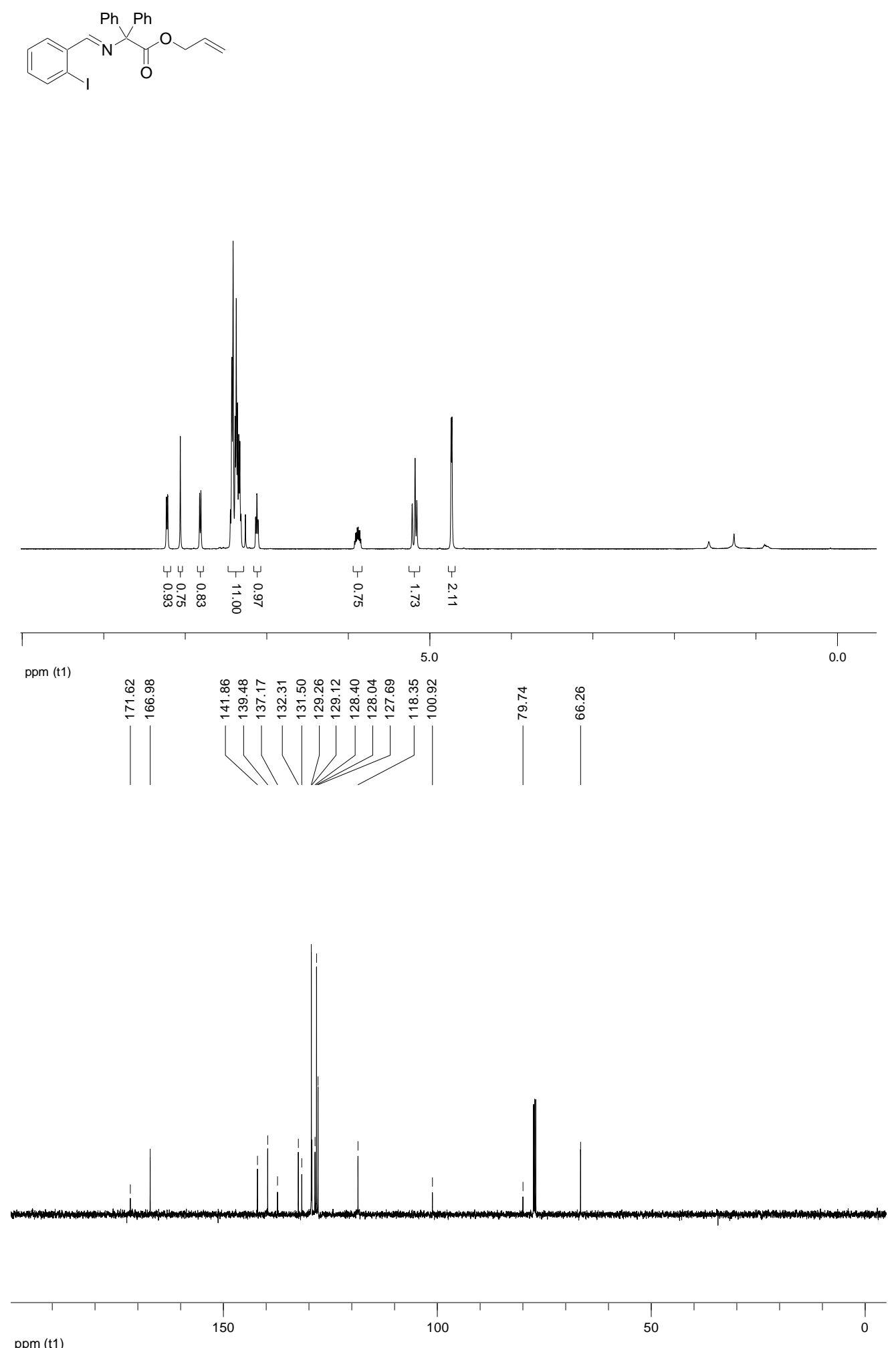

ppm (t1)

${ }^{1} \mathrm{H}-$ and ${ }^{13} \mathrm{C}-\mathrm{NMR}\left(\mathrm{CDCl}_{3}\right)$ Spectra of 3.1a 

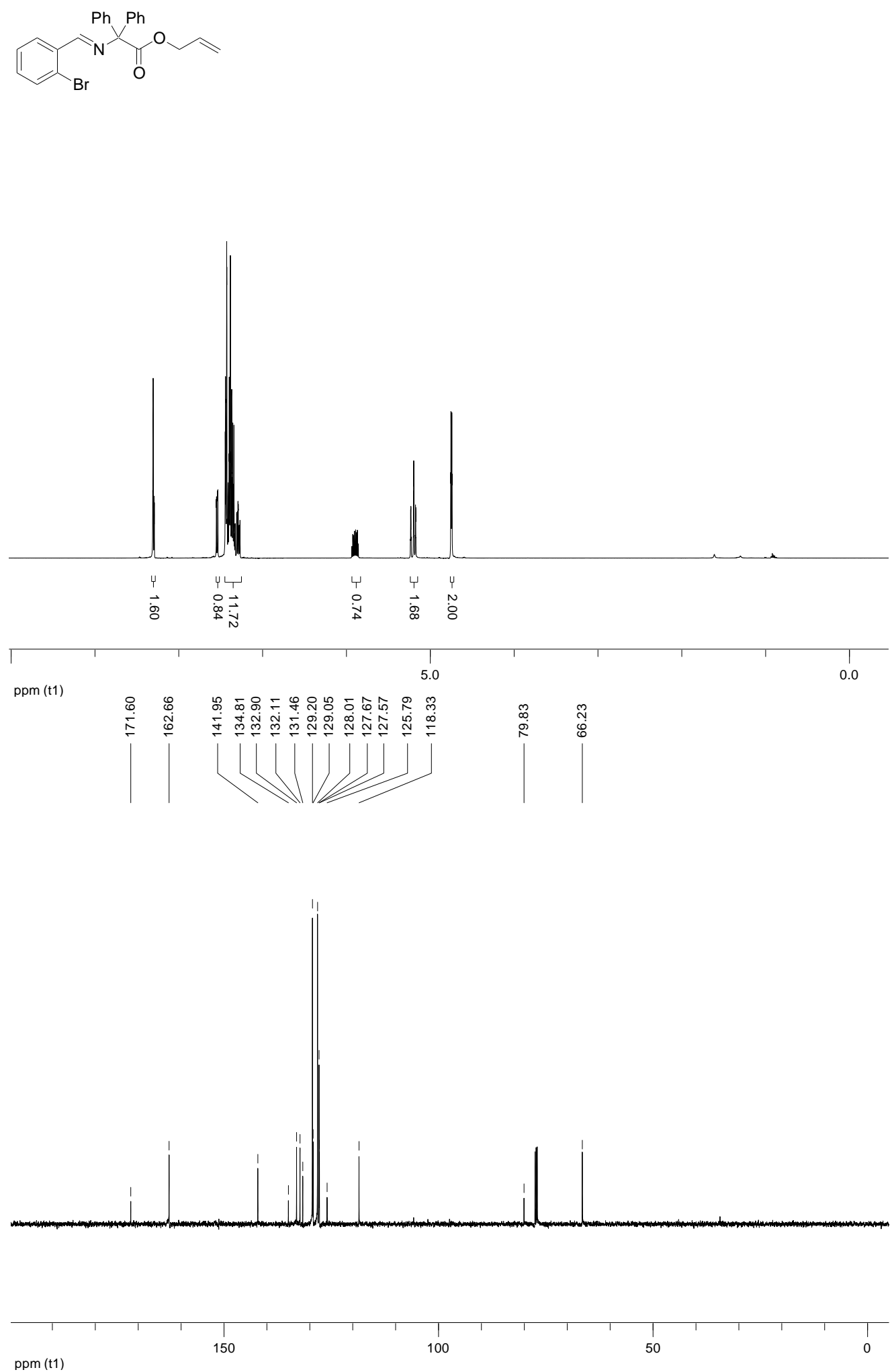

${ }^{1} \mathrm{H}$ - and ${ }^{13} \mathrm{C}-\mathrm{NMR}\left(\mathrm{CDCl}_{3}\right)$ Spectra of $\mathbf{3 . 1 b}$ 

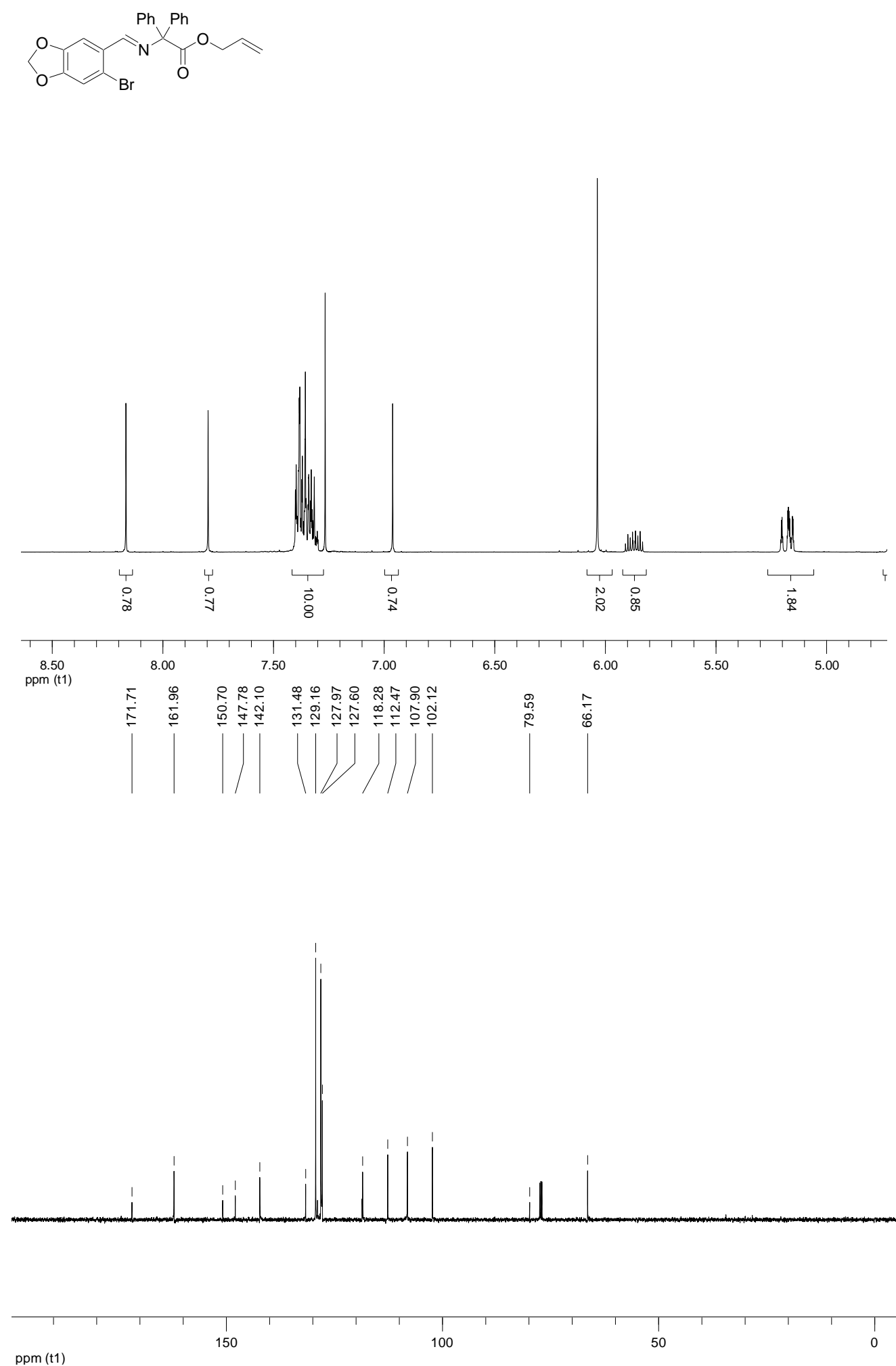

${ }^{1} \mathrm{H}$ - and ${ }^{13} \mathrm{C}$-NMR $\left(\mathrm{CDCl}_{3}\right)$ Spectra of 3.1c 

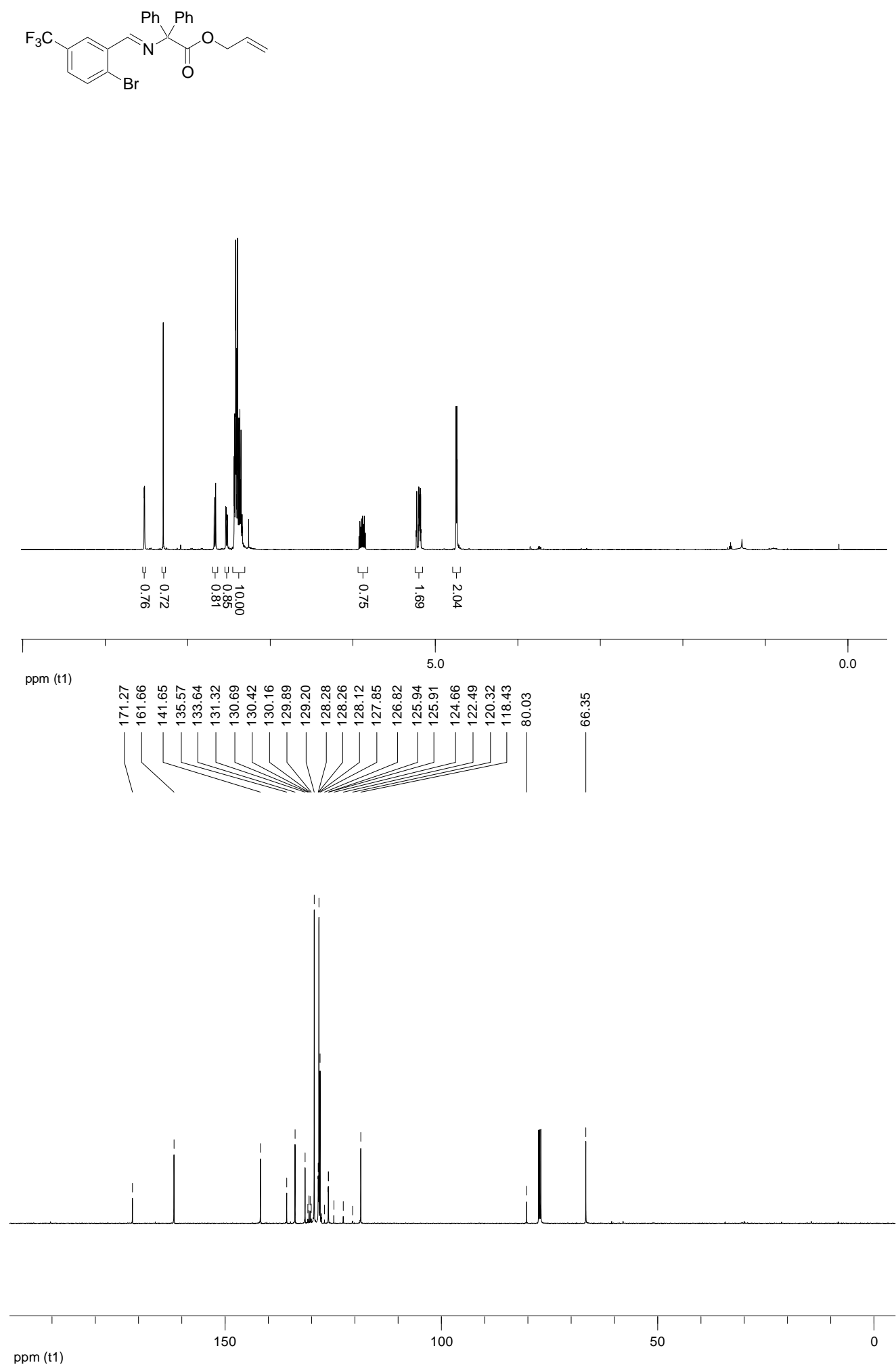

${ }^{1} \mathrm{H}$ - and ${ }^{13} \mathrm{C}-\mathrm{NMR}\left(\mathrm{CDCl}_{3}\right)$ Spectra of 3.1d 

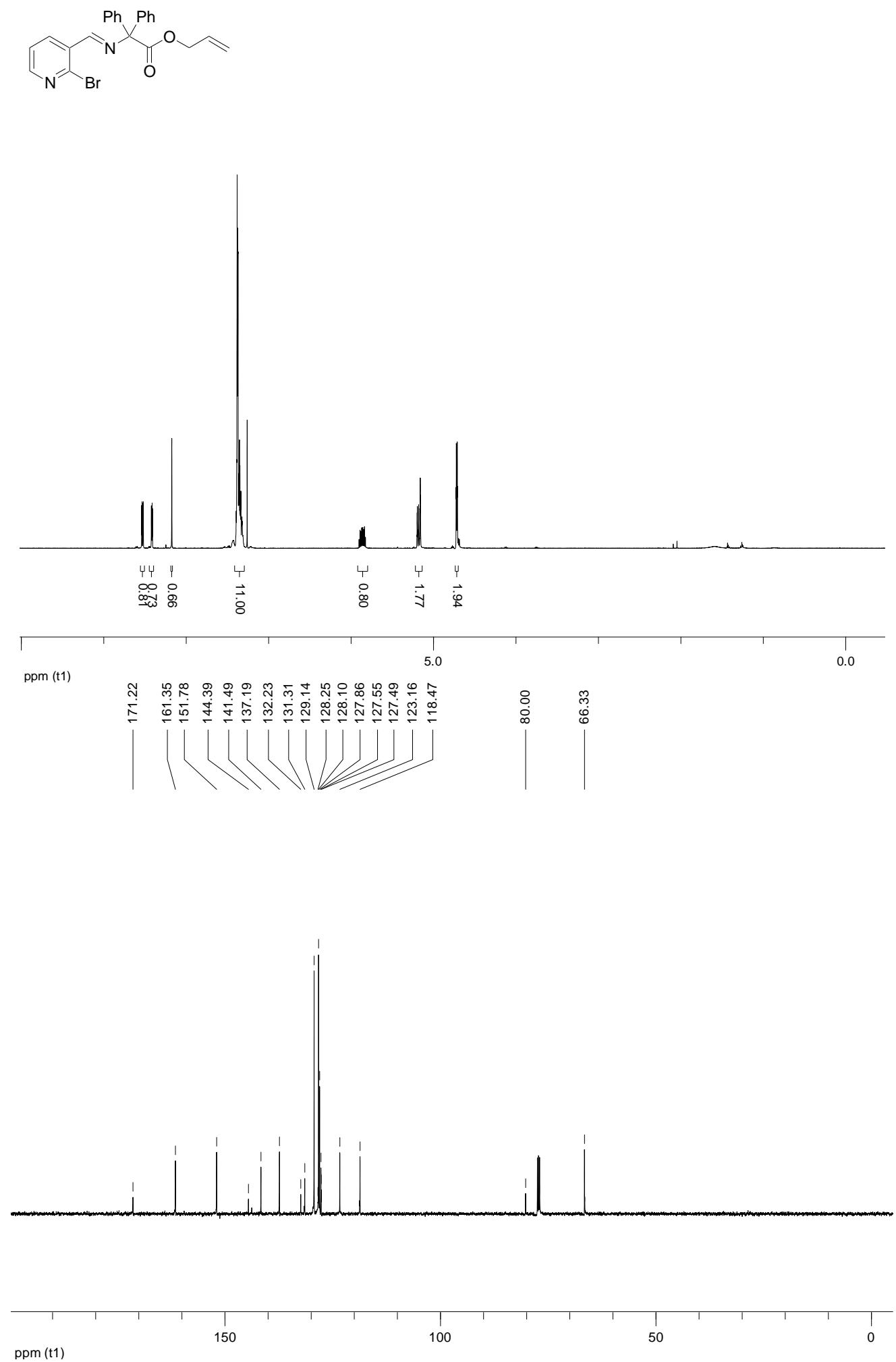

${ }^{1} \mathrm{H}-$ and ${ }^{13} \mathrm{C}-\mathrm{NMR}\left(\mathrm{CDCl}_{3}\right)$ Spectra of $\mathbf{3 . 1 f}$ 

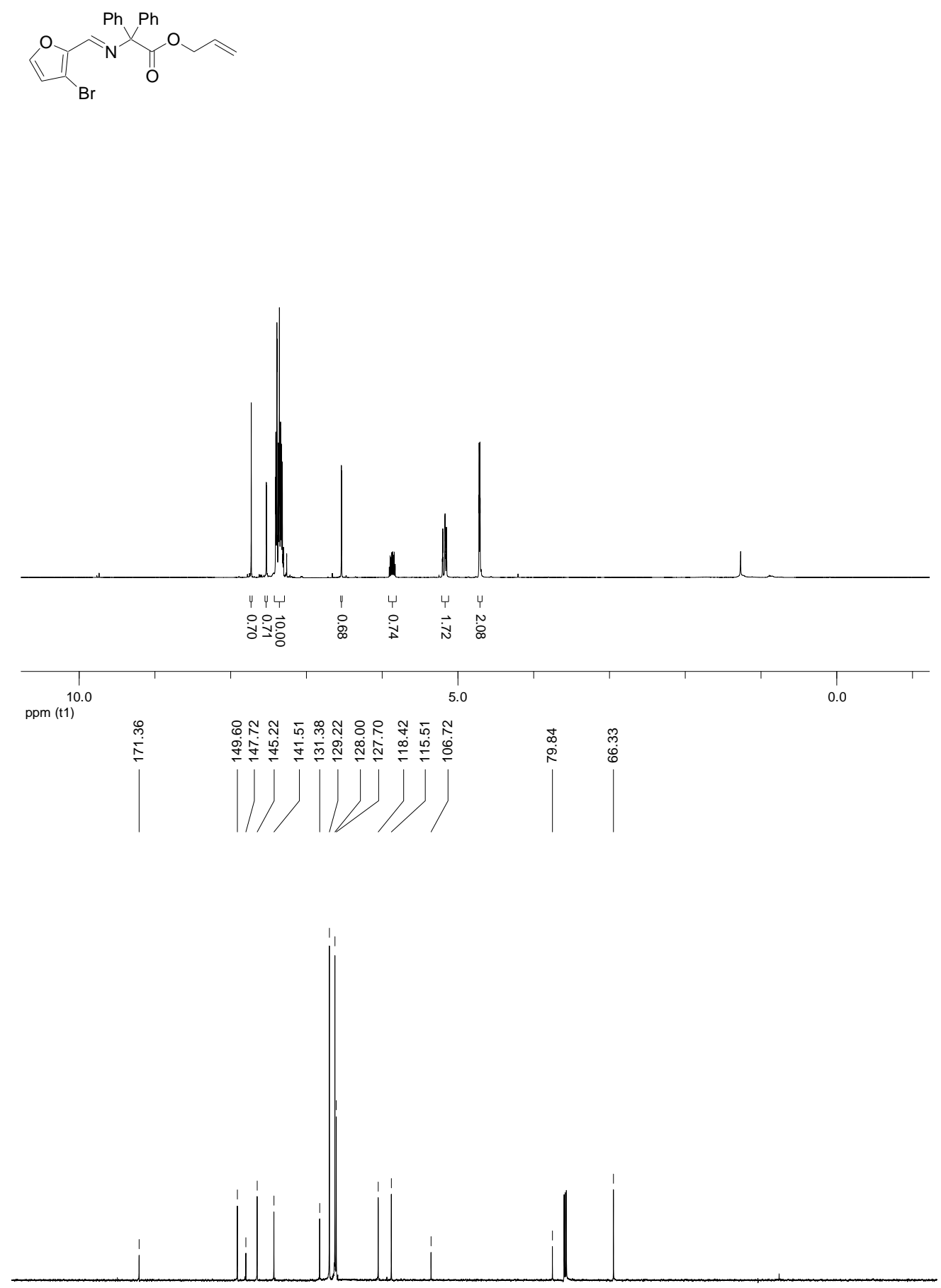

150
ppm (t1)
$1 \mathrm{H}$ - and ${ }^{13} \mathrm{C}$-NMR $\left(\mathrm{CDCl}_{3}\right)$ Spectra of $\mathbf{3 . 1 9}$



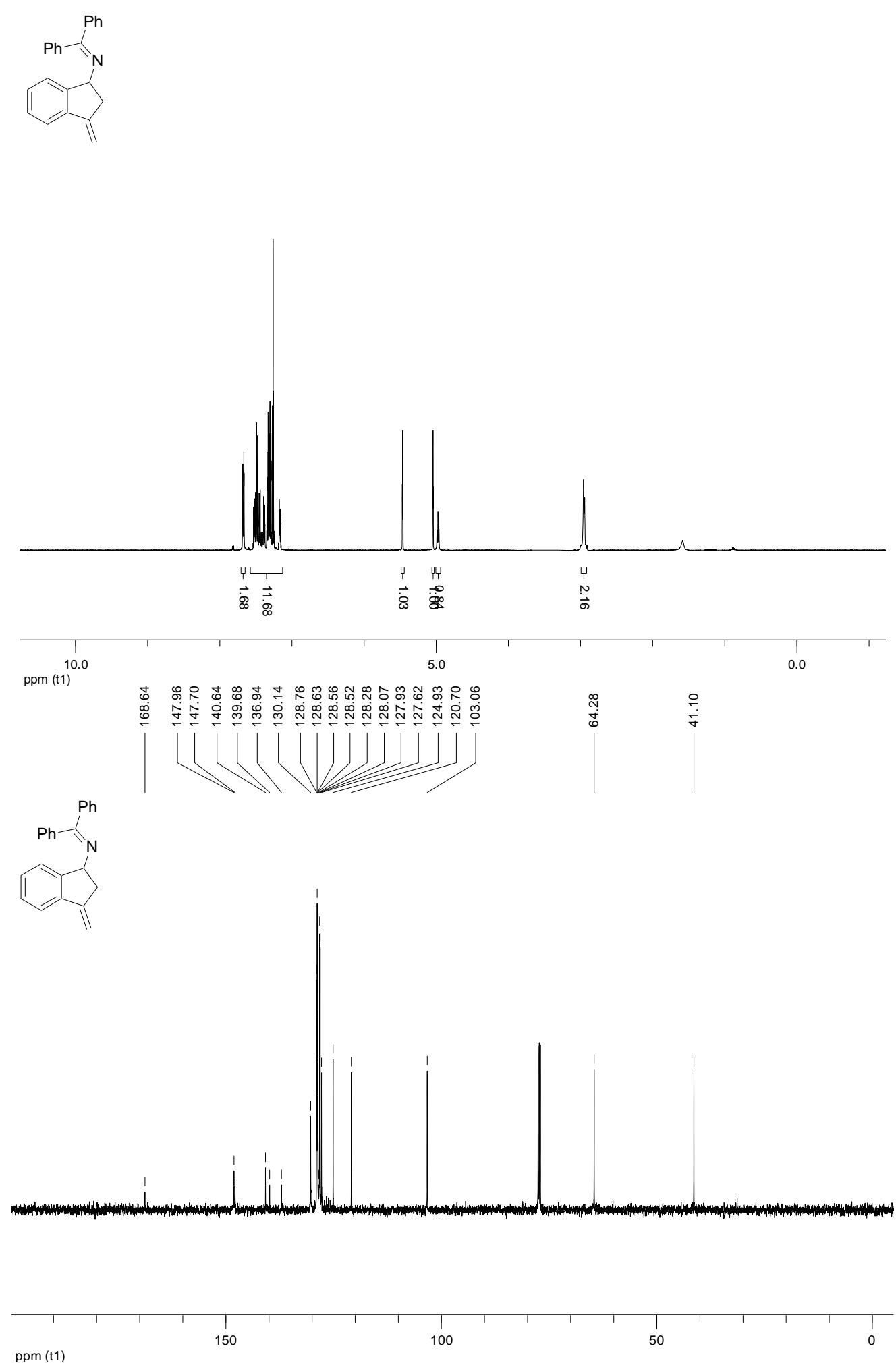

${ }^{1} \mathrm{H}-$ and ${ }^{13} \mathrm{C}-\mathrm{NMR}\left(\mathrm{CDCl}_{3}\right)$ Spectra of 3.4a 

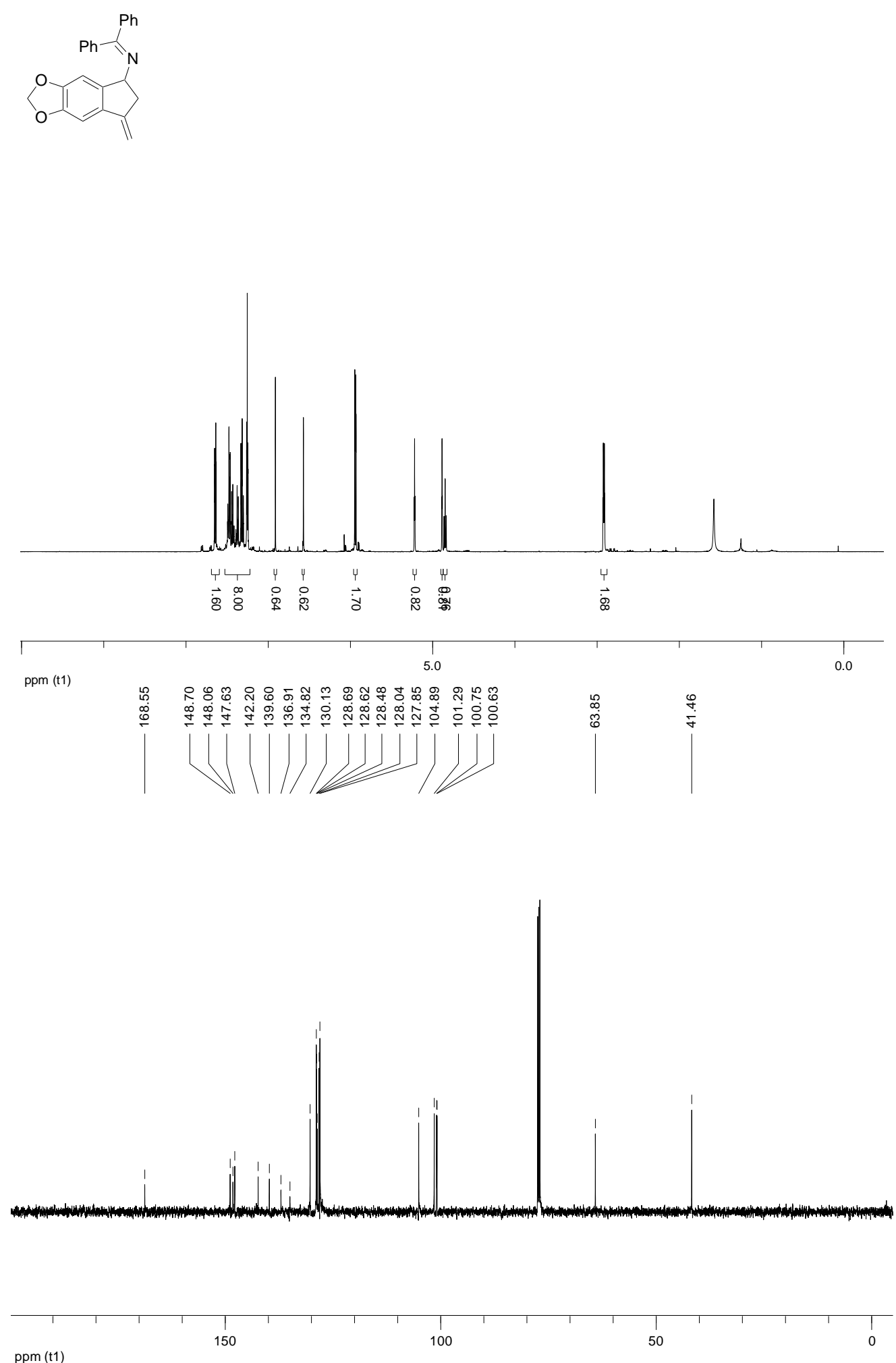

${ }^{1} \mathrm{H}$ - and ${ }^{13} \mathrm{C}-\mathrm{NMR}\left(\mathrm{CDCl}_{3}\right)$ Spectra of 3.4b 

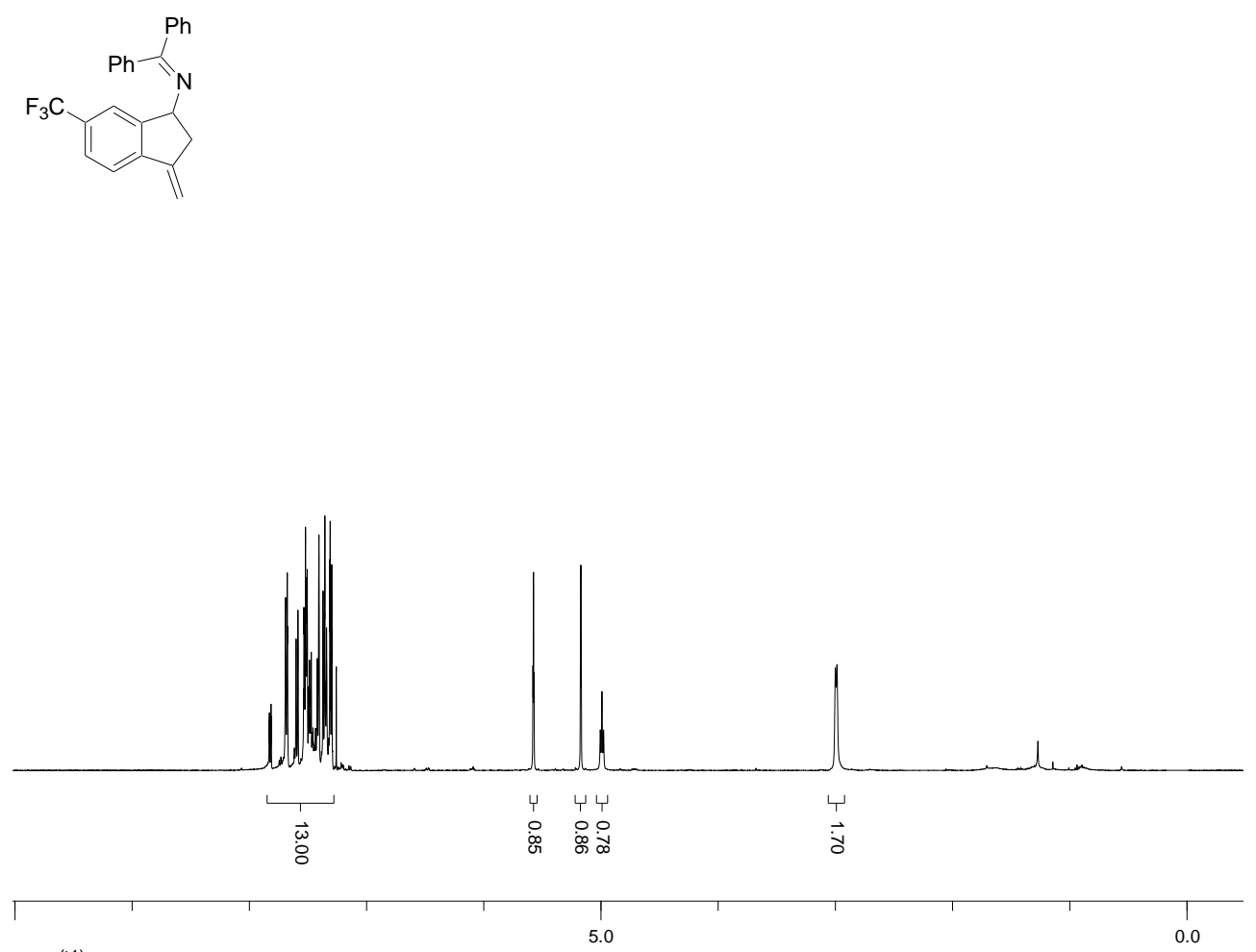

ppm (t1)

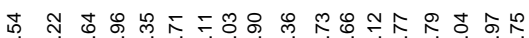

চ
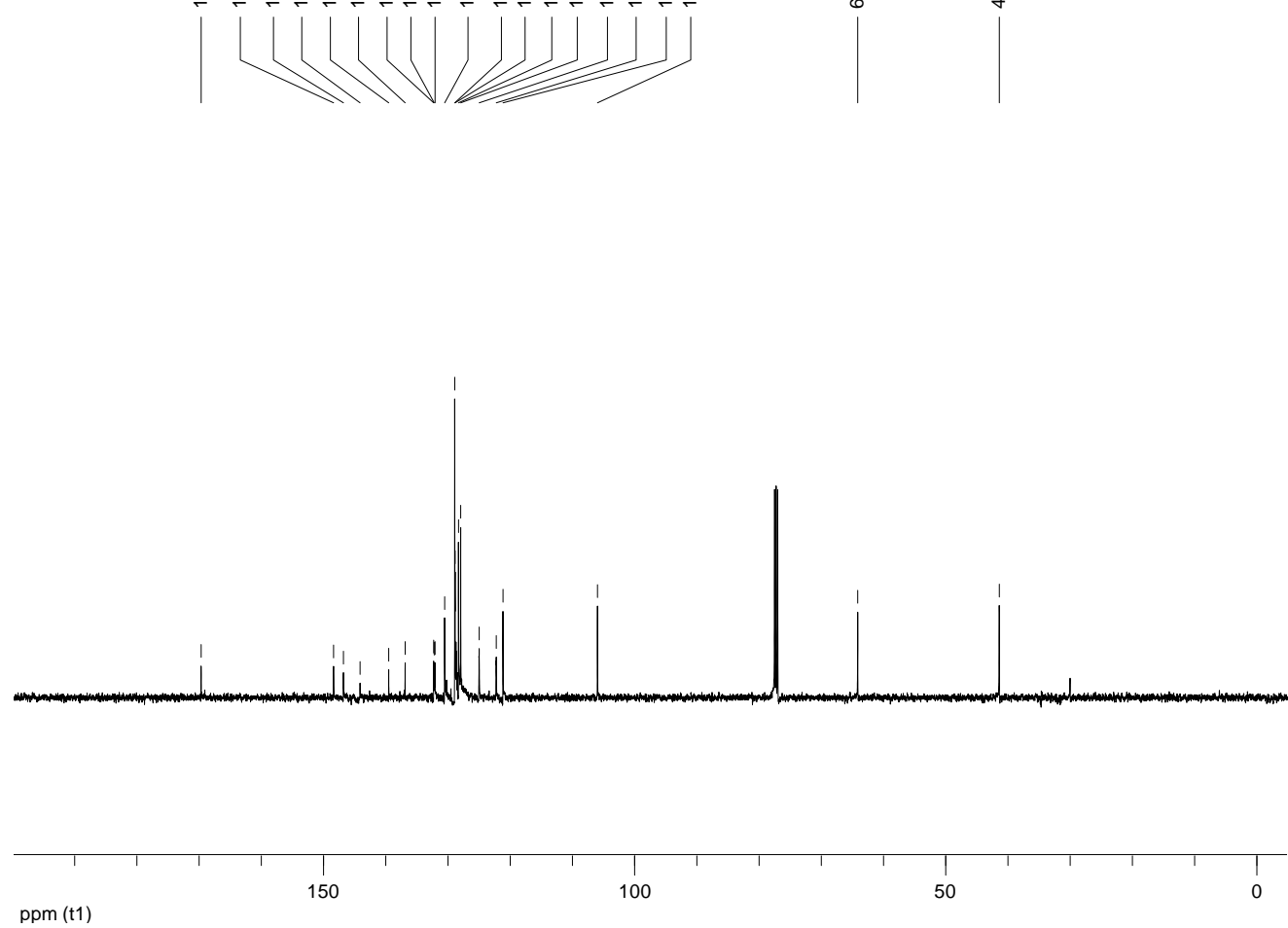

${ }^{1} \mathrm{H}$ - and ${ }^{13} \mathrm{C}$-NMR $\left(\mathrm{CDCl}_{3}\right)$ Spectra of 3.4c 

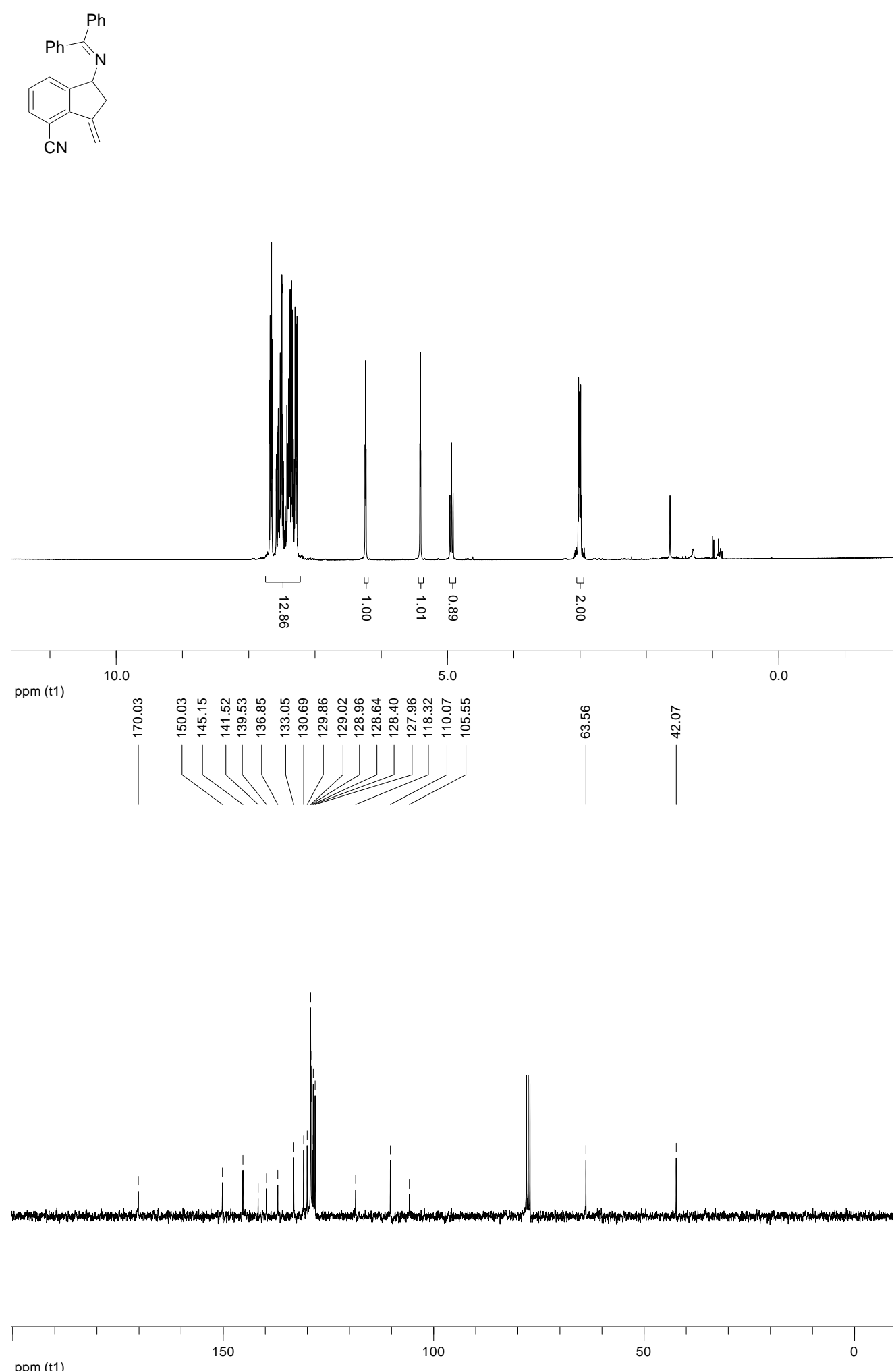

${ }^{1} \mathrm{H}-$ and ${ }^{13} \mathrm{C}-\mathrm{NMR}\left(\mathrm{CDCl}_{3}\right)$ Spectra of $\mathbf{3 . 4 d}$ 

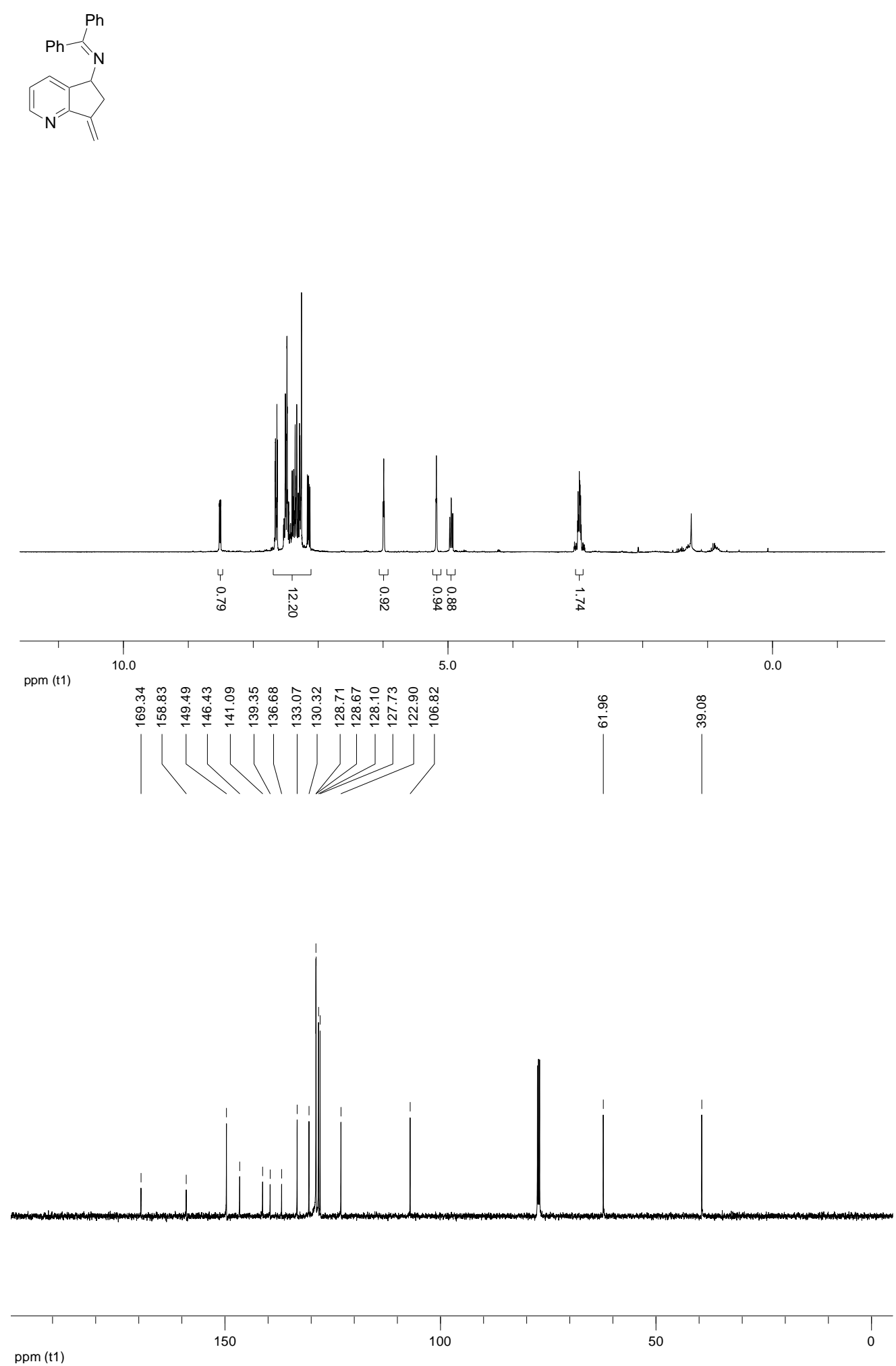

${ }^{1} \mathrm{H}$ - and ${ }^{13} \mathrm{C}-\mathrm{NMR}\left(\mathrm{CDCl}_{3}\right)$ Spectra of $\mathbf{3 . 4 e}$ 

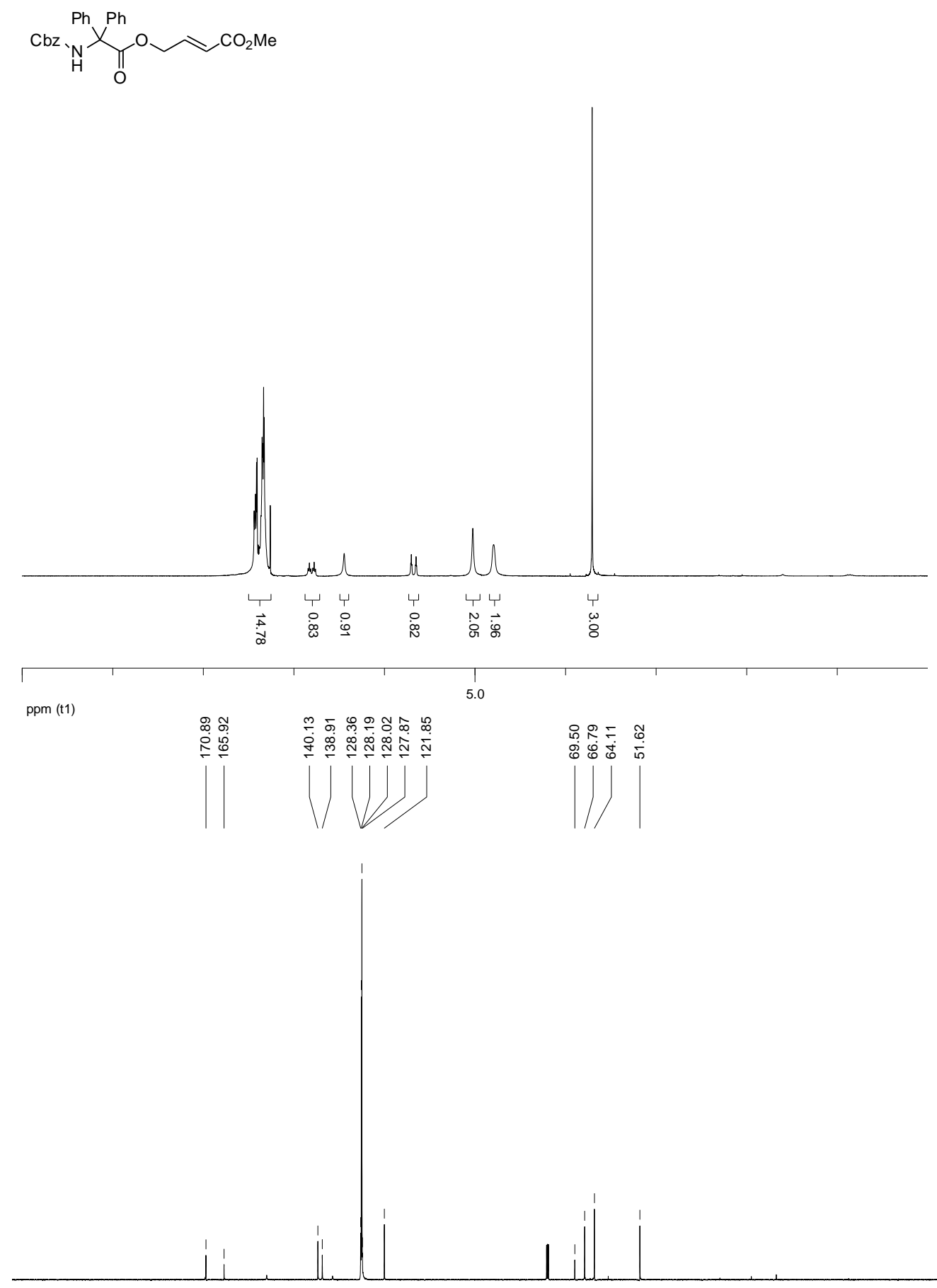

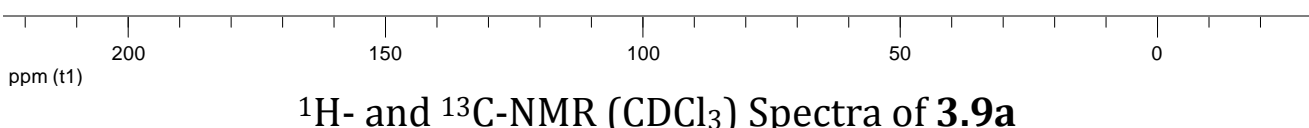

${ }^{1} \mathrm{H}$ - and ${ }^{13} \mathrm{C}-\mathrm{NMR}\left(\mathrm{CDCl}_{3}\right)$ Spectra of 3.9a 

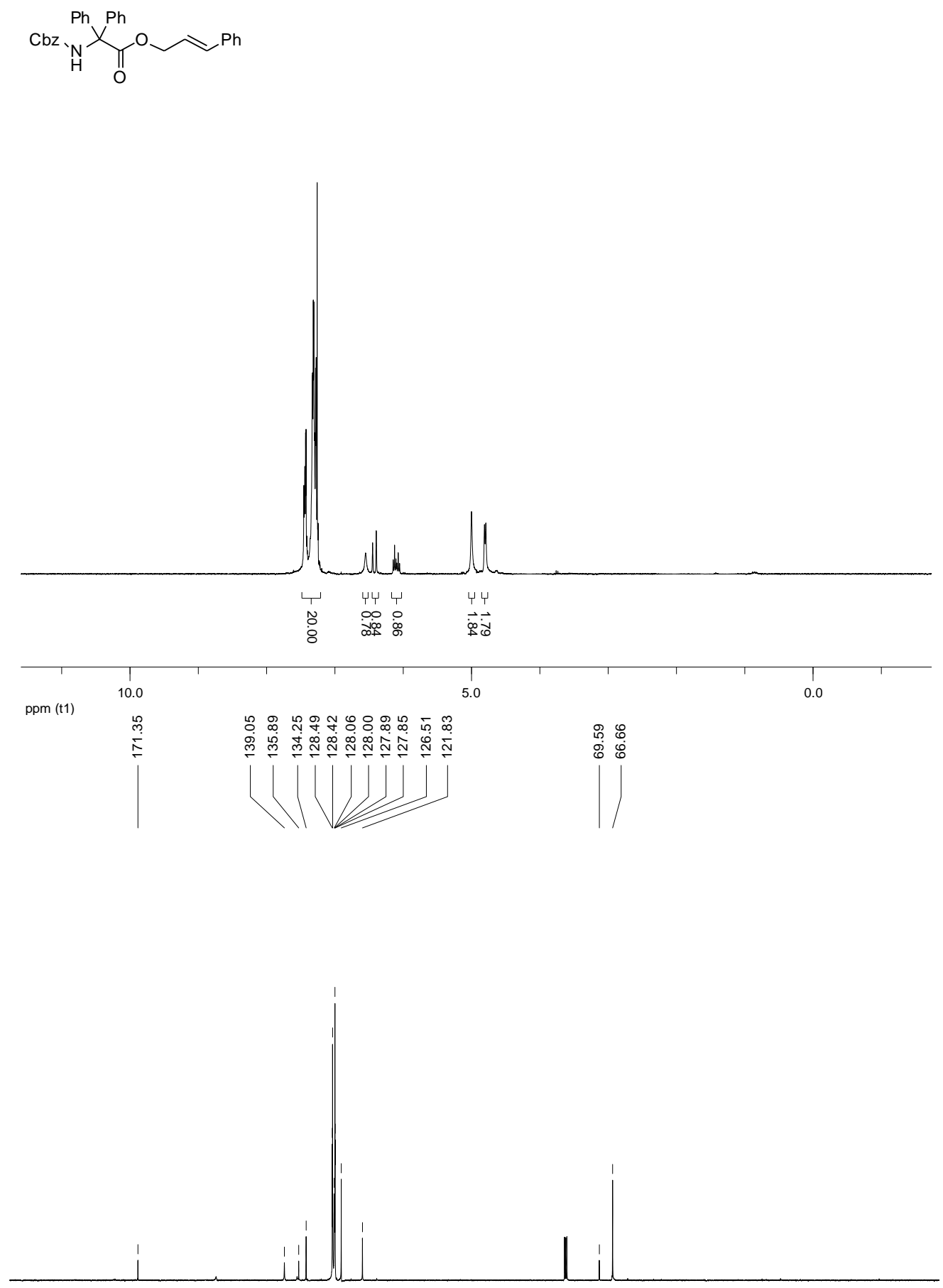

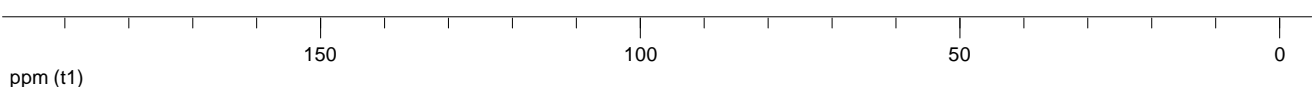

${ }^{1} \mathrm{H}$ - and ${ }^{13} \mathrm{C}-\mathrm{NMR}\left(\mathrm{CDCl}_{3}\right)$ Spectra of 3.9b 

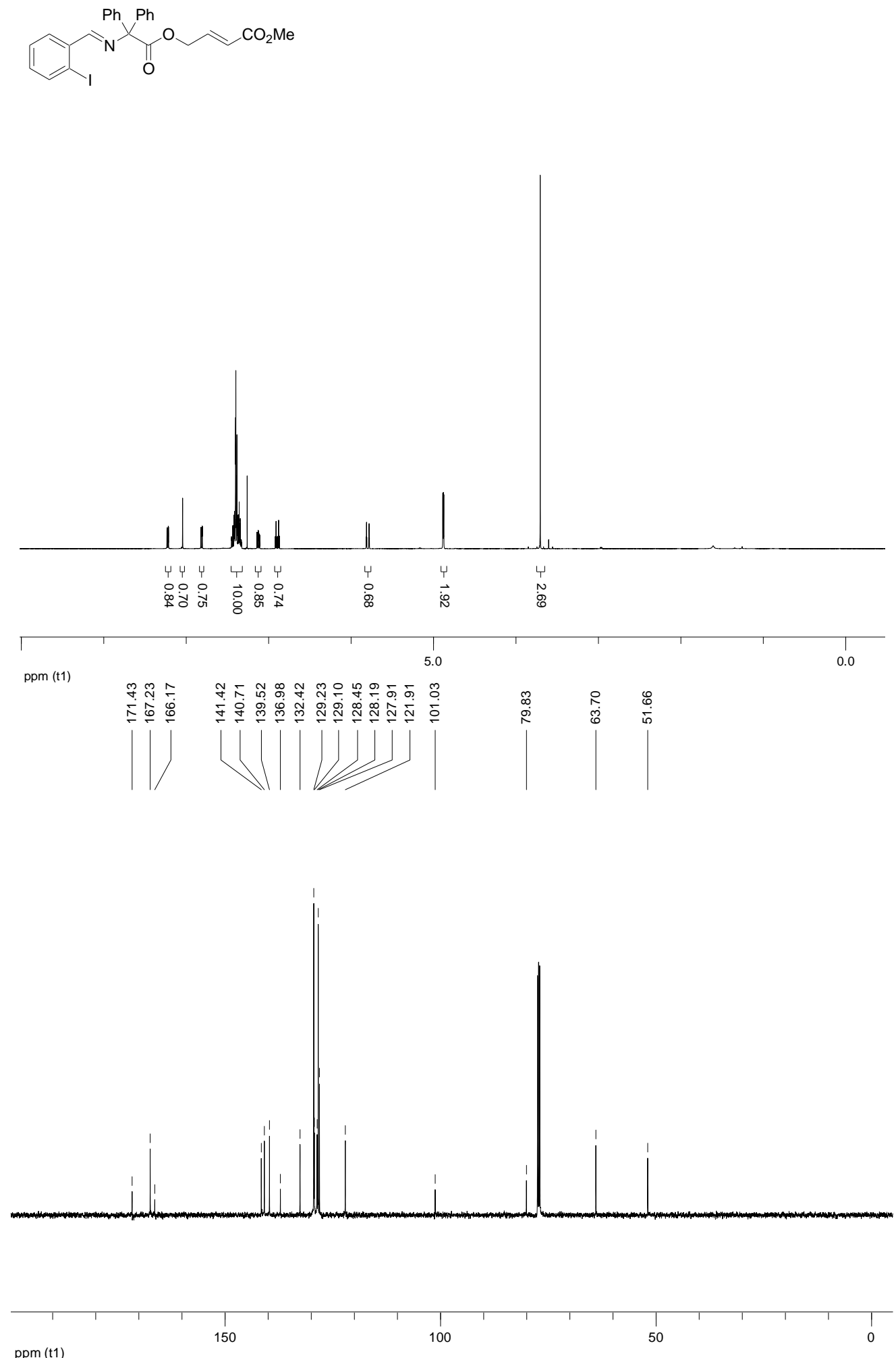

${ }^{1} \mathrm{H}-$ and ${ }^{13} \mathrm{C}-\mathrm{NMR}\left(\mathrm{CDCl}_{3}\right)$ Spectra of $\mathbf{3 . 1 2 a}$ 

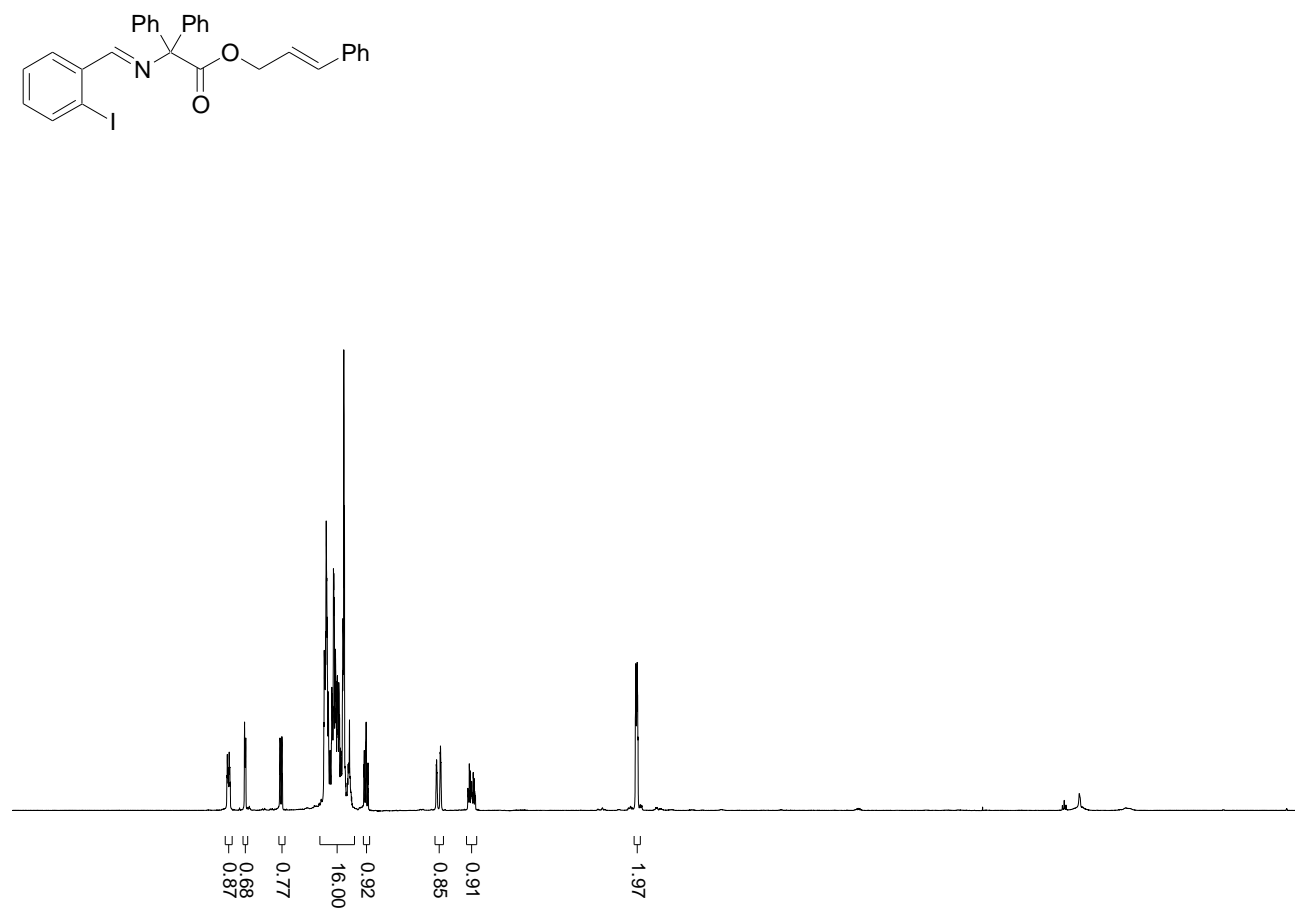

ppm (t1) 1
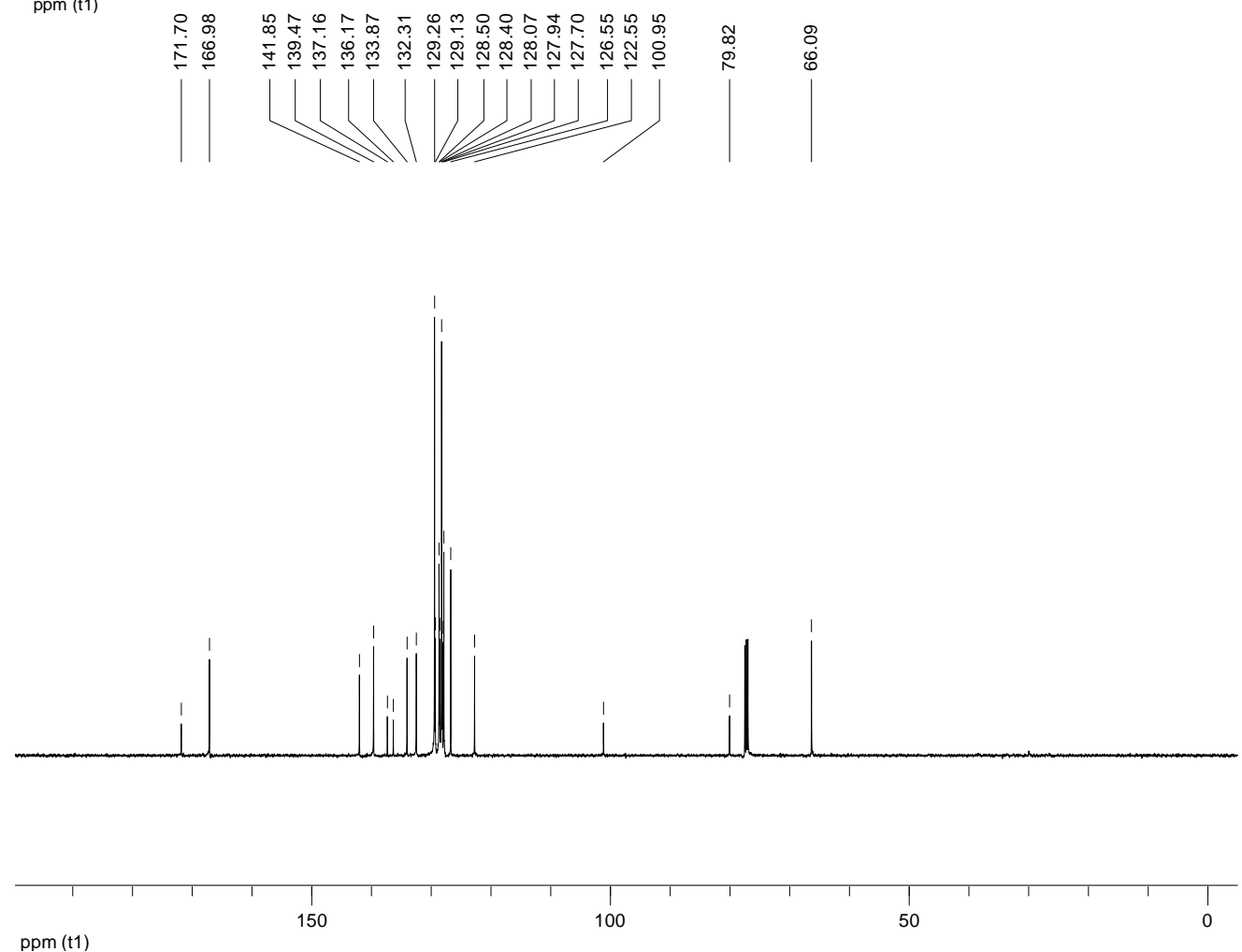

${ }^{1} \mathrm{H}-$ and ${ }^{13} \mathrm{C}-\mathrm{NMR}\left(\mathrm{CDCl}_{3}\right)$ Spectra of $\mathbf{3 . 1 2} \mathbf{b}$ 

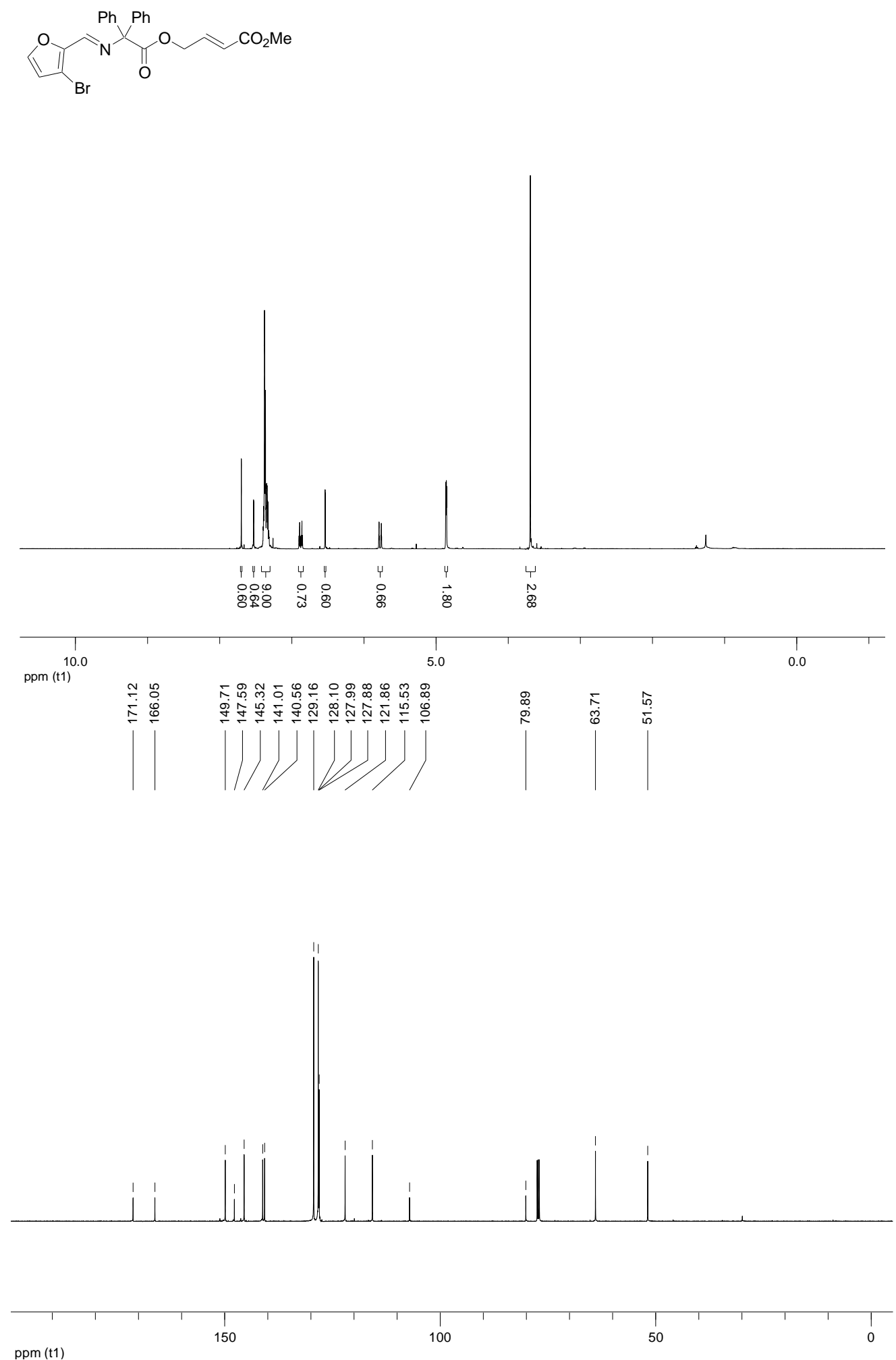

${ }^{1} \mathrm{H}$ - and ${ }^{13} \mathrm{C}-\mathrm{NMR}\left(\mathrm{CDCl}_{3}\right)$ Spectra of 3.12c 

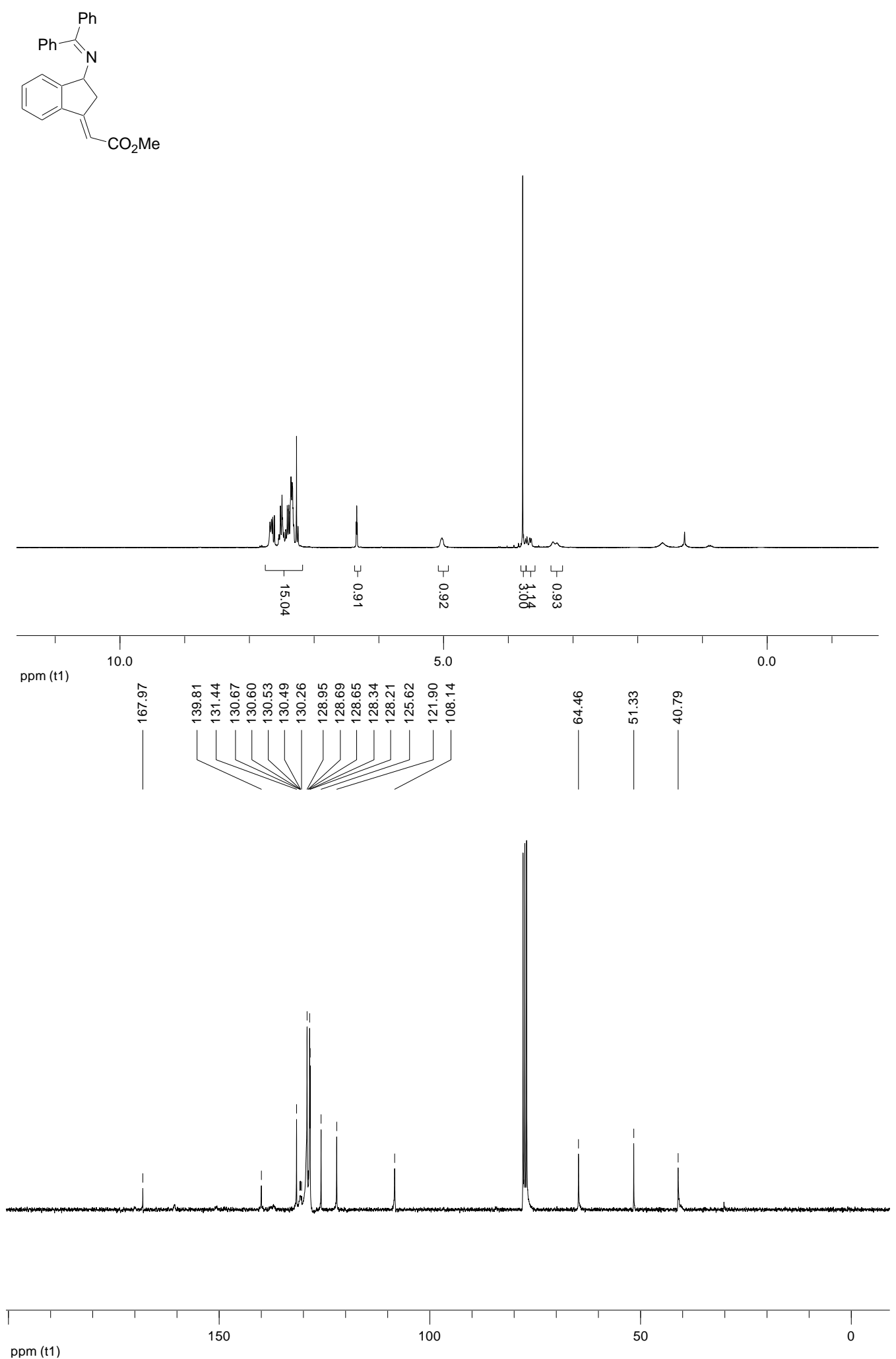

${ }^{1} \mathrm{H}-$ and ${ }^{13} \mathrm{C}-\mathrm{NMR}\left(\mathrm{CDCl}_{3}\right)$ Spectra of 3.13a 

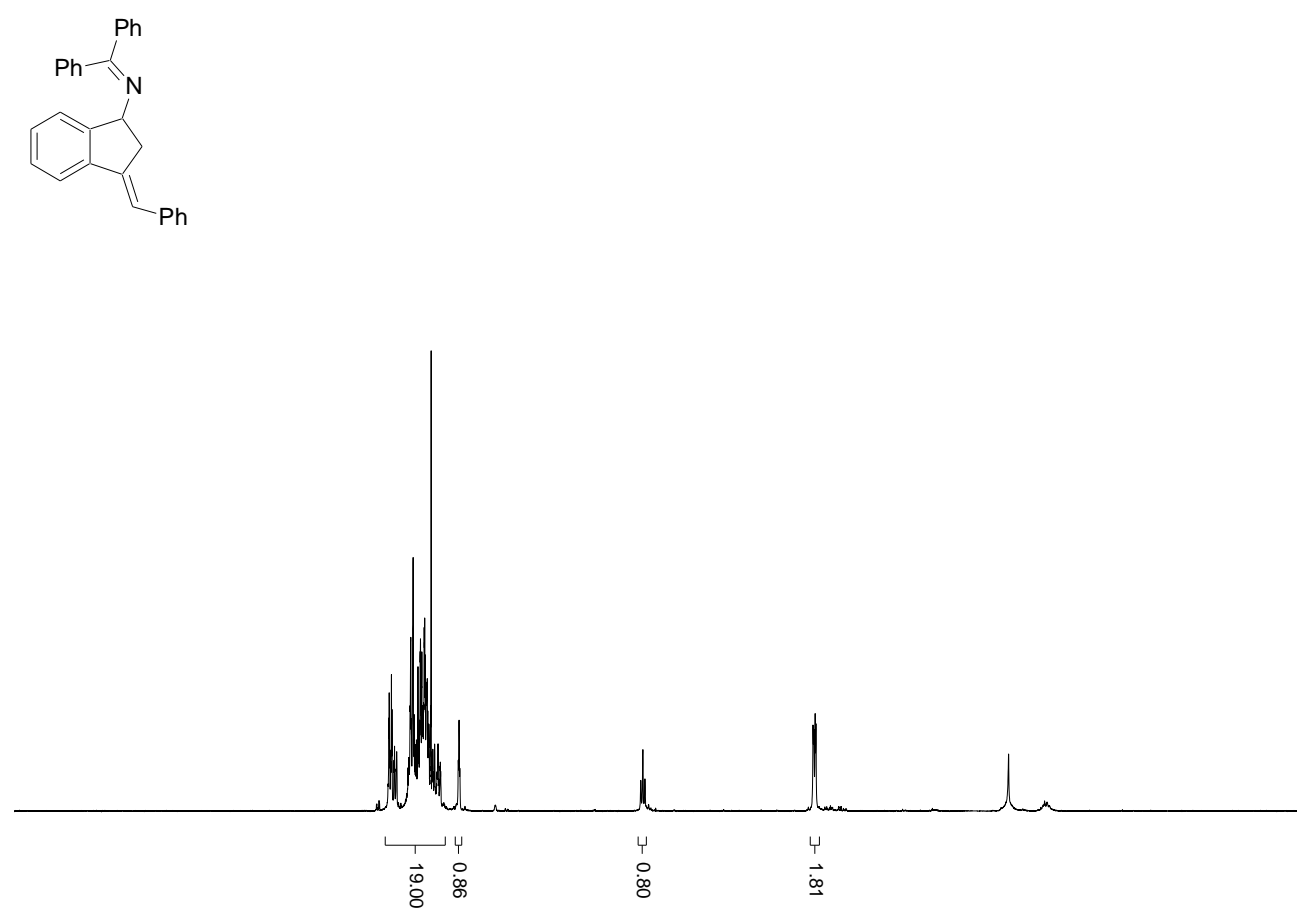

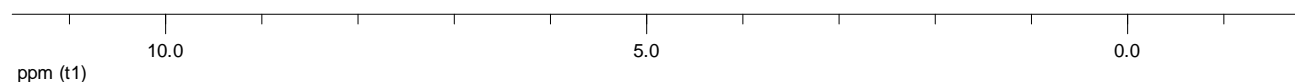

돈

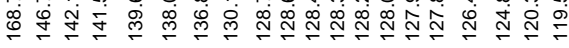
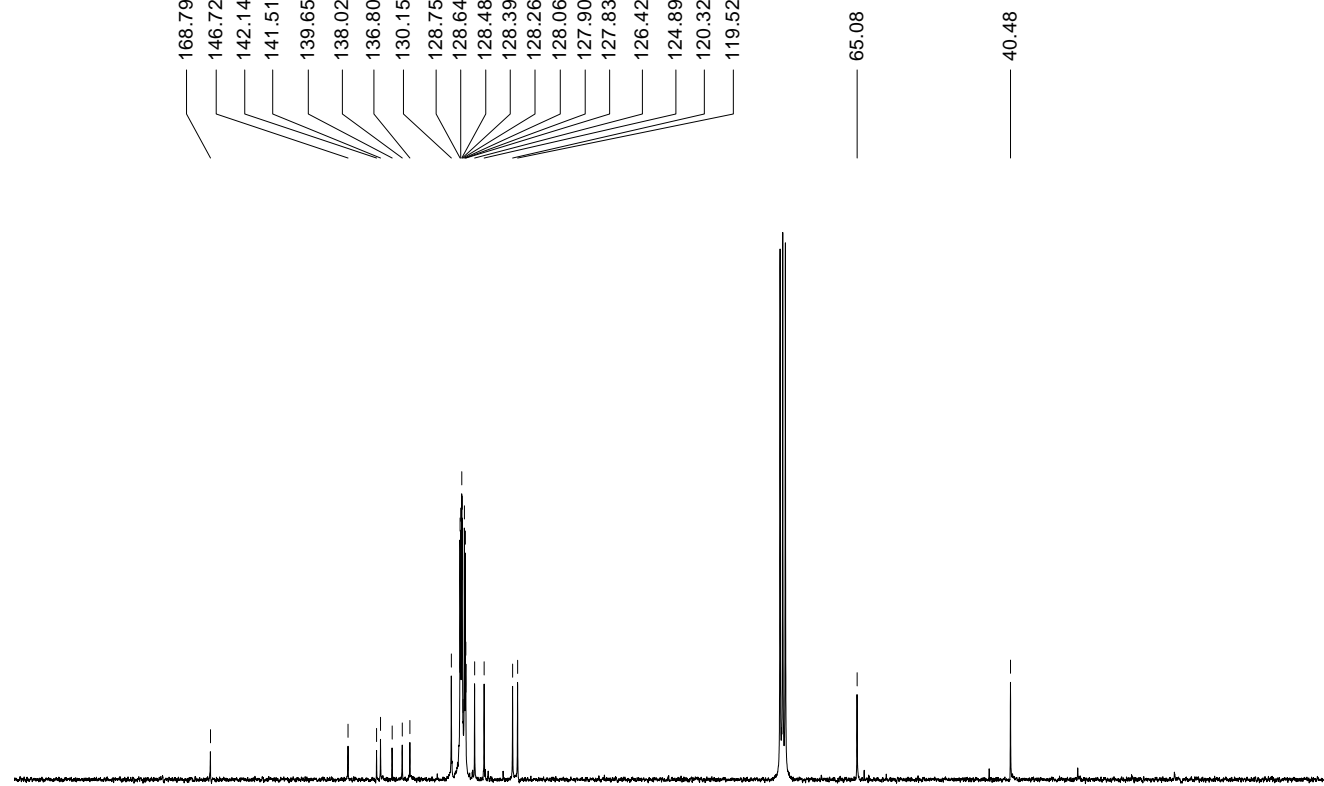

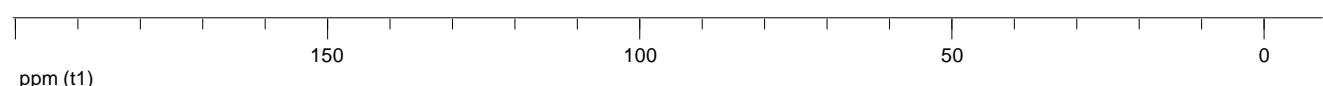

${ }^{1} \mathrm{H}-$ and ${ }^{13} \mathrm{C}-\mathrm{NMR}\left(\mathrm{CDCl}_{3}\right)$ Spectra of $\mathbf{3 . 1 3 b}$ 

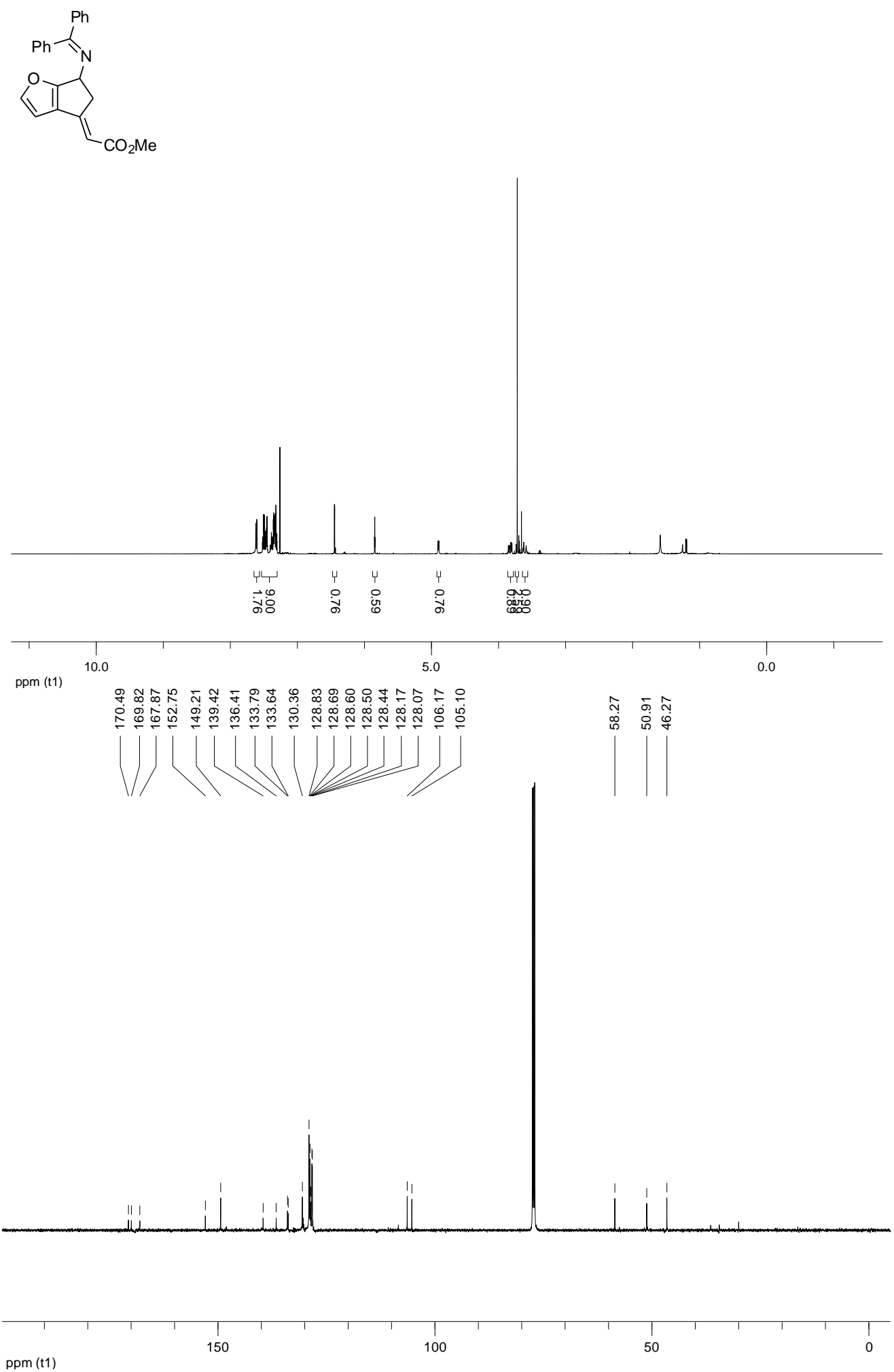

${ }^{1} \mathrm{H}$ - and ${ }^{13} \mathrm{C}-\mathrm{NMR}\left(\mathrm{CDCl}_{3}\right)$ Spectra of 3.13c 

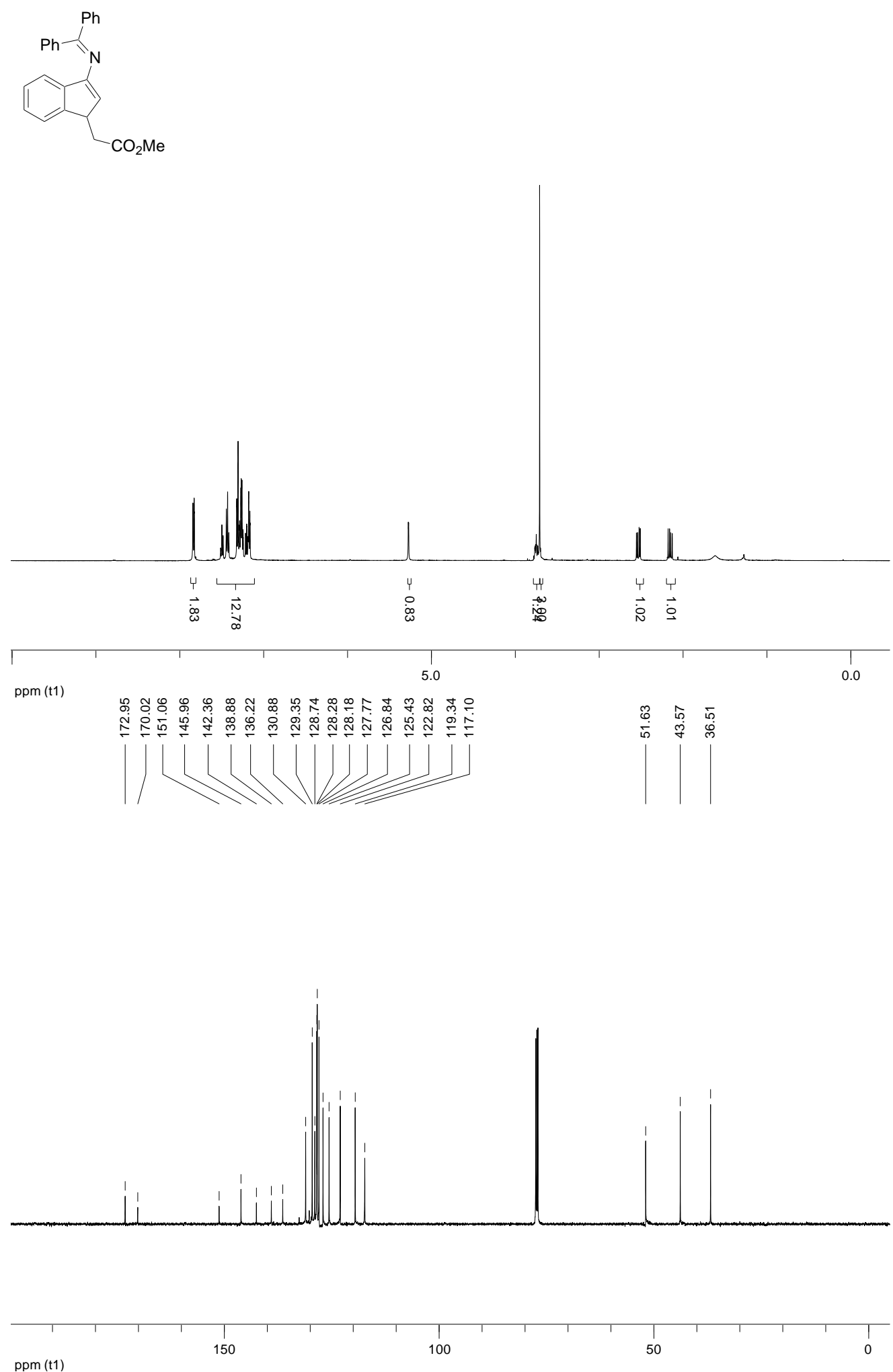

${ }^{1} \mathrm{H}$ - and ${ }^{13} \mathrm{C}-\mathrm{NMR}\left(\mathrm{CDCl}_{3}\right)$ Spectra of $\mathbf{3 . 1 4 a}$ 
<smiles>NC(C(=O)OCc1ccc(C(F)(F)F)cc1)(c1ccccc1)c1ccccc1</smiles>
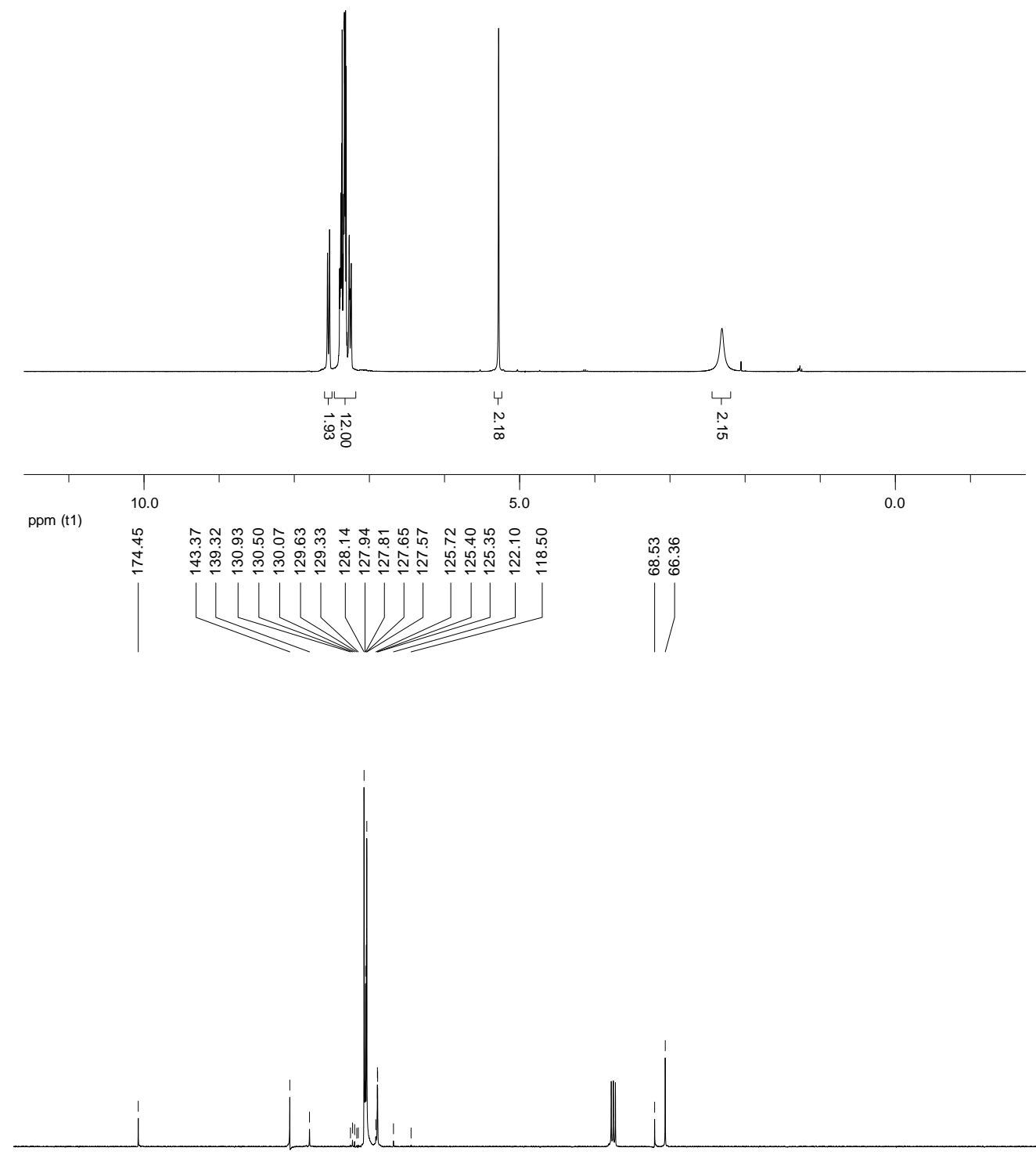

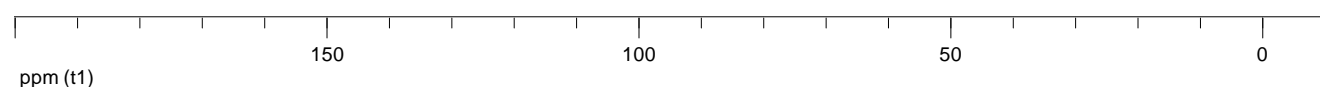

${ }^{1} \mathrm{H}-$ and ${ }^{13} \mathrm{C}-\mathrm{NMR}\left(\mathrm{CDCl}_{3}\right)$ Spectra of 4.3a 


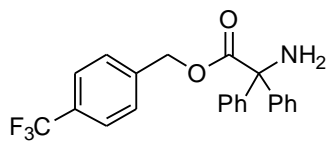

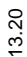

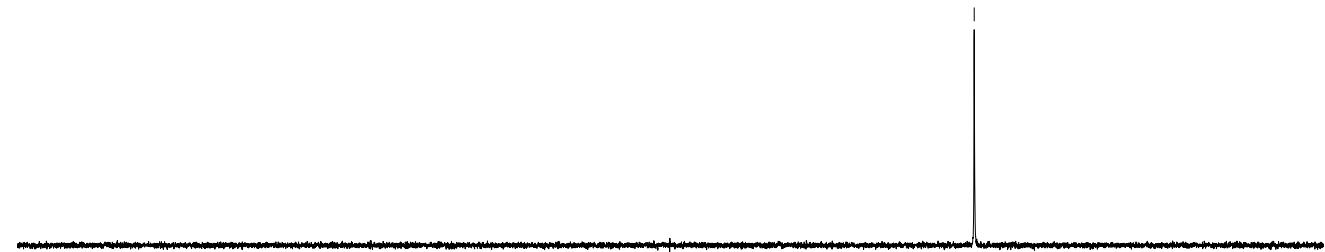

\begin{tabular}{c|c|c|c|c|c|c|c|c|c|}
\hline \\
50 \\
ppm (t1)
\end{tabular}

${ }^{19} \mathrm{~F}-\mathrm{NMR}\left(\mathrm{CDCl}_{3}\right)$ Spectra of $\mathbf{4 . 3 a}$ 

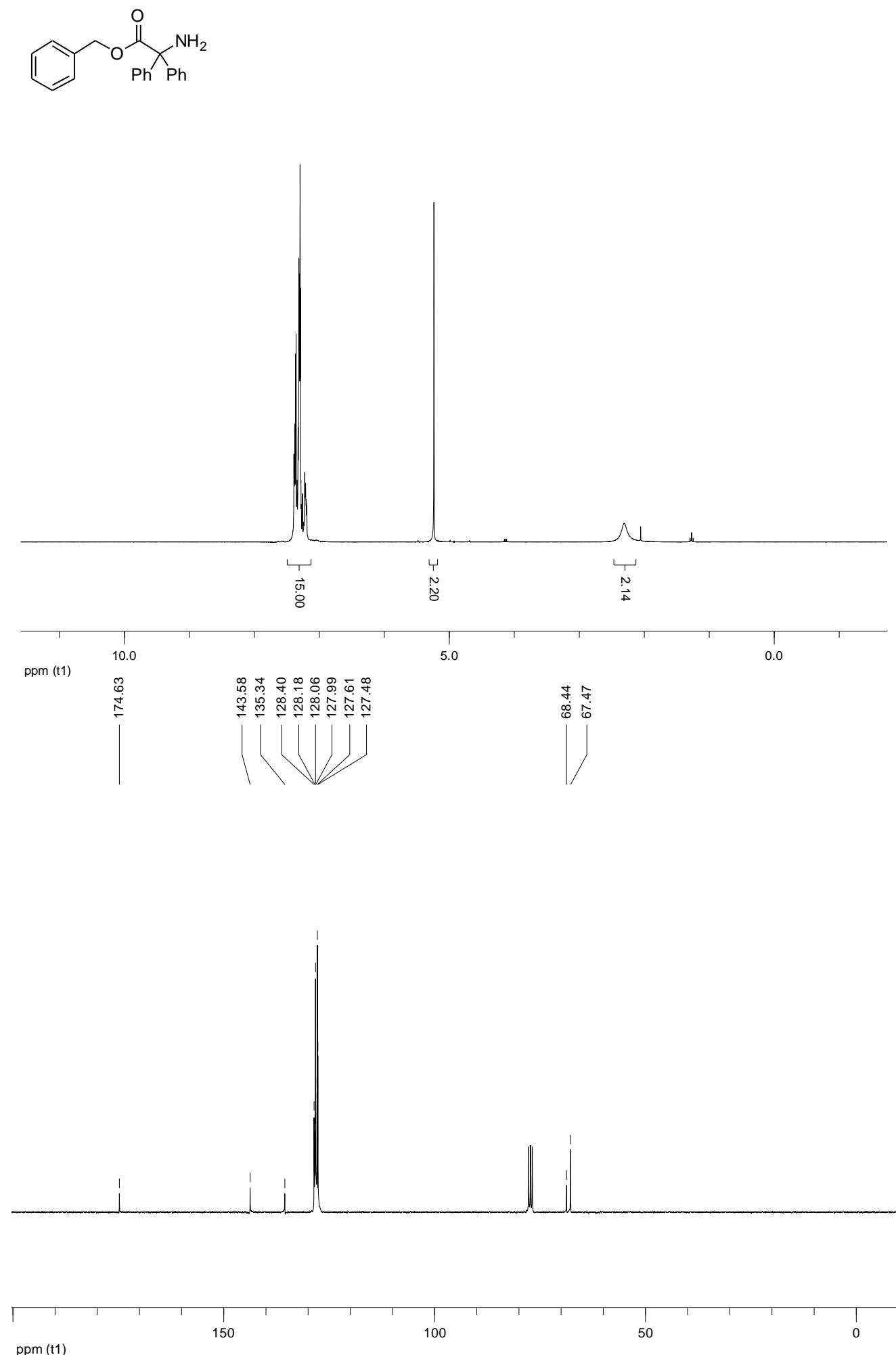

${ }^{1} \mathrm{H}-$ and ${ }^{13} \mathrm{C}-\mathrm{NMR}\left(\mathrm{CDCl}_{3}\right)$ Spectra of $4.3 \mathbf{b}$ 

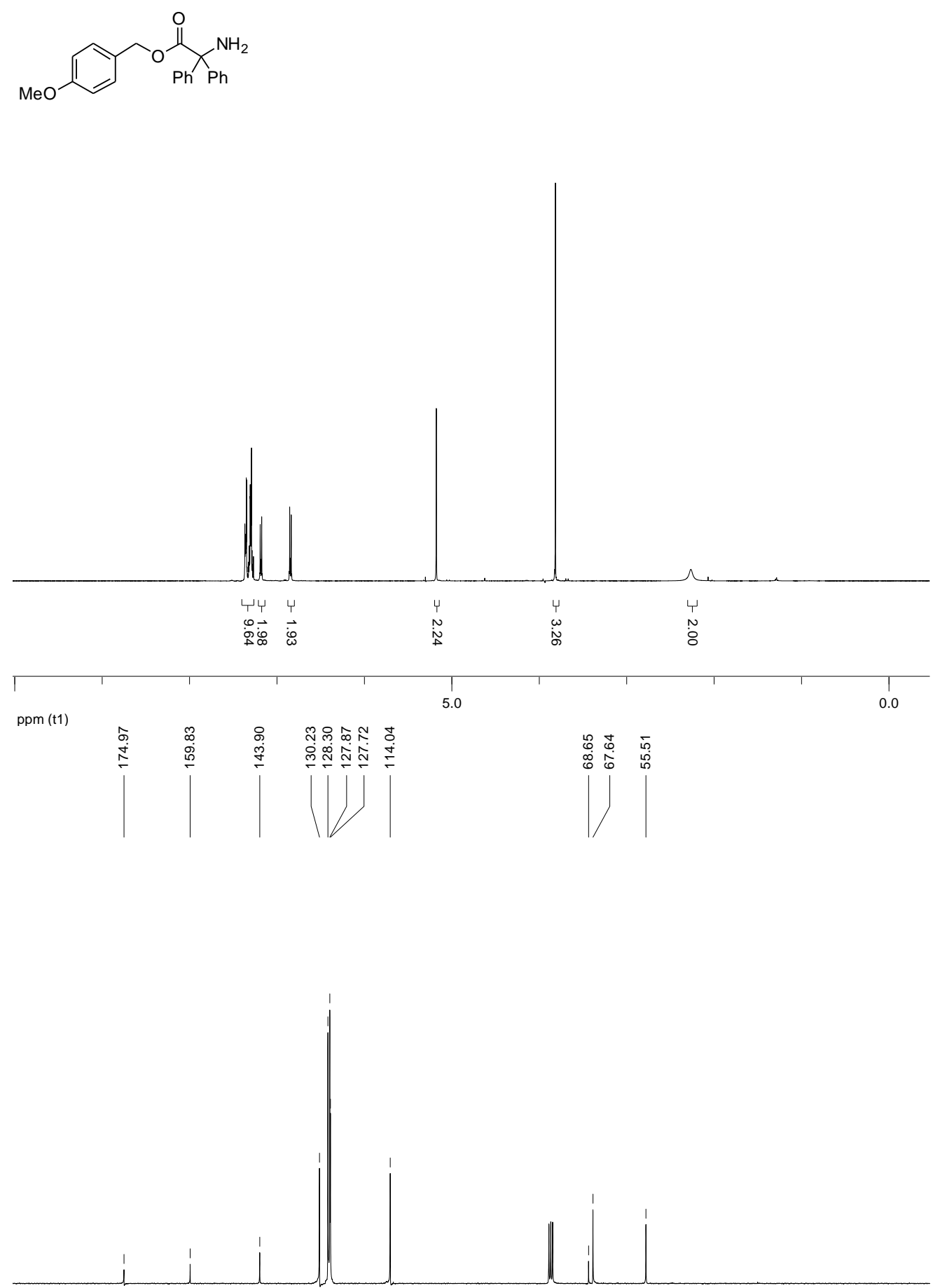

150
$\operatorname{ppm}($ (1)



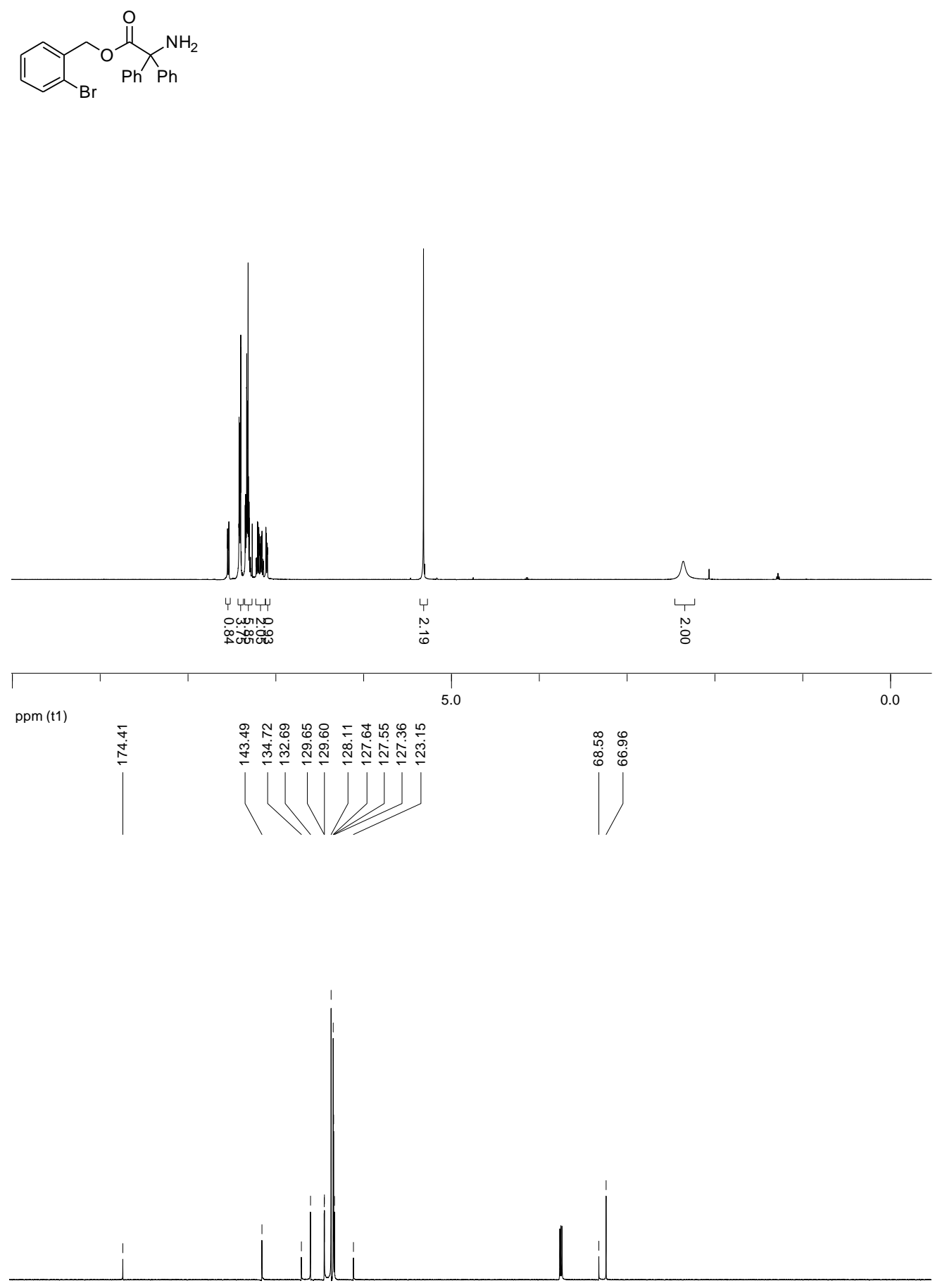

\begin{tabular}{|c|c|c|c|}
\hline & 150 & 100 & 50 \\
\hline
\end{tabular}

${ }^{1} \mathrm{H}-$ and ${ }^{13} \mathrm{C}-\mathrm{NMR}\left(\mathrm{CDCl}_{3}\right)$ Spectra of $4.3 \mathrm{~d}$ 

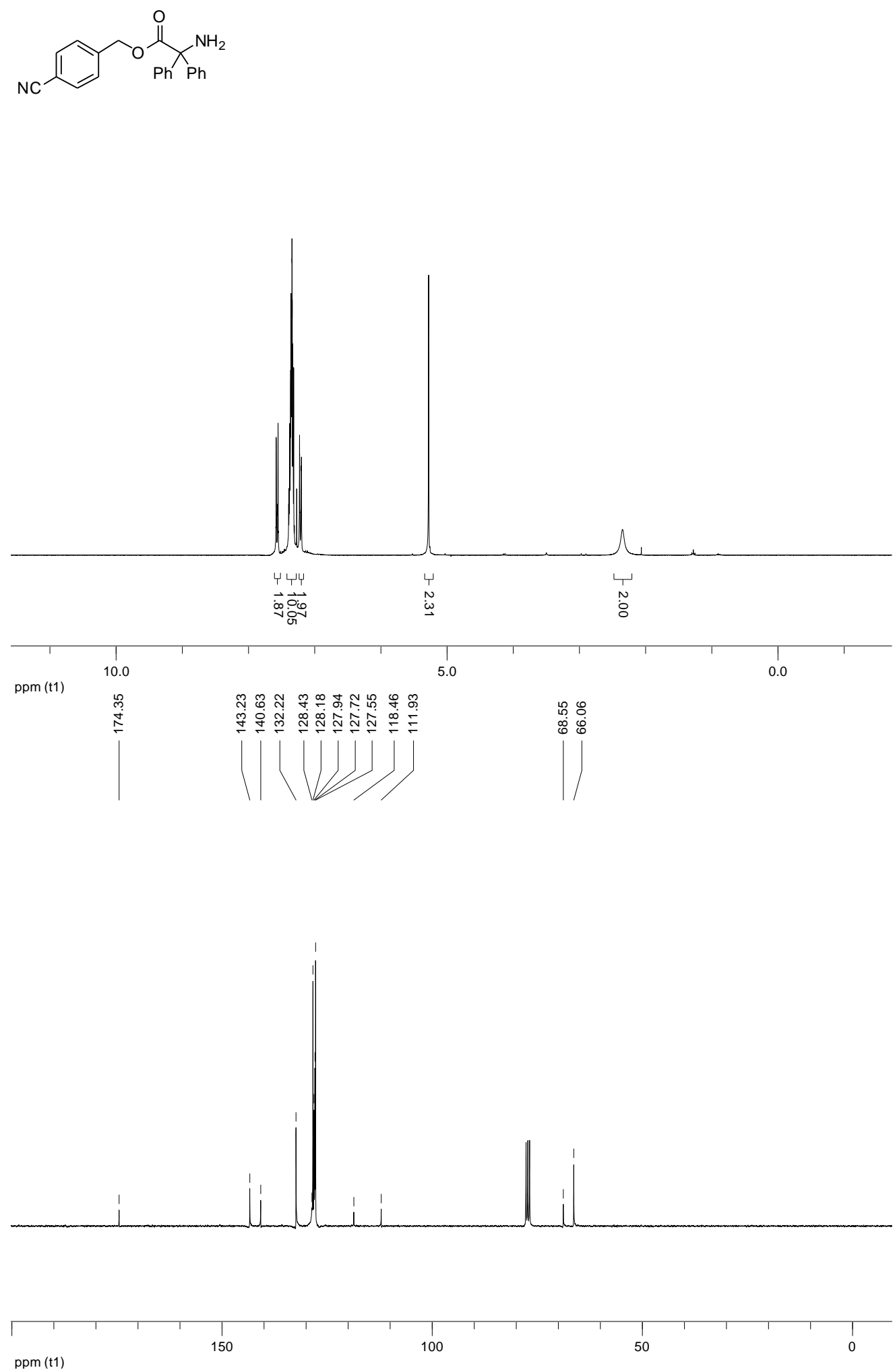

${ }^{1} \mathrm{H}$ - and ${ }^{13} \mathrm{C}$-NMR $\left(\mathrm{CDCl}_{3}\right)$ Spectra of $4.3 \mathbf{e}$ 

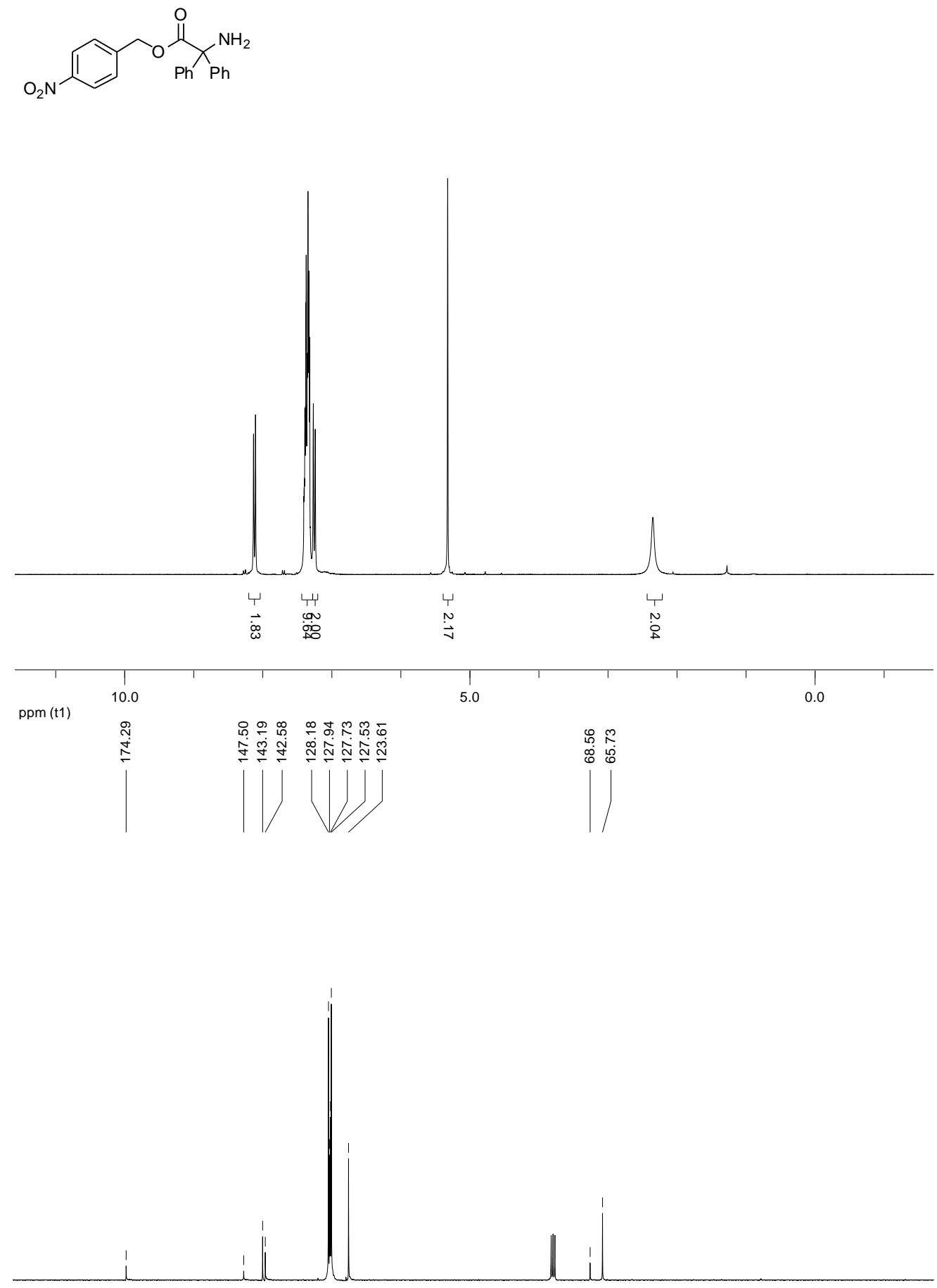

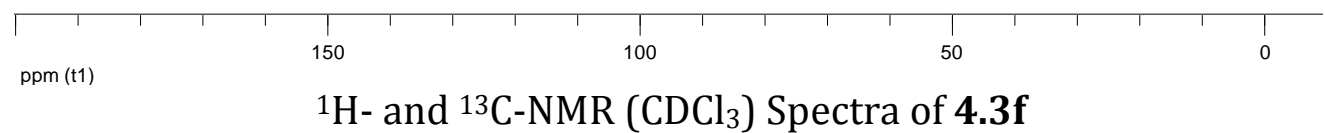



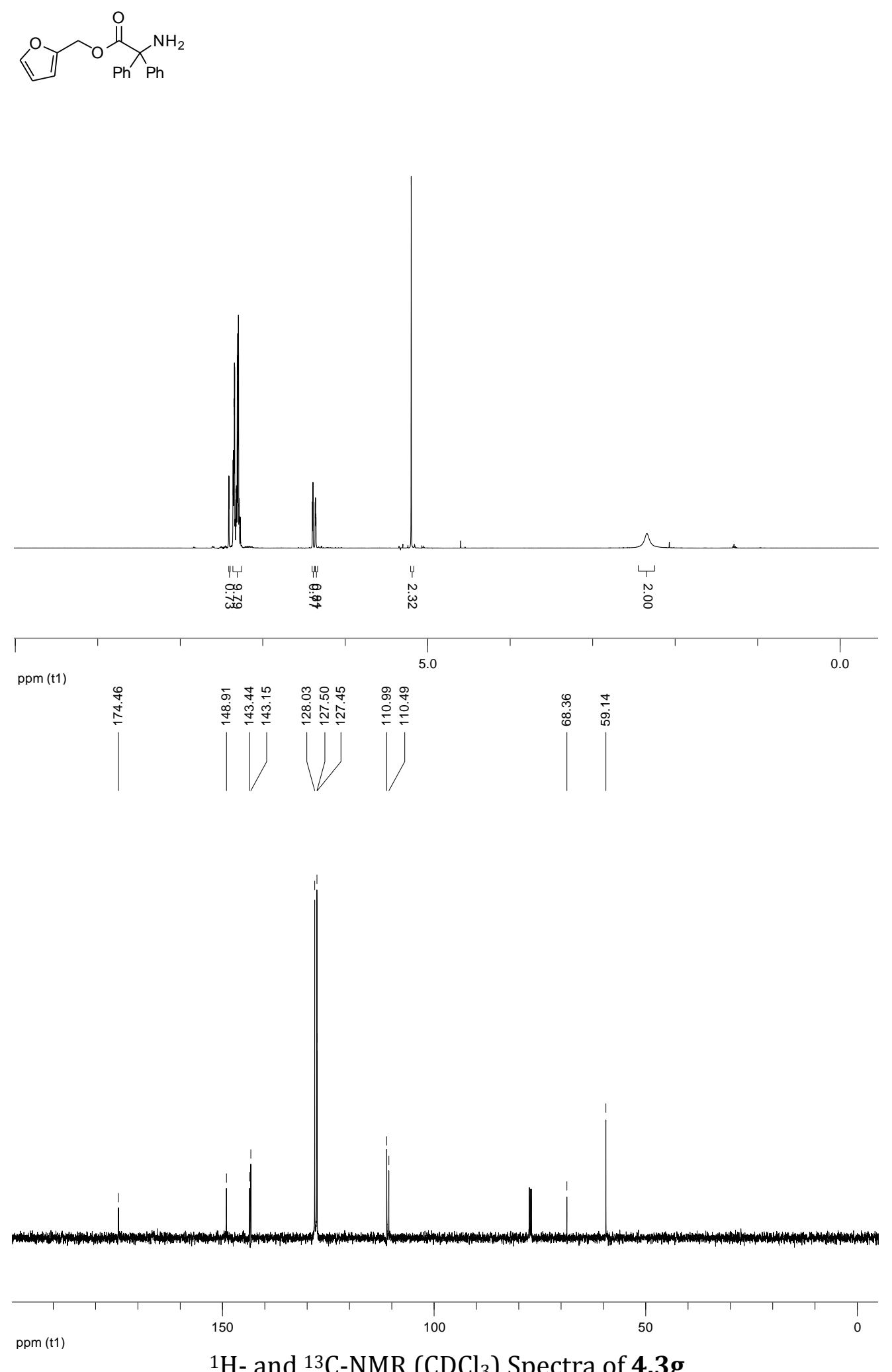

${ }^{1} \mathrm{H}$ - and ${ }^{13} \mathrm{C}-\mathrm{NMR}\left(\mathrm{CDCl}_{3}\right)$ Spectra of $4.3 \mathrm{~g}$ 

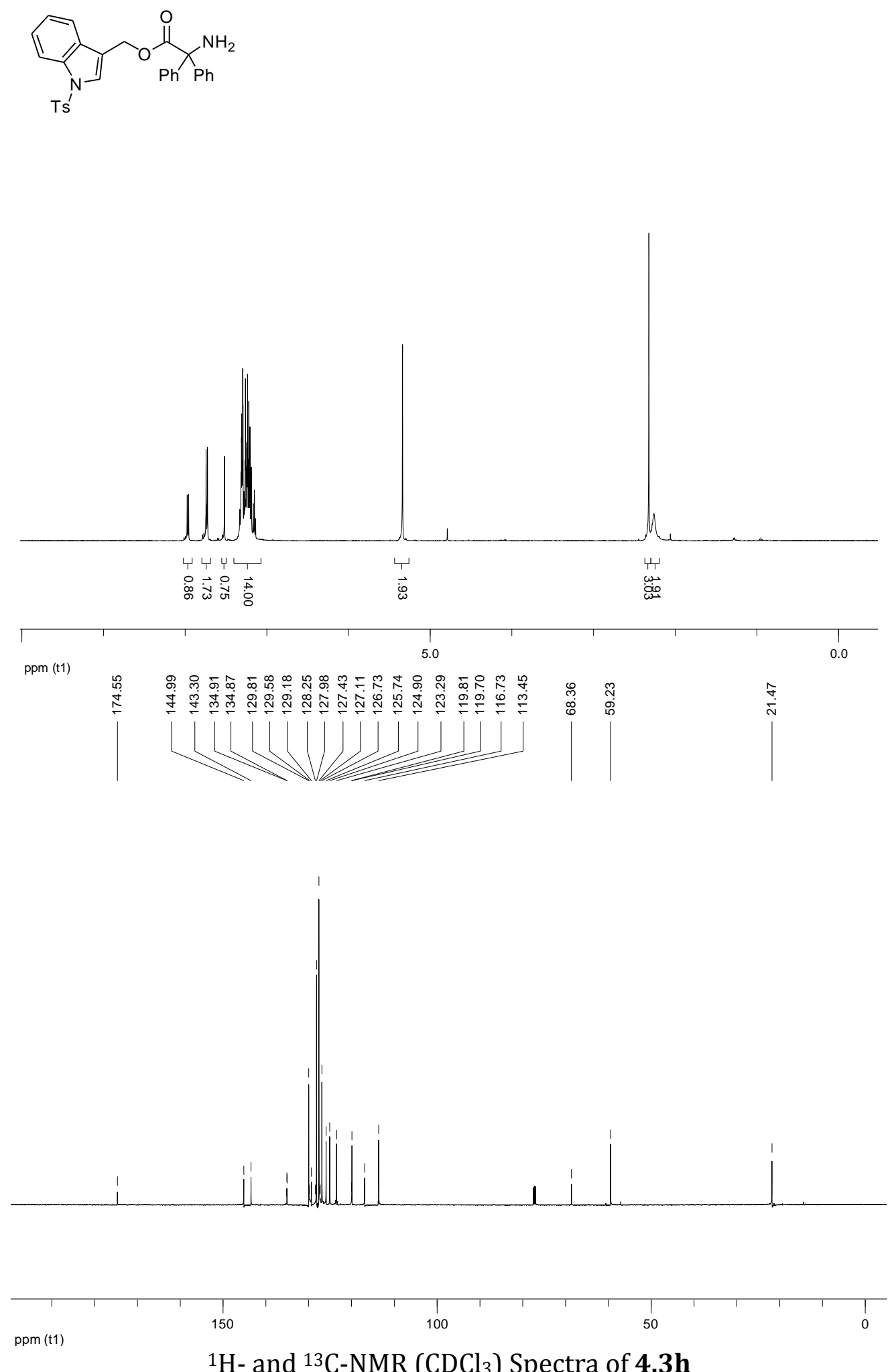

${ }^{1} \mathrm{H}$ - and ${ }^{13} \mathrm{C}-\mathrm{NMR}\left(\mathrm{CDCl}_{3}\right)$ Spectra of $\mathbf{4 . 3 h}$ 

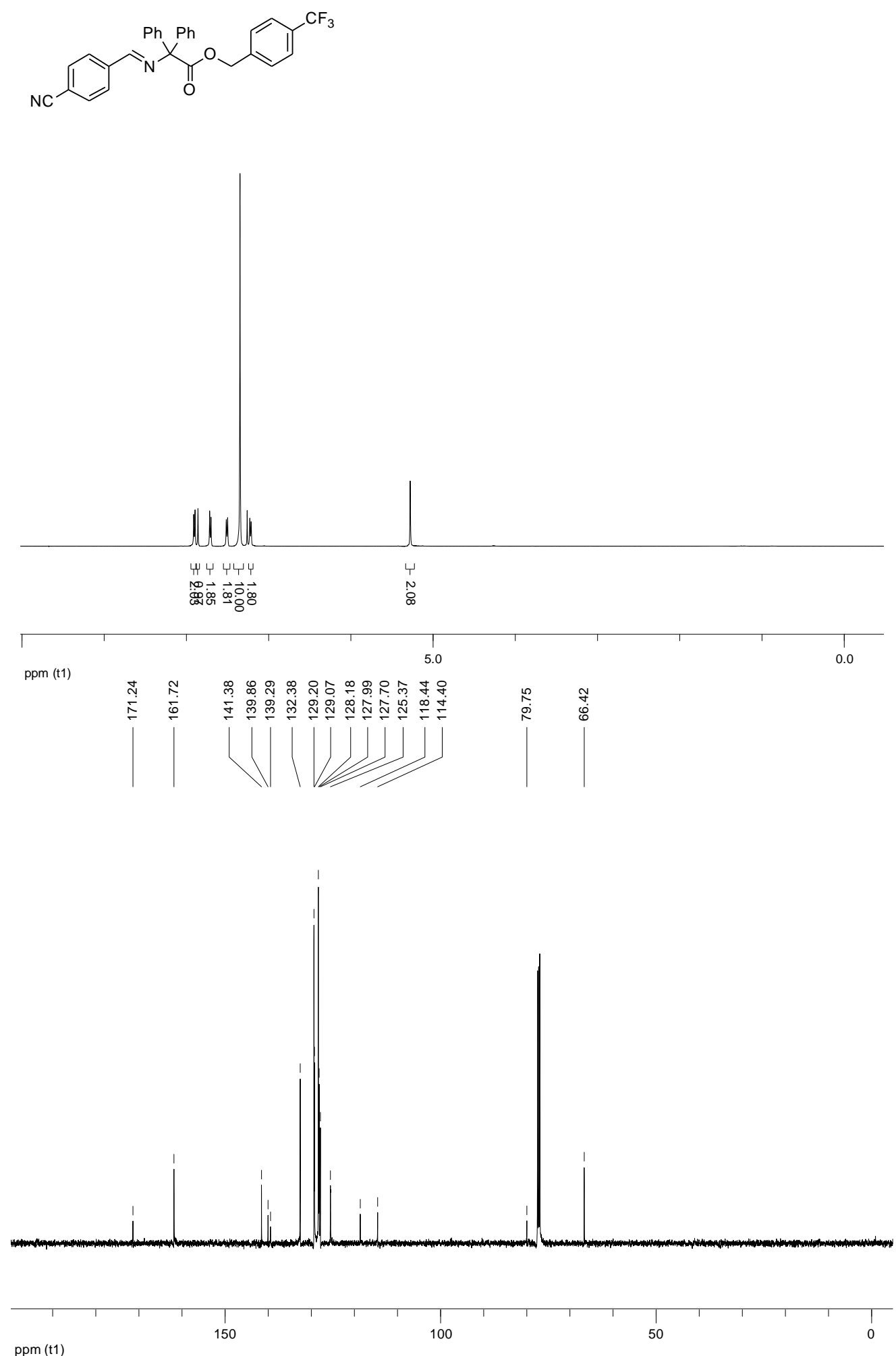

${ }^{1} \mathrm{H}-$ and ${ }^{13} \mathrm{C}-\mathrm{NMR}\left(\mathrm{CDCl}_{3}\right)$ Spectra of 4.1a 
$\stackrel{\circ}{9}$

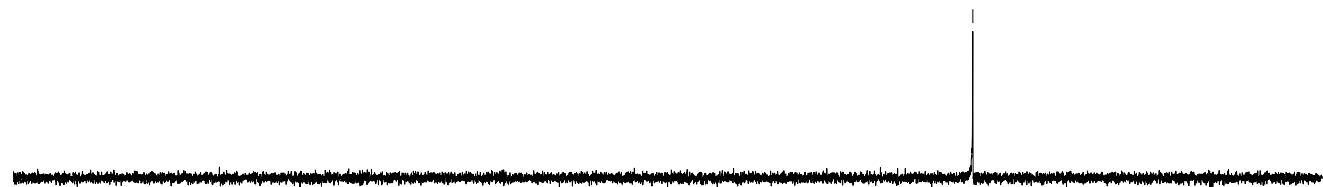

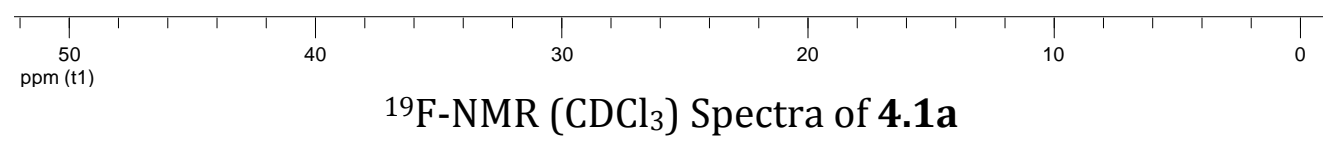



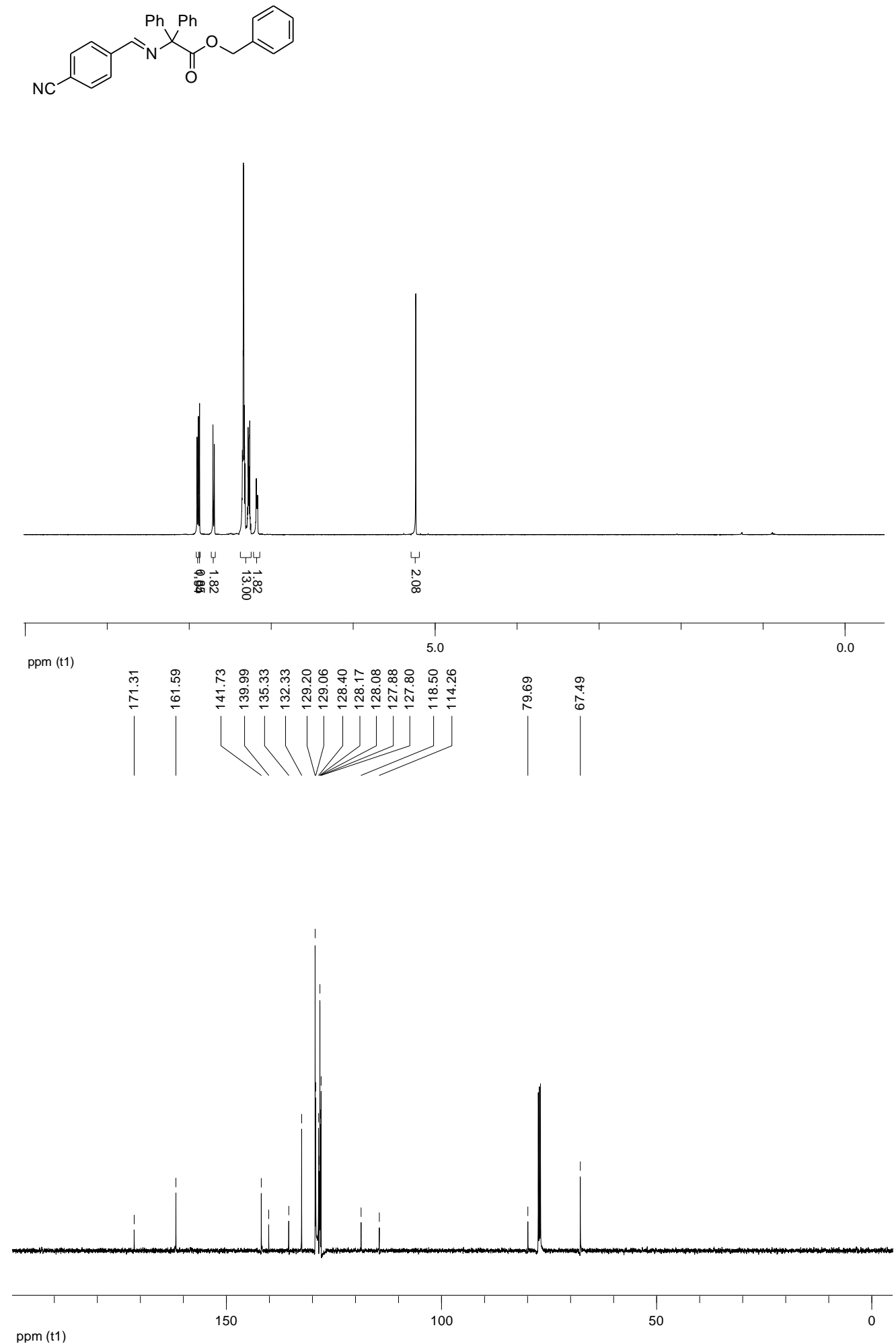

${ }^{1} \mathrm{H}$ - and ${ }^{13} \mathrm{C}-\mathrm{NMR}\left(\mathrm{CDCl}_{3}\right)$ Spectra of $\mathbf{4 . 1 b}$ 

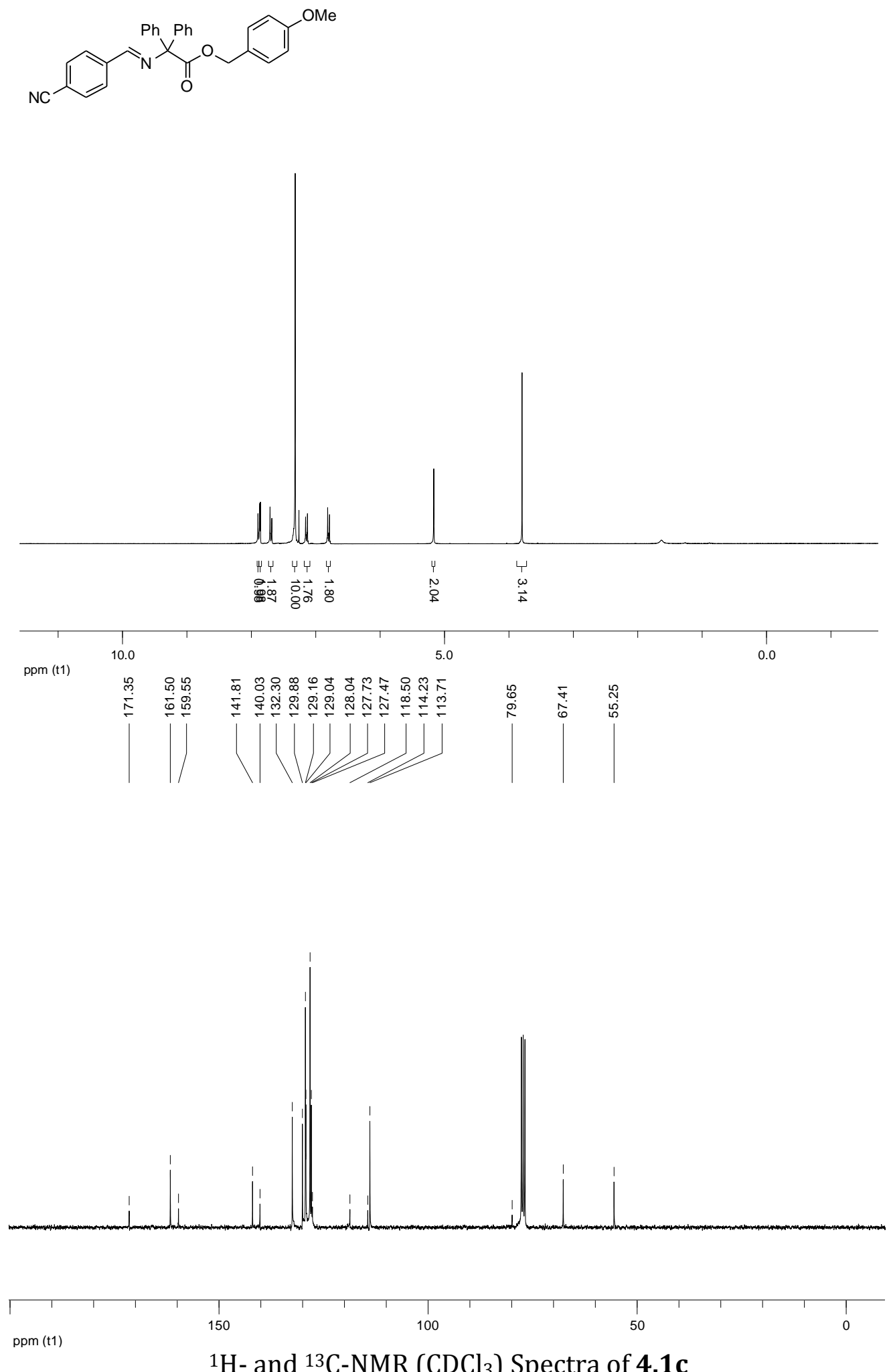

${ }^{1} \mathrm{H}$ - and ${ }^{13} \mathrm{C}-\mathrm{NMR}\left(\mathrm{CDCl}_{3}\right)$ Spectra of 4.1c 

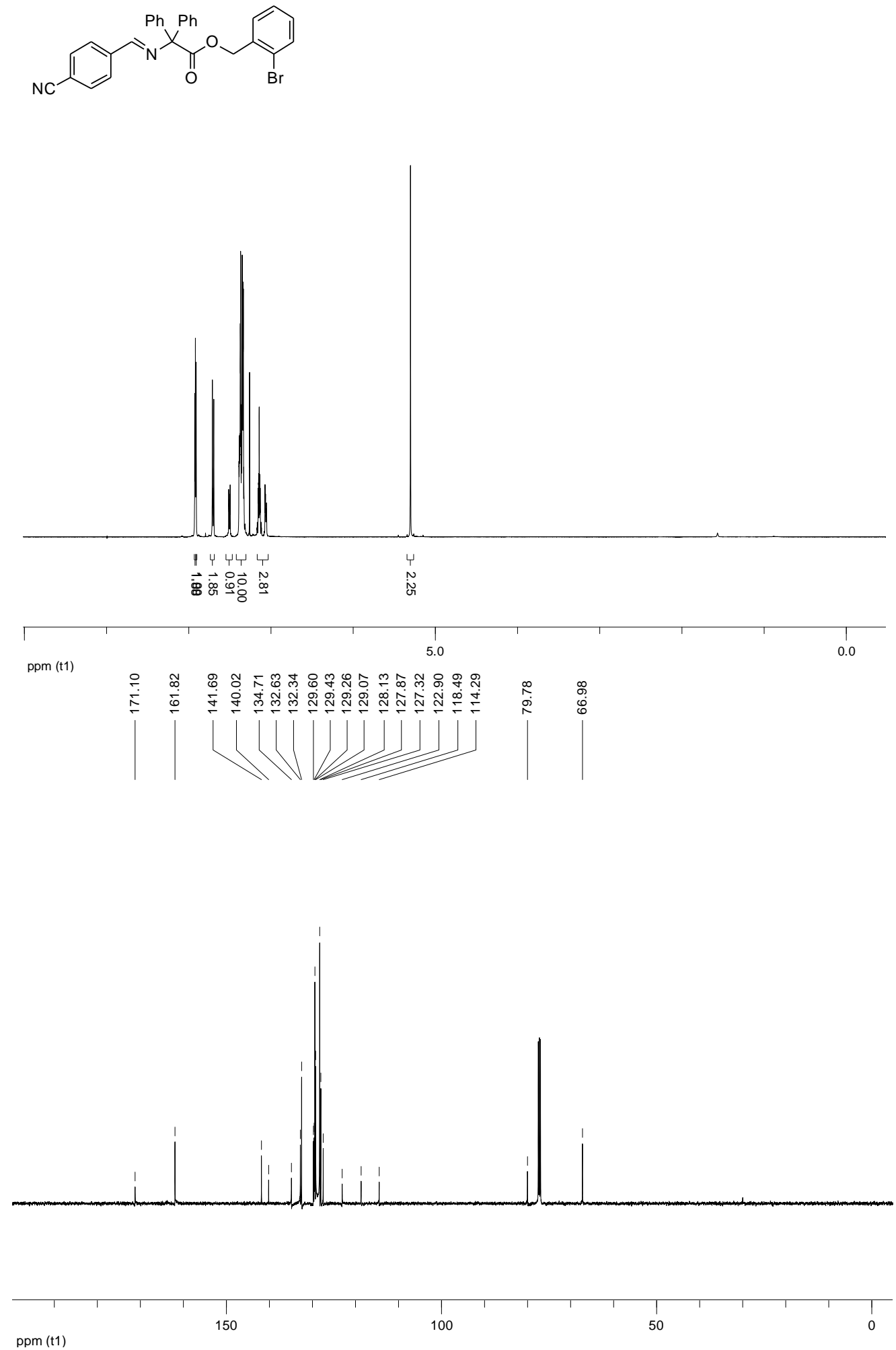

${ }^{1} \mathrm{H}-$ and ${ }^{13} \mathrm{C}-\mathrm{NMR}\left(\mathrm{CDCl}_{3}\right)$ Spectra of 4.1d 

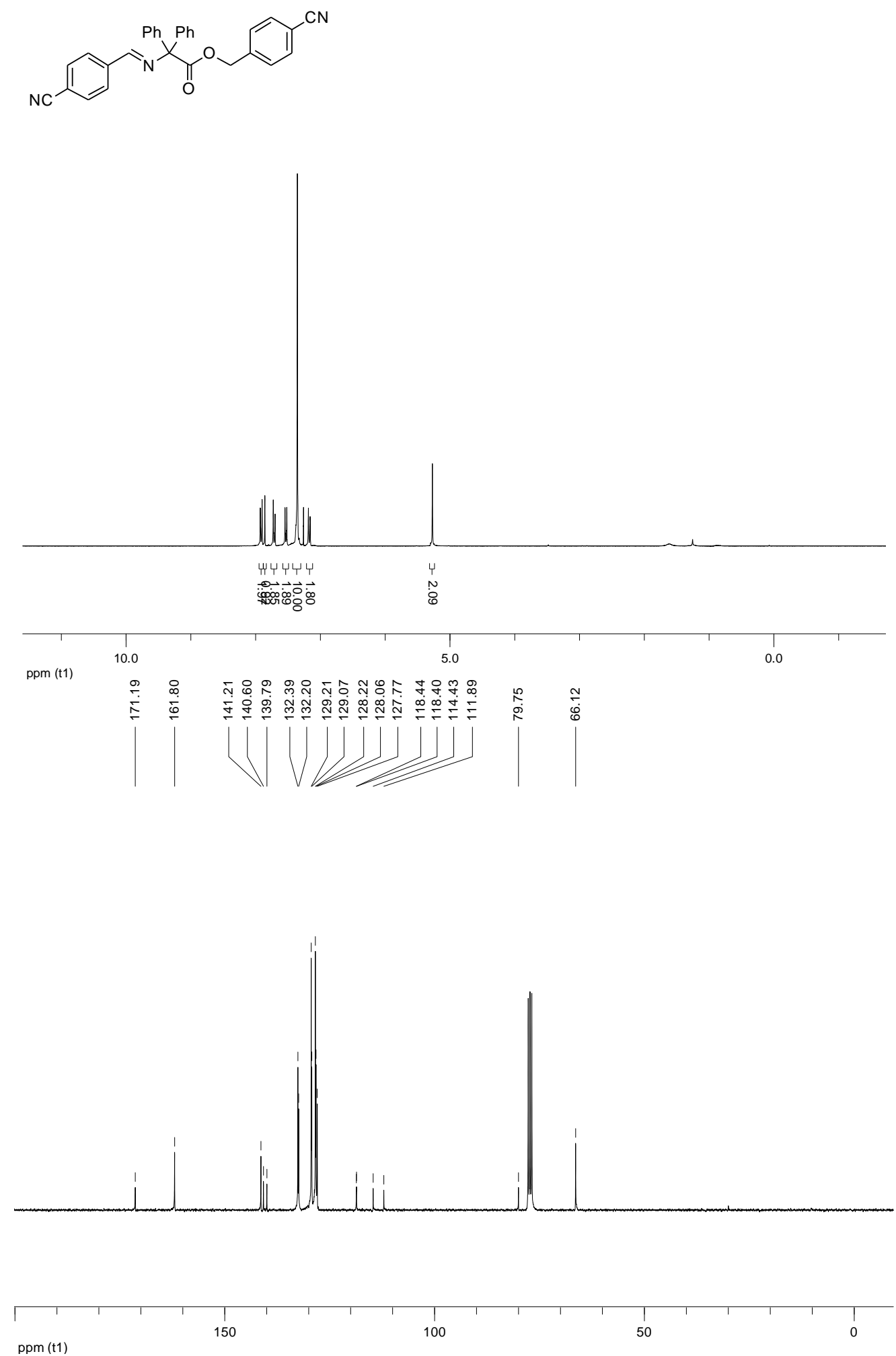

${ }^{1} \mathrm{H}$ - and ${ }^{13} \mathrm{C}-\mathrm{NMR}\left(\mathrm{CDCl}_{3}\right)$ Spectra of 4.1e 

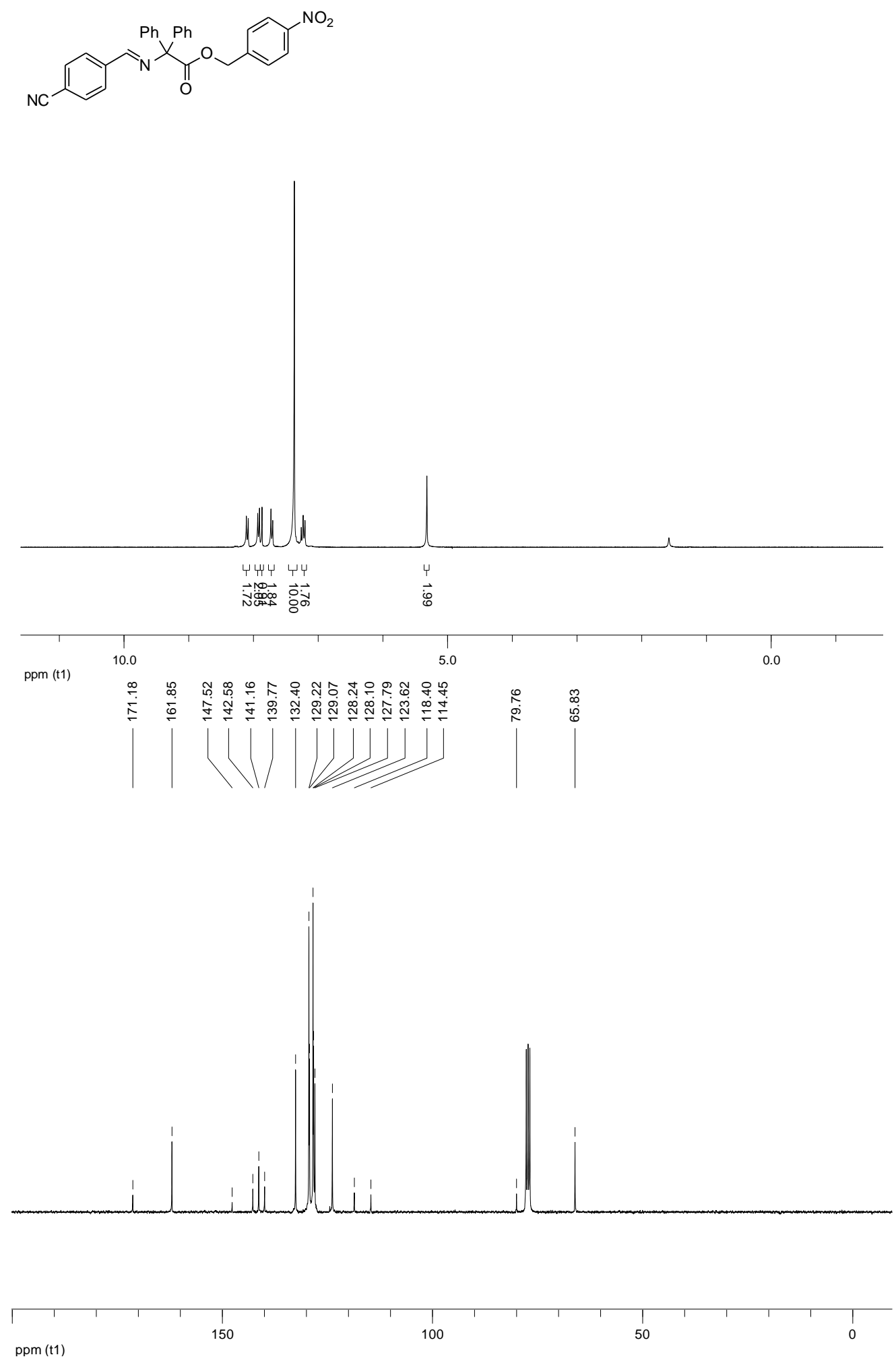

${ }^{1} \mathrm{H}$ - and ${ }^{13} \mathrm{C}-\mathrm{NMR}\left(\mathrm{CDCl}_{3}\right)$ Spectra of $\mathbf{4 . 1 f}$ 

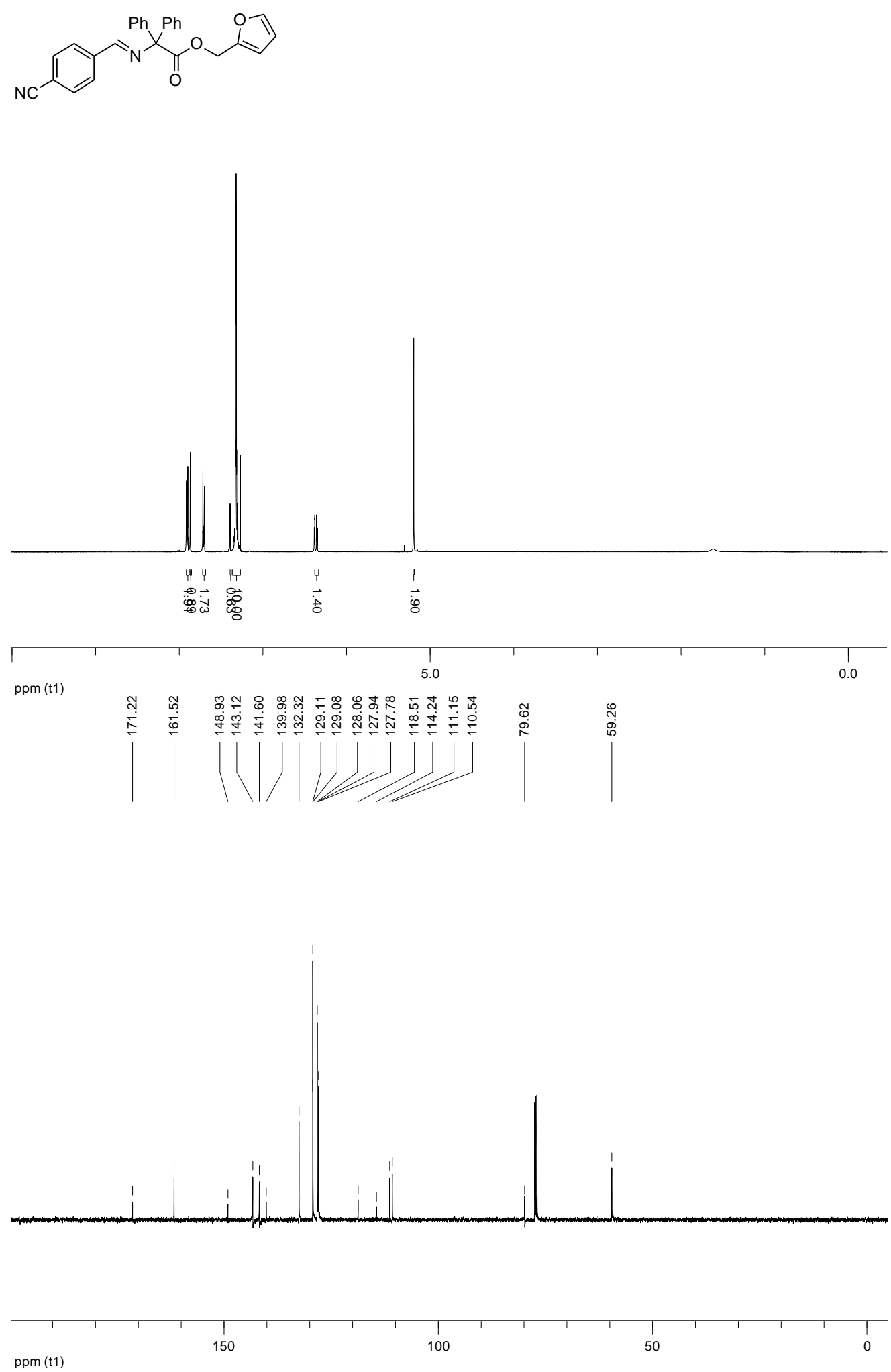

${ }^{1} \mathrm{H}$ - and ${ }^{13} \mathrm{C}-\mathrm{NMR}\left(\mathrm{CDCl}_{3}\right)$ Spectra of 4.1g 

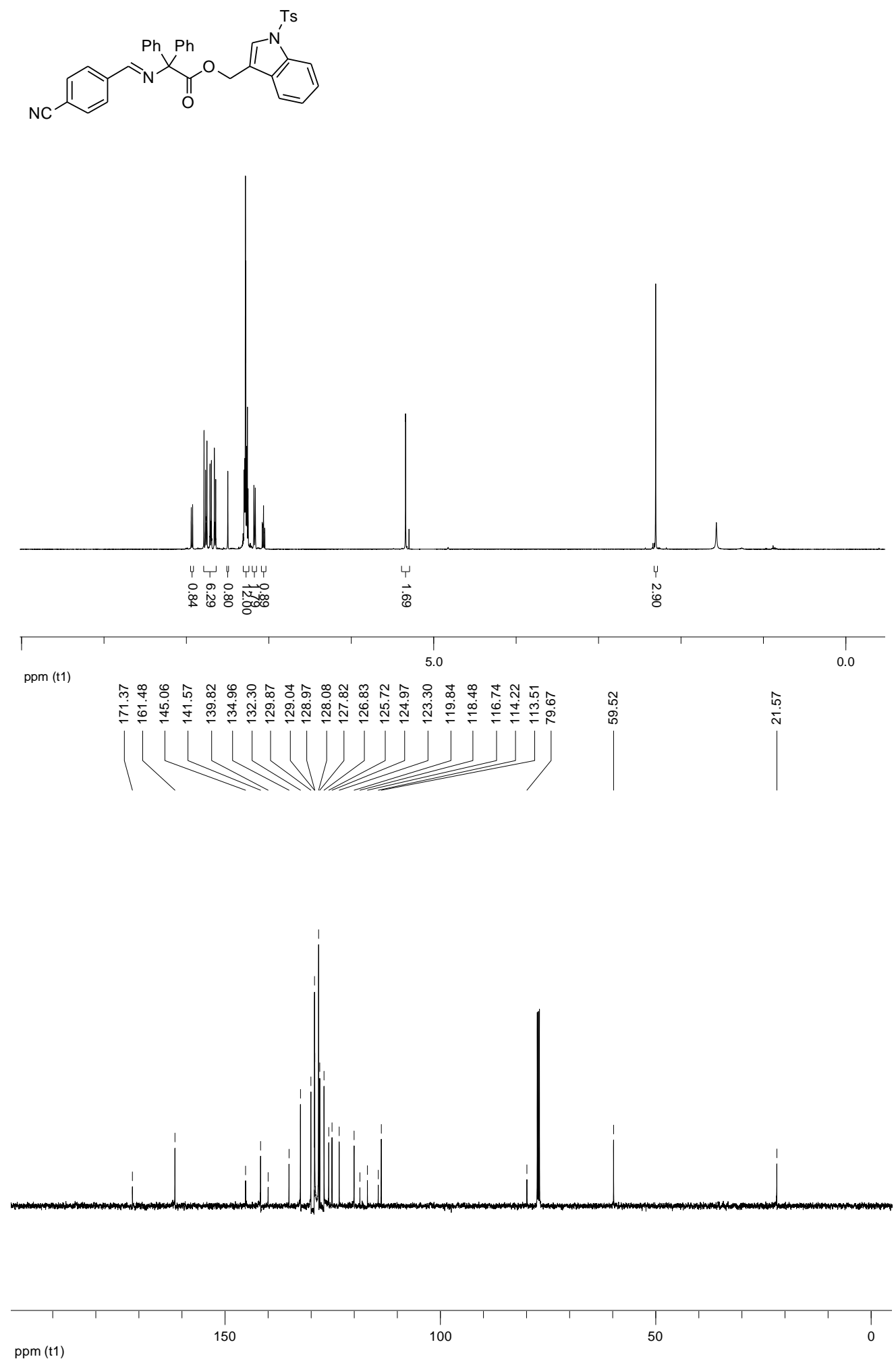

${ }^{1} \mathrm{H}$ - and ${ }^{13} \mathrm{C}$-NMR $\left(\mathrm{CDCl}_{3}\right)$ Spectra of $4.1 \mathbf{h}$ 
<smiles>O=C(OCc1ccccc1)C(c1ccccc1)(c1ccccc1)c1ccc(C(F)(F)F)cc1</smiles>
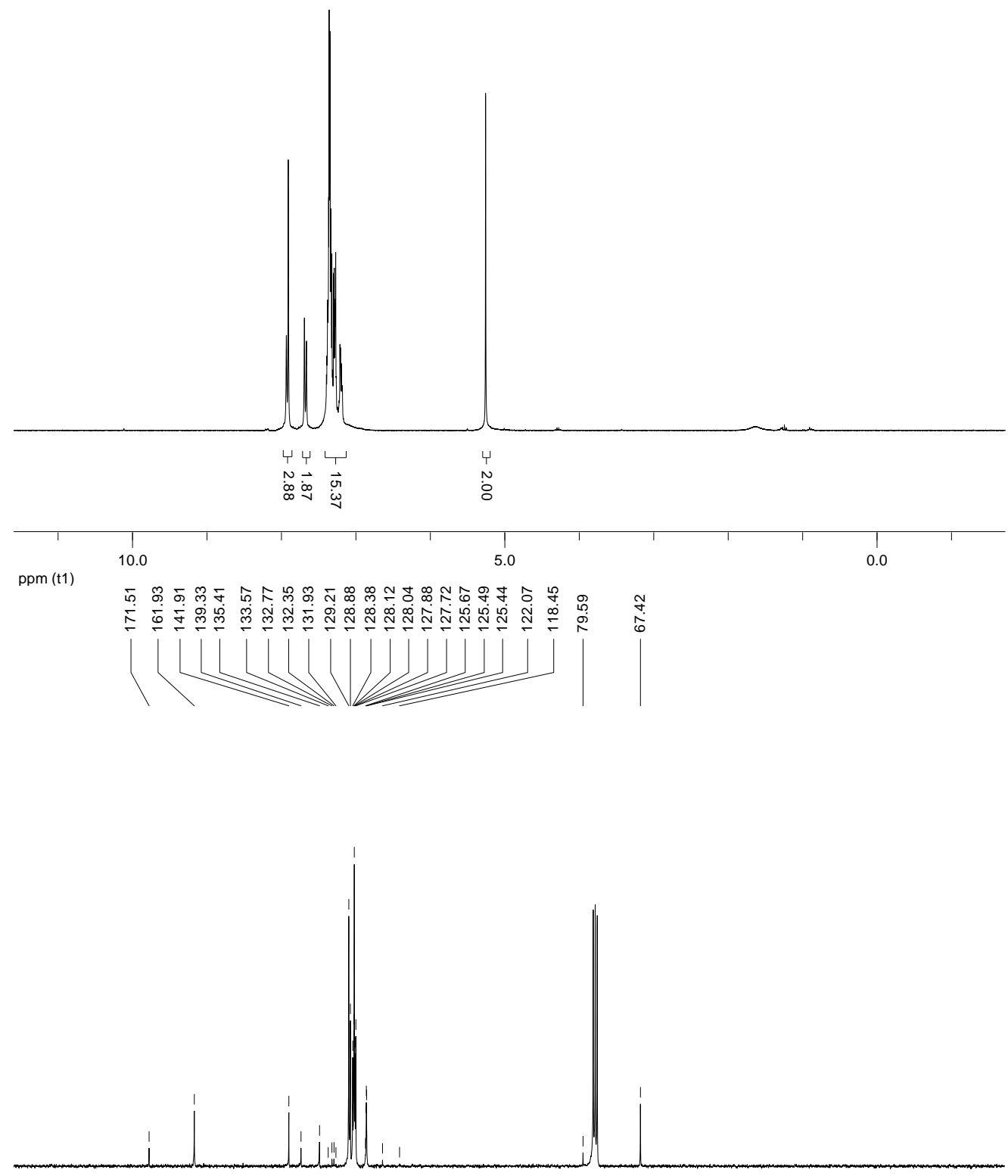

150
$1 \mathrm{Hpm}(\mathrm{t} 1)$
$1 \mathrm{H}-$ and ${ }^{13} \mathrm{C}-\mathrm{NMR}\left(\mathrm{CDCl}_{3}\right)$ Spectra of $\mathbf{4 . 1 i}$


$\stackrel{\hat{\circ}}{\stackrel{p}{0}}$

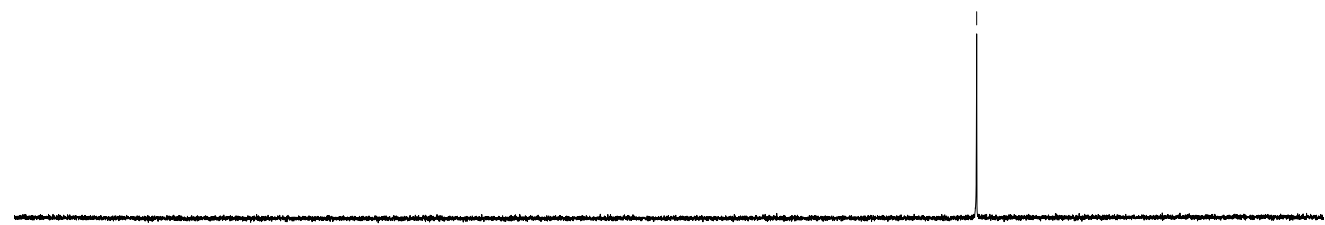

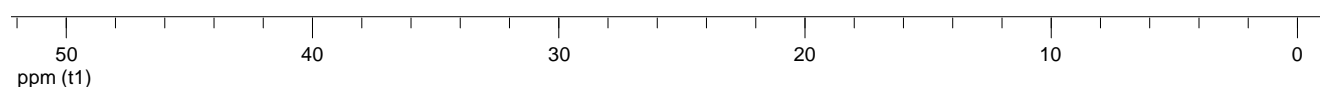

${ }^{19} \mathrm{~F}-\mathrm{NMR}\left(\mathrm{CDCl}_{3}\right)$ Spectra of $\mathbf{4 . 1 i}$ 

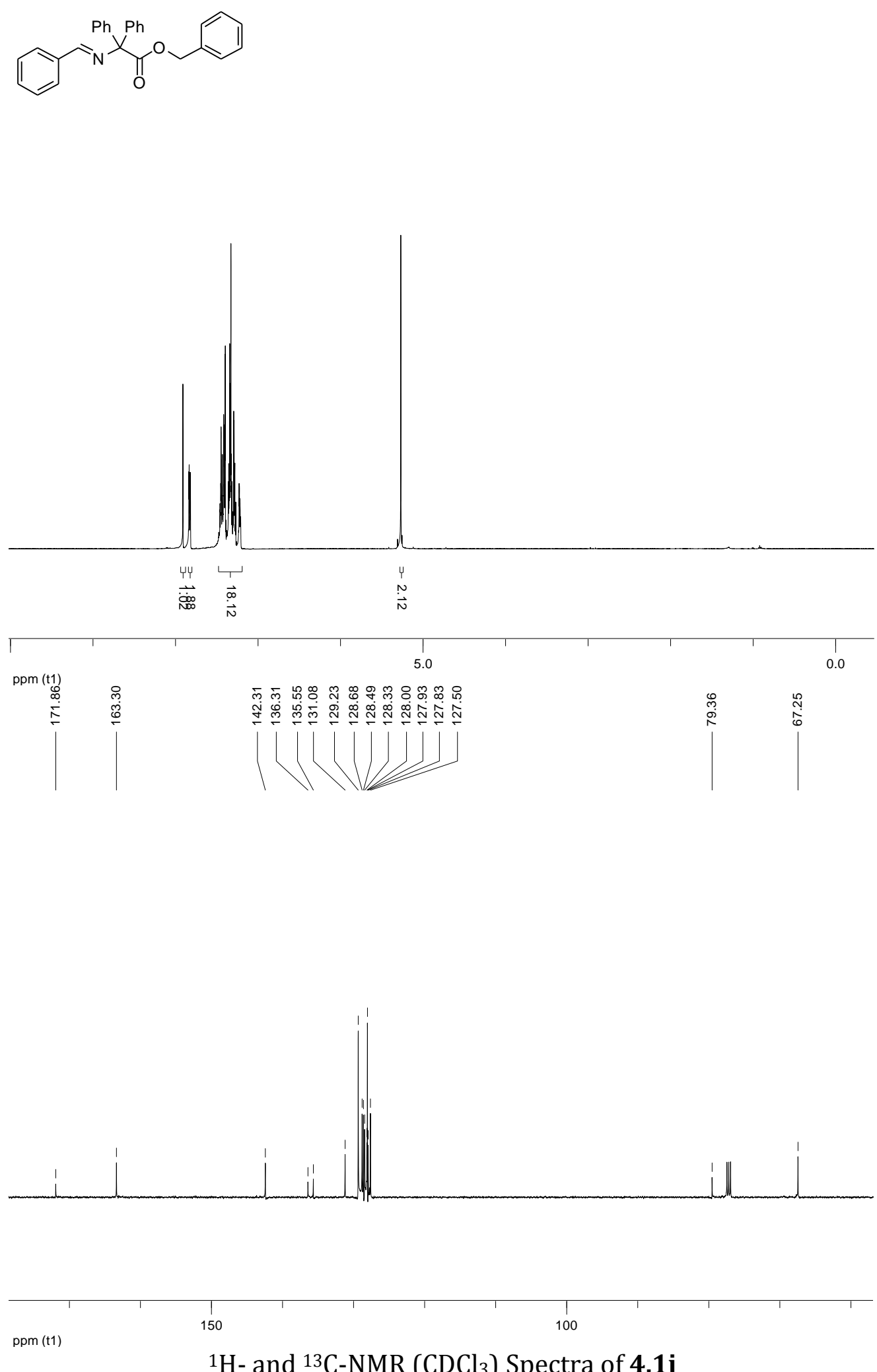

${ }^{1} \mathrm{H}$ - and ${ }^{13} \mathrm{C}-\mathrm{NMR}\left(\mathrm{CDCl}_{3}\right)$ Spectra of $\mathbf{4 . 1 j}$ 

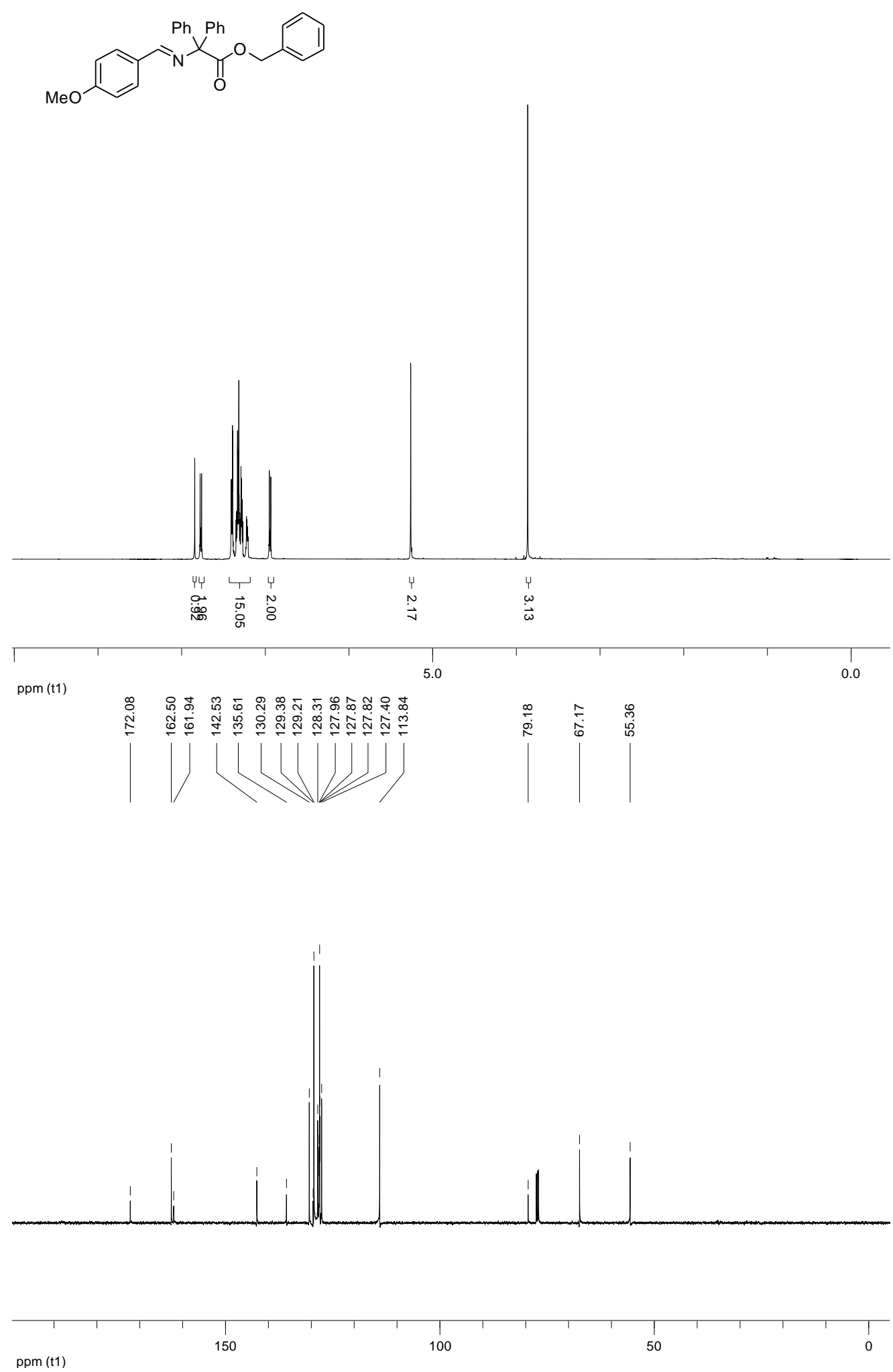

${ }^{1} \mathrm{H}-$ and ${ }^{13} \mathrm{C}-\mathrm{NMR}\left(\mathrm{CDCl}_{3}\right)$ Spectra of $\mathbf{4 . 1 k}$ 

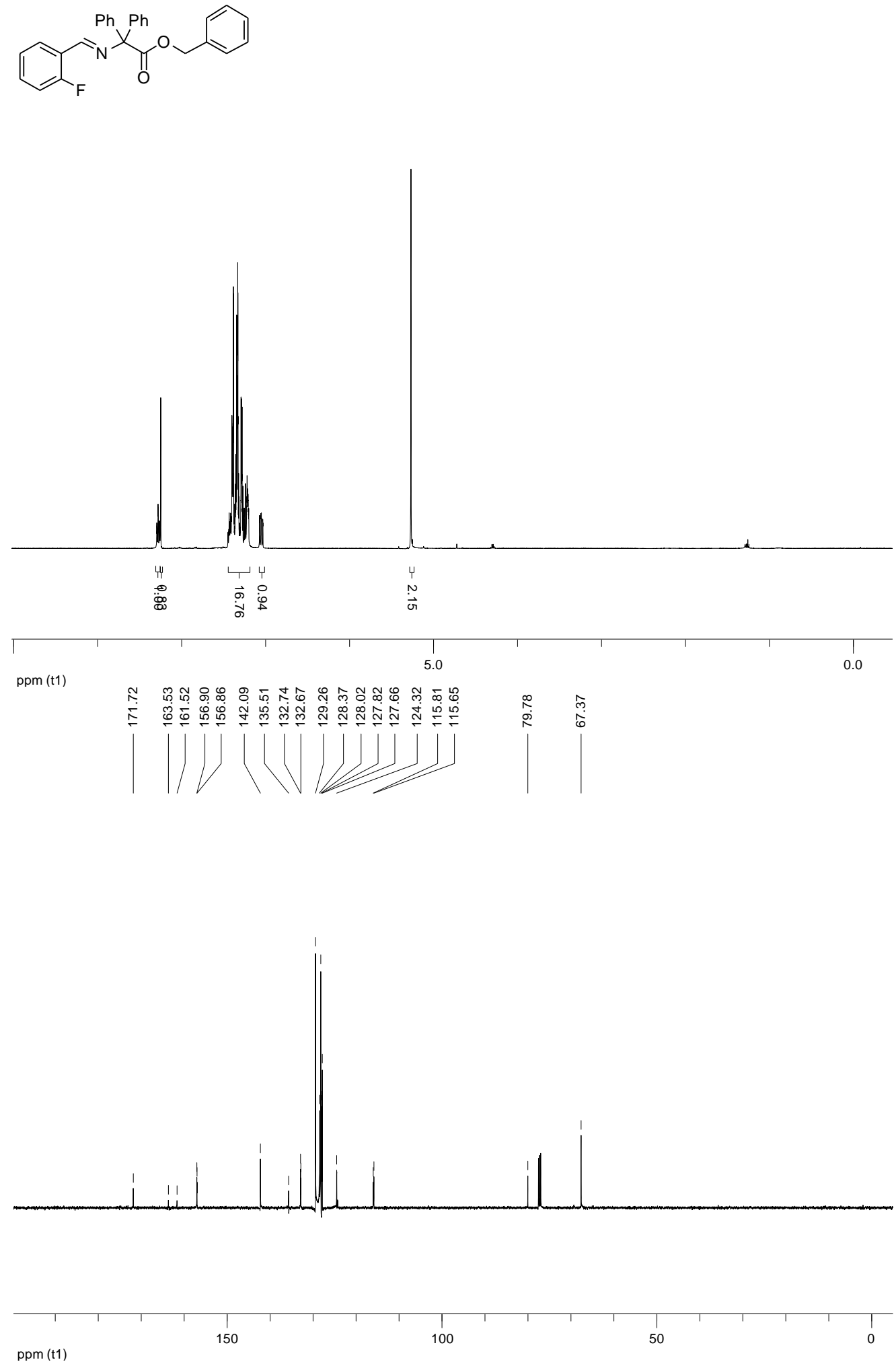

${ }^{1} \mathrm{H}$ - and ${ }^{13} \mathrm{C}-\mathrm{NMR}\left(\mathrm{CDCl}_{3}\right)$ Spectra of 4.11 


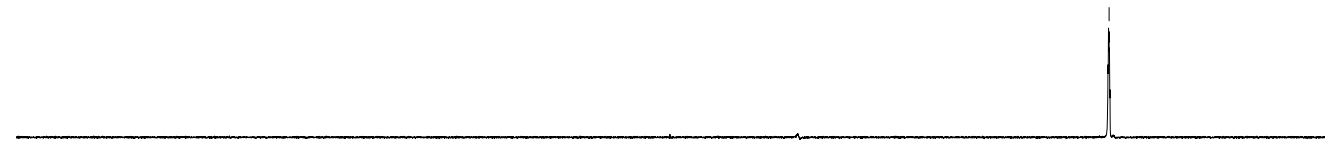

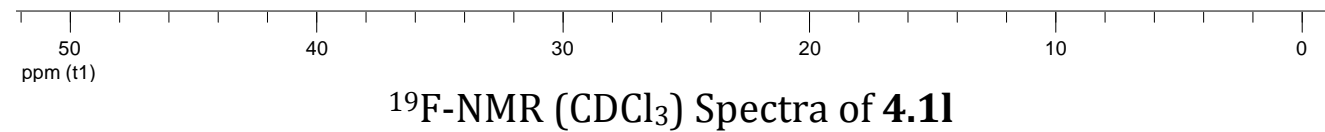



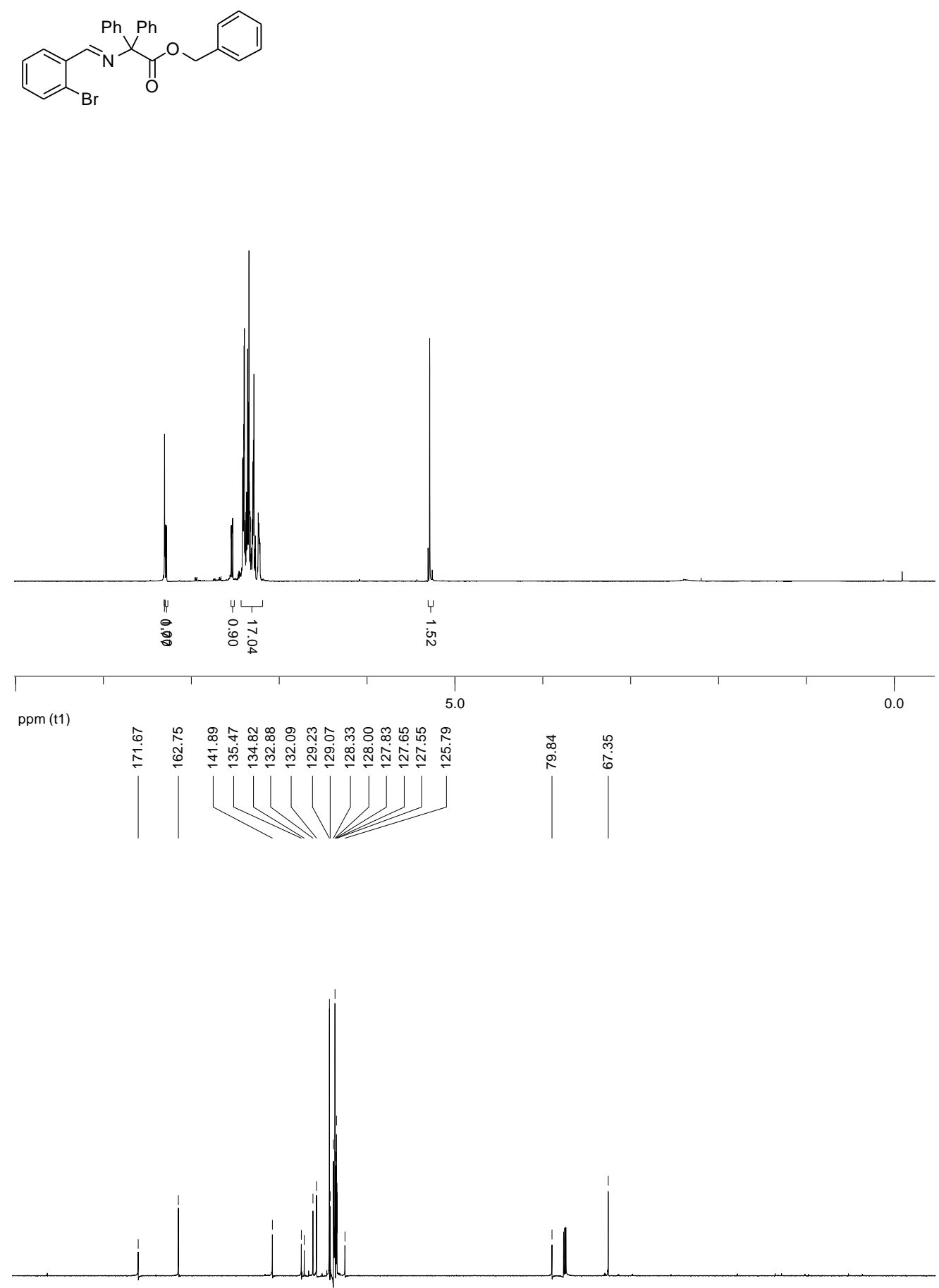

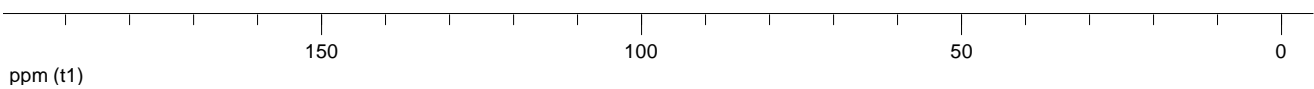

${ }^{1} \mathrm{H}-$ and ${ }^{13} \mathrm{C}-\mathrm{NMR}\left(\mathrm{CDCl}_{3}\right)$ Spectra of $\mathbf{4 . 1 m}$ 

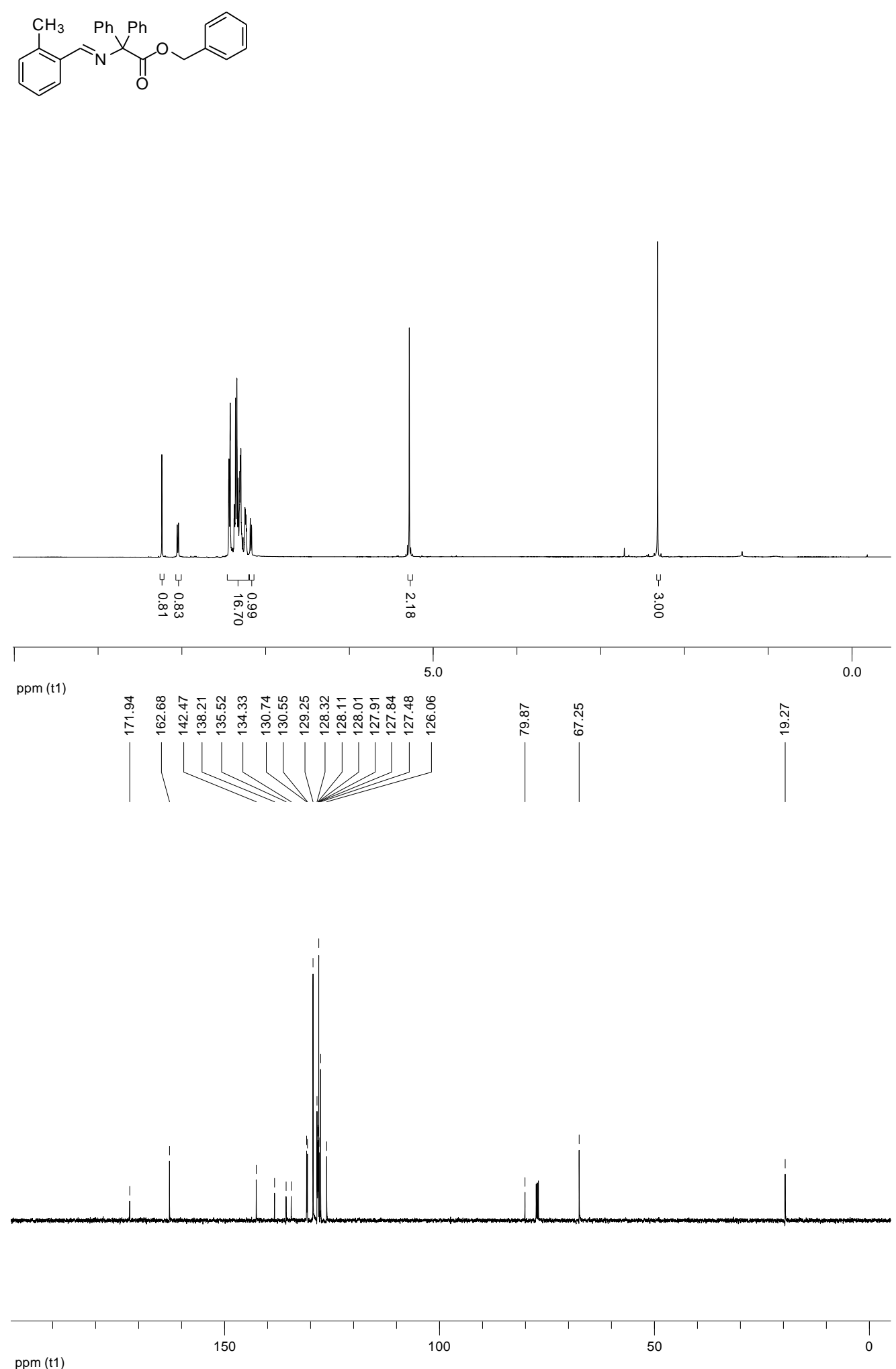

${ }^{1} \mathrm{H}$ - and ${ }^{13} \mathrm{C}-\mathrm{NMR}\left(\mathrm{CDCl}_{3}\right)$ Spectra of 4.1n 

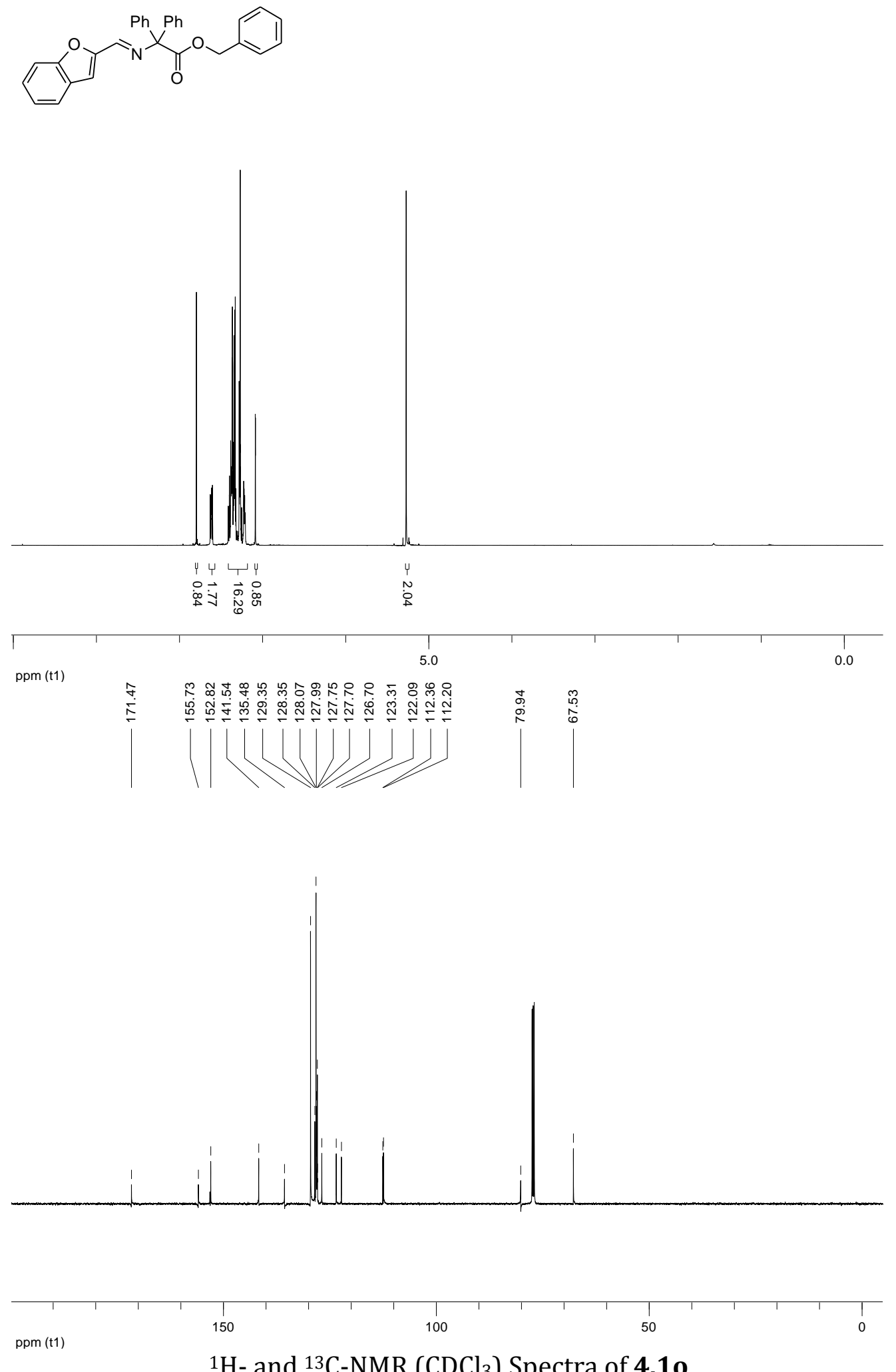

${ }^{1} \mathrm{H}$ - and ${ }^{13} \mathrm{C}-\mathrm{NMR}\left(\mathrm{CDCl}_{3}\right)$ Spectra of 4.10 

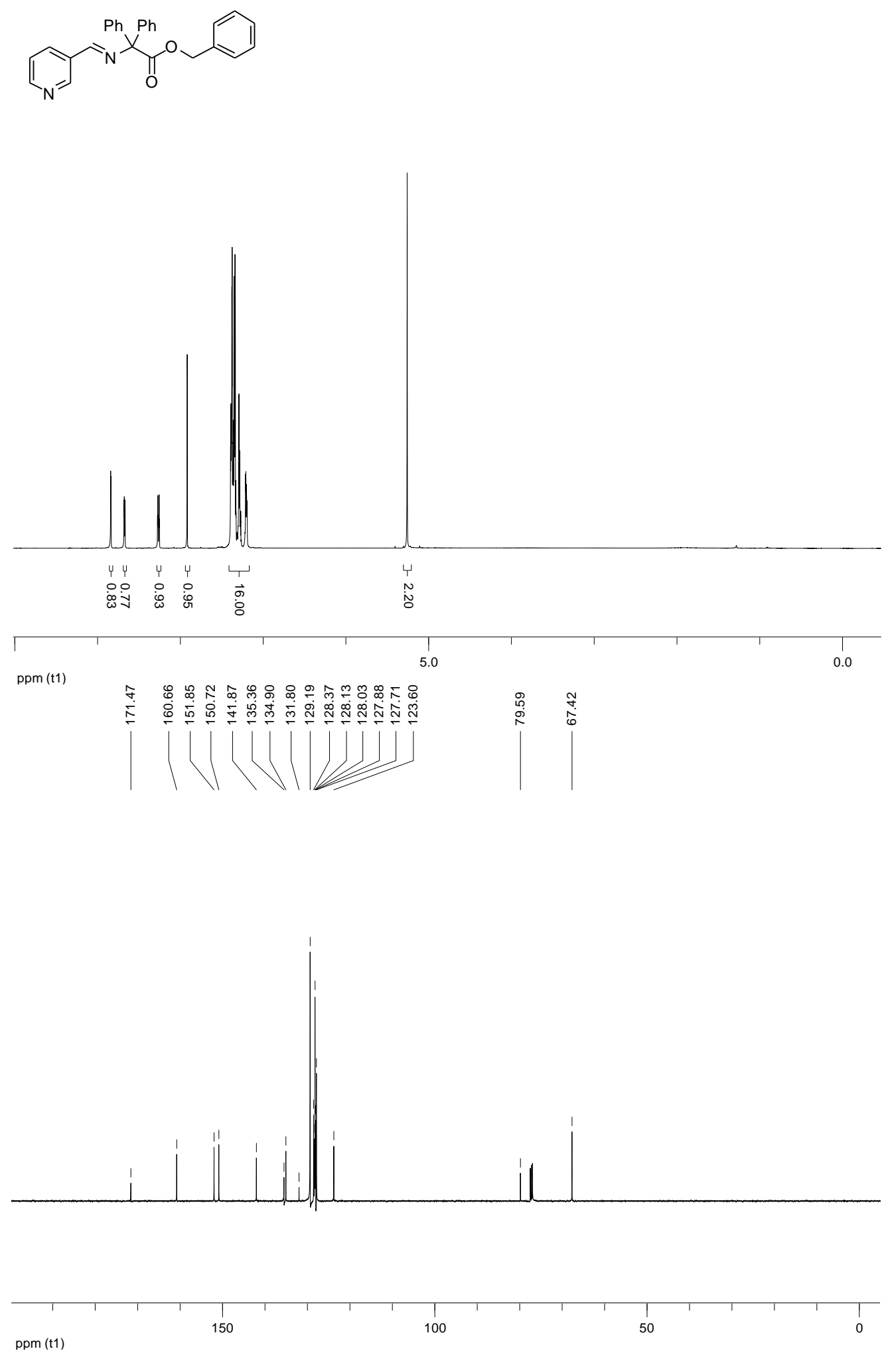

${ }^{1} \mathrm{H}$ - and ${ }^{13} \mathrm{C}-\mathrm{NMR}\left(\mathrm{CDCl}_{3}\right)$ Spectra of 4.1p 

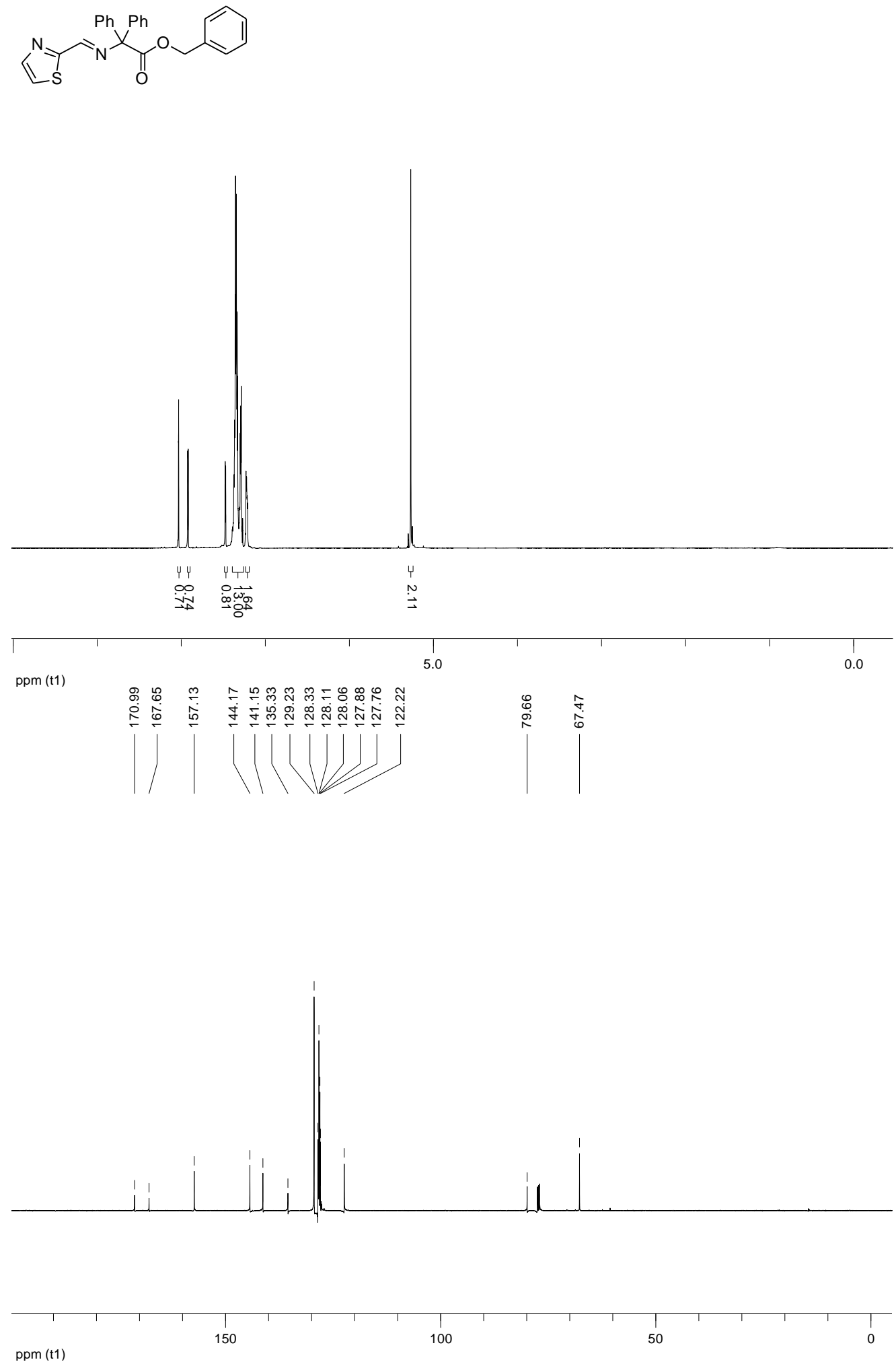

${ }^{1} \mathrm{H}$ - and ${ }^{13} \mathrm{C}-\mathrm{NMR}\left(\mathrm{CDCl}_{3}\right)$ Spectra of 4.1q 

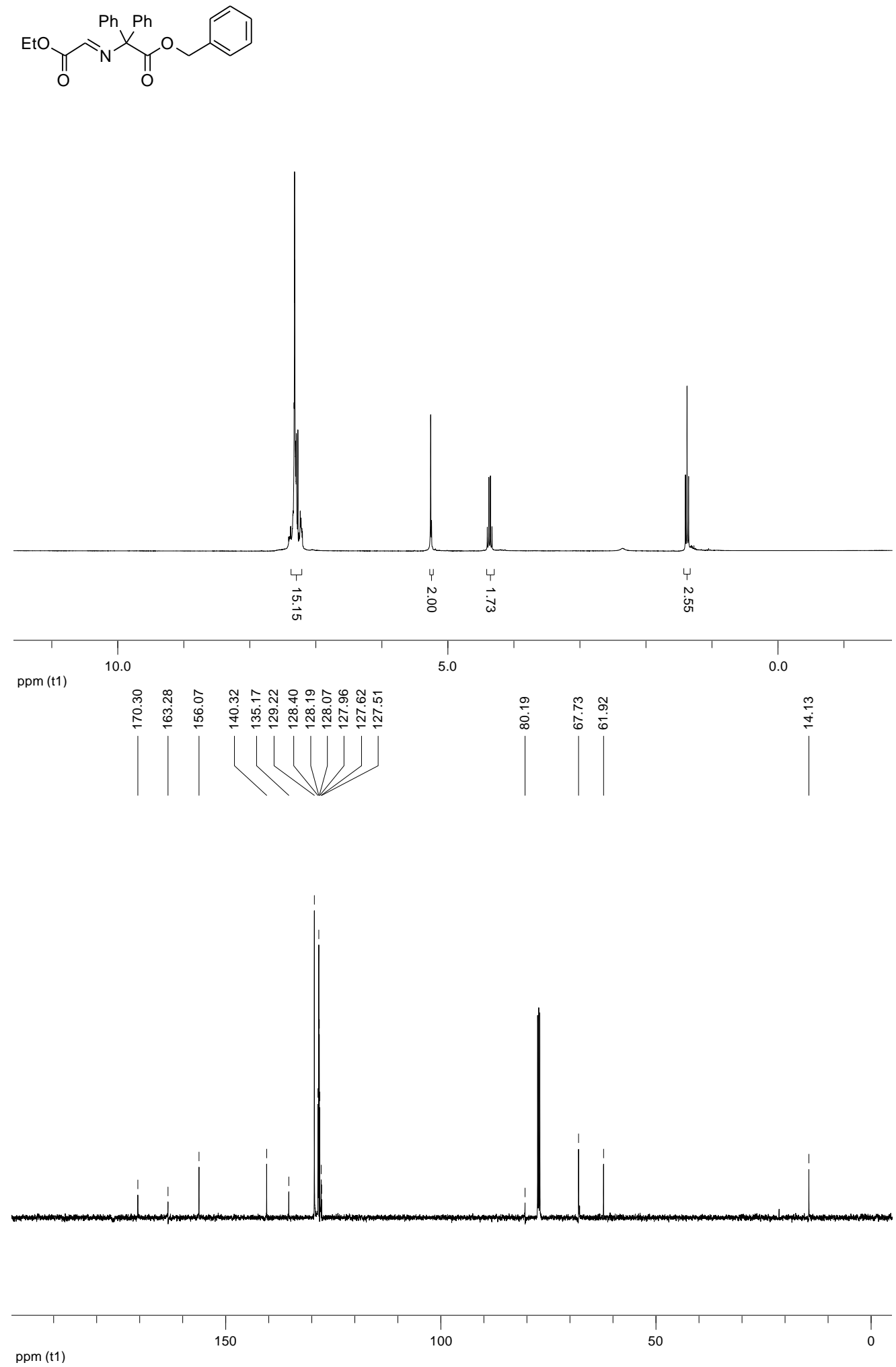

${ }^{1} \mathrm{H}$ - and ${ }^{13} \mathrm{C}-\mathrm{NMR}\left(\mathrm{CDCl}_{3}\right)$ Spectra of $\mathbf{4 . 1} \mathbf{r}$ 

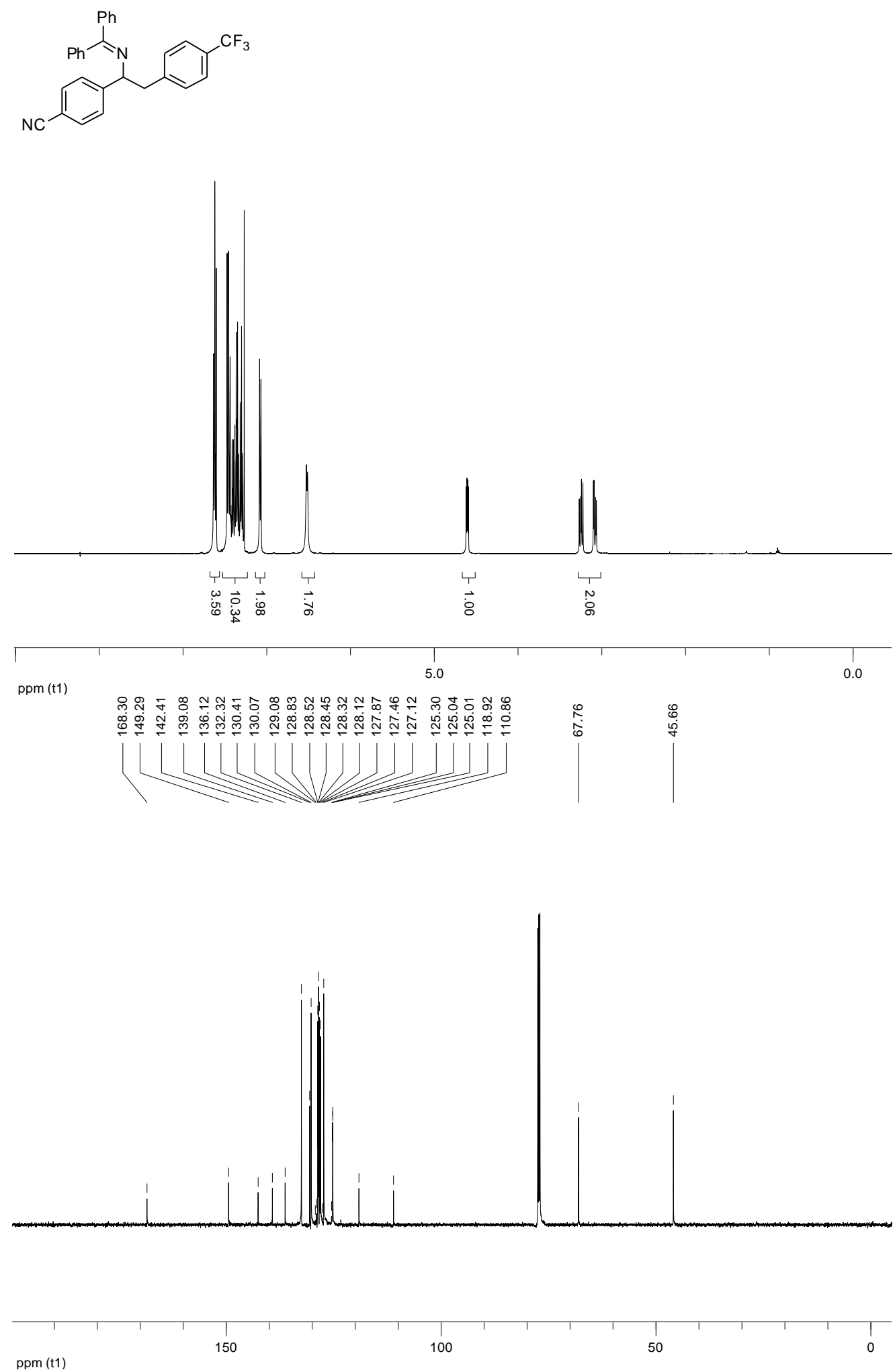

${ }^{1} \mathrm{H}$ - and ${ }^{13} \mathrm{C}$-NMR $\left(\mathrm{CDCl}_{3}\right)$ Spectra of 4.2a 


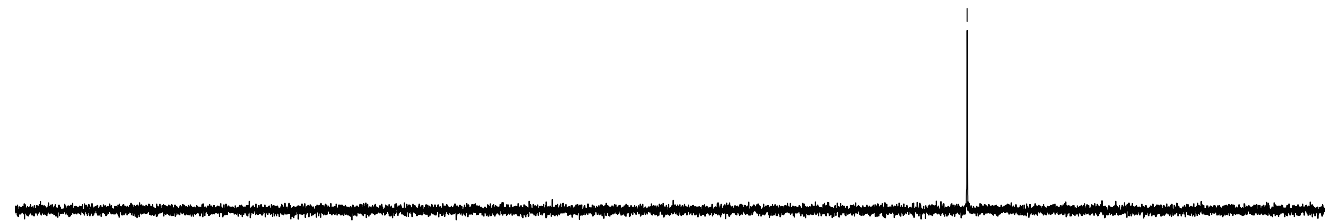

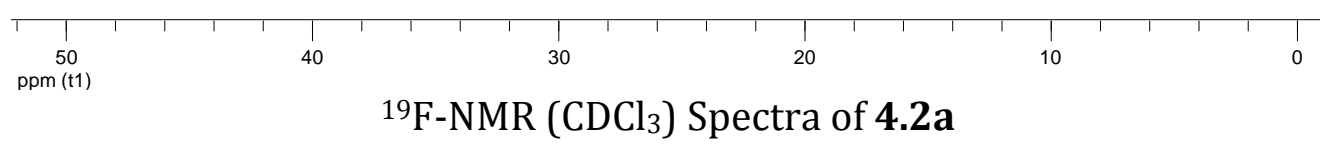



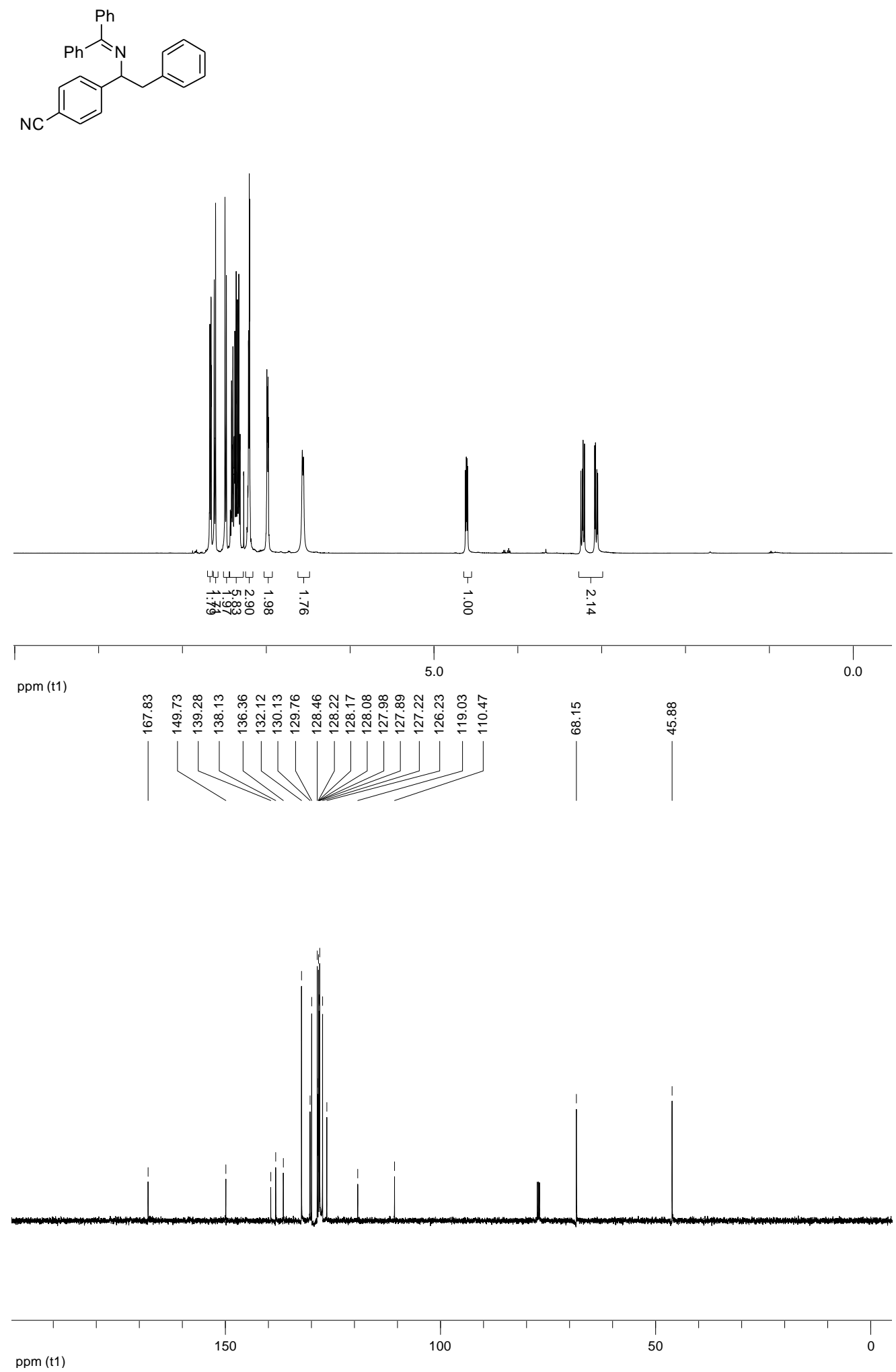

${ }^{1} \mathrm{H}$ - and ${ }^{13} \mathrm{C}-\mathrm{NMR}\left(\mathrm{CDCl}_{3}\right)$ Spectra of $4.2 \mathbf{b}$ 

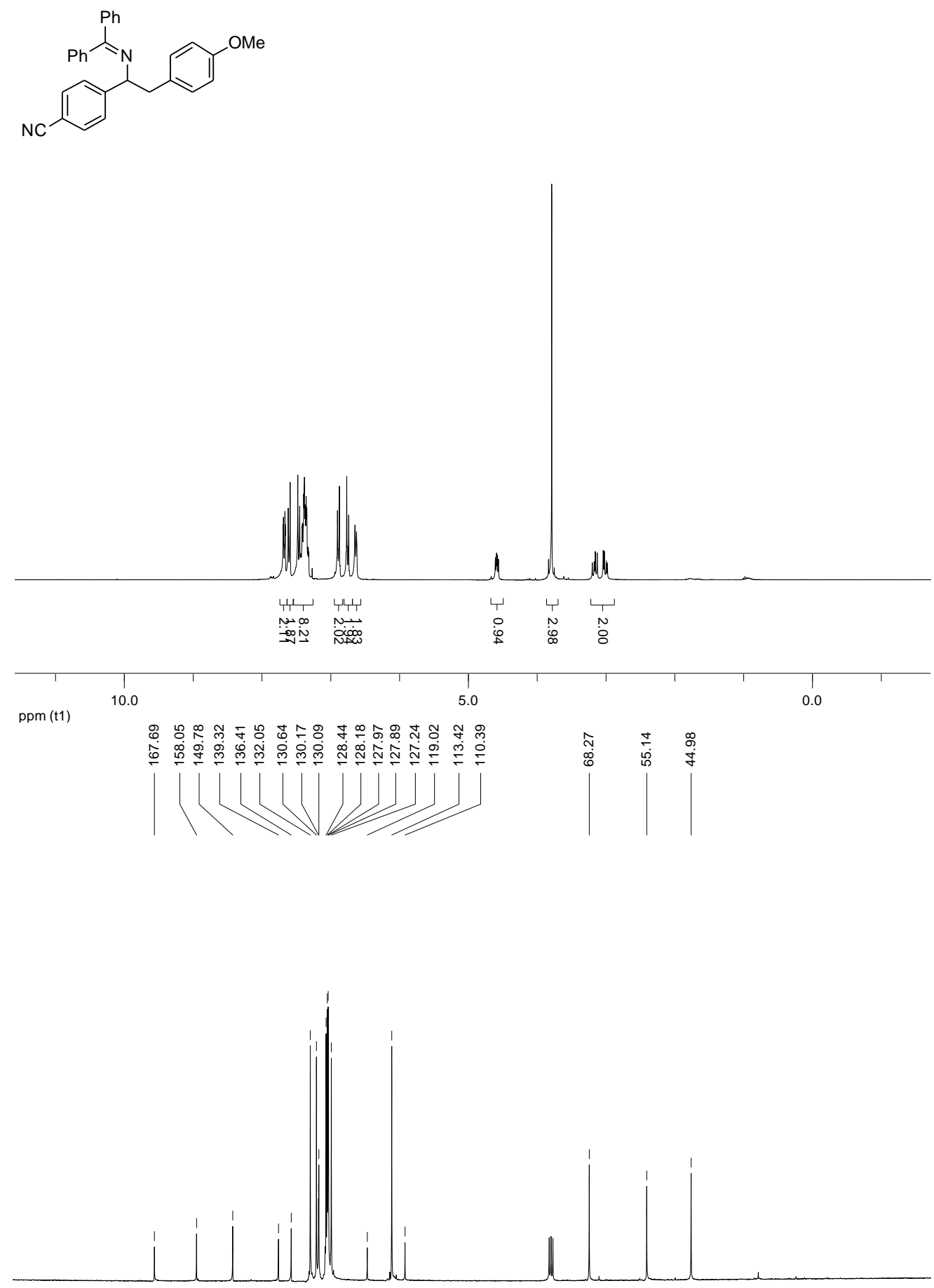

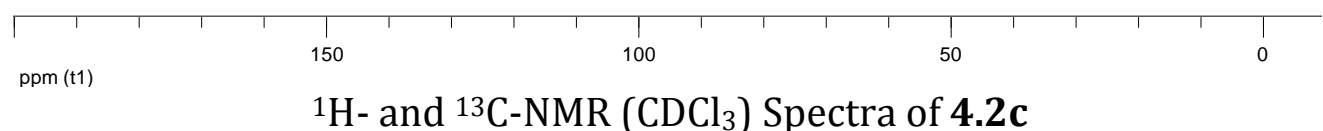



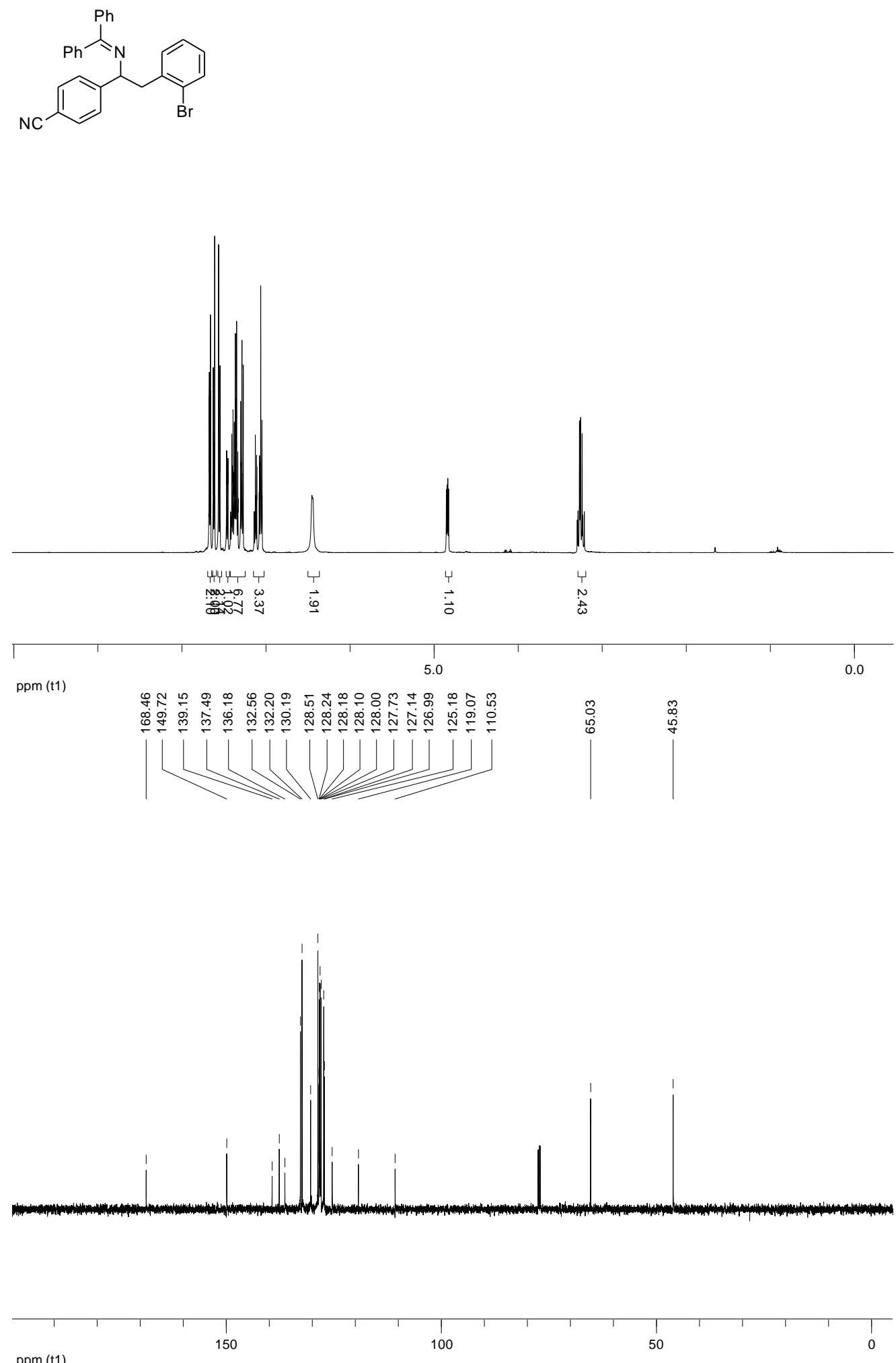

${ }^{1} \mathrm{H}$ - and ${ }^{13} \mathrm{C}$-NMR $\left(\mathrm{CDCl}_{3}\right)$ Spectra of $4.2 \mathrm{~d}$ 

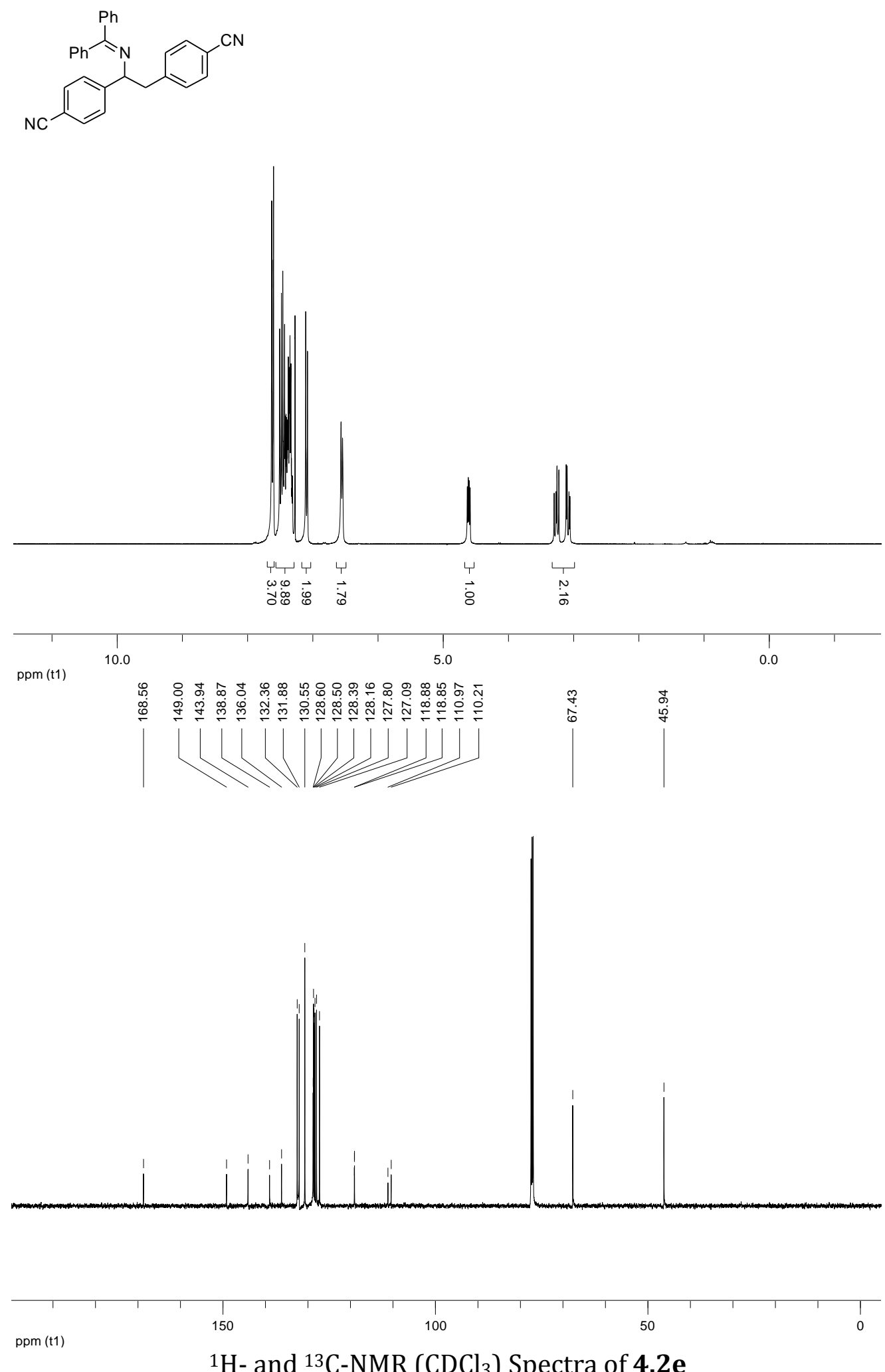

${ }^{1} \mathrm{H}$ - and ${ }^{13} \mathrm{C}$-NMR $\left(\mathrm{CDCl}_{3}\right)$ Spectra of $4.2 \mathrm{e}$ 

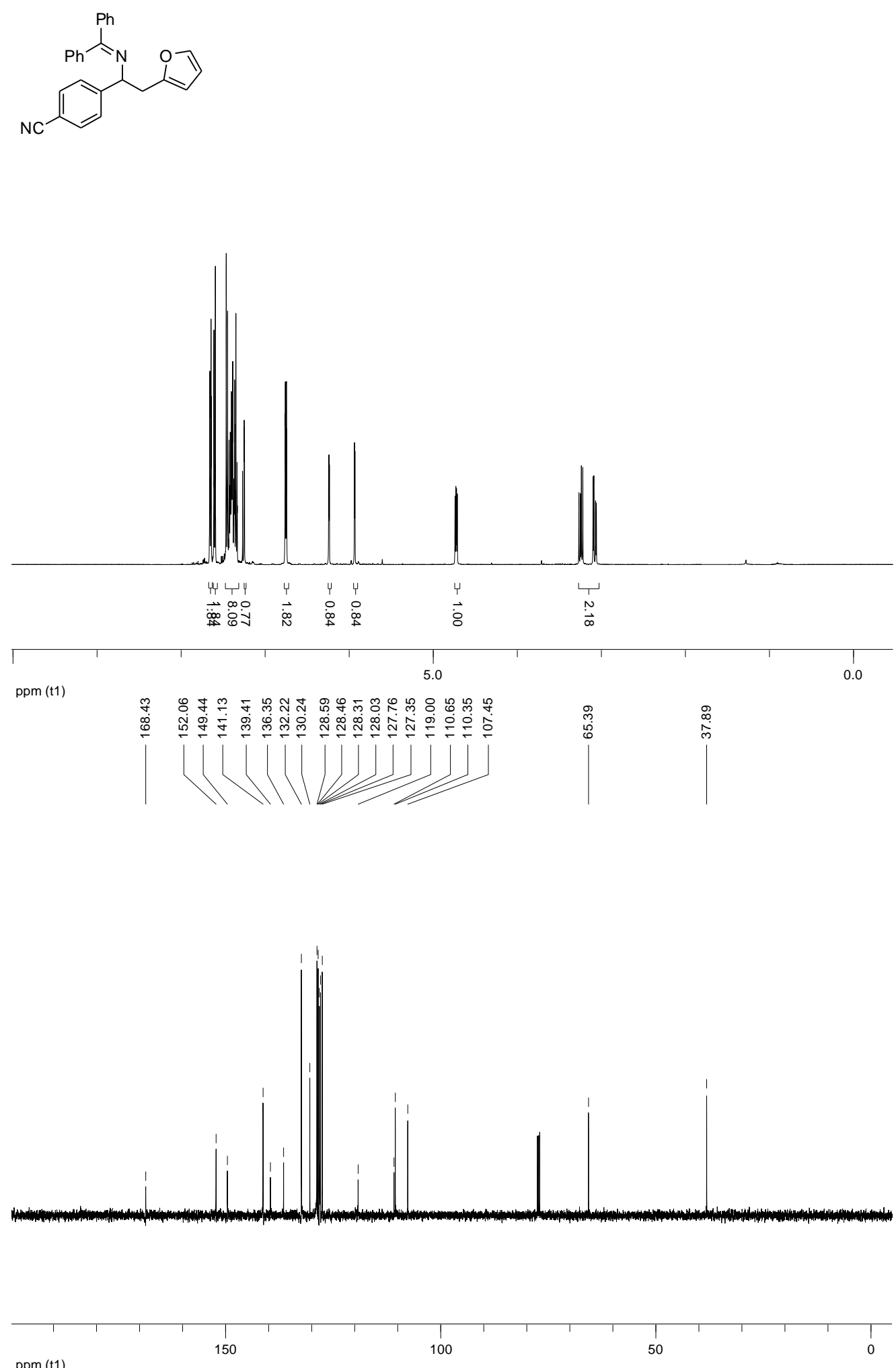

${ }^{1} \mathrm{H}$ - and ${ }^{13} \mathrm{C}$-NMR $\left(\mathrm{CDCl}_{3}\right)$ Spectra of $4.2 \mathrm{~g}$ 

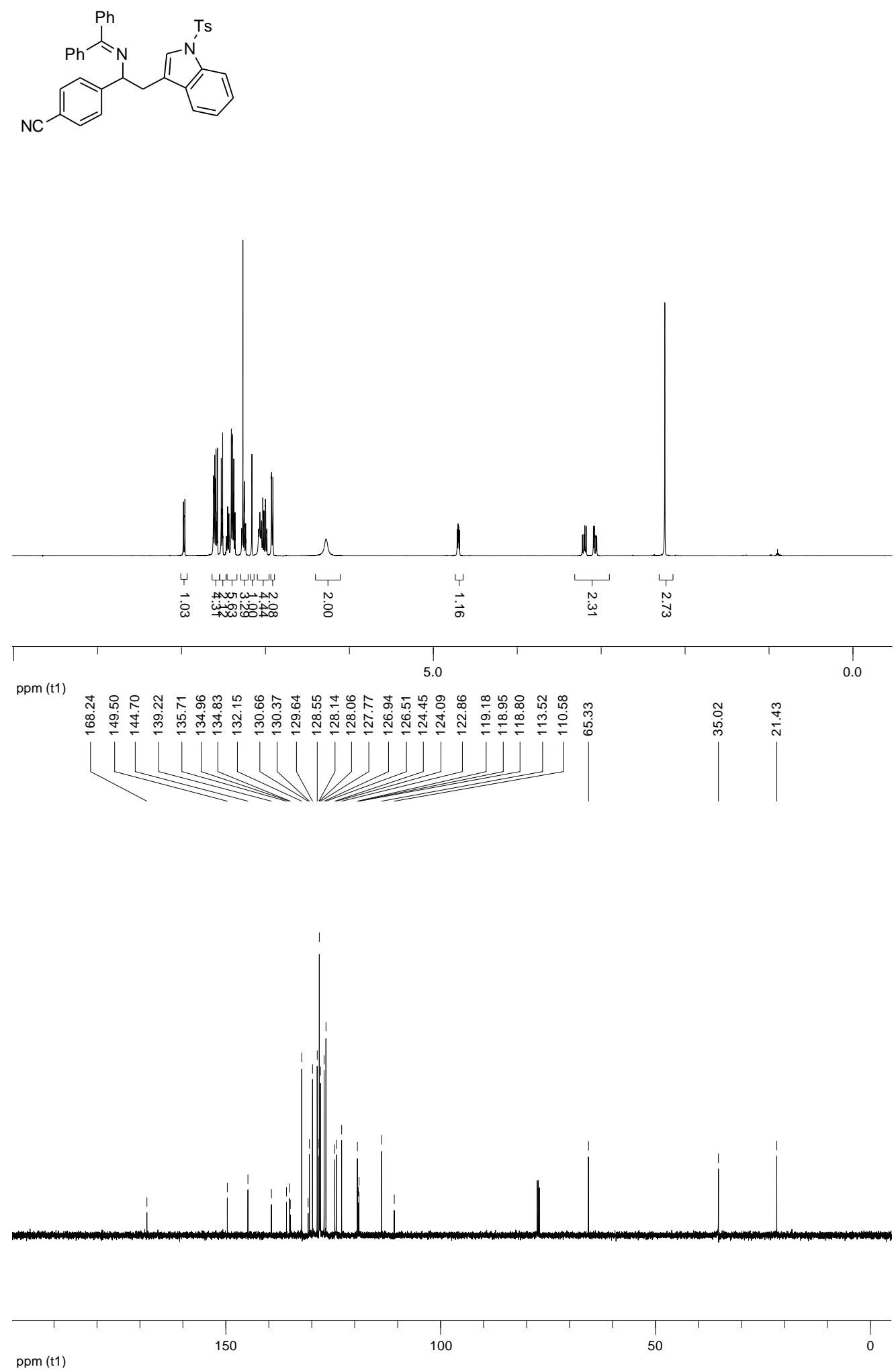

${ }^{1} \mathrm{H}$ - and ${ }^{13} \mathrm{C}$-NMR $\left(\mathrm{CDCl}_{3}\right)$ Spectra of $4.2 \mathrm{~h}$ 

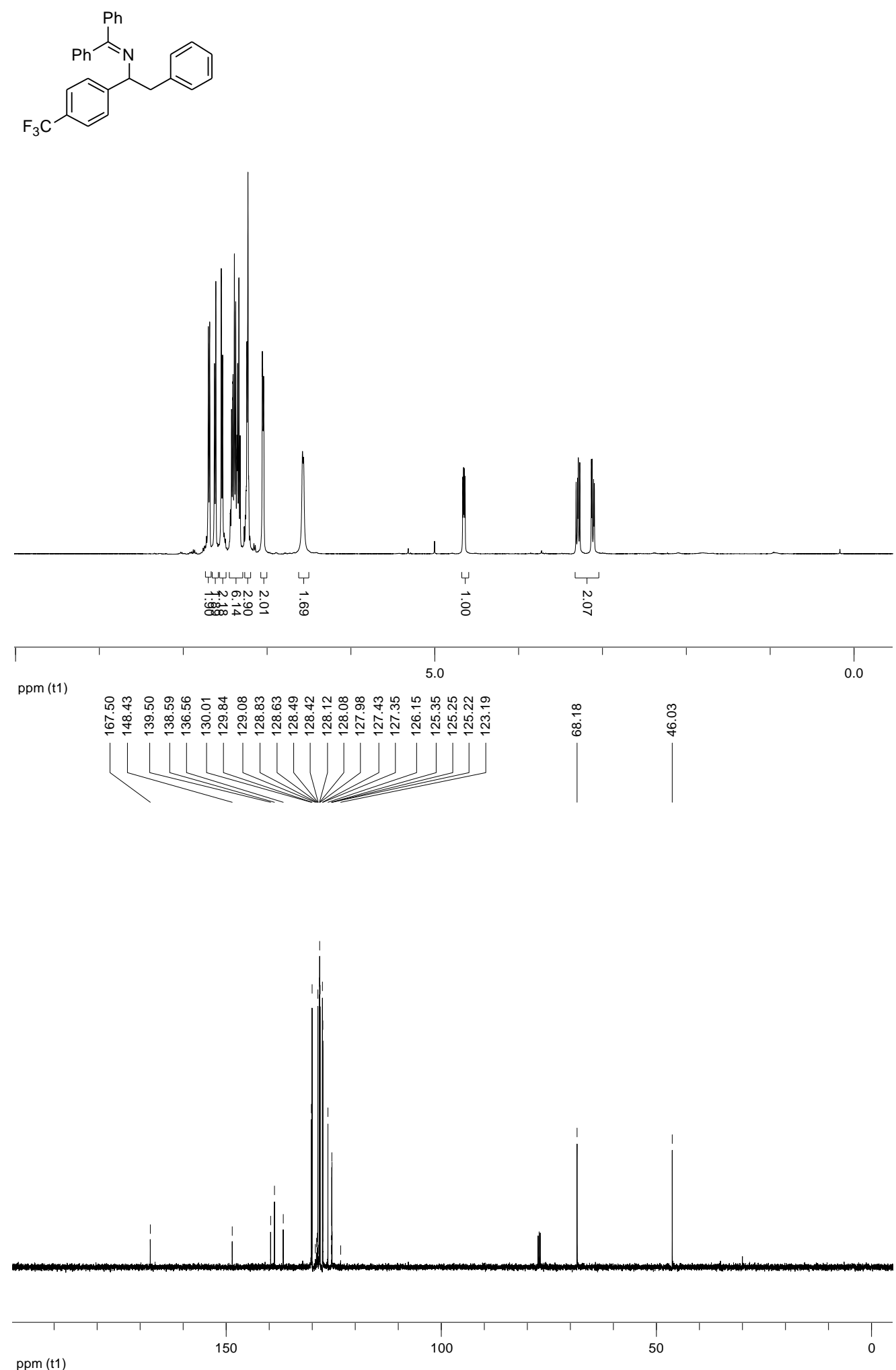

${ }^{1} \mathrm{H}-$ and ${ }^{13} \mathrm{C}-\mathrm{NMR}\left(\mathrm{CDCl}_{3}\right)$ Spectra of $\mathbf{4 . 2} \mathbf{i}$ 


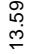

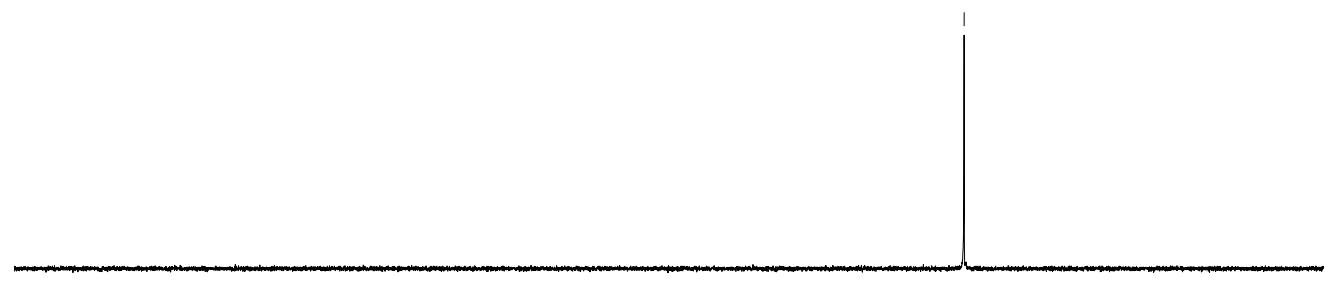

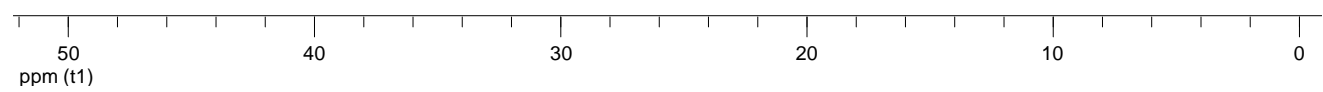

${ }^{19} \mathrm{~F}-\mathrm{NMR}\left(\mathrm{CDCl}_{3}\right)$ Spectra of $\mathbf{4 . 2} \mathbf{i}$ 

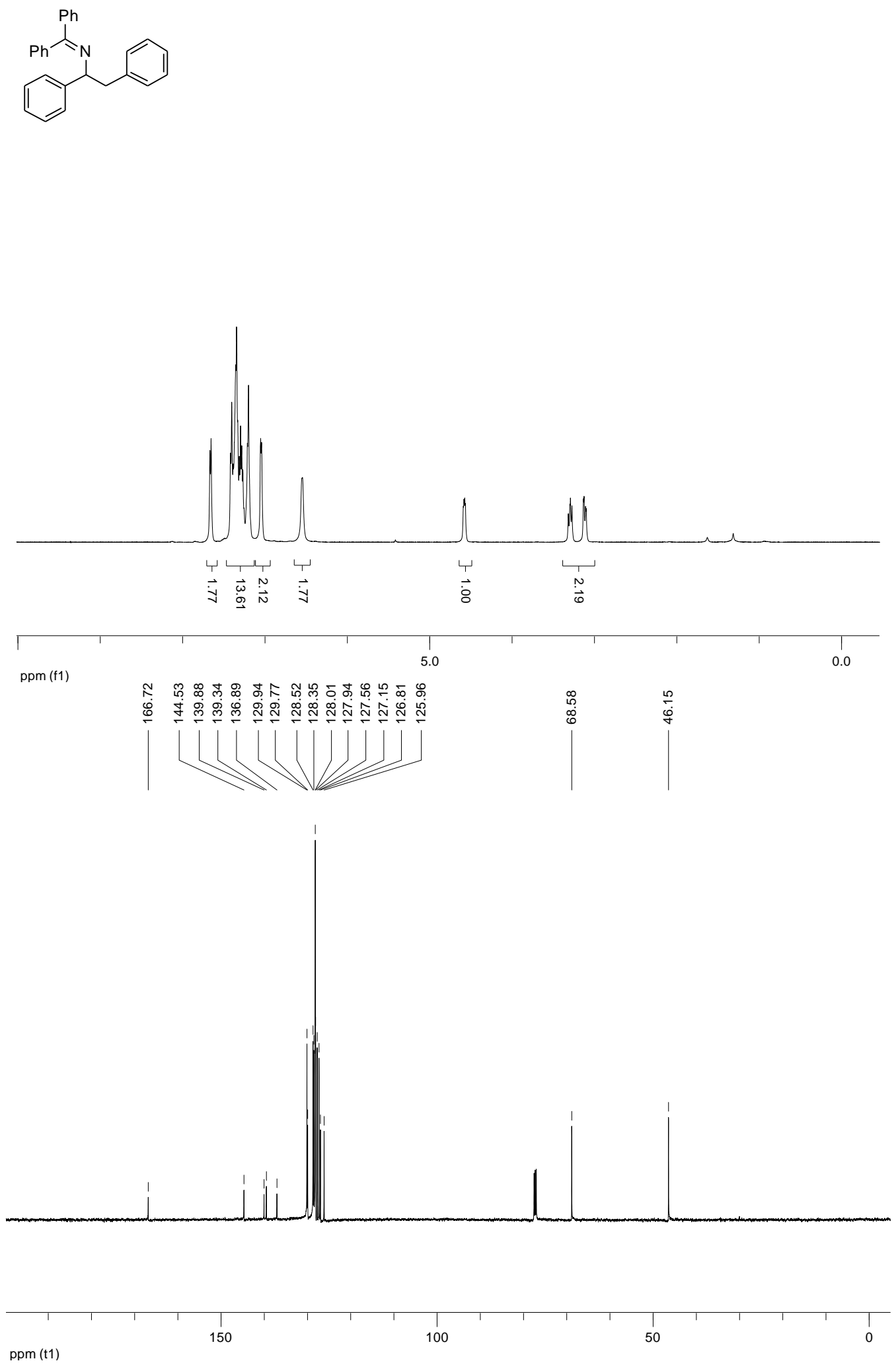

${ }^{1} \mathrm{H}$ - and ${ }^{13} \mathrm{C}-\mathrm{NMR}\left(\mathrm{CDCl}_{3}\right)$ Spectra of $\mathbf{4 . 2 j}$ 

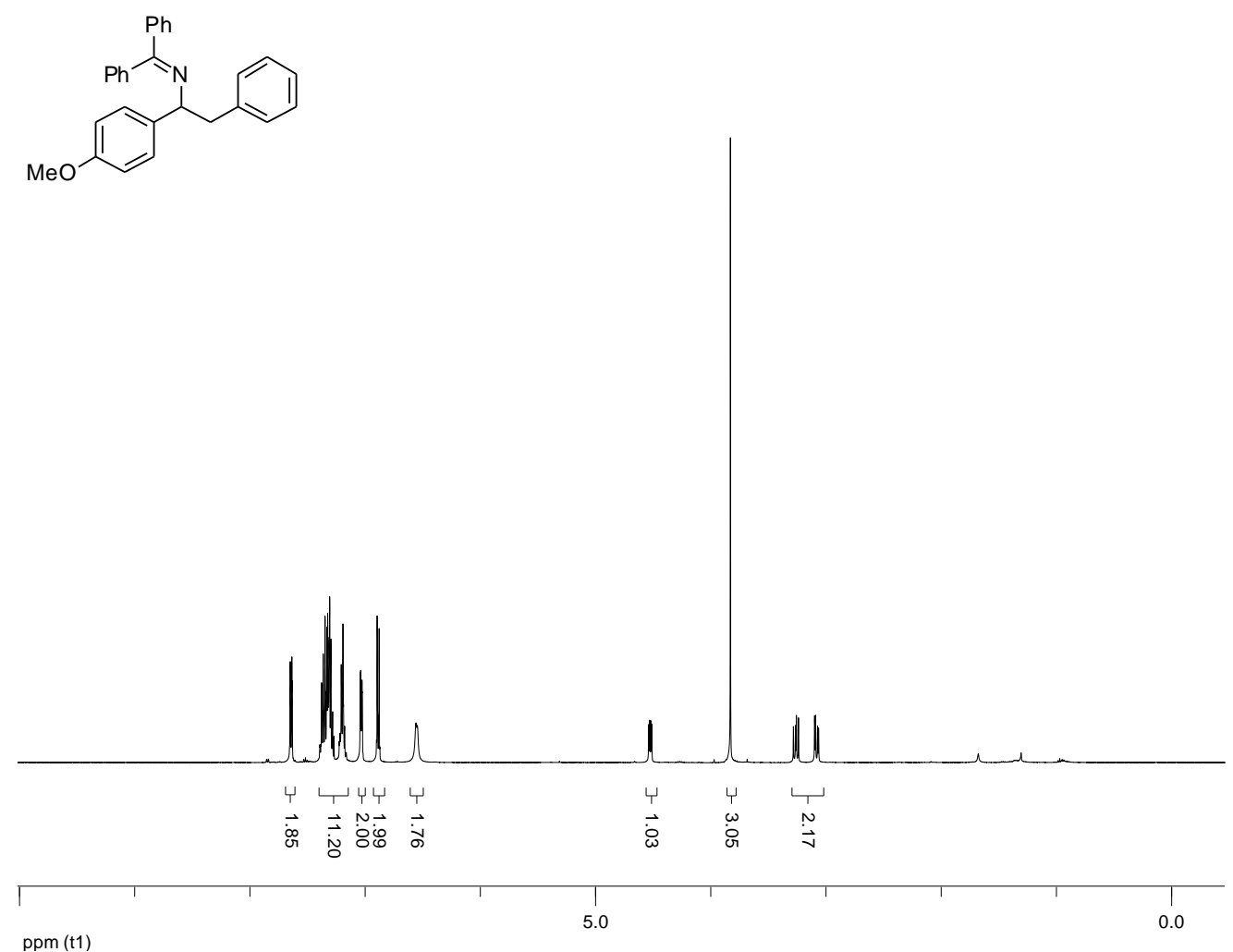

ppm (t1)

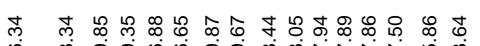

年
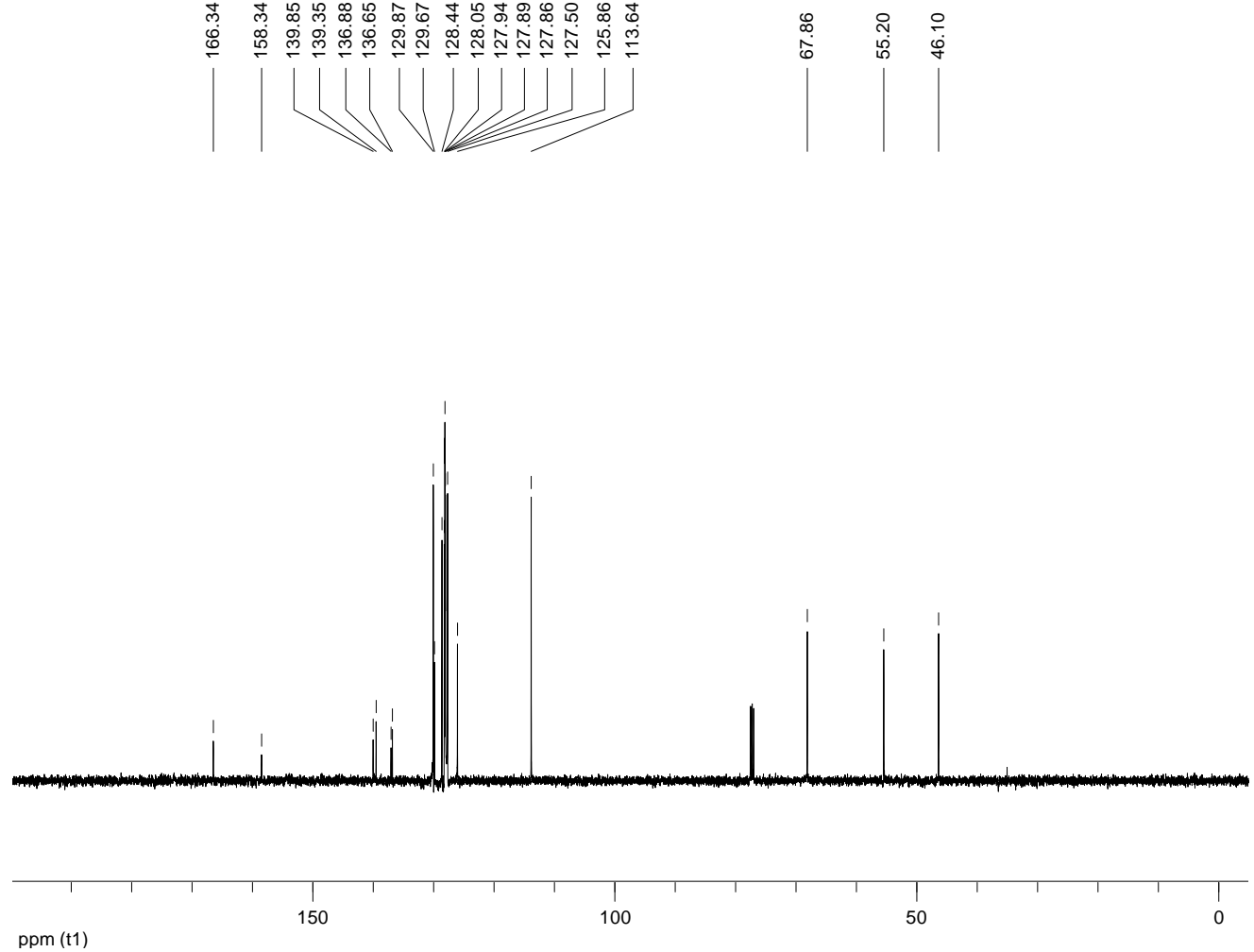

${ }^{1} \mathrm{H}-$ and ${ }^{13} \mathrm{C}-\mathrm{NMR}\left(\mathrm{CDCl}_{3}\right)$ Spectra of $\mathbf{4 . 2 k}$ 

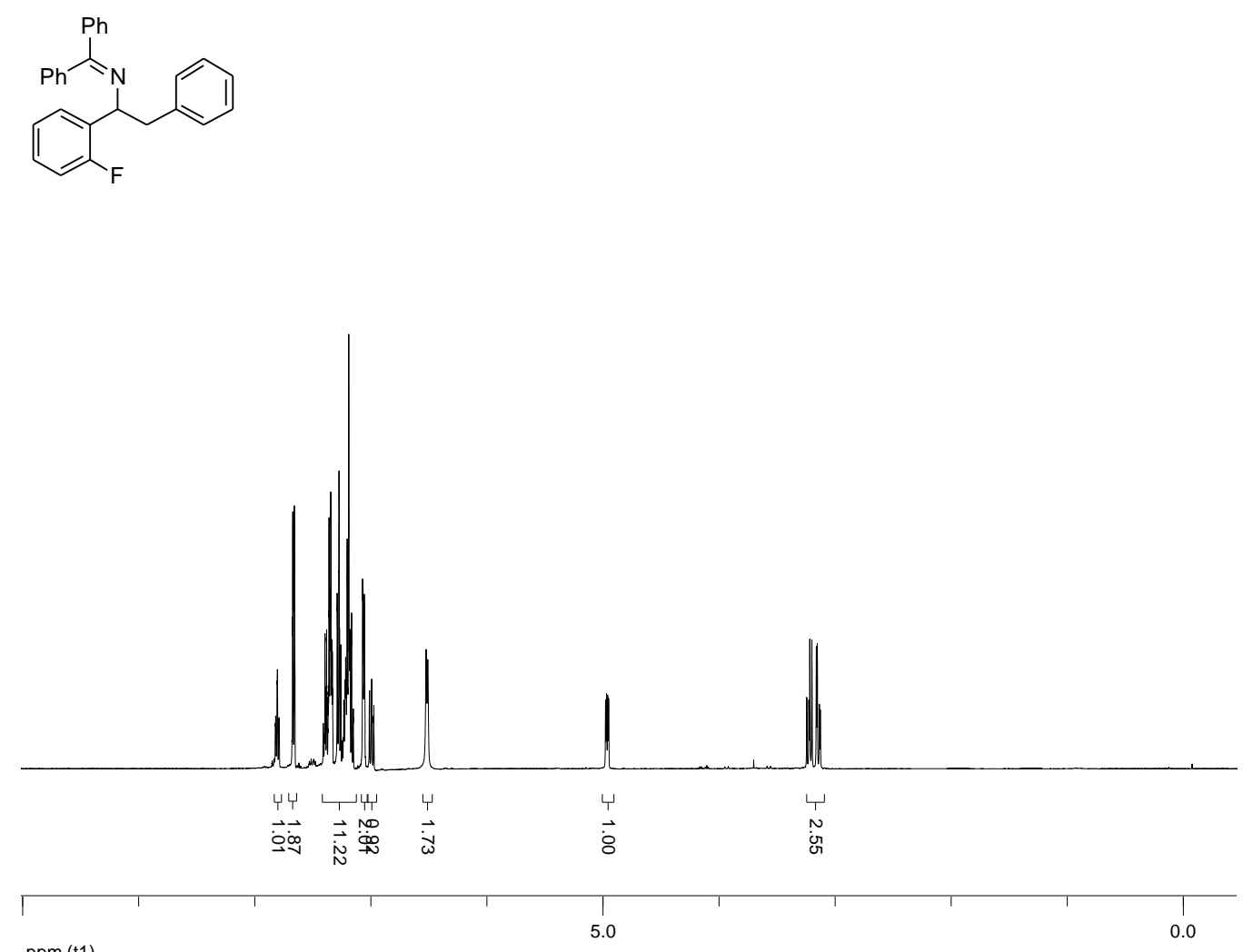

ppm (t1)

ำกำก น

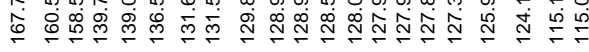
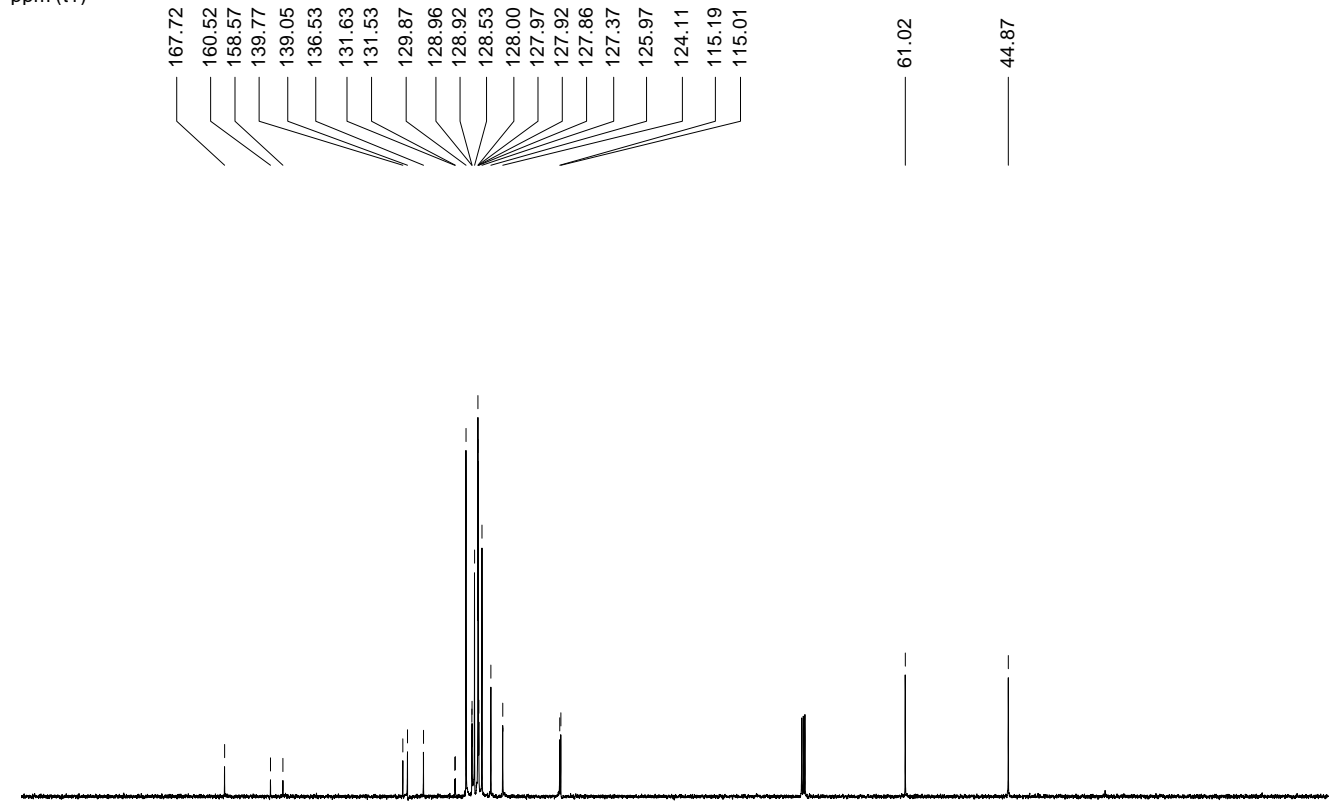

ppm (t1)

150

100

50

${ }^{1} \mathrm{H}-$ and ${ }^{13} \mathrm{C}-\mathrm{NMR}\left(\mathrm{CDCl}_{3}\right)$ Spectra of $\mathbf{4 . 2 \mathrm { l }}$ 


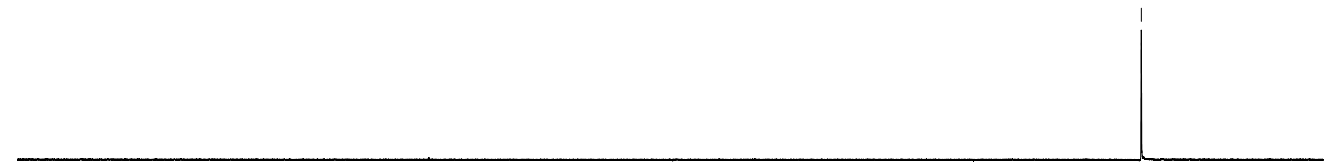

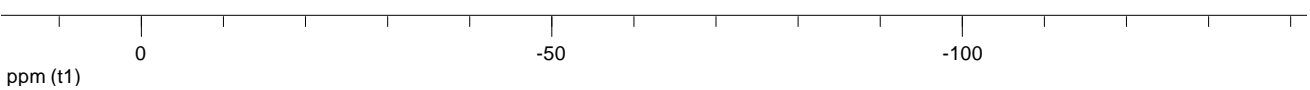

${ }^{19} \mathrm{~F}-\mathrm{NMR}\left(\mathrm{CDCl}_{3}\right)$ Spectra of $\mathbf{4 . 2 1}$ 

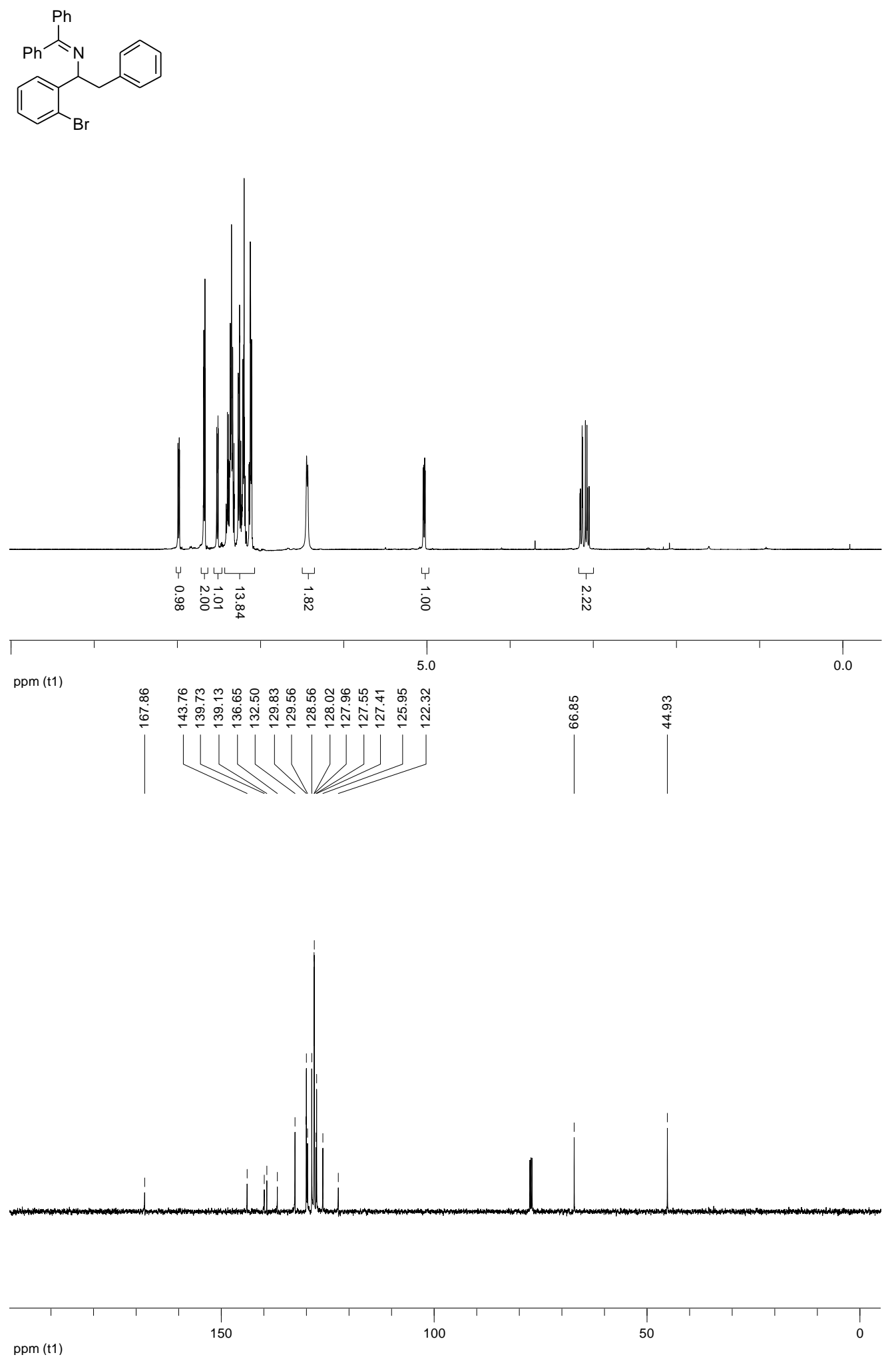

${ }^{1} \mathrm{H}-$ and ${ }^{13} \mathrm{C}-\mathrm{NMR}\left(\mathrm{CDCl}_{3}\right)$ Spectra of $4.2 \mathrm{~m}$ 

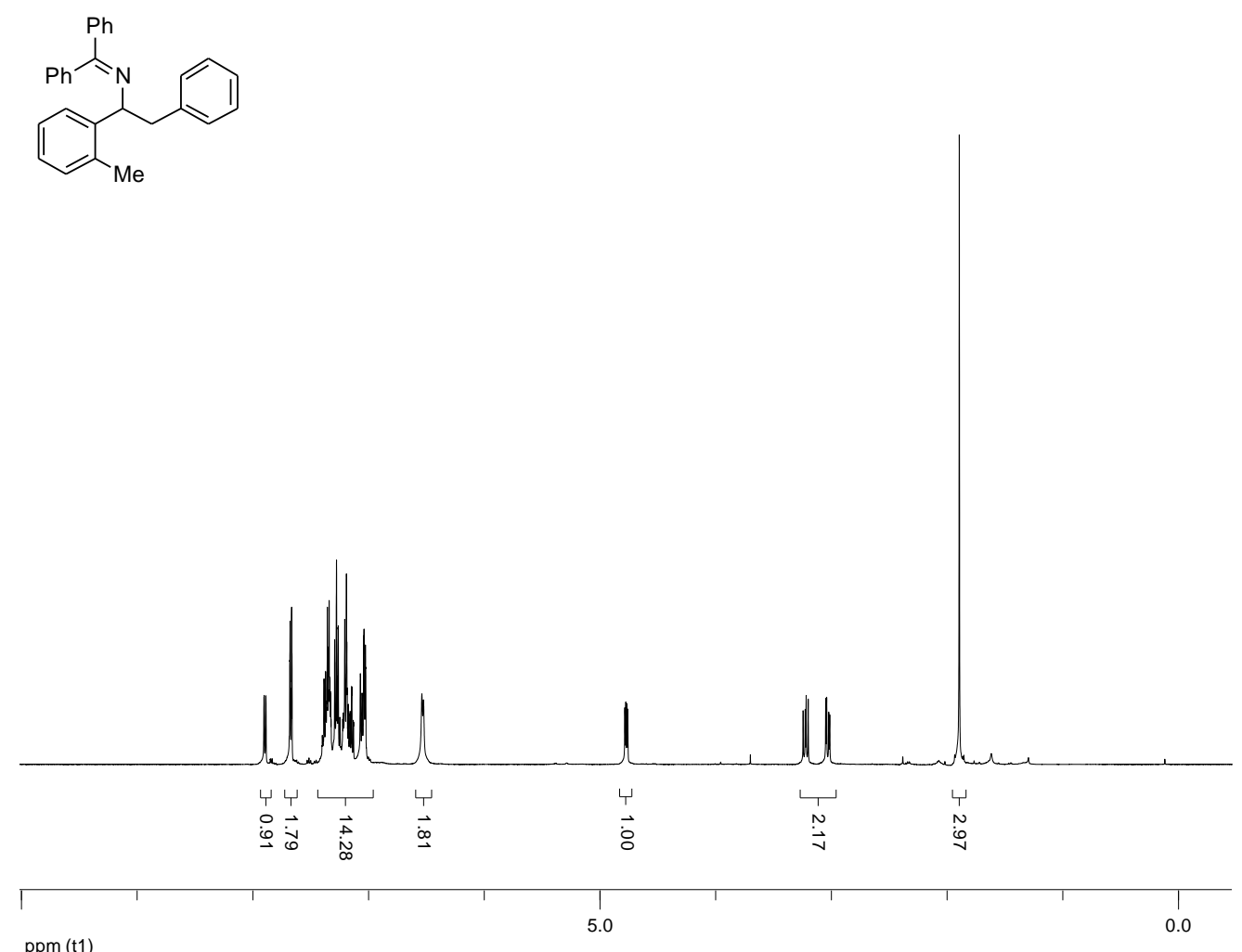

ppm (t1)

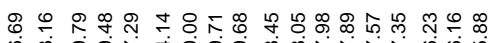

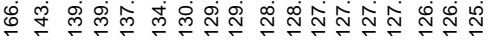
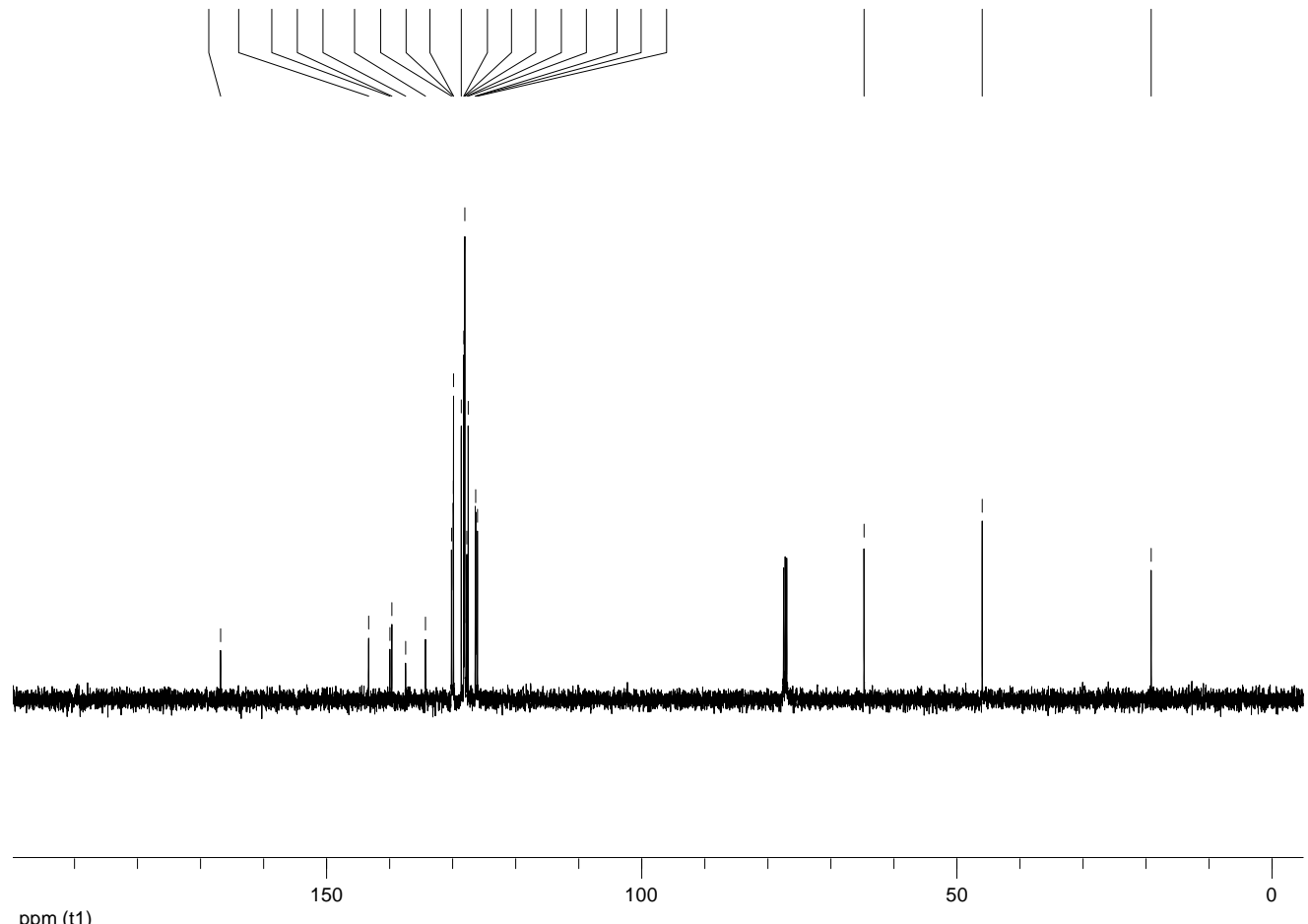

${ }^{1} \mathrm{H}$ - and ${ }^{13} \mathrm{C}-\mathrm{NMR}\left(\mathrm{CDCl}_{3}\right)$ Spectra of 4.2n 

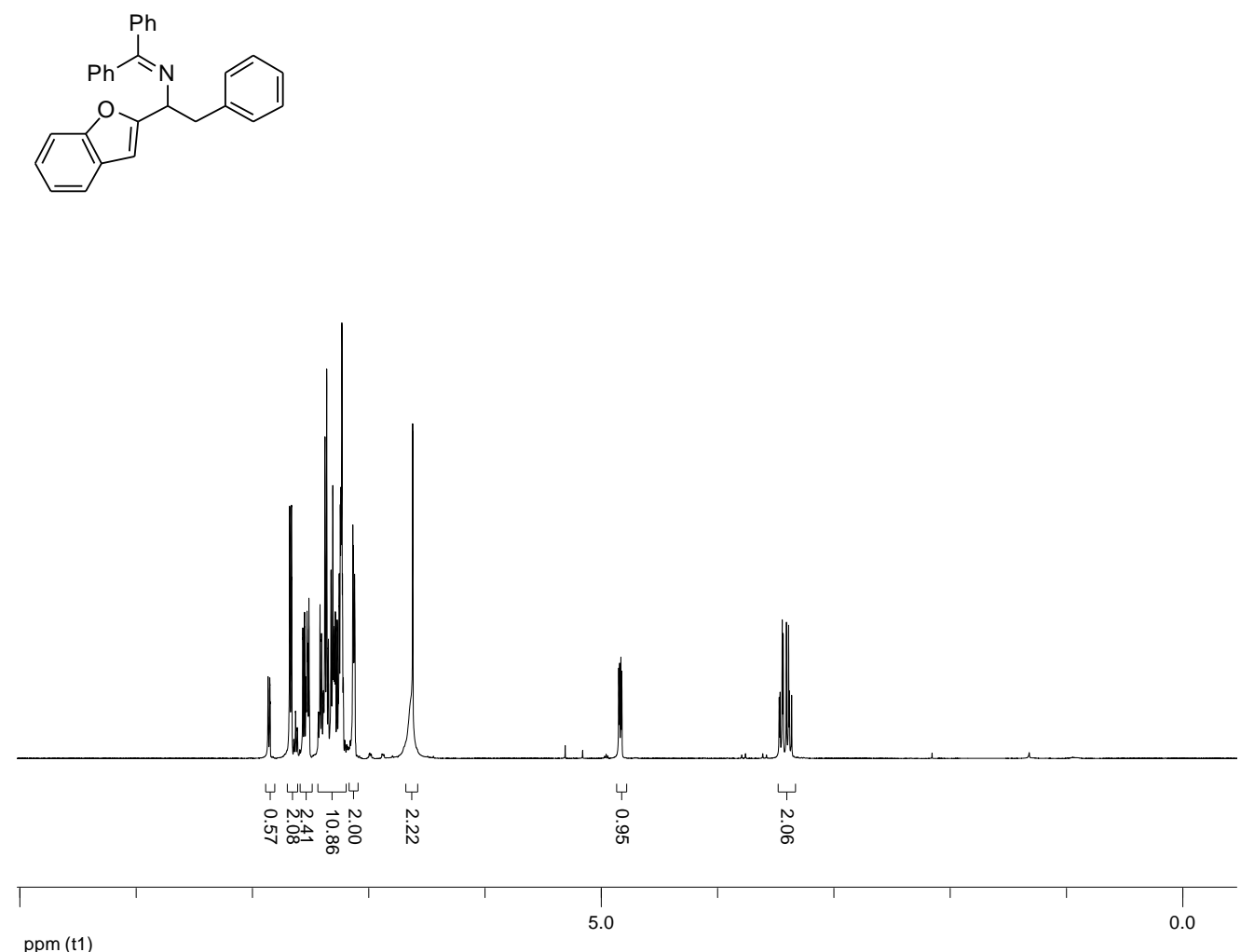

$\mathrm{ppm}(\mathrm{t} 1)$

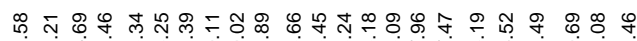
음
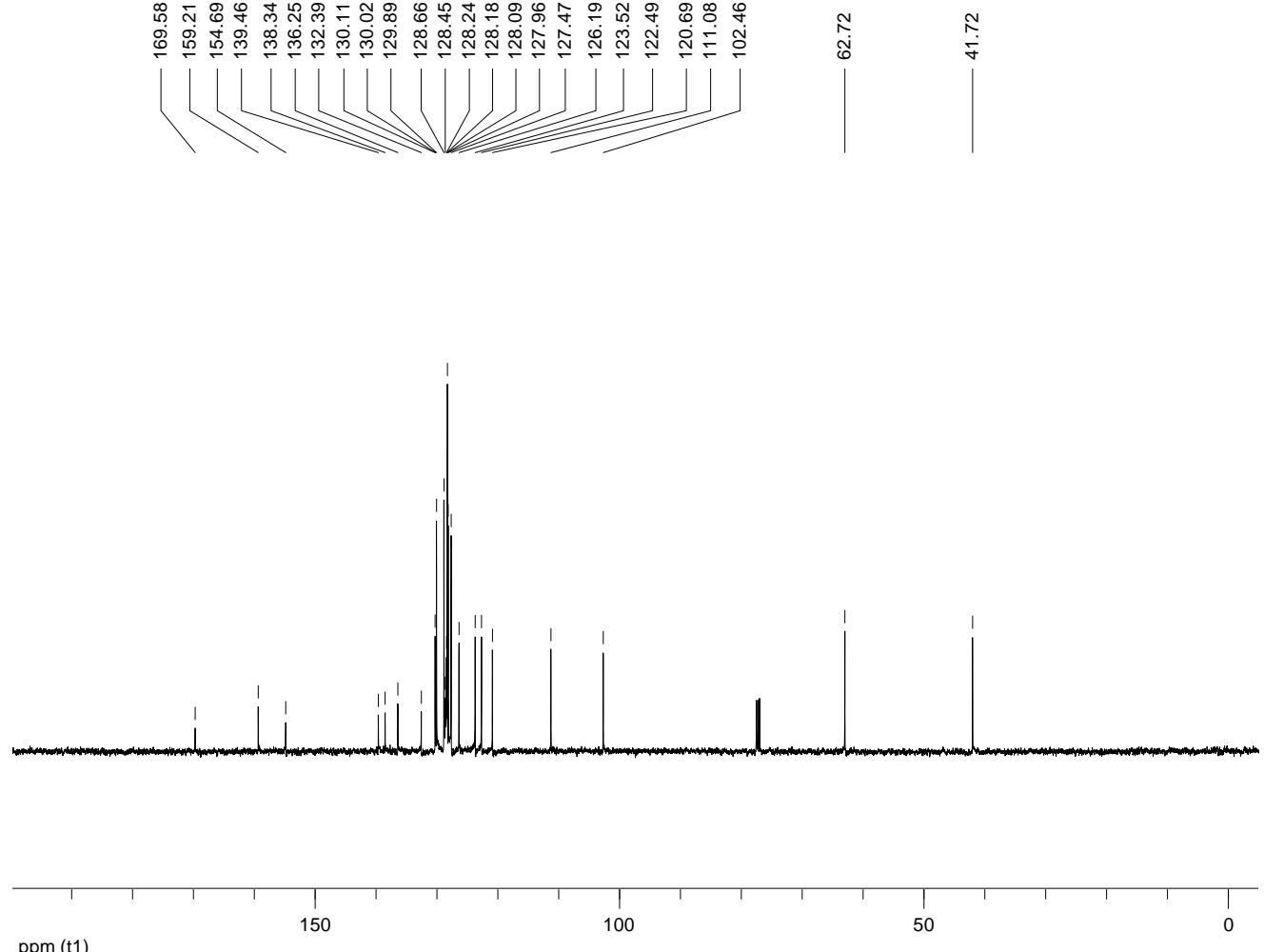

150

100

${ }^{1} \mathrm{H}-$ and ${ }^{13} \mathrm{C}-\mathrm{NMR}\left(\mathrm{CDCl}_{3}\right)$ Spectra of $4.2 \mathrm{o}$ 

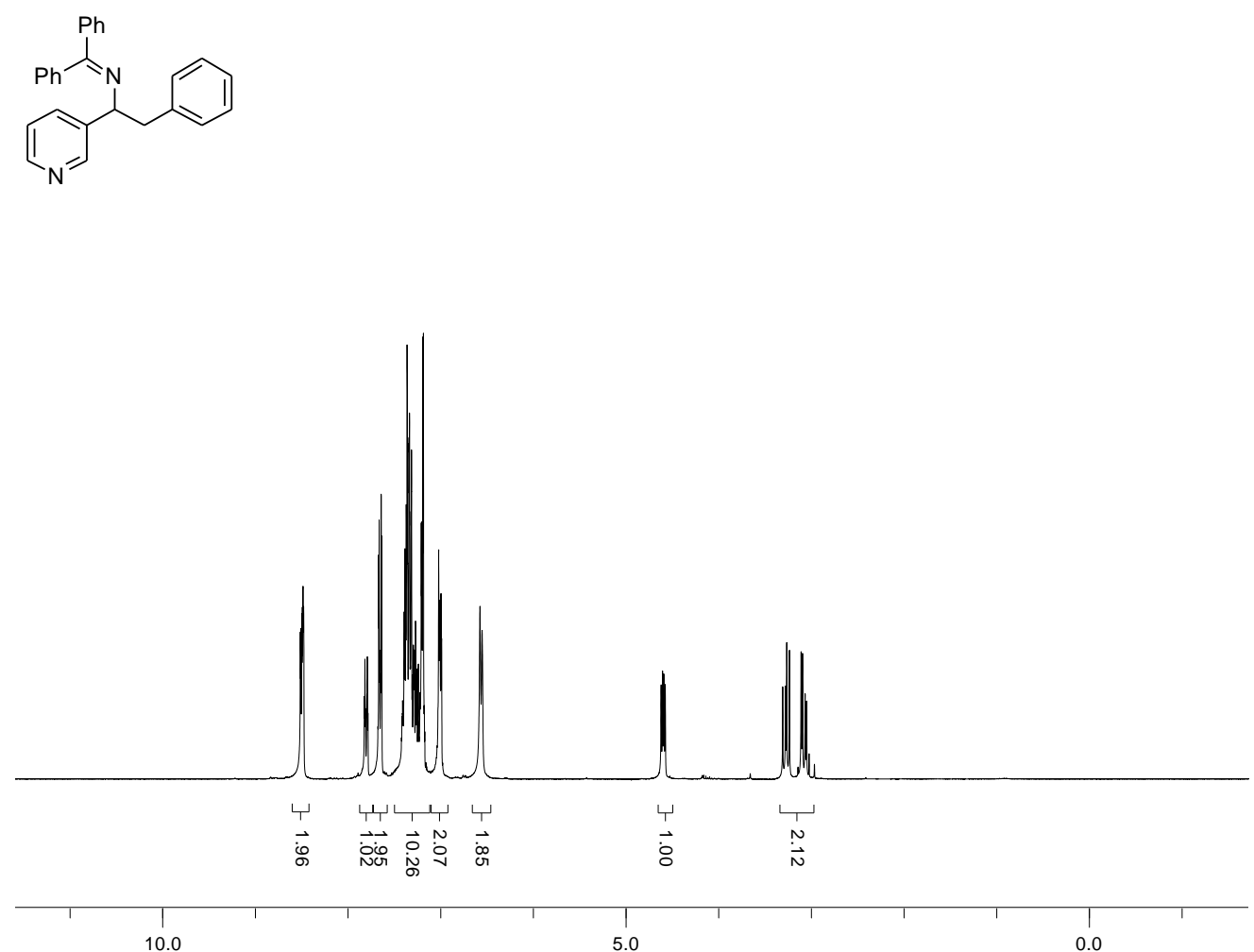

ppm (t1)

웅 숭 웅

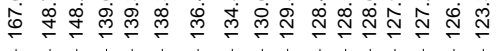
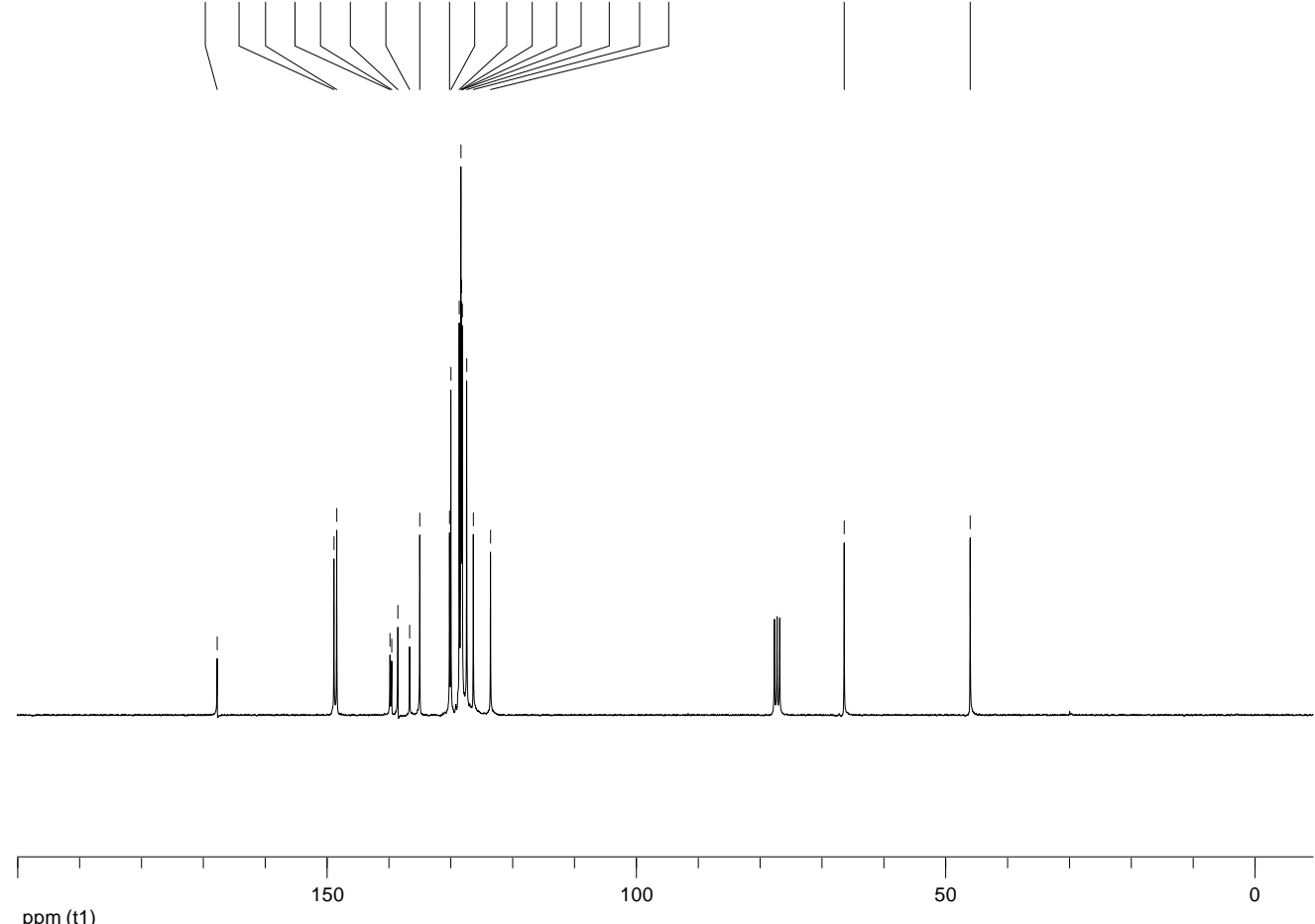

${ }^{1} \mathrm{H}-$ and ${ }^{13} \mathrm{C}-\mathrm{NMR}\left(\mathrm{CDCl}_{3}\right)$ Spectra of 4.2p 

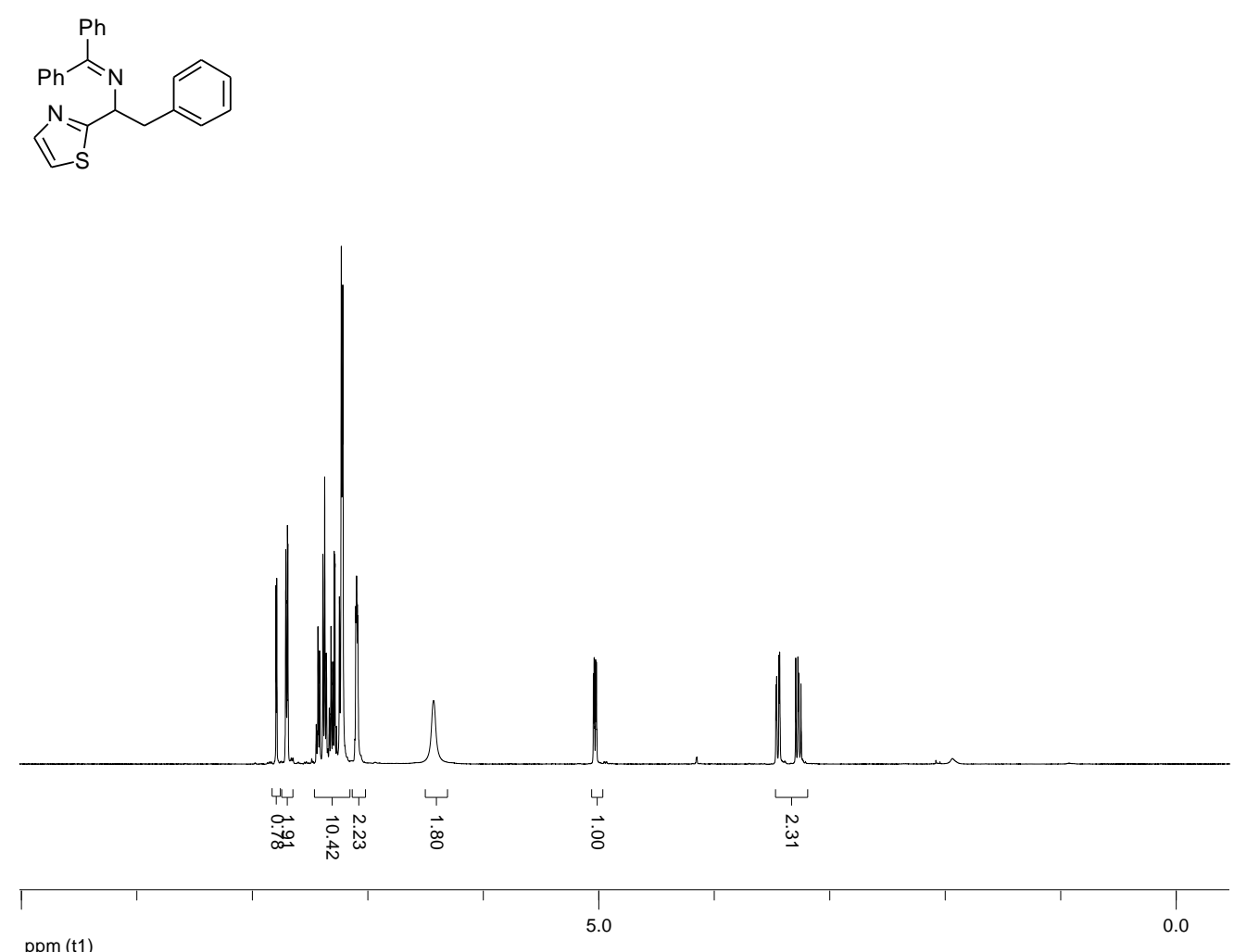

ppm (t1)

กิ

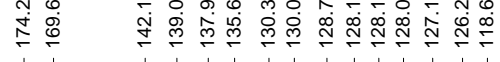

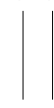

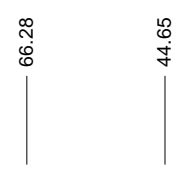
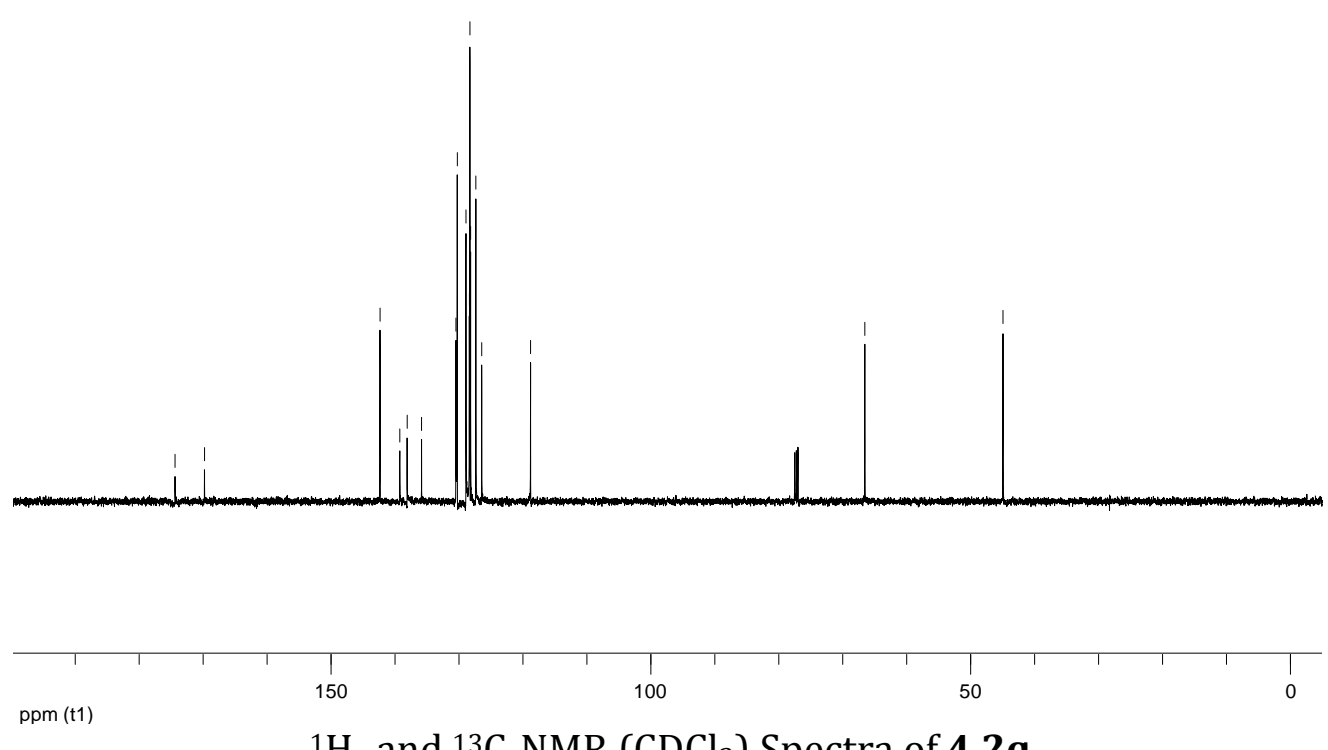

${ }^{1} \mathrm{H}$ - and ${ }^{13} \mathrm{C}-\mathrm{NMR}\left(\mathrm{CDCl}_{3}\right)$ Spectra of 4.2q 

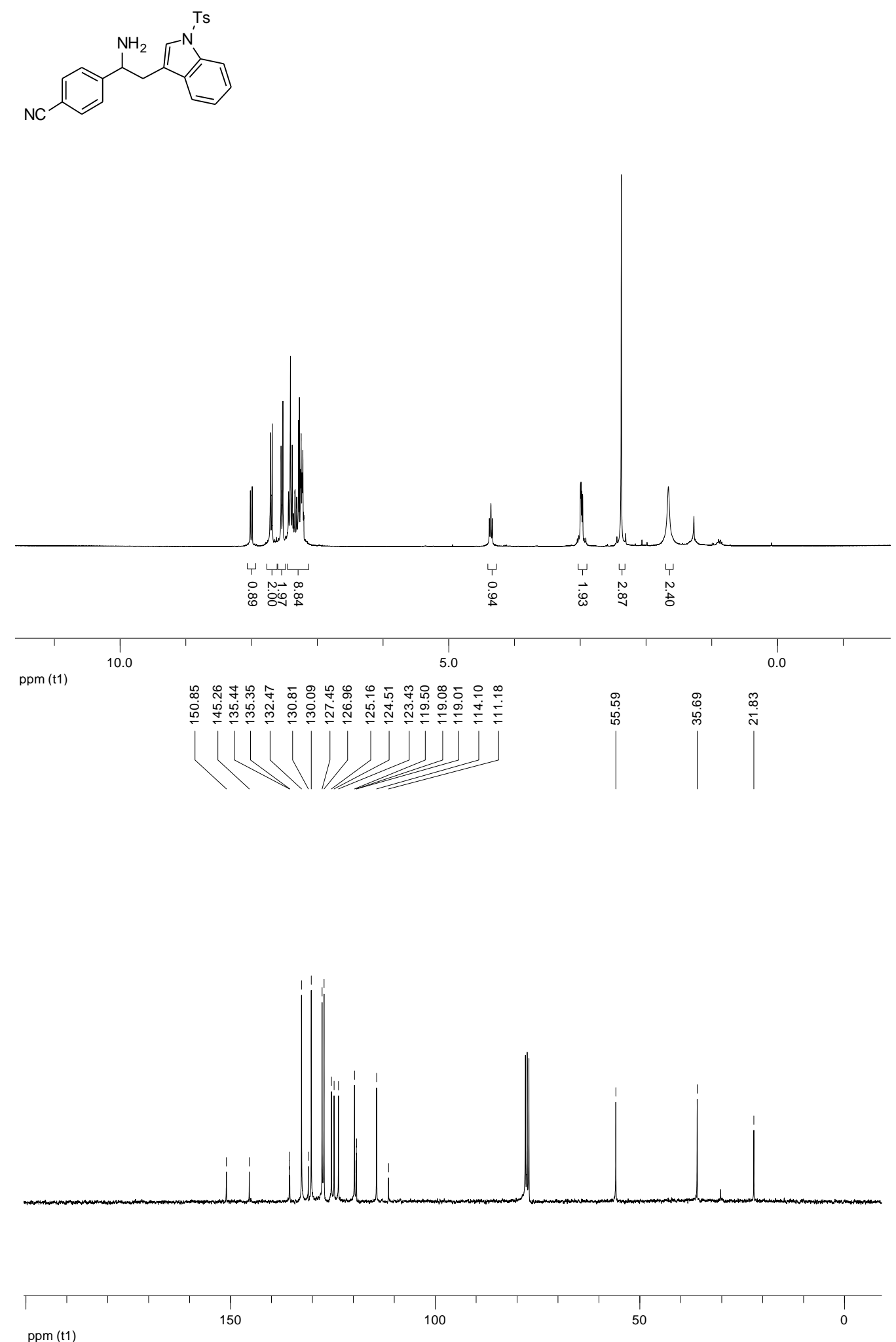

${ }^{1} \mathrm{H}$ - and ${ }^{13} \mathrm{C}$-NMR $\left(\mathrm{CDCl}_{3}\right)$ Spectra of 4.14 

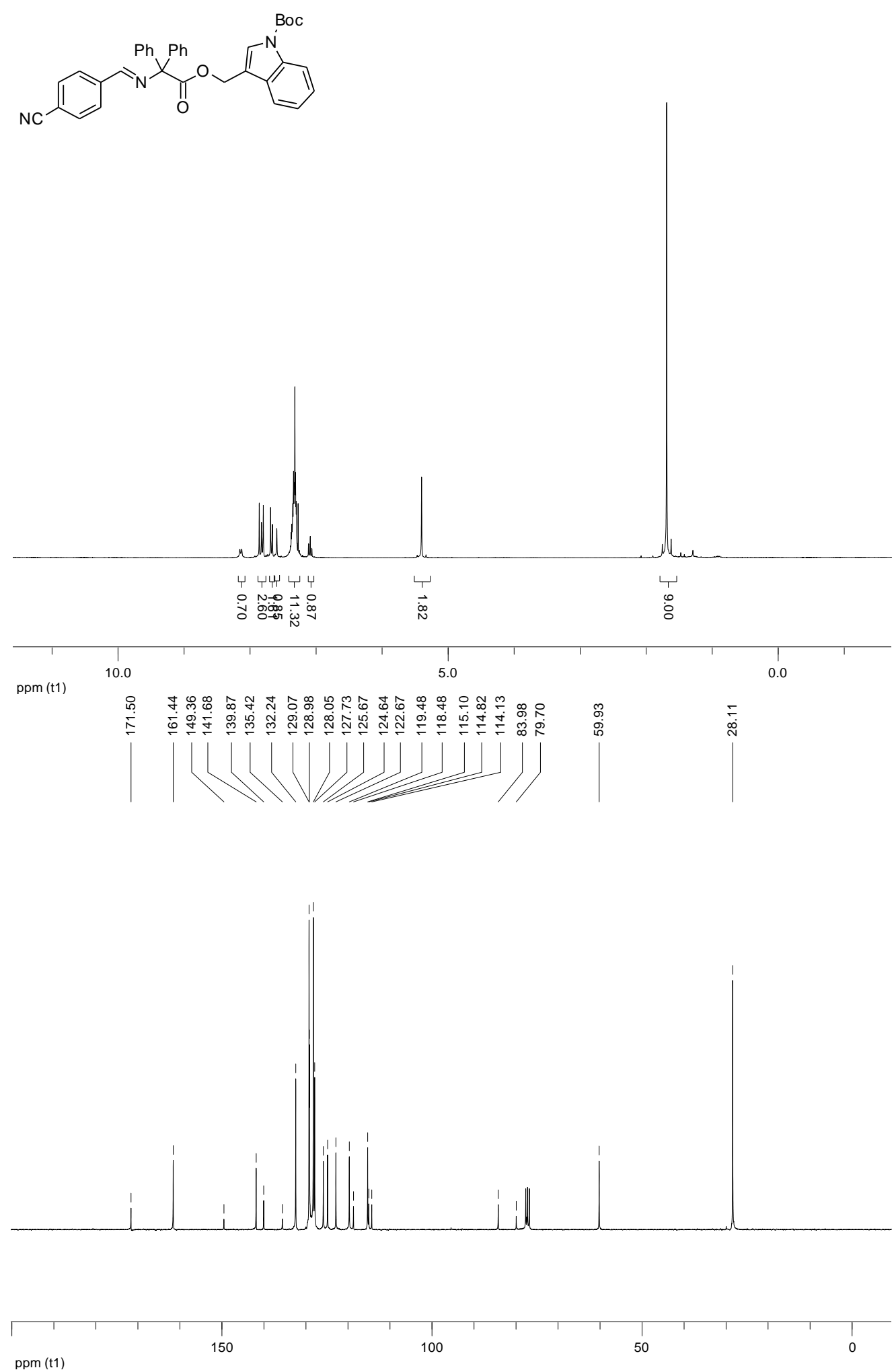

${ }^{1} \mathrm{H}$ - and ${ }^{13} \mathrm{C}$-NMR $\left(\mathrm{CDCl}_{3}\right)$ Spectra of $\mathbf{4 . 1 7}$ 

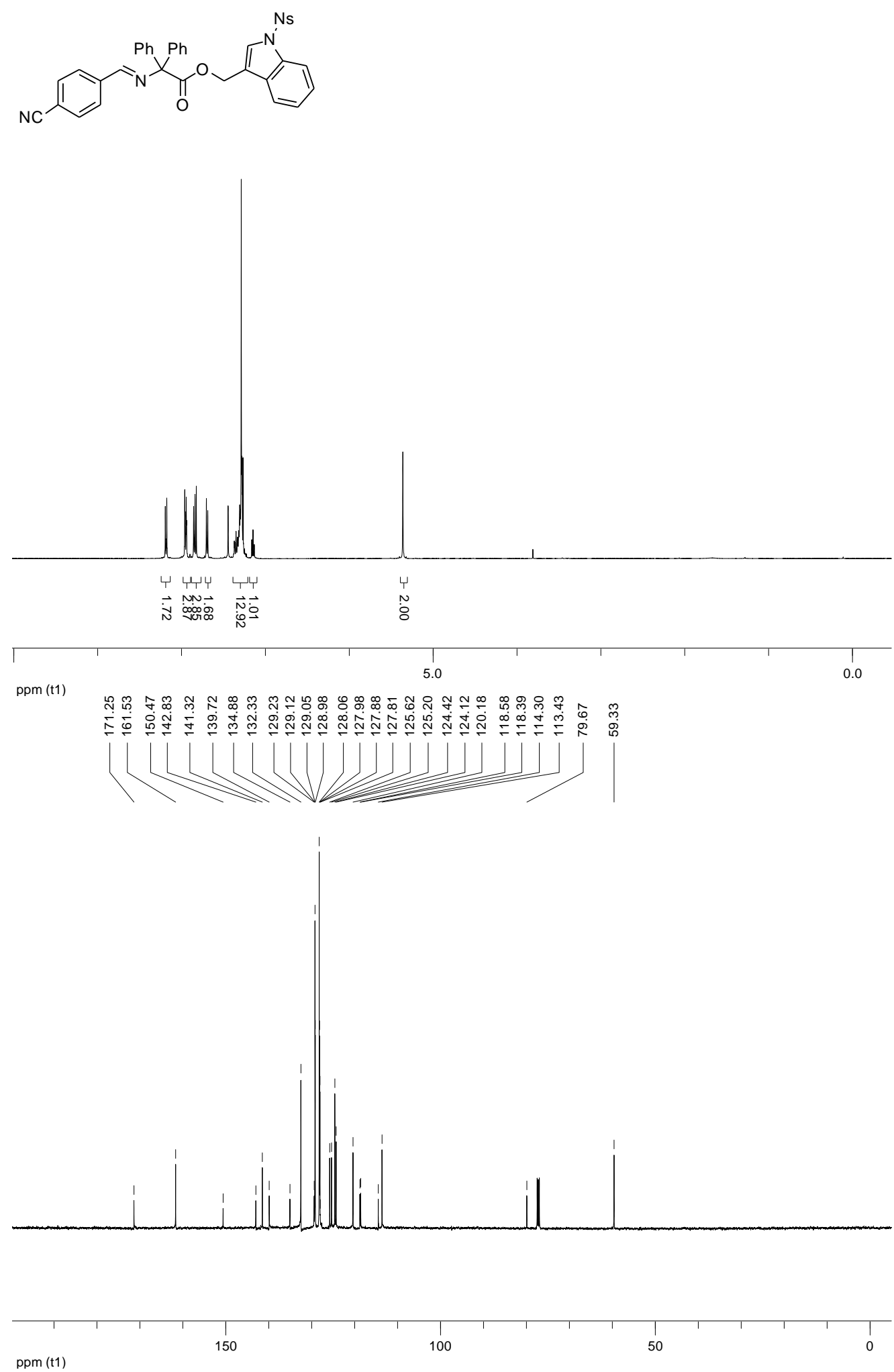

${ }^{1} \mathrm{H}-$ and ${ }^{13} \mathrm{C}-\mathrm{NMR}\left(\mathrm{CDCl}_{3}\right)$ Spectra of $\mathbf{4 . 1 9}$ 

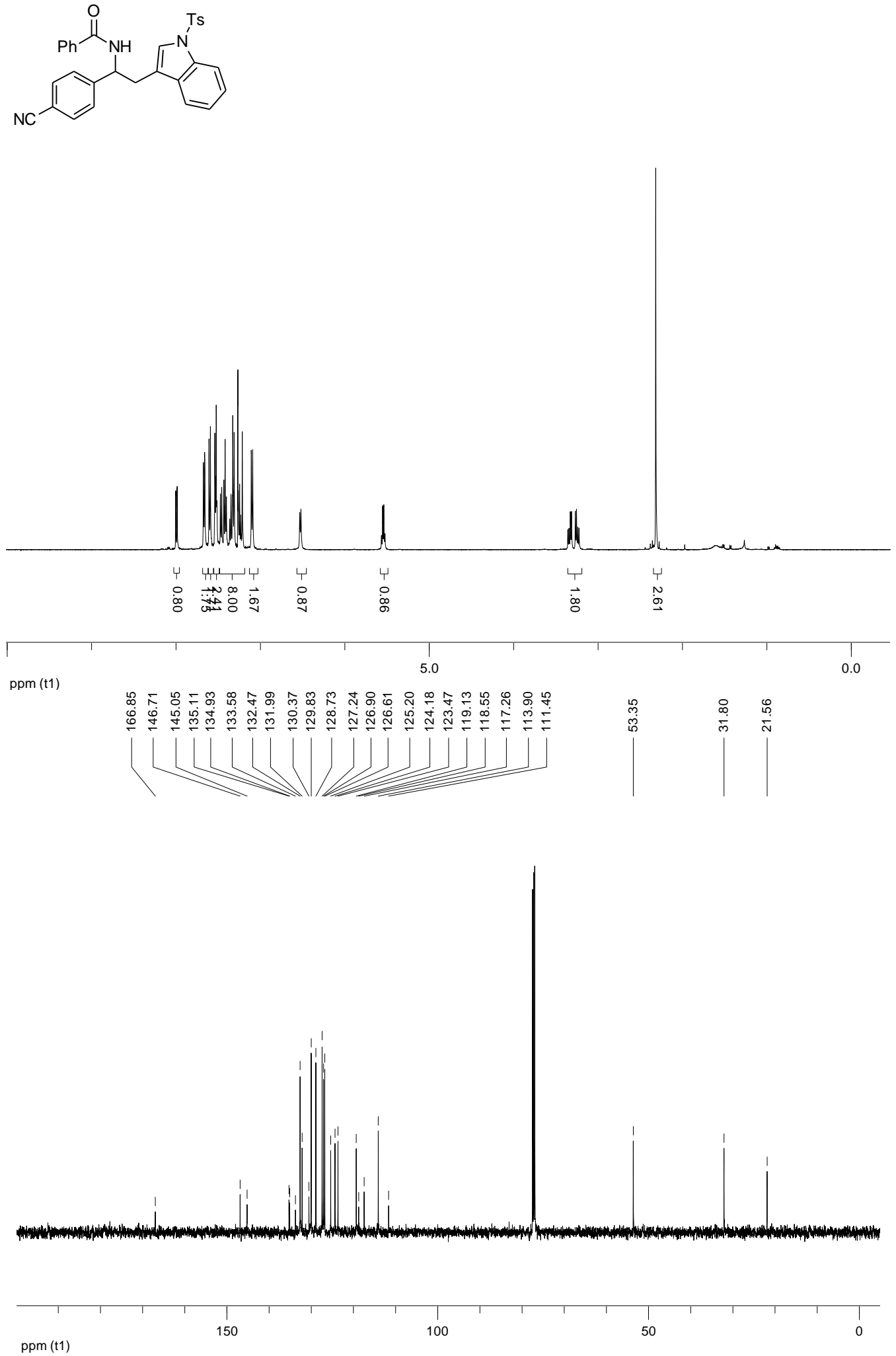

${ }^{1} \mathrm{H}$ - and ${ }^{13} \mathrm{C}-\mathrm{NMR}\left(\mathrm{CDCl}_{3}\right)$ Spectra of 4.22a 

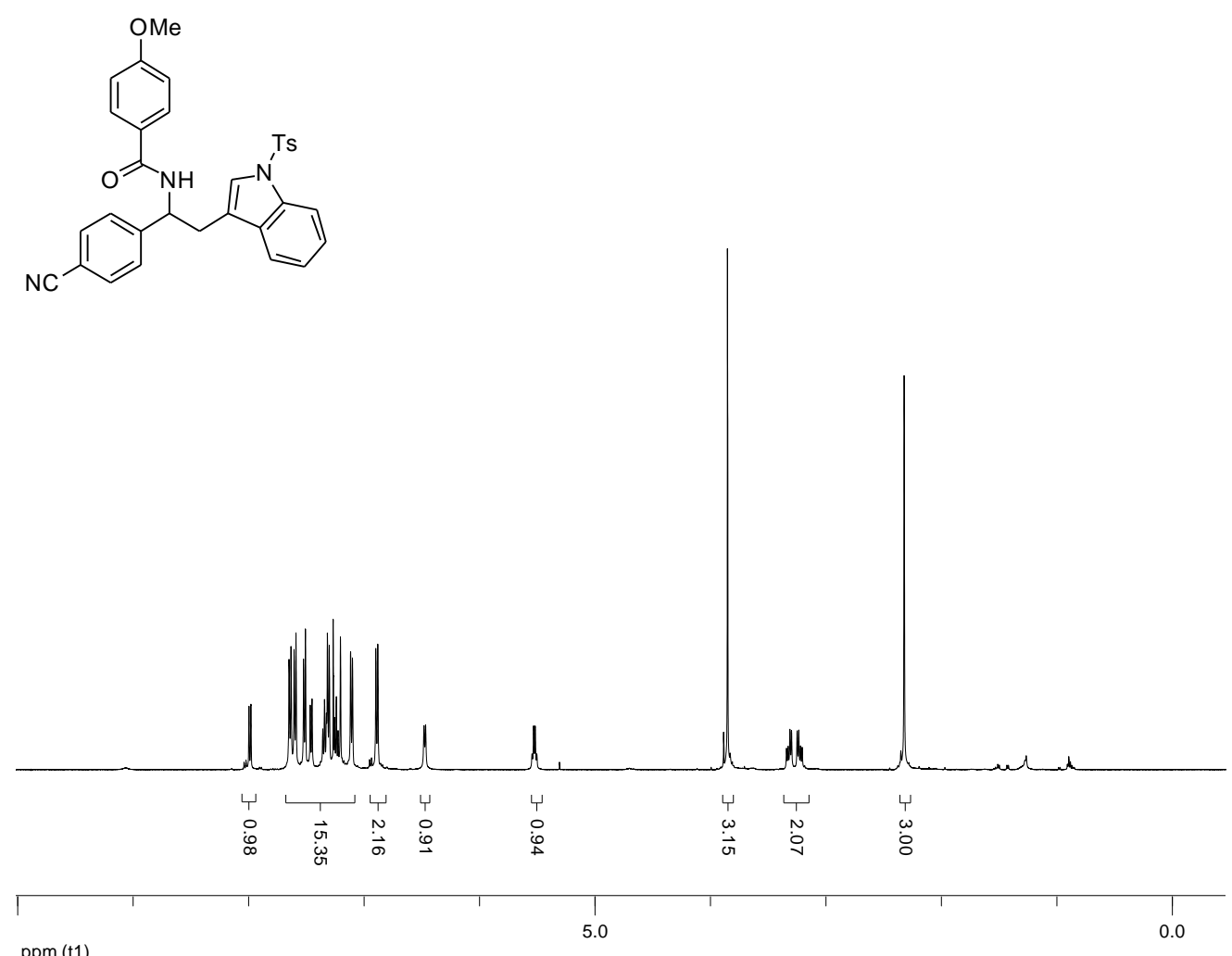

ppm (t1)

め స్

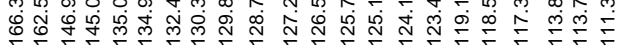
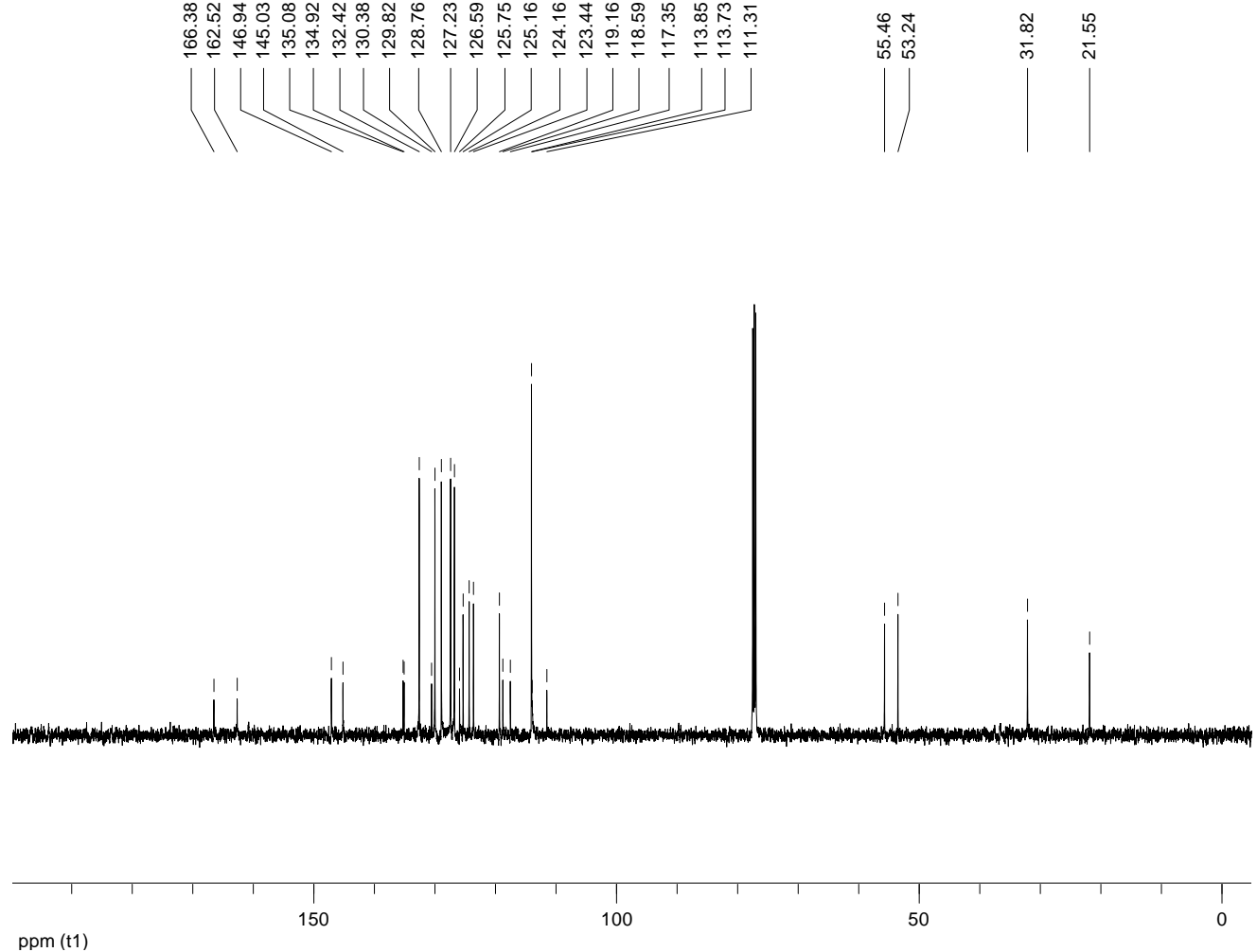

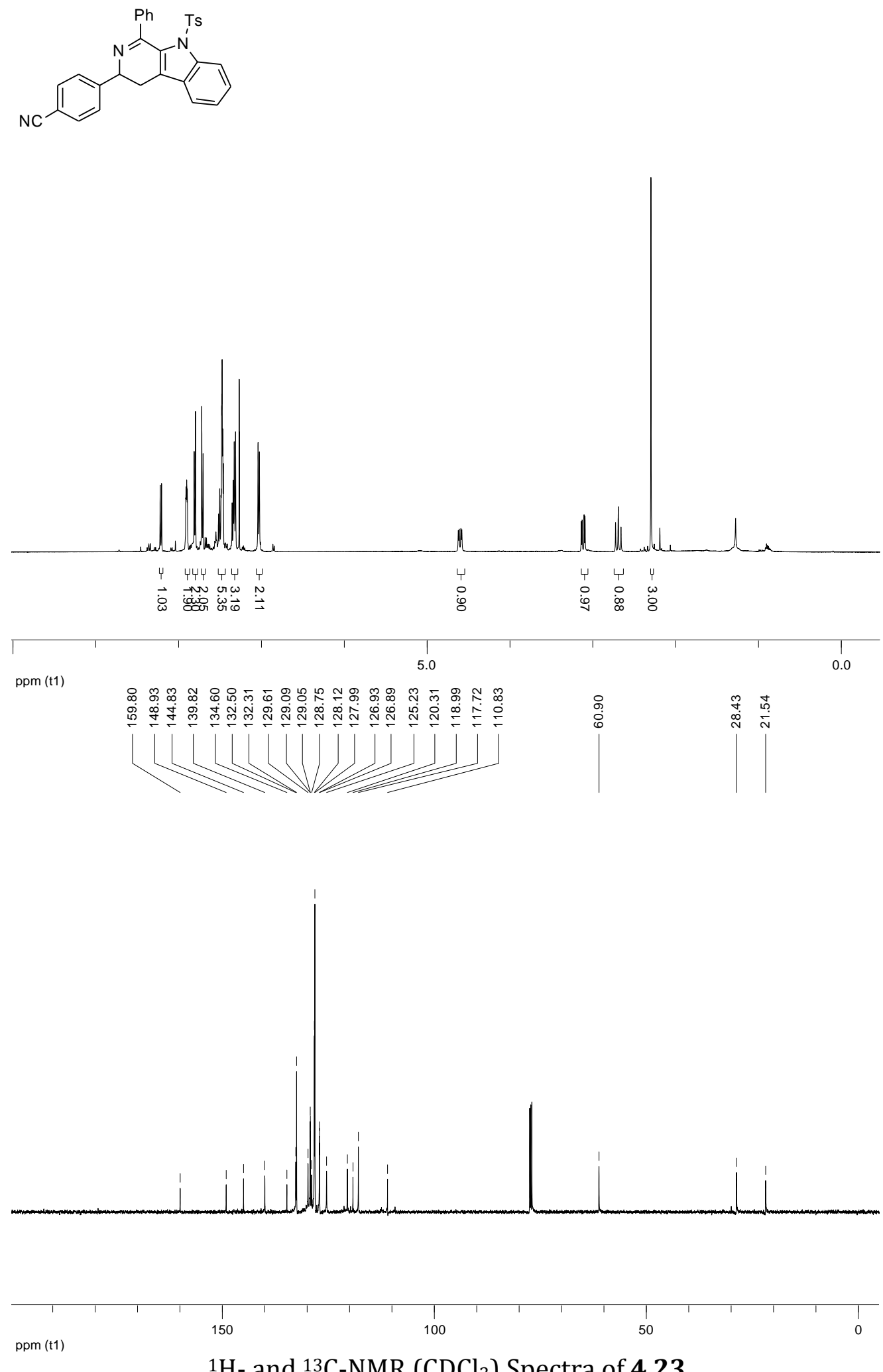

${ }^{1} \mathrm{H}$ - and ${ }^{13} \mathrm{C}$-NMR $\left(\mathrm{CDCl}_{3}\right)$ Spectra of 4.23 

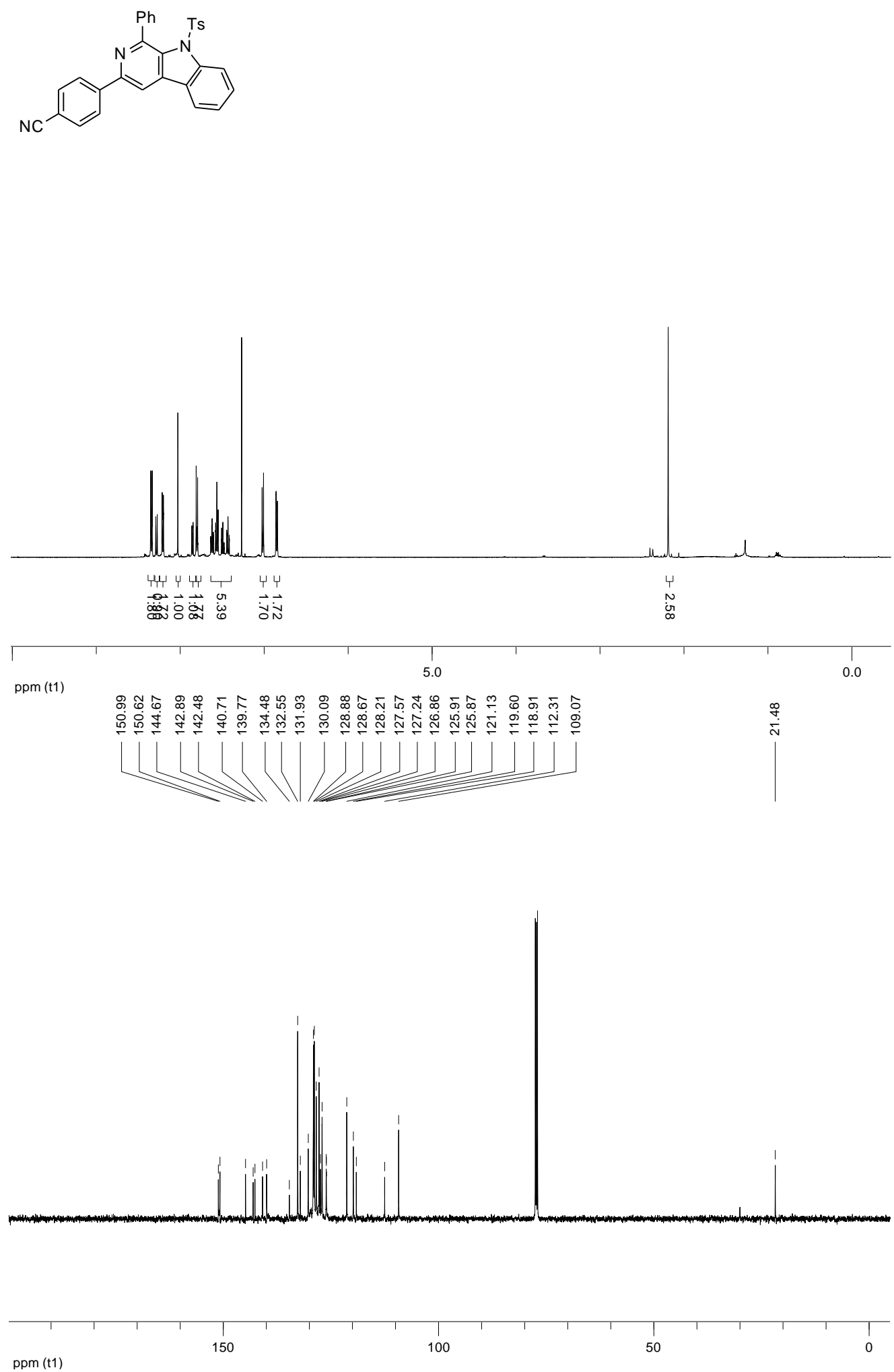

${ }^{1} \mathrm{H}$ - and ${ }^{13} \mathrm{C}$-NMR $\left(\mathrm{CDCl}_{3}\right)$ Spectra of 4.13 
NOESY spectrum of 3.13a ( $\left.500 \mathrm{MHz}, \mathrm{CDCl}_{3}\right)$
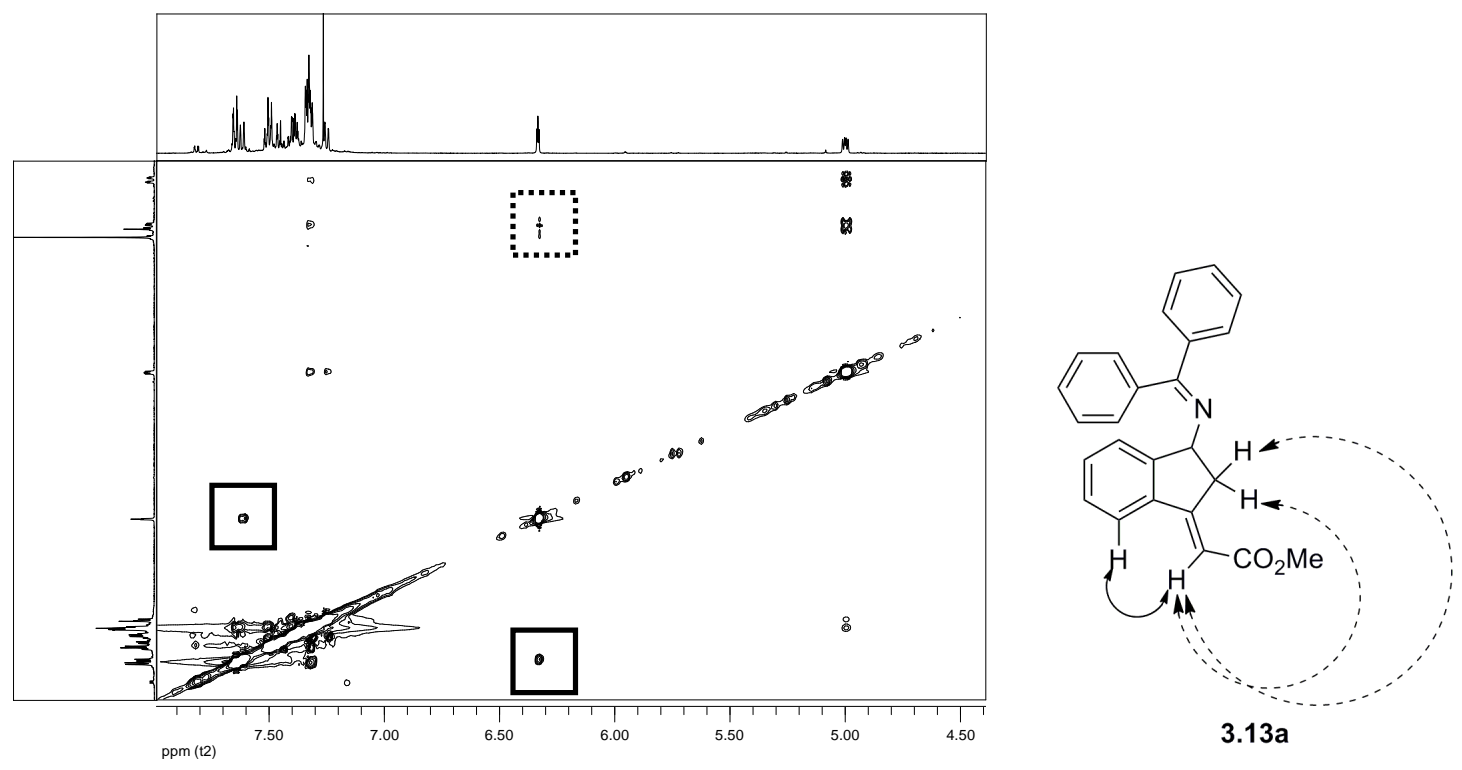

NOE coupling

COSY coupling

NOESY spectrum of 3.13b $\left(300 \mathrm{MHz}, \mathrm{CDCl}_{3}\right)$
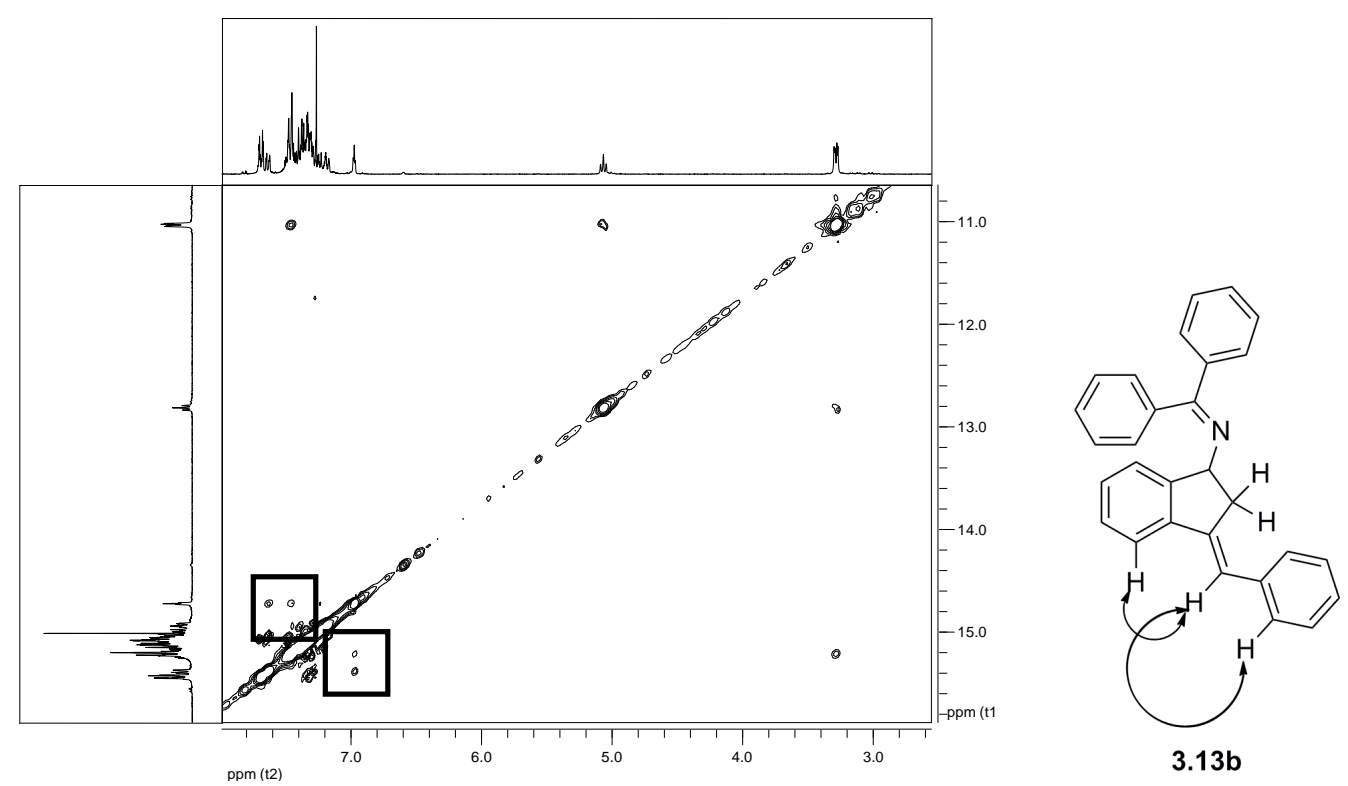
NOESY spectrum of $\mathbf{3 . 1 3 c}\left(500 \mathrm{MHz}, \mathrm{CDCl}_{3}\right)$
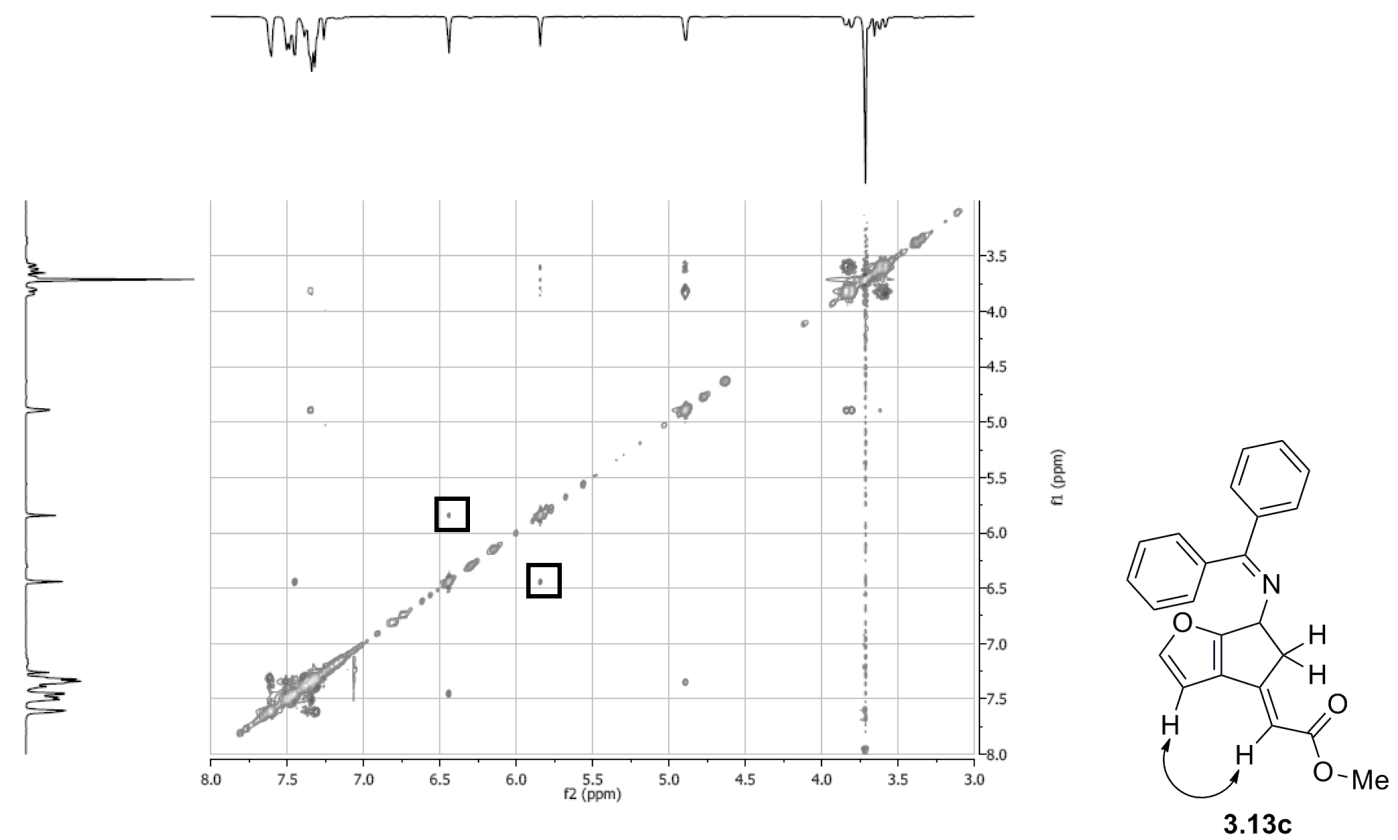

NOE coupling 


\section{APPENDIX B.}

X-ray Crystallographic Analysis of 3.4a: The orange solid ( \pm )-3a was recrystallized from EtOAc-hexanes to obtain colorless crystals at room temperature. Crystal data: C23H19N, $M=309.39$, crystal dimensions: $0.36 \times 0.22 \times 0.21 \mathrm{~mm} 3$, monoclinic, space group $P 21 / c, a=14.7133(1), b=8.3268(6), c=15.9547(1) \AA ̊ ., \beta=$ 116.296(2)o, $V=1752.4(2) \AA ̊, Z=4, D c=1.17 \mathrm{~g} / \mathrm{cm} 3, T=293(2) \mathrm{K} . \mathrm{X}$-Ray data collection was carried out on a Bruker SMART APEX CCD diffractometer using MoK $\alpha$ radiation $(\lambda=0.71073 \AA)$. The structure was solved applying direct methods techniques in SHELXTL (Sheldrick, G. M. SHELXTL Version 5.1 Reference Manual, Bruker AXS, Inc.: Madison, WI, 1997). Full-matrix least-squares refinement with anisotropic thermal displacement parameters for all non-hydrogen atoms yielded $\mathrm{R}$ $=0.081(\mathrm{Rw}=0.305)$ for 3085 reflections with $\mathrm{I}>2 \sigma(\mathrm{I})$. The indenyl ring system was found to be disordered between two enantiomers (Figure S1b). Atoms belonging to the enantiomers were refined with anisotropic thermal displacement parameters and the population factors of 0.7 (enantiomer A) and 0.3 (enantiomer B). The final electron density map was essentially featureless with the highest peak of 0.21 e/Å3.

Crystallographic data have been deposited with the Cambridge Crystallographic Data Center: Deposition number CCDC-696890. Copies of the data can be obtained free of charge via http://www.ccdc.cam.uk/conts/retrieving.html (or from the Cambridge Crystallographic Data Centre, 12, Union Road, Cambridge, CB2 1EZ, UK; Fax +44 1223 336033; e-mail: deposit@ccdc.cam.ac.uk). 
(a)

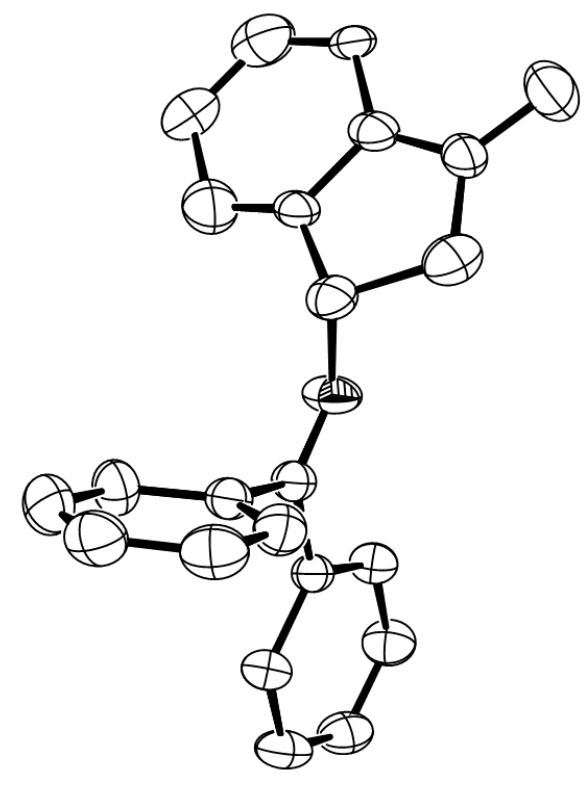

(b)

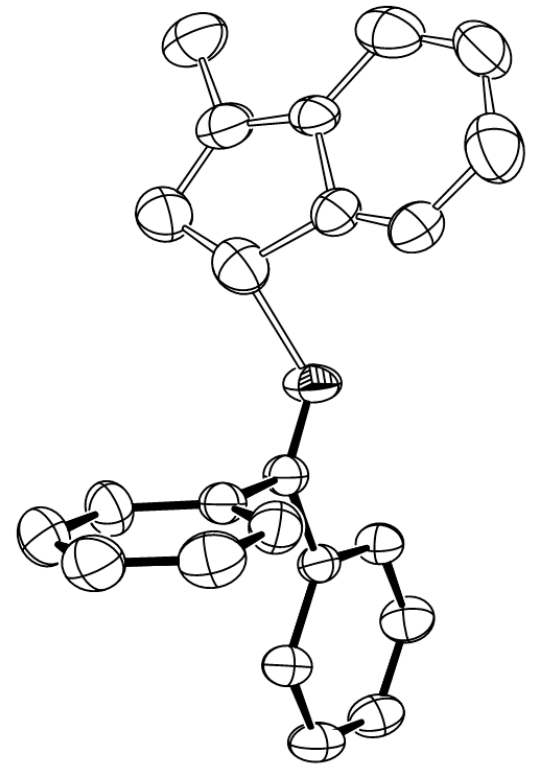

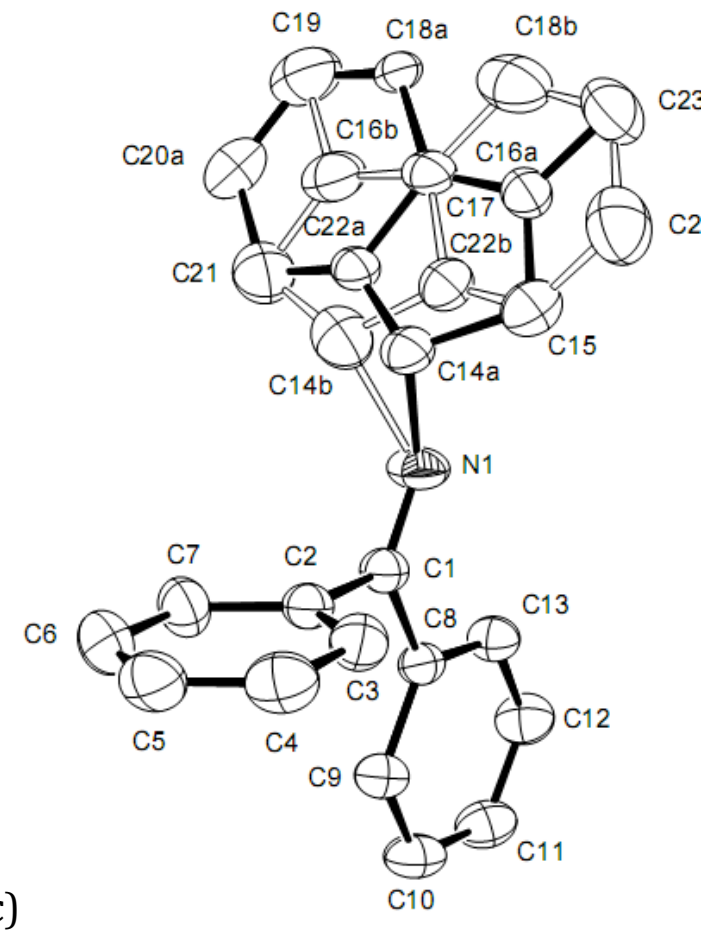

Figure S1. (a) ORTEP drawing (30\% probability ellipsoids) of enantiomers A (left) and B (right); (b) diagram of the disorder. 